\title{
Ocean Circulation and Dynamics on the West Antarctic Peninsula Continental Shelf
}

\author{
by \\ Carlos F. Moffat Varas \\ B.S., Universidad de Concepción (Chile), 1998 \\ Submitted in partial fulfillment of the requirements for the degree of \\ Doctor of Philosophy \\ at the \\ MASSACHUSETTS INSTITUTE OF TECHNOLOGY \\ and the \\ WOODS HOLE OCEANOGRAPHIC INSTITUTION
}

September 2007

(C) 2007 Carlos F. Moffat Varas. All rights reserved.

The author hereby grants to WHOI and MIT permission to reproduce and to distribute publicly paper and electronic copies of this thesis document in whole or in part in any medium now known or hereafter created.

Signature of Author

Joint Program in Oceanography/Applied Ocean Science and Engineering Massachusetts Institute of Technology and Woods Hole Oceanographic Institution August 16, 2007

Certified by

Robert C. Beardsley

Emeritus Scientist, Woods Hole Oceanographic Institution

Thesis Supervisor

Certified by

W. Brechner Owens

Senior Scientist, Woods Hole Oceanographic Institution

Thesis Supervisor

Accepted by

Raffaele Ferrari

Chairman, Joint Committee for Physical Oceanography Massachusetts Institute of Technology

Woods Hole Oceanographic Institution 


\title{
Ocean Circulation and Dynamics on the West Antarctic Peninsula Continental Shelf
}

\author{
by \\ Carlos F. Moffat Varas \\ Submitted to the Department of Physical Oceanography \\ on August 16, 2007, in partial fulfillment of the \\ requirements for the degree of \\ Doctor of Philosophy
}

\begin{abstract}
Observations of current velocity, temperature, salinity and pressure from a 2-year moored array deployment and four hydrographic cruises conducted by the United States Southern Ocean GLOBEC program on the western Antarctic Peninsula continental shelf are used to characterize the ocean circulation and its connection to fresh water and heat fluxes on the shelf. Mean velocities on the shelf are of the order of $5 \mathrm{~cm} / \mathrm{s}$ or less. Tidal motions are dominated by the $M_{2}$ and $S_{2}$ semi-diurnal tides and the $O_{1}$ and $K_{1}$ diurnal tides, although the tidal velocities are typically less than $2 \mathrm{~cm} / \mathrm{s}$. Near-inertial motions are relatively large, with current velocities as high as $26 \mathrm{~cm} / \mathrm{s}$. It is shown that Marguerite Trough, a large bathymetric feature connecting the shelf-break to Marguerite Bay, plays a critical role in determining the circulation. The mean flow is strongly steered in the along-slope direction, and the tidal currents also show increasing current polarization at depth in Marguerite Trough. At timescales of 5 to 20 days, the observations show bottom-intensified motion in Marguerite Trough consistent with bottom-trapped topographic Rossby waves. The subtidal circulation in the trough has a significant wind-driven component in Marguerite Trough, with downwelling-favorable winds forcing cross-shelf flow on the northern side of the trough and along the shore on the outer shelf. Upwelling-favorable winds force roughly the opposite circulation. The cyclonic circulation on the trough helps advect blobs of salty, warm and nutrient-rich water across the shelf. These intrusions are small $(\approx 4 \mathrm{~km})$ and frequent (4 events/month). Also, the Antarctic Peninsula Coastal Current (APCC), a coastal buoyant current which is described for the first time here. The APCC is a seasonal current which is only present during the ice-free season and is forced by freshwater fluxes associated with large glacier melt and precipitation rates in the region.
\end{abstract}

Thesis Supervisor: Robert C. Beardsley

Title: Emeritus Scientist, Woods Hole Oceanographic Institution

Thesis Supervisor: W. Brechner Owens

Title: Senior Scientist, Woods Hole Oceanographic Institution 


\section{Acknowledgments}

First, I would like to thank my co-advisors, Bob Beardsley and Breck Owens. Their unwavering support and enthusiasm has been fundamental to the successful outcome of my life as a graduate student. They are also great examples for me to follow. In my six years in the Joint Program, I had the chance to discuss many interesting scientific problems with Bob. I can't recall a single time when he didn't show interest, and more importantly, when he didn't know anything about the subject at hand. I have often been surprised by how he can bring people together to work on a problem, a testimony to his ability to transmit to others his enthusiasm for science. And he even let me use his houseboat, for crying out loud. Breck had the (somewhat mysterious) ability to look at some of my very initial, exploratory plots of the data, and provide a suggestion that would turn out to be spot on. Breck is also a careful and dedicated sea-going oceanographer, and my frequent conversations with him regarding the pleasures and difficulties of collecting those very valuable observations has taught me a lot about how to become a better scientist. And I want my own glider now. He also seemed to show up at my office with a word of encouragement just when it was needed. Thank you both!

Steve Lentz was a natural choice for my thesis committee, and it turned out, a lucky one for me too. Steve is always thinking about the fundamental dynamics behind the (often) messy observations we collect, and his care for the details and his uncanny ability to find the gaps in my reasoning made my interactions with him tremendously rewarding. He must be looking forward to the more peaceful time coming, now that some of the loudest coastal oceanography grads are leaving. Finally, Glenn Flierl's encyclopedic knowledge of all things fluid dynamics was extremely useful when I was trying to get a broader perspective of the scientific questions that were the focus of my work. It was always interesting and useful to get his advice. Finally, Ken Brink was the most conscientious (and funny) thesis defense chair any graduate student could hope to have during those last few weeks.

I also want to mention my teachers in Chile, who inspired me to learn more and 
encouraged me to explore new fields of study: Dante Figueroa was largely responsible for getting me initiated into Physical Oceanography, and Wolfgang Schneider, Renato Quiñones, Silvio Pantoja, Samuel Hormazábal and Oscar Pizarro all helped me learn more about how to be a good scientist. I met some WHOI scientists in Chile while I was applying to graduate school: Fred Sayles, Bob Weller, John Farrington and Chris Reddy, who all encouraged me when I sent my application to the Joint Program. I'm glad oceanographers have to go to distant places from time to time.

One of my teachers in the Joint Program, Dave Chapman, passed away shortly after my classmates and I took the coastal oceanography class from him. I was very impressed by the dedication and care he put into his teaching, and since then I have also learned more about the insights he brought into our field. Even though I only knew him for a short time, I was saddened by his death. I am sure many students and colleagues of Dave's find inspiration for their work and personal life in the example he set out.

The Joint Program is a great academic challenge. Fortunately, both MIT and Woods Hole have amazing groups of people who care deeply about the quality of life of the students, inside and outside classrooms and laboratories. The people at the Academic Programs Office at WHOI and their counterparts at MIT deserve a lot of the credit for making the Joint Program enjoyable. Ronni, Stacey, Shona and Valerie have made my life much easier during my time here. Wherever I go next, I know I will especially miss Marsha and Julia, who got me out of trouble more than once and who are awesome advocates for the students. John Farrington, whom I met in Chile back in the day and has recently stepped down as the head of the Academics Programs Office, is a great example of what a Dean for the students should be. Annie Doucette, Maryanne Wray and Hazel Salazar keep the PO department going, and we are all indebted to their continuous efforts.

This section would be in danger of becoming a Chapter were I to list all of the good friends I've met here. But! Special mention to the PO crowd: Tom Farrar, Dave Sutherland, Greg Gerbi, Jason Hyatt, Beatriz Pena-Molino, Stephanie Waterman, Ted Durland, Leif Tomas, Irene Garcia, Fiamma Straneo, Luc Rainville, Mary-Louise 
Timmermans, Malcolm Scully, Dave Ralston and Peter Winsor and all the other great students. And to the many other friends who were around from day one: Stephen Licht, Rachel Stanley, Clare Williams, Seth John and Andrea Ryan, Elke Hodson, Emily van Ark, Fabian Tapia, Anna Michel and Carolyn Walker. And also to the friends who lured me into the movie-theater business: John McGrath, Mea Cook, Heidi Fuchs, Uli Riemenschneider and Dirk Koopmans. Finally to my three classmates, who became life-long friends: Jim Thomson (and his amazing wife Jess), Andrew Mosedale and Melanie Fewings. You guys made my time here a blast. I'm looking forward to keeping on exploring with all of you.

My sisters María Teresa, Isabel and Alejandra cheered me all through graduate school and sent me good vibes whenever they were needed. I'm lucky to have parents, Sergio and María Teresa, who always encouraged me to find a path that would be rewarding to me both personally and professionally. Being an oceanographer is definitely it. And you get to play with water.

And to Jessica, whose love and support are my anchor.

And two final thanks: First, the U.S. SO GLOBEC data set is extensive and many people were involved in the collection of the observations. I want to thank the crews of the research vessels $R V L$. M. Gould and $R V / I B$ N. B. Palmer for their help in the collection of the data used here, and Richard Limeburner and Scott Worrilow (both at WHOI) and his crew in the Subsurface Mooring Operations Group and the Rigging Shop at WHOI for the successful deployment and recovery of the moored array and the preliminary data processing. John Klinck (Old Dominion University) did the initial analysis of the hydrographic data from the broad-scale cruises. Peter Wiebe, Carin Ashjian and Gareth Lawson (all at WHOI) helped get access to the BIOMAPPER data and provided useful discussions about the biology of the region. Melanie Fewings, Tom Farrar, Dave Sutherland and Steve Lentz (all at WHOI), as well as Mike Meredith (from the British Antarctic Survey) provided valuable comments to improve this thesis.

The second final thanks goes to the agencies who made this thesis possible: the National Science Foundation Office of Polar programs through U.S. Southern Ocean 
GLOBEC grants OPP 99-10092 and 06-23223, the Chilean government through its Presidential Fellowship program and the Coastal Ocean Institute and the Cooperative Institute for Climate and Ocean Research, both at WHOI. The atmospheric modelling presented in Chapter 5 was performed at the British Antarctic Survey with funding from a European Commission Marie Curie Fellowship for Nicole van Lipzig and high-performance computer facilities provided by the Computer Services for Academic Research. 


\section{Contents}

$\begin{array}{lll}1 & \text { Introduction } & 19\end{array}$

1.1 The Circulation on the wAP Shelf from Prior Studies . . . . . . . . 21

1.2 Thesis Outline. . . . . . . . . . . . . . . . . . . . . . . . . . . 22

2 The U.S. Southern Ocean GLOBEC data set and study area 25

2.1 The mooring array $\ldots \ldots \ldots \ldots \ldots \ldots$

2.2 Automatic Weather Stations . . . . . . . . . . . . . . 27

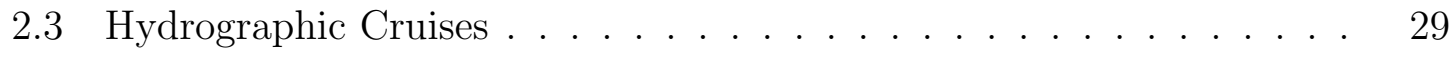

2.4 Shelf Bathymetry $\ldots \ldots \ldots \ldots \ldots \ldots$

3 Description of current and pressure variability in the SO GLOBEC $\begin{array}{ll}\text { study area } & 37\end{array}$

3.1 Introduction . . . . . . . . . . . . . . . . . . . . . . 37

3.2 Mean and Variability of the Subtidal Flow . . . . . . . . . . . 38

$3.2 .1 \quad$ A Coordinate System for the Moored Array . . . . . . . . . . 39

3.2 .2 The Mean Circulation . . . . . . . . . . . . . . . . . 40

3.2 .3 Consistency with Previous Studies $\ldots \ldots$. . . . . . . . 42

$3.2 .4 \quad$ Blocking Effects in the Mean Flow . . . . . . . . . . . . 43

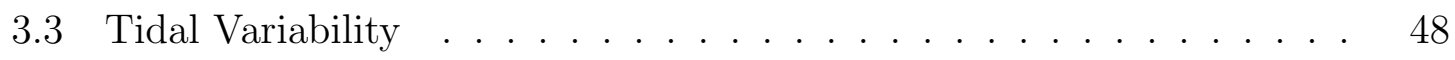

$3.3 .1 \quad$ Semi-diurnal Components . . . . . . . . . . . . . . 50

3.3 .2 Diurnal Components . . . . . . . . . . . . . . . . . . . 52

3.3 .3 Comparison with the AntPen04.01 Tidal Model . . . . . . . 53

$3.3 .4 \quad$ Discussion and Summary of the Tidal Analysis . . . . . . . . . 57 
3.4 Near-inertial Motions . . . . . . . . . . . . . . . . . . . . . . 73

3.4 .1 Rotary Spectra . . . . . . . . . . . . . . . . . . 73

$3.4 .2 \quad$ Band-pass Filtering $\ldots \ldots \ldots \ldots \ldots$

3.4 .3 Near-inertial Currents . . . . . . . . . . . . . . . 75

3.4 .4 Vertical Structure . . . . . . . . . . . . . . . . . 76

3.4 .5 Horizontal Scales . . . . . . . . . . . . . . . . . . 77

3.4 .6 Seasonal Evolution . . . . . . . . . . . . . . . . . . . 77

3.4 .7 Discussion and Summary of Near-inertial Variability . . . . 78

$3.5 \quad$ Bottom-trapped Topographic Waves in Marguerite Trough . . . . . 86

$3.5 .1 \quad$ Dynamics $\ldots \ldots \ldots \ldots \ldots \ldots$

$3.5 .2 \quad$ Topographic Waves at A2 $\ldots \ldots \ldots \ldots \ldots$

3.5.3 Discussion and Summary of Bottom-trapped Topographic Waves 90

$3.6 \quad$ Alongshore Wind Response in Marguerite Trough . . . . . . . . . 97

3.6 .1 Wind Data $\ldots \ldots \ldots \ldots$. . . . . . . . . . . . 97

3.6 .2 Correlations with the Wind-stress . . . . . . . . . . . . . 99

$3.6 .3 \quad$ Magnitude and Structure of the Response . . . . . . . . . . 99

3.6.4 Summary of the Subtidal Current Wind Response in Marguerite Trough . . . . . . . . . . . . . . . . . 100

\begin{tabular}{|ll|}
4 & Circumpolar Deep Water Intrusions \\
\hline
\end{tabular}

4.1 Background . . . . . . . . . . . . . . . . . . . . . . . . . . 105

4.2 Characteristics of Oceanic Waters . . . . . . . . . . . . . 107

4.2 .1 Definition of an Oceanic Intrusion . . . . . . . . . . . 108

$4.3 \quad$ Spatial Distribution of UCDW Events. . . . . . . . . . . . . . . 111

4.3 .1 UCDW in the Hydrographic Surveys . . . . . . . . . . 111

4.3 .2 UCDW in the Moored Array . . . . . . . . . . . . . . . . 114

$4.4 \quad$ Frequency and Duration of Warm Events . . . . . . . . . . 116

4.5 Circulation Associated with the Warm Events . . . . . . . . . . 117

$4.5 .1 \quad$ Eddies Advected Pass a Mooring . . . . . . . . . . . . . 120

4.5 .2 Eddy-like Events in the A2 Records . . . . . . . . . . . . . 123 
$4.6 \quad$ Events Intensity and Depth Scale $\ldots \ldots \ldots \ldots \ldots \ldots$

$4.7 \quad$ Horizontal Scale of the Eddies . . . . . . . . . . . . . . . . . 127

4.8 Heat Content . . . . . . . . . . . . . . . . . . . . . . . . . . . . . . . . 129

4.9 Discussion and Conclusions $\ldots \ldots \ldots \ldots$. . . . . . . . . . . . . 131

5 A First Description of the Antarctic Peninsula Coastal Current 135

5.1 Introduction . . . . . . . . . . . . . . . . . . . . . . . . 135

5.2 Data Sources . . . . . . . . . . . . . . . . . . . . . 137

5.3 Background . . . . . . . . . . . . . . . . . . . . . . . . . . 139

5.4 Structure and Dynamics of the APCC $\ldots \ldots \ldots \ldots$

$5.4 .1 \quad$ Spatial Structure . . . . . . . . . . . . . . . . . . . . . 140

5.4 .2 Volume and Fresh Water Transports . . . . . . . . . . . . 142

5.4 .3 Comparison with Theoretical Scales . . . . . . . . . . . . . . 143

5.4 .4 Temporal Evolution: The Winter Shutdown . . . . . . . . . 145

5.5 Discussion . . . . . . . . . . . . . . . . . . . . . . . . . 147

$5.5 .1 \quad$ Fresh water budget $\ldots \ldots \ldots \ldots \ldots$

5.5 .2 Wind Effects . . . . . . . . . . . . . . . . . . . 155

$5.6 \quad$ Summary and Open Questions . . . . . . . . . . . . . . . 156

$\begin{array}{lll}6 & \text { Discussion and Summary } & 173\end{array}$

\begin{tabular}{ll}
\hline Bibliography & 177
\end{tabular} 


\section{List of Figures}

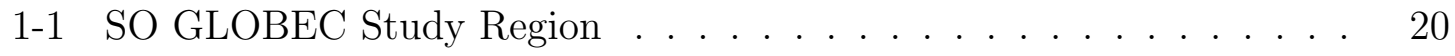

1-2 Location of the Antarctic Circumpolar Current Fronts. . . . . . . . . 23

1-3 Dynamic Topography Map for the wAP Shelf (Smith et al.[] 1999)] . . 24

2-1 Map of the SO GLOBEC Mooring Locations . . . . . . . . . . . . 31

$2-2$ Typical Hydrographic Profiles on the Shelf . . . . . . . . . . . . . 32

2-3 Location of the CTD Stations Visited During the SO GLOBEC Broadscale Cruises . . . . . . . . . . . . . . . . . . . . . . . . . 33

$2-4$ Bathymetric Map of the Study Region . . . . . . . . . . . . . 34

$2-5$ Bathymetry of Marguerite Trough $\ldots \ldots \ldots \ldots \ldots$

3-1 $\quad$ Kinetic Energy Spectrum (A2 Mooring) $\ldots \ldots \ldots \ldots$

3 3-2 Mean and Principal Axes, Low-pass Filtered Mooring Records . . . . 46

3-3 Map of Bathymetry and Coordinate System of the Mooring Array . . 47

3-4 Power Spectrum of the Pressure Records (A2 Mooring) . . . . . . . . 49

$3-5 \quad$ Tidal Ellipses, $M_{2} \ldots \ldots \ldots \ldots \ldots \ldots$

$3-6 \quad$ Tidal Ellipses, $S_{2} \ldots \ldots \ldots \ldots \ldots \ldots \ldots$

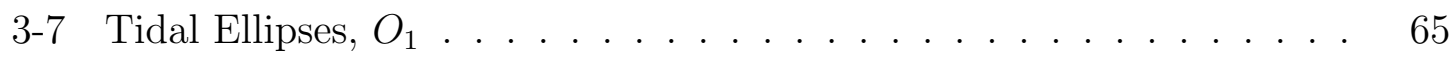

$3-8 \quad$ Tidal Ellipses, $K_{1} \ldots \ldots \ldots \ldots$

3-9 Tidal Sea-level Amplitude from AntPen04.01 Model (Semi-diurnal Components $] \ldots \ldots \ldots \ldots \ldots$. . . . . . . . . . . . . . . 67

3-10 Tidal Sea-level Amplitude from AntPen04.01 Model (Diurnal Compo-

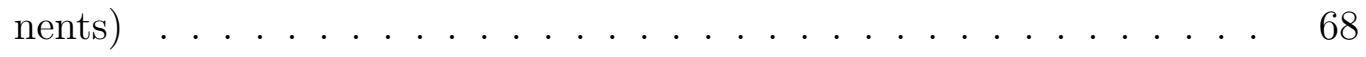

3-11 Tidal sea-level Amplitudes (A-line Moorings) . . . . . . . . . . . 71 
3-12 Tidal Sea-level Amplitudes (B- and C-line Moorings) . . . . . . . . . 72

3-13 Rotary Spectrum (A2 Mooring) . . . . . . . . . . . . . . 74

3-14 Counterclockwise Component of the Rotary Spectra for the Mooring Records . . . . . . . . . . . . . . . . . . . . . 82

$3-15$ Ratio of Maj/Min Axis as a Function of $\omega / f \ldots \ldots \ldots$

3-16 First Complex Empirical Function, Band-Pass Current Velocity Records 84

3-17 Monthly Averaged Near-inertial Kinetic Energy, Ice Concentration and Wind-stress Standard Deviation . . . . . . . . . . . . . . . . . 85

3-18 Power spectra of the along-slope velocity (left panel) and the crossslope velocity (right panel) for the A2 (top panels) and C2 (bottom panels) mooring records. . . . . . . . . . . . . . . . . . . 92

3-19 Schematic of a Bottom-trapped Topographic Rossby Wave Structure 93

3-20 Orientation of the Band-Pass Velocity Records as a Function of Frequency 94

3-21 Coherence and Phase Between Downslope Velocity and Density, A2 Mooring . . . . . . . . . . . . . . . . . . . . . . 95

3-22 Wavelet Variance at A2 Averaged (7-20 Days) . . . . . . . . . 96

3-23 Map of the Mean and Principal Axes of the Wind-stress _ . . . . . . 102

3-24 Along-isobath current response to along-shelf wind-stress in Marguerite Trough . . . . . . . . . . . . . . . . . . . . . . . . 103

3-25 Cross-isobath current response to along-shelf wind-stress in Marguerite Trough . . . . . . . . . . . . . . . . . . . . . . . . . 104

4-1 Evolution of the Hydrographic Structure at the A2 Mooring Site . . . 106 $4-2$ Location of the SO4P CTD Stations $\ldots \ldots \ldots \ldots \ldots$

4-3 Cross-shelf Section of Hydrographic Structure from the SO4P Cruise 109

$4-4 \quad \theta$-S Diagram of Off-shelf CTD Stations $\ldots \ldots \ldots \ldots \ldots \ldots$

4-5 Map of Maximum Potential Temperature Below the Pycnocline . . . 112

$4-6 \quad \theta$-S diagram of the All SO GLOBEC Broad-scale Hydrographic Cruises 113

4-7 $\quad$ Hydrographic Section Across Marguerite Trough . . . . . . . . . . . 114

$4-8$ Example UCDW Intrusion . . . . . . . . . . . . . . . . . . . 116 
4-9 Histogram of Potential Temperature (A2 and A3 Moorings) . . . . . 117

4-10 Histogram of Warm-water Events Duration . . . . . . . . . . . . . . . 118

4-11 Number of Warm-water Intrusions per Month (A2 and A3 Moorings) 118

4-12 Time Series of Potential Temperature and Along- and Cross-isobath Velocity (A2 Mooring) . . . . . . . . . . . . . . . . . . . 119

4-13 Horizontal Velocity Average for Warm-water Events (A2 Mooring) . . 121

4-14 Velocity Structure of a Rankine Vortex . . . . . . . . . . . . . . . . . 122

4-15 Examples of Warm-water Events at the A2 Mooring . . . . . . . . . . 124

4-16 Eddy-like Velocity Structure at A2 . . . . . . . . . . . . . . . . 126

4-17 Vertical Profiles of Averaged Hydrographic Properties for the Warmwater Events . . . . . . . . . . . . . . . . . . . . . . . 128

$4-18 \quad$-S Diagram for the Warm-water Events at A2 . . . . . . . . . . . . . 129

4-19 Depth Scale of the Intrusion Events at A2 . . . . . . . . . . . . 130

4-20 Effect of the Band-pass Filtering of the Velocity Records . . . . . . . 134

5-1 Map Showing Location of Data Used to Characterize the APCC . . . 158

$5-2 \quad$ Schematic of the A1 Mooring Design . . . . . . . . . . . . . . 159

5-3 Evolution of the Hydrographic Structure at the A2 Mooring Site . . . 160

5-4 Sea Surface Salinity and Temperature Maps . . . . . . . . . . . . . . 161

5-5 $\quad \theta$-S Diagrams of Cross-shelf Sections Along the wAP Shelf . . . . . . 162

5-6 $\quad$ Hydrographic and Velocity Section Off Adelaide Island . . . . . . . . 163

5-7 Comparison of Mean ADCP and Geostrophic Shear off Adelaide Island 164

5-8 Location of Cross-shore ADCP Sections Along the wAP Shelf . . . . 165

5-9 $\quad$ Cross-shore ADCP Sections Along the wAP Shelf . . . . . . . . . . . 166

5-10 Schematic of the Relevant Scales of a Coastal Buoyant Plume. . . . . 167

5-11 Time-series of Along-shelf Velocity, Ice Concentration and Ice Draft off Adelaide Island . . . . . . . . . . . . . . . . . . . . . . . . . . . . . . 168

5-12 Seasonal Averages of Along-shelf Velocities from the A1 Records . . . 169

5-13 Map of Modeled Precipitation Minus Evaporation $(P-E)$. . . . . . 170

5-14 Schematic of the path of the APCC. . . . . . . . . . . . . 171 


\section{List of Tables}

2.1 SO GLOBEC Mooring Locations $\ldots \ldots \ldots$

2.2 Instrumentation Used in the Moored Array . . . . . . . . . . . 28

2.3 Summary of the Cruise dates and Number of CTD Stations Conducted. 29

3.1 Basic Statistics of the Current Velocity Records. . . . . . . . . . . 45

3.2 Instruments Used to Calculate Vertically-averaged Records. . . . . . . 56

3.3 Tidal Ellipses of the Semi-diurnal Components . . . . . . . . . . . . 61

3.4 Tidal Ellipses of the Semi-diurnal Components . . . . . . . . . . . 62

3.5 Tidal Sea-level Amplitude from the Pressure Records … . . . . . . 69

3.6 Tidal Ellipses from AntPen04.01 and Moored Array . . . . . . . . 70

3.7 Statistics of Near-inertial Band Motions on the wAP shelf . . . . . 81

$3.8 \quad$ Relevant Non-dimensional Parameters for Bottom-trapped Topographic Rossby Waves Dynamics . . . . . . . . . . . . . . . . . . . 90

3.9 Wind Stress Statistics (AWS and MM5) $\ldots \ldots \ldots \ldots$

$5.1 \quad$ Summary of the Dates and Locations of the Hydrographic Cruises and Moored Array. . . . . . . . . . . . . . . . . . . . . . . . 172 


\section{Chapter 1}

\section{Introduction}

Polar continental shelves remain one of the least studied ocean ecosystems in the world. This is partly due to the fact that it involves collection of observations in distant places, under generally harsh weather conditions and with the added complication of a permanent or seasonal ice cover. Many polar shelves host, however, very diverse and highly productive biological communities, and their unique physical setting and characteristics makes them distinctive from their mid-latitude counterparts. Moreover, many studies have shown these regions to be especially sensitive to recent changes in the global climate.

The continental shelf off the west coast of the Antarctic Peninsula (Figure 1-1), which extends for some $1200 \mathrm{~km}$ from the southern tip of Alexander Island to the tip of the peninsula, is one such system. It hosts a rich biological community, including large colonies of penguins, whales and other mammals, whose main food source is Antarctic Krill (Euphasia superba). Marguerite Bay and the surrounding shelf play a central role in the life cycle of krill (Hofmann et al., 2002, 2004), and it is believed that a unique combination of physical and biological factors in the bay and its surroundings explain the success of the local krill population, which also sustains other biological communities in the southern ocean, especially east of the Drake Passage Murphy et al. 1998, 2007). Studies of the regional climate strongly suggest that the Antarctic Peninsula has one of the fastest changing environments in the world, with recent warming of $3{ }^{\circ} \mathrm{C}$ in the surface air temperature and $1^{\circ} \mathrm{C}$ in the ocean since 1950 
(Meredith and King, 2005), fast retreating glaciers (Cook et al., 2005) and gradually shorter winter seasons (Harangozo, 2006). For convenience, we will call the region around Marguerite Bay, from the southern tip of Alexander Island on the south to the northern tip of Adelaide Island, the western Antarctic Peninsula (wAP) shelf.

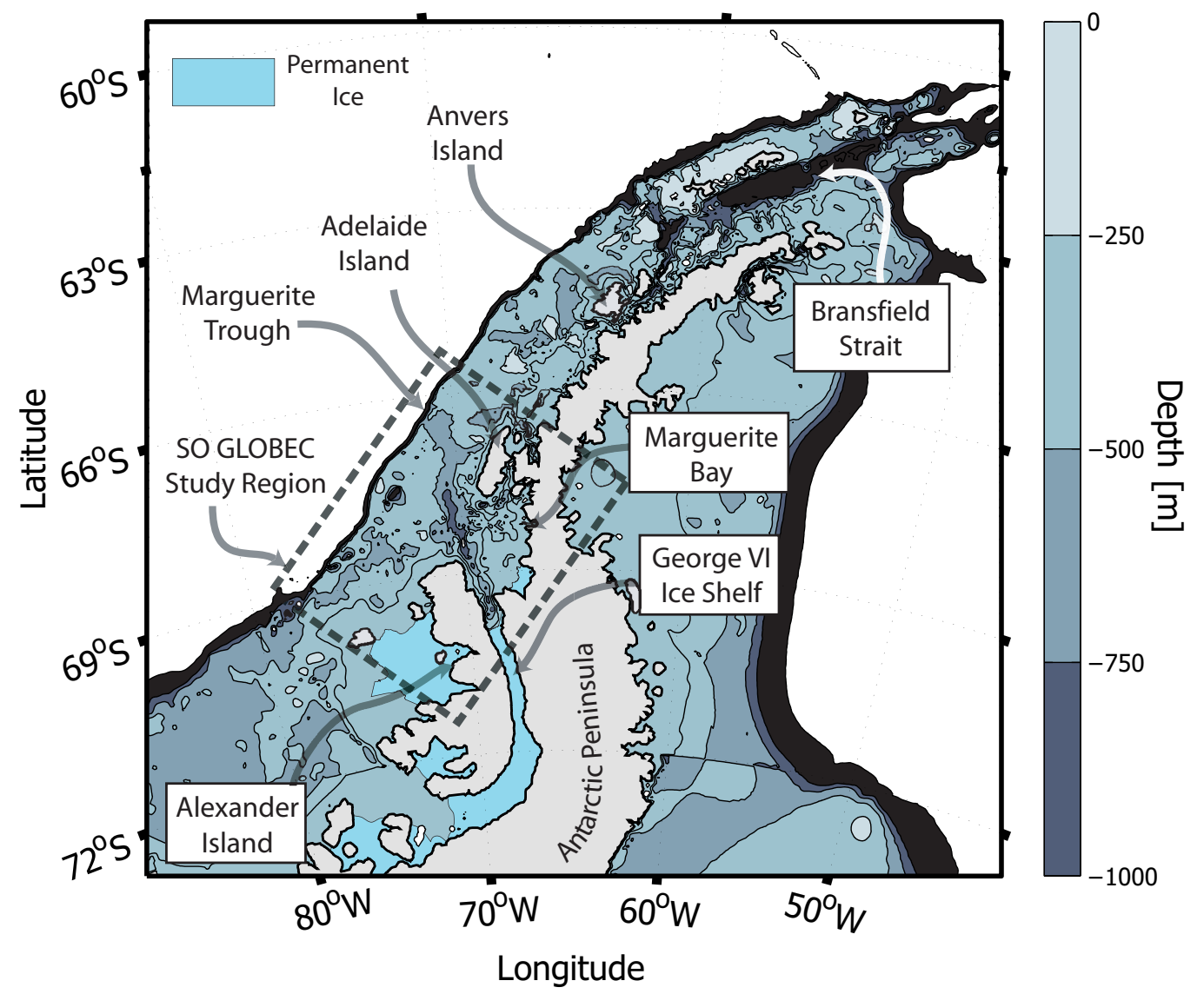

Figure 1-1: The Antarctic Peninsula continental shelf. The SO GLOBEC region is outlined by the dashed black line, and the main geographical features are indicated.

The ocean circulation and dynamics of the wAP shelf are, despite its relevance for the life cycle of Krill, poorly understood. The observations of water properties are historically mostly limited to the summer months, as observations during the winter are impeded by weather conditions and a seasonal ice cover which forms over most of the wAP shelf from July to October (Stammerjohn and Smith, 1996). As for observations of current velocity on the shelf, there were limited to the region of the shelf north Adelaide Island, particularly in Bransfield Strait (Niiler et al., 1990; 
Huntley and Niiler, 1995; Zhou et al., 2002). To my knowledge, there are no historical observations of current velocity on the shelf of the study region.

The need to understand the physical processes and their connection to biological dynamics in the wAP region led to the United States Southern Ocean Global Ocean Ecosystems Dynamics (U.S. SO GLOBEC) program, a multi-disciplinary effort whose field work component included several broad-scale cruises during the fall and winter of 2001 and 2002, the deployment of the first long-term mooring array on the shelf, and a host of biogeochemical observations.

Both the earlier studies and initial analysis of the U.S. SO GLOBEC hydrographic data suggest several important component of the wAP shelf circulation and dynamics. To motivate this thesis, a brief summary of the regional circulation and previous studies of the circulation are given below.

\subsection{The Circulation on the wAP Shelf from Prior Studies}

The main component of the large scale circulation in the Southern Ocean and offshore of the wAP shelf is the Antarctic Circumpolar Current (ACC - Figure 1-2), which flows towards the northeast, roughly parallel to the direction of the shelf-break. The ACC features three distinct fronts: the Subantarctic Front (SAF), the Polar Front (PF) and the Southern ACC Front (SACCF) (Orsi et al., 1995). Deflected northwards by the presence of the Antarctic Peninsula, the ACC moves closer to the continental margin, and the Southern ACC Front is found at 80 to $200 \mathrm{~km}$ from the shelfbreak (Figure 1-2). Notice, however, that the Southern ACC Front is not considered a shelf-break front.

Prior to U.S. SO GLOBEC, only geostrophic velocities from hydrographic sections had been obtained on the shelf surrounding Marguerite Bay, the study region (Hofmann and Klinck, 1998; Smith et al., 1999). Mid-depth dynamic height fields referenced at $400 \mathrm{db}$, corresponding to the mean baroclinic, geostrophic component 
of the circulation, suggested the presence of a large cyclonic circulation off Adelaide Island, with currents of the order of $1 \mathrm{~cm} / \mathrm{s}$ flowing southward near the shore and northeastwards along the shelf-break (Figure 1-3). The flow towards the north-east on the outer branch of this gyre was thought to be "attached" to the ACC (Smith et al., 1999). This shelf-scale gyre was thought to provide a retention mechanism for plankton on the shelf.

Although the processes determining the observed hydrographic structure are still being investigated, it is clear that transport of warm, salty, and nutrient-rich water from the Antarctic Circumpolar Current (ACC) onto the shelf is a critical factor Klinck, 1998; Smith et al., 1999). These intrusions are also believed to influence the seasonal ice thickness over the shelf during the winter (Smith and Klinck, 2002).

The above studies provided much of the motivation for the physical oceanography component conducted as part of SO GLOBEC, and of this thesis. The present study includes a basic description of the flow and the main scales of variability. It also explores two major components of the circulation according to prior knowledge: the presence of a southwards circulation which forms part of a larger gyre, and the intrusions of warm water onto the shelf.

\subsection{Thesis Outline}

The thesis is organized as follows: Chapter 2 summarizes the SO GLOBEC observations relevant to this thesis, Chapter 3 deals with the mean flow, tidal motions, near-inertial variability, bottom-trapped topographic waves and the wind-driven response on the shelf. Chapter 4 explores the characteristics of warm water intrusions onto the shelf, and Chapter 5 provides the first description of a seasonal buoyant current flowing along the wAP coast. Finally, Chapter 6 provides the overall conclusions of this work. 


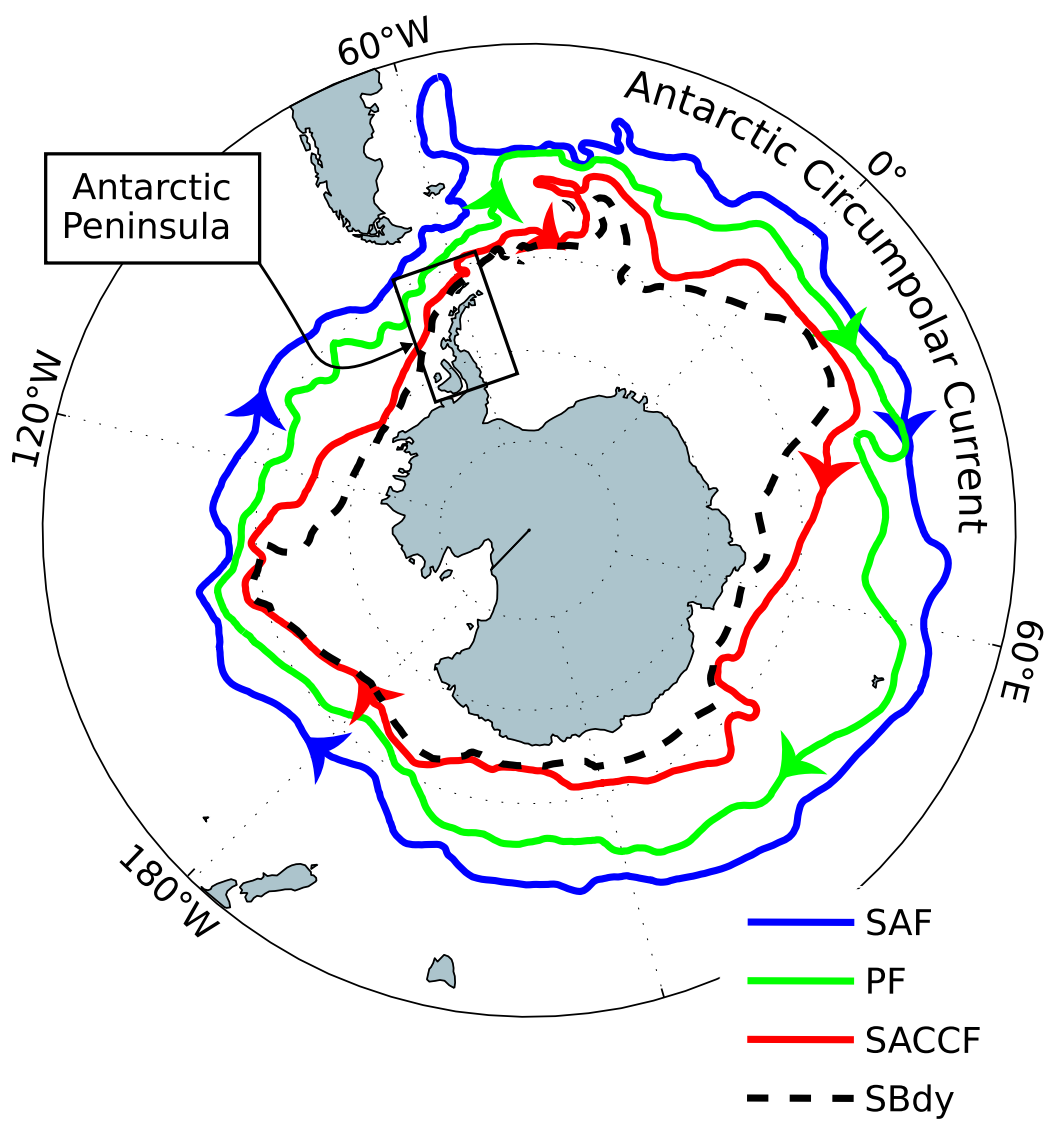

Figure 1-2: Location of the Subantarctic (SAF), Polar (PF), Southern ACC (SACCF) fronts and the Southern Boundary of the ACC (SBdy). Data from Orsi et al. (1995). 


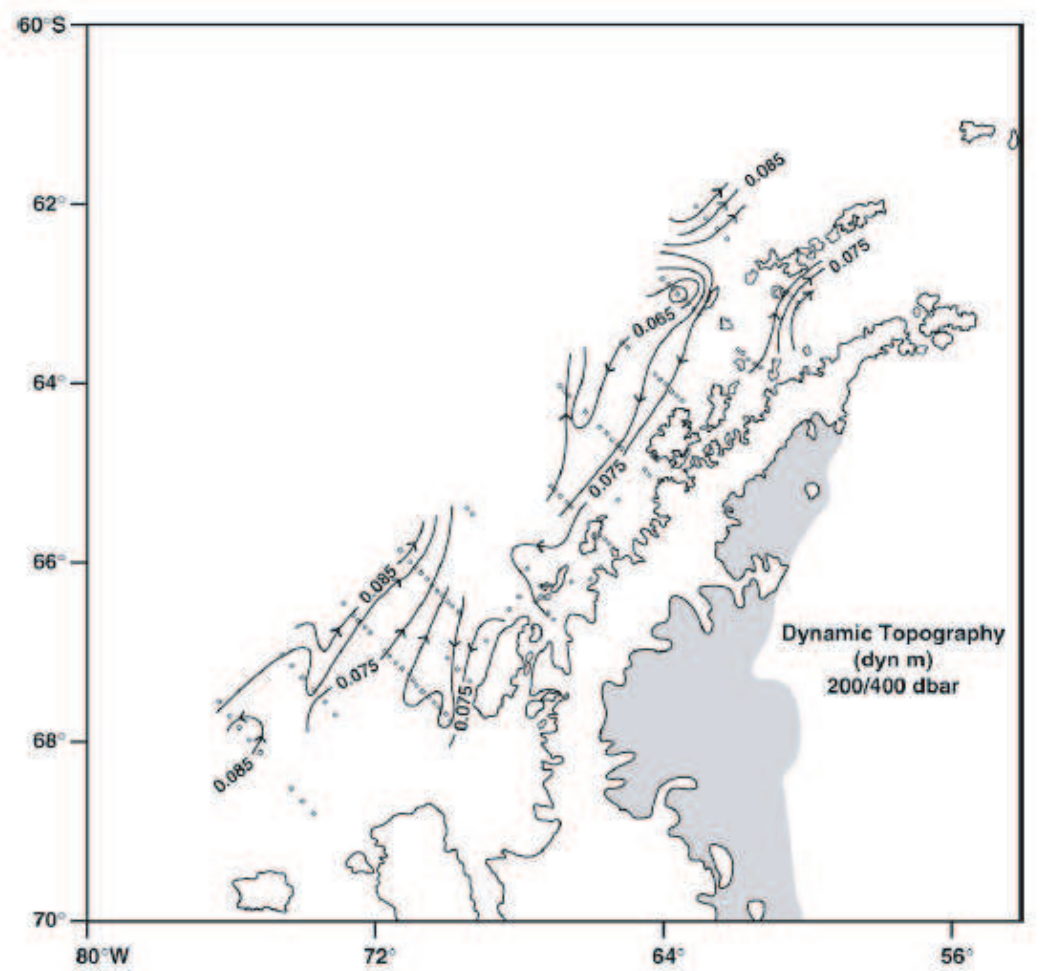

Figure 1-3: Dynamic height at $200 \mathrm{db}$ (referenced at $400 \mathrm{db}$ ) for the shelf west of the Antarctic Peninsula (from Smith et al., 1999) 


\section{Chapter 2}

\section{The U.S. Southern Ocean}

\section{GLOBEC data set and study area}

The physical oceanographic component of the U.S. Southern Ocean GLOBEC (SO GLOBEC) Program included the deployment of three mooring lines, four broad-scale hydrographic cruises and deployment of surface drifters and subsurface floats. The following is a brief description of the data sets used in this thesis. The moored array, automatic weather stations and the bathymetric survey information presented here were mostly extracted from the Southern Ocean GLOBEC moored array and automated weather station data report (Moffat et al., 2005), where a more detailed description is given.

\subsection{The mooring array}

The WHOI SO GLOBEC mooring locations are shown in Figure 2-1. The 2001-2002 array consisted of one transect (the "A-line") of three moorings (A1-A3) deployed across the shelf west of Adelaide Island and a second transect (the "B-line") of three moorings (B1-B3) deployed west of the mouth of Marguerite Bay. The 2002-2003 array consisted of a L-shaped transect (the "C-line") of three moorings (C1-C3) deployed slightly inshore of the B-line.

The A-line was designed to investigate the shelf-scale gyre, with A1 in the coastal 
southwestward flow and A3 on the outer shelf in the northeastward flow. A2 was located between A1 and A2 on the eastern side of Marguerite Trough, where deep intrusions of Upper Circumpolar Deep Water (UCDW) were thought to occur. The B-line was deployed across the mouth of Marguerite Bay, with B1 and B3 on the east and west flanks and B2 in the center. This line was designed to look for clockwise flow around the basin, the southward continuation of the surface coastal current towards the mouth of Marguerite Bay, and the filling and flushing of the deepest part of the basin. Based in part on the preliminary results of surface drifters deployed during 2001 austral summer/fall plus a desire to learn more about flow and water properties within the mouth of Marguerite Bay, the C-line array was set across Marguerite Trough, with $\mathrm{C} 1$ and $\mathrm{C} 2$ aligned with the mouth of the Bay and C2 and C3 on the east and west sides of the trough. C3 was deployed at the B2 site to provide a two-year time-series at this central location.

Table 2.1: SO GLOBEC mooring locations, bottom depths and dates of deployment and recovery.

\begin{tabular}{lccccc}
\hline Mooring & Latitude & Longitude & Bottom Depth & Deployment & Recovery \\
\hline A1 & $671.134^{\prime}$ & $691.217^{\prime}$ & 509 & $3 / 26 / 01$ & $2 / 13 / 02$ \\
A2 & $661.883^{\prime}$ & $700.683^{\prime}$ & 561 & $3 / 30 / 01$ & $2 / 13 / 02$ \\
A3 & $665.002^{\prime}$ & $709.991^{\prime}$ & 480 & $3 / 31 / 01$ & $2 / 13 / 02$ \\
\hline B1 & $676.890^{\prime}$ & $694.398^{\prime}$ & 444 & $3 / 30 / 01$ & Not Recovered \\
B2 & $686.091^{\prime}$ & $701.675^{\prime}$ & 811 & $3 / 29 / 01$ & $2 / 14 / 02$ \\
B3 & $685.345^{\prime}$ & $709.853^{\prime}$ & 447 & $3 / 29 / 01$ & $2 / 14 / 02$ \\
\hline C1 & $682.940^{\prime}$ & $691.790^{\prime}$ & 432 & $2 / 18 / 02$ & $2 / 22 / 03$ \\
C2 & $683.331^{\prime}$ & $701.730^{\prime}$ & 859 & $2 / 19 / 02$ & $2 / 26 / 03$ \\
C3 & $686.006^{\prime}$ & $701.799^{\prime}$ & 806 & $2 / 21 / 02$ & $2 / 26 / 03$ \\
\hline
\end{tabular}

The moorings were designed to measure the following physical variables at common depths: (a) temperature at 50, 100, 150, 200, 250, $400 \mathrm{~m}$ and close to the bottom using SeaBird (SBE) temperature sensors; (b) conductivity (salinity) at 50, 100, 250, and $400 \mathrm{~m}$ using SBE conductivity sensors; and (c) currents at 250 and $400 \mathrm{~m}$ using Vector Averaging Current Meters (VACMs). To obtain vertical profiles 
of currents and acoustic back-scatter intensity in the upper water column where krill are commonly found (Lascara et al., 1999), 300-kHz broadband RDI Acoustic Doppler Current Profilers (ADCPs) would be deployed at $100 \mathrm{~m}$ on all moorings except the B2/C3 moorings which would feature a $150-\mathrm{kHz}$ broadband RD Instruments (RDI) ADCP moored at $250 \mathrm{~m}$. These design depths were chosen based on regional mean profiles of $\mathrm{T}$ and $\mathrm{S}$ (Figure 2-2), the desire to better sample the upper water column, the idea from hydrography that the deeper flow would be more barotropic, and the instrumentation and mooring resources available.

The A- and B-line recovery and C-line deployment were conducted on the $R / V$ L.M. Gould SO GLOBEC mooring cruise LMG02-1A (Beardsley et al., 2002). A CTD cast was made before each mooring recovery for later use in checking temperature and conductivity sensor performance and drift. The three A-line moorings were recovered successfully while the two southernmost moorings, B2 and B3, were recovered in patchy ice, with damage to the upper instruments due to passing icebergs. The B1 mooring was lost with no trace.

The final position, bottom depth and deployment and recovery times for each mooring are listed in Table 2.1. The basic instrumentation used in the moored array is listed in Table 2.2. Details on the quality control tests and corrections of the data can be found in (Moffat et al., 2005).

\subsection{Automatic Weather Stations}

To help interpret the moored array data and monitor the surface forcing during the SO GLOBEC field program, Raytheon Polar Services Corporation (RPSC) technicians and WHOI investigators deployed Automatic Weather Stations (AWSs) on Kirkwood (AWS-K) and Dismal (AWS-D) Islands, located near the center of Marguerite Bay (Figure 2-1). The two self-contained AWSs, provided by the University of Wisconsin Antarctic Automatic Weather Station Project (AWSP), transmitted vector-averaged wind speed and direction, air temperature, relative humidity and barometric pressure data back to AWSP via ARGOS, where the raw data were decoded and sent to WHOI 
Table 2.2: Instruments used in the moorings. The acronyms listed in the second column are used throughout the rest of this thesis. The physical variables are $\mathrm{T}=$ Temperature; $\mathrm{C}=$ Conductivity; $\mathrm{P}=$ Pressure; $\mathrm{UV}=$ Horizontal velocity; $\mathrm{W}=$ Vertical velocity; $\mathrm{B}=$ Backscatter intensity; and I = Ice draft.

\begin{tabular}{lcc}
\hline Type & Variables & Sample Rate (s) \\
\hline RDI ADCP (WorkHorse) & $\mathrm{UV}, \mathrm{W}, \mathrm{B}$ & 1800 \\
RDI ADCP (BroadBand) & $\mathrm{UV}, \mathrm{W}, \mathrm{B}$ & 3600 \\
ALS Ice Profiler & $\mathrm{I}$ & 50 \\
SBE MicroCat & $\mathrm{T}, \mathrm{C}$ & $150{ }^{\dagger}$ \\
SBE SeaCat & $\mathrm{T}, \mathrm{C}, \mathrm{P}$ & 900 \\
SBE TempRecorder & $\mathrm{T}$ & 225 \\
VACM & $\mathrm{UV}, \mathrm{T}, \mathrm{P}^{\ddagger}, \mathrm{C}^{\ddagger}$ & 900 \\
SBE SeaGauge & $\mathrm{P}, \mathrm{T}, \mathrm{P}$ & 300 \\
\hline
\end{tabular}

${ }^{\dagger}$ Except $\mathrm{A} 1$ at $309 \mathrm{~m}$ and $\mathrm{A} 3$ at 250 . Both sampled at $300 \mathrm{~s}$

$\ddagger$ Only when indicated

for final processing. The two AWSs were deployed in May 2001 and produced highquality data through March 2003, with only a few short periods of zero wind speed or constant wind direction thought due to anemometer icing.

At Kirkland Island, the AWS (\#8930) site is on a slab rock shoulder on the northwestern side of the island, at an estimated height above sea level (rough estimate) of $25 \mathrm{~m}$. The winds from the south might be distorted by the main snow cap, but the site has open exposure from west through northeast (Wiebe et al., 2001). The other AWS (\#8932) was installed on a small rocky island east of Dismal Island. The AWS was installed on the north end of the island, with open exposure to the west through southeast, at roughly $12 \mathrm{~m}$ above sea level (Wiebe et al., 2001).

The AWS data are self-consistent, and compare favorably with that from the British research station Rothera (R-sta) located on the southeastern side of Adelaide Island (Figure 2-1), except for wind speed and direction at Rothera which differ strongly from the AWS winds due to the rugged coastal topography around Rothera. 


\subsection{Hydrographic Cruises}

During 2001 and 2002, four hydrographic cruises were conducted off the west coast of the Antarctic Peninsula aboard the $R V / I B N$. B. Palmer as part of the SO GLOBEC field program (Table 2.3). These broad-scale cruises attempted to cover the entire study region, and provided CTD (conductivity for salinity, temperature and pressure for depth) profile observations on a grid with a nominal cross-shelf resolution of $20 \mathrm{~km}$ (Figure 2-3). The fall surveys provided a larger spatial coverage than the winter surveys, in which weather conditions and sea-ice coverage impeded access to Marguerite Bay and other nearshore areas. Sea surface temperature (SST) and sea surface salinity (SSS) as well as wind speed and direction data were also collected throughout the cruises using the $R V / I B N$. B. Palmer continuous sampling systems. Details of the processing of the data set can be found in Wiebe et al. (2001) and Klinck et al. (2004).

Table 2.3: Summary of the cruise dates and number of CTD stations conducted.

\begin{tabular}{llccc}
\hline Cruise & Objective & Start & End & \# CTD \\
\hline LMG01-03 & Mooring Deployment & $03 / 18 / 01$ & $04 / 13 / 01$ & 6 \\
NBP01-03 & Fall 2001 Survey & $04 / 24 / 01$ & $06 / 05 / 01$ & 84 \\
NBP01-04 & Winter 2001 Survey & $07 / 24 / 01$ & $08 / 31 / 01$ & 70 \\
LMG02-1A & Mooring Recovery/Deployment & $02 / 06 / 02$ & $03 / 03 / 02$ & 9 \\
NBP02-02 & Fall 2002 Survey & $04 / 09 / 01$ & $05 / 21 / 01$ & 92 \\
NBP02-04 & Winter 2002 Survey & $07 / 31 / 02$ & $09 / 18 / 02$ & 102 \\
LMG03-02 & Mooring Recovery & $02 / 12 / 03$ & $03 / 07 / 03$ & 4 \\
\hline
\end{tabular}

As part of these broad-scale cruises, conductivity, temperature and pressure data from depths of roughly $15 \mathrm{~m}$ to $250 \mathrm{~m}$ were also collected using the Bio-Optical Multi-frequency Acoustical and Physical Environmental Recorder (BIOMAPER-II), a towed undulating multi-sensor system (Wiebe et al., 2002). Unfortunately, the conductivity sensor had an unknown malfunction during the winter of 2001 and both the fall and winter 2002 surveys and these data are not of sufficient quality to calculate salinity reliably.

Velocity data were obtained during the cruises with a shipboard-mounted RD 
Instruments (RDI) 150-kHz narrow-band Acoustic Doppler Current Profiler (ADCP) sampling from 31 to $431 \mathrm{~m}$. The ADCP was configured with fifty eight-meter bins, an eight-meter pulse length, and five-minute ensemble averages. During most of the cruise, the ADCP operated in bottom-tracking mode. The data processing was initially done during the cruise using the Common Oceanographic Data Access System (CODAS). Final processing and quality control were done by J. Hummon (University of Hawaii) and S. Howard (Earth Systems Research) (Klinck et al., 2004). ADCP data return during both winter cruises was greatly reduced while the $R V / I B N$. B. Palmer was moving through sea-ice.

\subsection{Shelf Bathymetry}

Since much of the study area was uncharted prior to 2001, the SO GLOBEC program collected as much multibeam bathymetric data as possible during the field program using the RV/IB N.B. Palmer SeaBeam swath mapping system. These data were then merged with other available digital along-track and multibeam data to create a high-resolution digital bathymetric data set for the study area (Bolmer et al., 2004).

The bathymetric survey resulted in a new high-resolution bathymetry which resolved many previously unknown features and areas on the shelf's sea floor Bolmer et al., 2004). As can be seen in Figure 2-4, the wAP shelf is characterized by a relatively deep shelf with very rough topography. The shelf is approximately $400 \mathrm{~m}$ deep on average, with the maximum depth of $\approx 1600 \mathrm{~m}$. The cross-shelf bathymetric features tend to be deeper next to the coast and shallow towards the outer shelf.

The large channel connecting the shelf break to Marguerite Bay, Marguerite Trough, is the most prominent of these features (Figure 2-5). The structure of this fjord-like canyon is rather complex: at the shelf break, it is characterized by a shallow, gentle depression, which becomes steeper, narrower and deeper onshore, extending for roughly $250 \mathrm{~km}$ where the canyon reaches its maximum depth of $1600 \mathrm{~m}$ (the deepest location on the shelf), to become shallower again closer to George VI Sound (Fig. 2-4. 


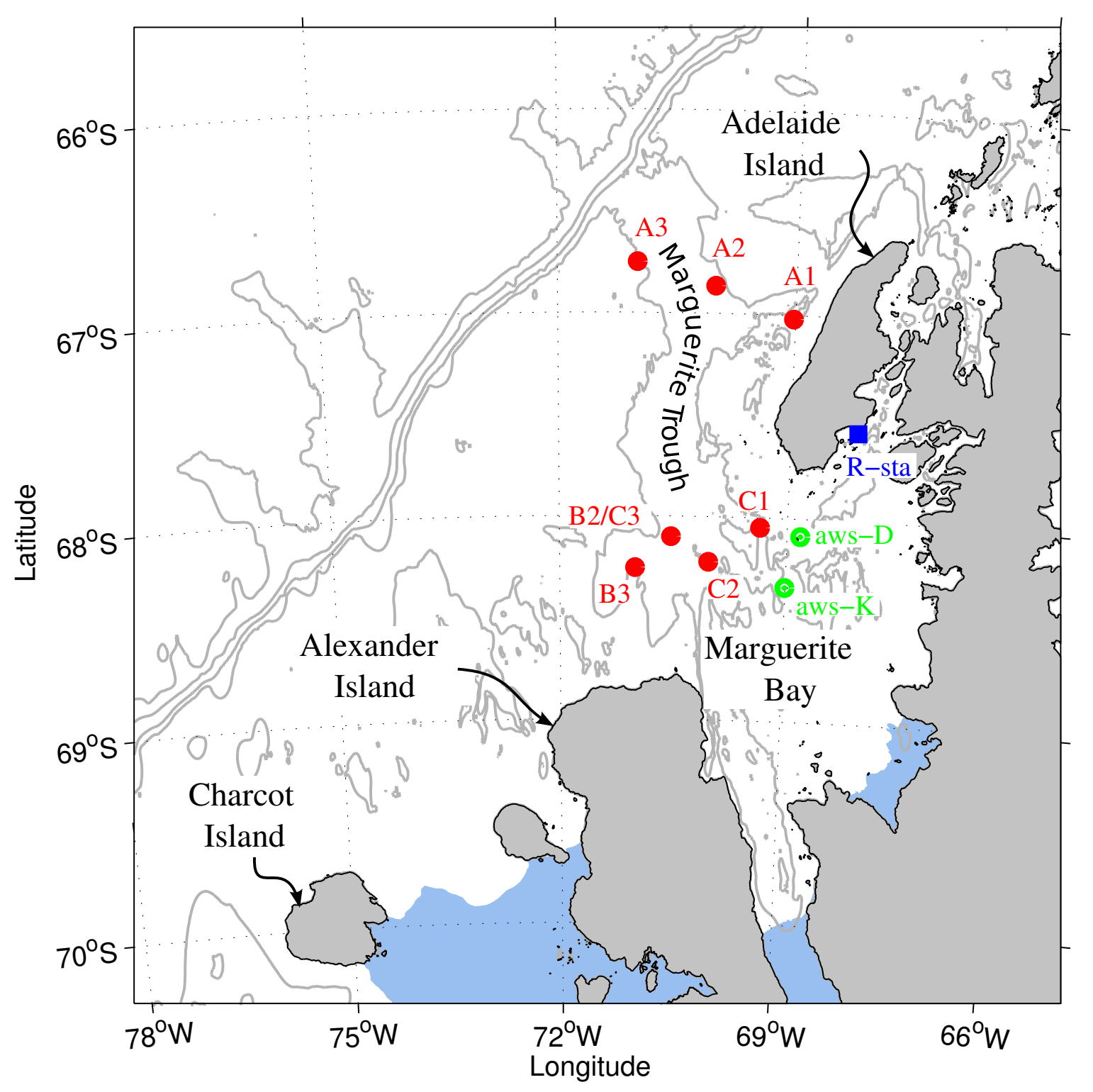

Figure 2-1: Map of the western Antarctic Peninsula shelf region showing the locations of the WHOI SO GLOBEC moored arrays and the AMRC Automated Weather Stations. The A- and B-line moorings were deployed during 2001/02 and the C-line moorings was deployed during 2002/03. B1, shown in the figure, was not recovered. The two AWSs at Dismal Island (D-aws) and Kirkwood Island (K-aws) were deployed in 2001. Also shown in the figure is the location of the British Antarctic Survey station Rothera (R-sta). 

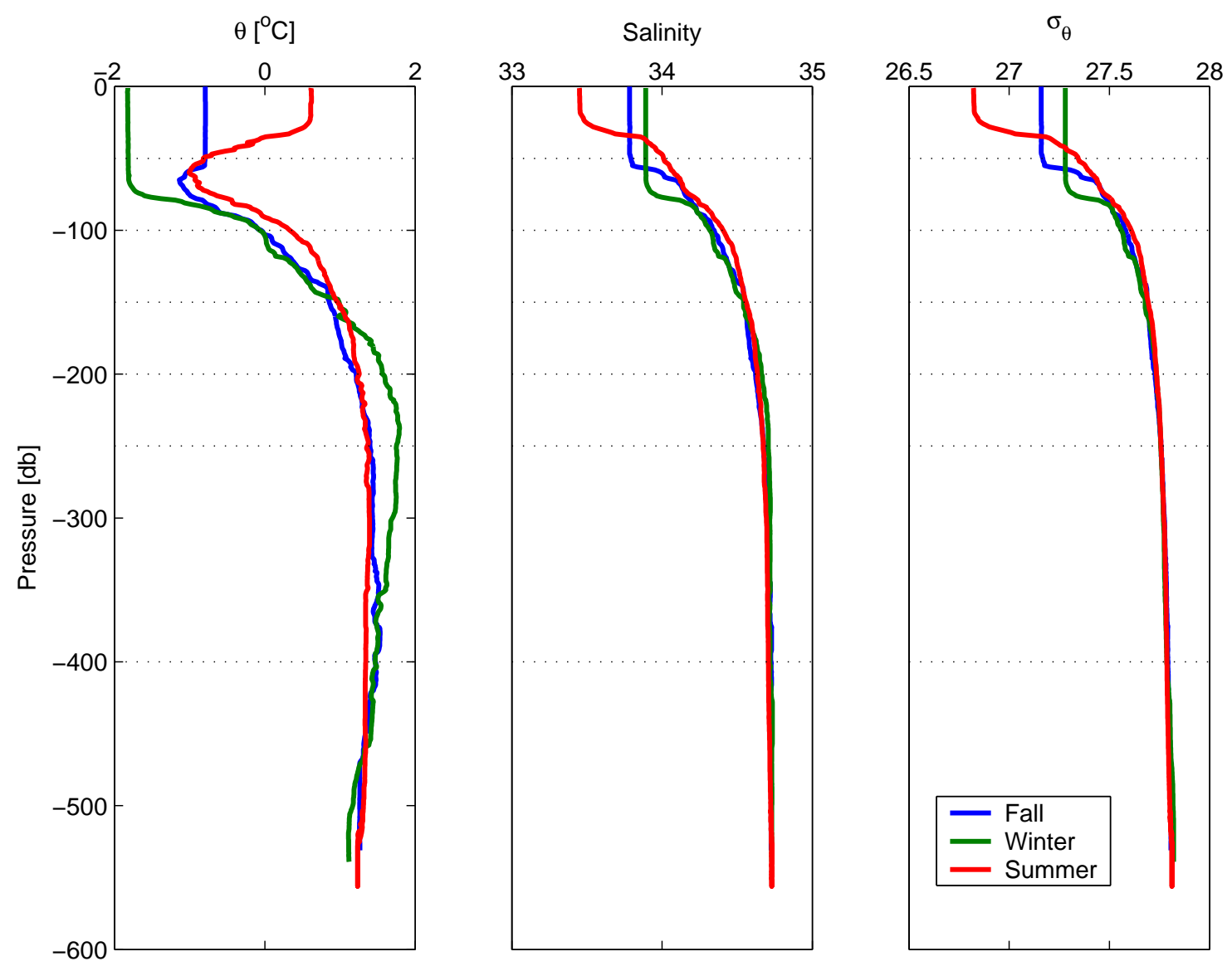

Figure 2-2: Vertical Profiles of potential temperature, salinity and potential density obtained during 2001 and early 2002. The CTD profiles were taken near the A2 mooring during fall (blue), winter (green) and summer (red). At these cold temperatures, density is determined primarily by salinity. Note the cooling and increase in salinity and density of the surface $50 \mathrm{~m}$ from summer to fall/winter; the deep winter surface mixed layer; the summer and fall temperature minimum layer at 80/100 m, the remnant of last winter's mixed layer; the permanent pycnocline (120 to $150 \mathrm{~m}$ ); and the deeper UCDW. The dotted lines indicate the design measurement depths in the moored array. 

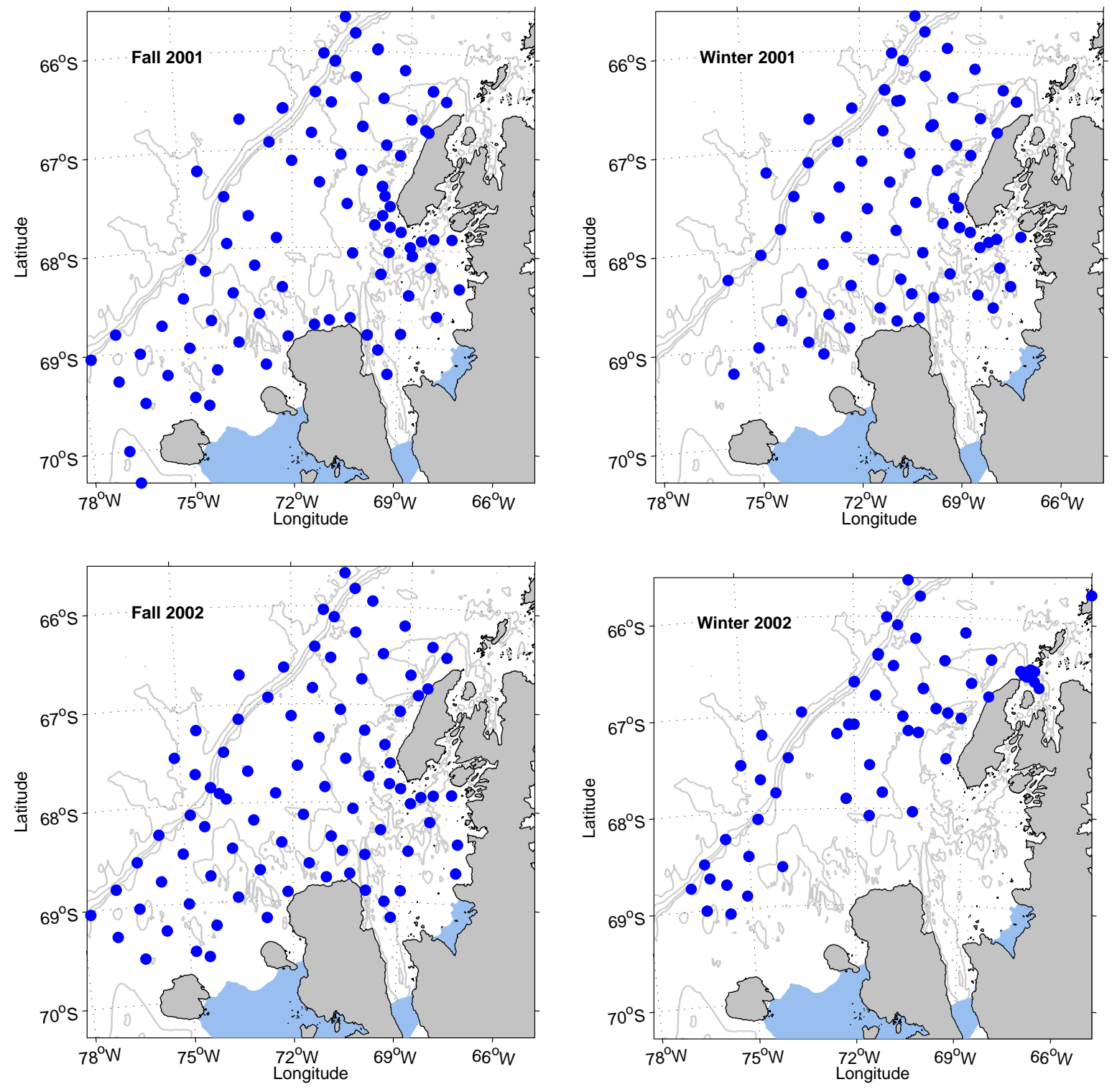

Figure 2-3: Location of the CTD stations visited during each of the four broad-scale SO GLOBEC cruises. 


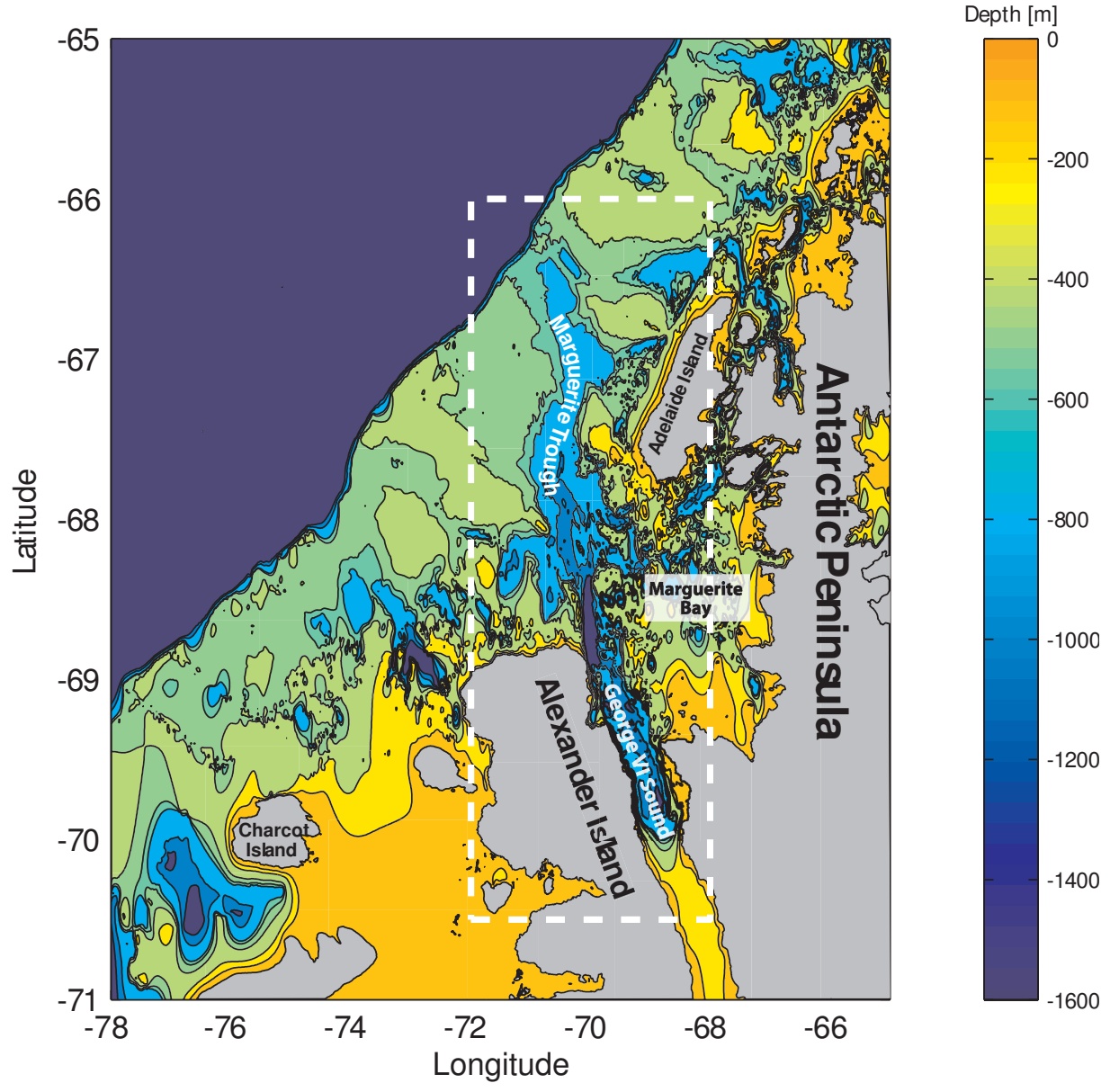

Figure 2-4: Bathymetry of the SO GLOBEC study region. A detailed view of the area indicated by the dashed white line is plotted in Figure 2-5 (Data from Bolmer et al., 2004). 

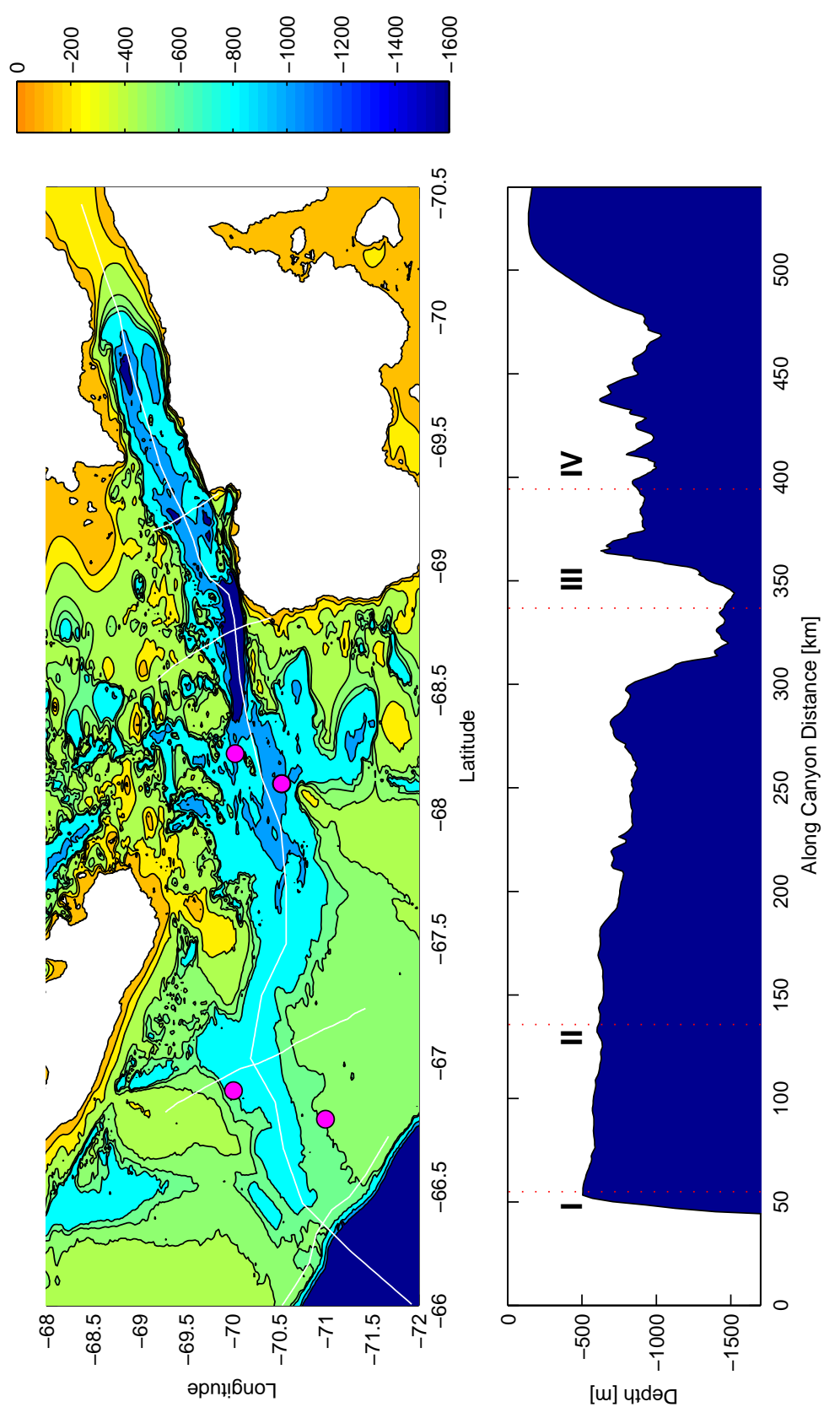

[ய] ułdə0
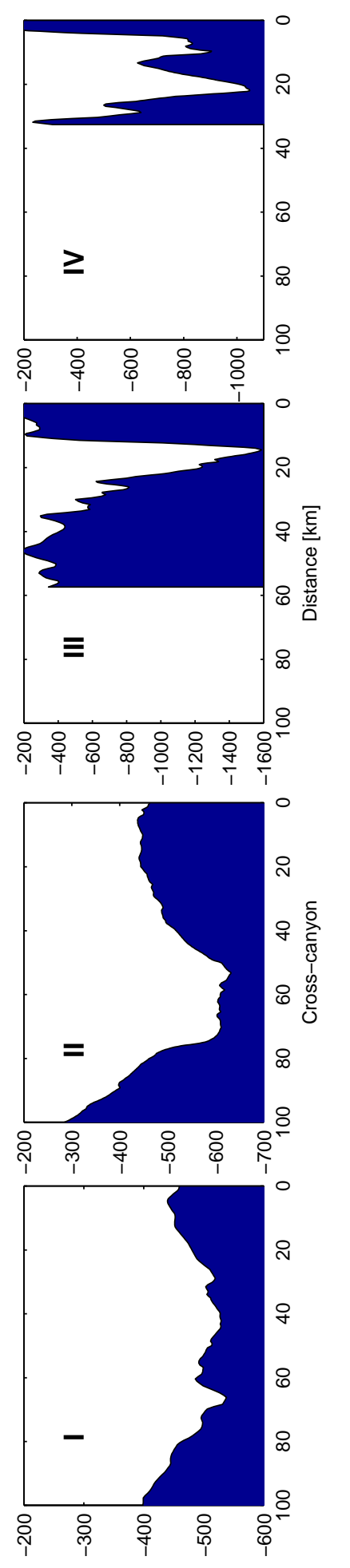

โயu] uıdəત

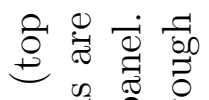

की

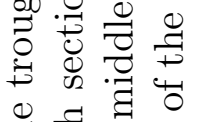

\begin{tabular}{ccc}
0 & $\Xi$ & 0 \\
1 & 0 & 0 \\
\hline & 0 & 0
\end{tabular}

$\overrightarrow{0}$

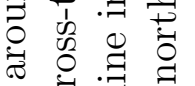

者芯导

.$\exists \stackrel{0}{0}$

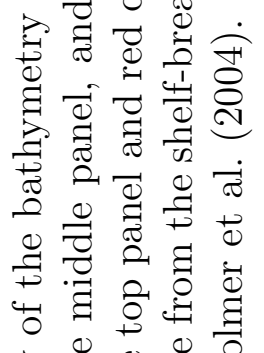

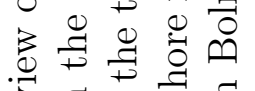

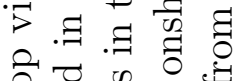

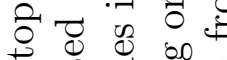

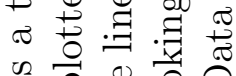

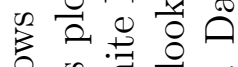

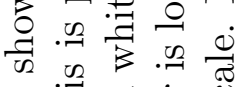

0

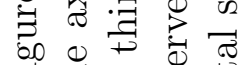

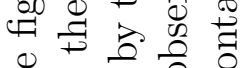

E

두 $\frac{0}{\varpi} \leftrightarrows$

島记

$\forall \begin{array}{llll}0 & 0 & 0 & 0\end{array}$

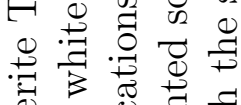

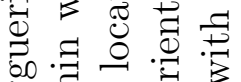

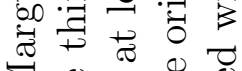

$\sum \underset{1}{2} \frac{0}{0}$

$\rightarrow$ 舟

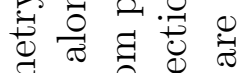

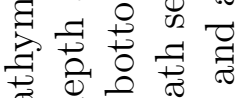

西 00

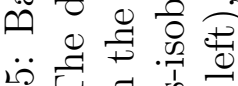

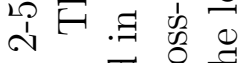

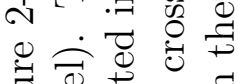

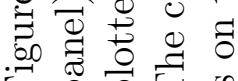




\section{Chapter 3}

\section{Description of current and pressure variability in the SO GLOBEC study area}

\subsection{Introduction}

This chapter explores general aspects of the circulation on the wAP shelf using the SO GLOBEC moored array dataset. Figure 3-1 shows the kinetic energy spectrum of the 318-day long horizontal current at $247 \mathrm{~m}$ on the A2 mooring. The spectrum shows the typical flow variability on the shelf. At high frequencies (1 day or shorter), there are peaks at the primary four tidal components (See section 3.3 for details) and a large, broad peak centered at the inertial frequency. At subtidal time scales (the spectrum includes variability for period shorter than 60 days), the spectrum has a broad significant peak at 10 days or so. In this chapter and elsewhere in this thesis, these spectral peaks in the current variability are referred to as 'tidal', 'inertial' or 'subtidal'. To obtain the latter, all the velocity records were low-pass filtered with a parabolic-linear filter with a 33-h half-amplitude period (Flagg et al., 1976; Limeburner et al., 1983).

In the following sections, I describe the basic structure of the mean flow, the tidal 
motions, the inertial frequency variability, and explore some of the subtidal variability in Marguerite Trough.

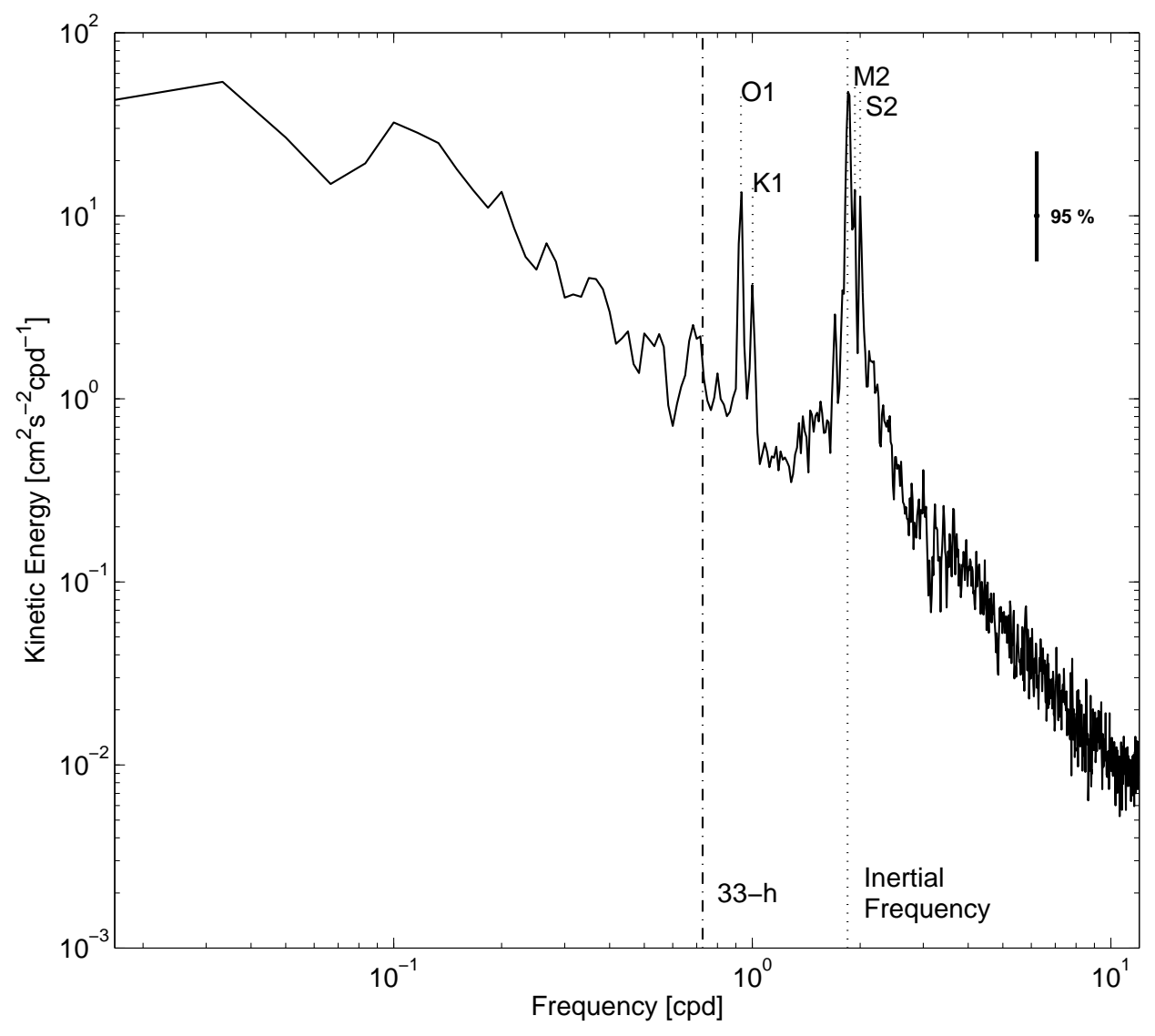

Figure 3-1: Kinetic energy spectrum of the VACM velocity at $247 \mathrm{~m}$ on the A2 mooring. The inertial frequency and the principal tidal components $\left(O_{1}, K_{1}, M_{2}\right.$ and $S_{2}$ ) are indicated with vertical lines, as well as the half-amplitude period of the low-pass filter used to generate the subtidal time series.

\subsection{Mean and Variability of the Subtidal Flow}

In this section, basic statistics of the subtidal current velocity, including mean, standard deviations, and principal axes are presented. For the basic description, nominal depths of 50,100, 250, 400 and $800 \mathrm{~m}^{1}$ were chosen. The statistics were calculated

\footnotetext{
${ }^{1}$ The A1 mooring was located in a deep depression $50 \mathrm{~m}$ deeper that its design depth, and therefore the deeper records are at 309 and $459 \mathrm{~m}$.
} 
for both the original and rotated records. The coordinate system used for the rotated records is explained below.

\subsubsection{A Coordinate System for the Moored Array}

The means and principal axes of the subtidal currents (Figure 3-2 show large spatial variability. Only the A1 mooring off Adelaide Island appears to have mean and principal axis aligned with the coast, while across the mouth of Marguerite Bay the direction of the coastline is ambiguous. The influence of the main bathymetric feature, Marguerite Trough, on the orientation of the axes of maximum variance is evident at several mooring sites, suggesting that the flow variability is mostly along isobaths in the trough.

In order to rotate the velocity records, the principal axes of the vertically-averaged velocity were calculated for each mooring. In the case of the nearly co-located B2/C3 mooring pair, the resulting orientations differed by $2^{\circ}$. The orientation calculated from the C3 mooring data was used for both of them, as this mooring provided better depth coverage of the water column. For C1, the deepest instrument was at $232 \mathrm{~m}$ (bottom depth at $859 \mathrm{~m}$ ), so that the records were averaged down to this depth only $^{2}$. Except at A1 and B3, where the direction of the local isobaths is ambiguous, the rotation to the direction of the vertically-averaged principal axes results in the rotated velocity being roughly in a coordinate system aligned with the local isobaths. The sign convention was chosen such that $x$ is positive towards the shelf-break along the axis of the trough.

The resulting rotated coordinate systems for each mooring are shown in Figure $3-$ 3. together with high resolution maps of the bathymetry around each mooring. At A1 (bottom depth $509 \mathrm{~m}$ ), there is a shallow sill $300 \mathrm{~m}$ deep only a few kilometers to the south-west of the mooring. The A2 and A3 axes are aligned with the local isobaths, but notice that the slope in the vicinity of A3 is much gentler than at A2. At C1, $\mathrm{C} 2$ and $\mathrm{B} 2 / \mathrm{C} 3$, the rotated axes are also clearly defined by the local bathymetry.

\footnotetext{
${ }^{2}$ Assuming a barotropic velocity from $232 \mathrm{~m}$ to the bottom results in a $10^{\circ}$ difference in the principal axis orientation.
} 
The $\mathrm{C} 1$ mooring was located between a small island $\approx 14 \mathrm{~km}$ to the north-east and a small sea-mount to the south-west. The same is true for $\mathrm{C} 2$, located in a section of Marguerite Trough where a small sea mount is located in the middle of the trough. At $\mathrm{B} 2 / \mathrm{C} 3$, the axes are aligned with the main axis of the trough, and the moorings were flanked by a very shallow $(<200 \mathrm{~m})$ mount. Finally, the B3 mooring was located in a lateral extension of the trough, where the direction of the local isobaths is ambiguous.

\subsubsection{The Mean Circulation}

Basic statistics of the low-pass filtered SO GLOBEC moored array velocity records are given in Table 3.1. The uncertainties presented in Table 3.1 correspond to the 95\% confidence intervals computed as

$$
\bar{u} \pm 1.96 \frac{\sigma}{(N \delta t / \epsilon)^{1 / 2}}
$$

where $\bar{u}$ is the record mean velocity, $\sigma$ is the standard deviation, and $N \delta t / \epsilon$ is the number of independent observations of a time series of length $N \delta t$ and integral time-scale $\epsilon$, calculated from the autocorrelation function of each set of the hourly observations before any filtering (Emery and Thompson, 1998). For the velocity records, $\epsilon$ is typically of the order of 1 to 2 days. Overall, the mean velocities in the study region are of the order of $5 \mathrm{~cm} / \mathrm{s}$ or less, and the variability of the subtidal currents is generally of the order of the mean or larger.

The mean circulation (Figure 3-2 is characterized by two main components. First, near the coast, the surface flow (above $\approx 100 \mathrm{~m}$ ) is characterized by southward flow along Adelaide Island (at A1) and into Marguerite Bay, which is explained by the presence of a coastal current, the Antarctic Peninsula Coastal Current (APCC, see Chapter 5). The mean records above $100 \mathrm{~m}$ at C1 also show flow into Marguerite Bay, but the magnitude is smaller, and the velocity records do not show the consistent flow seen at A1. This might be because the APCC was weaker during 2002 or because the current shows larger lateral displacements at C1. In the southern half of the mouth of the bay, the flow above $100 \mathrm{~m}$ is out of the bay. At B3 the flow has a strong mean 
with considerable polarization of the axes of variance. At B2/C3 the mean also tends to be out of the Bay, although it is much weaker than at B3, located some $25 \mathrm{~km}$ to the south-west. This indicates that the flow scales are small across the mouth of the bay, which is consistent with a internal radius of deformation of only 4 to $7 \mathrm{~km}$.

The second fundamental component of the mean circulation is determined by the local bathymetry. As is characteristic of polar shelves, the wAP shelf is deep and with variations of the order of the mean depth. At A1, the mean flow below $250 \mathrm{~m}$ is relatively weak and towards the shelf break, likely a result of blocking of the flow by the presence of a 300-m sill just a few kilometers south of the mooring site (Figure 3-3). The rest of the SO GLOBEC moored array was located in or near Marguerite Trough (Figure 3-2, , one of the main features of the wAP bathymetry, and its influence is clear in the orientation of the major axis of the subtidal flow at several deep locations around the trough.

On the eastern side of the trough ${ }^{3}$, at A2, C1 and $\mathrm{C} 2$, the principal axes have relatively strong polarization (major/minor axes ratios from 1.4 at $232 \mathrm{~m}$ at $\mathrm{C} 1$ to 3.7 at $\mathrm{C} 2$ at $810 \mathrm{~m}$ ) and the major axis is aligned with the local isobaths. At A2, the mean shows a small intensification with depth (and anti-clockwise veering), but the velocity is barotropic in the along-isobath direction, and the mean values are largest mean values measured at or below $250 \mathrm{~m}$ in the entire array. The mean is directed onshore at these three moorings, although the along-isobath component is indistinguishable from zero at $232 \mathrm{~m}$ at $\mathrm{C} 1$ and at $810 \mathrm{~m}$ at $\mathrm{C} 2$. At these two moorings, the mean $(0.2-3.1 \mathrm{~cm} / \mathrm{s})$ is weak compared to the subtidal variability $(0.9-5.5 \mathrm{~cm} / \mathrm{s})$.

On the western side of the trough, the mean flow is toward the shelf-break, except at $247 \mathrm{~m}$ at B3, where the flow is weak and toward Marguerite Bay. At A3, although there is a weak but significant offshore mean, the principal axes are weakly polarized (unlike at A2) and the major axis is oriented in the cross-isobath direction, that is, roughly in the direction of the coastline, which would be expected in the absence of

\footnotetext{
${ }^{3}$ The main axis of Marguerite Trough is roughly aligned in the north-northwest direction. For simplicity, the right (left) side of the trough, looking from the coast to the shelf break, will be referred to as the 'eastern' (western) edge
} 
Marguerite Trough ${ }^{4}$. At B2/C3, the flow is weakly polarized in the top $100 \mathrm{~m}$ but becomes strongly polarized at the deepest records, which were taken below $200 \mathrm{~m}$, the depth of the tip of a sea mount located $\approx 12.5 \mathrm{~km}$ to the southwest of the mooring site (Figure 3-3). Notice also that there are some interannual differences at this site. The flow is stronger below $100 \mathrm{~m}$ during 2001 (e.g. $3.1 \pm 0.5 \mathrm{~cm} / \mathrm{s}$ at $250 \mathrm{~m}$ in B2) than during $2002(2.0 \pm 0.2 \mathrm{~cm} / \mathrm{s}$ at $250 \mathrm{~m}$ in C3). Finally, the B3 mooring, which shows a strong mean with weak polarization in the top $100 \mathrm{~m}$ becomes strongly polarized at depth but with relatively weak $(<1 \mathrm{~cm} / \mathrm{s})$ means. Notice that the flow becomes aligned in the general direction of the small side extension of Marguerite Trough, and not the main axis of the trough as with the other moorings located in it.

\subsubsection{Consistency with Previous Studies}

As noted in the introductory chapter, the SO GLOBEC moored array provides the first set of direct current observations spanning several seasons on the wAP shelf. However, a handful of previously published observations are available for comparison with the analysis presented here. In two separate studies using CTD observations to calculate geostrophic shear (Smith et al., 1999; Klinck et al., 2004), it was suggested that the nearshore circulation along Adelaide Island, which was shown to be consistently towards the southwest during the ice-free season, might be part of a shelfscale gyre or a coastal current. This was shown to be consistent with a study using drifter observations of the near-surface lagrangian currents collected during the SO GLOBEC program (Beardsley et al., 2004). The coastal current, which dominates the flow at A1, and which is largely baroclinic, is explored further in Chapter 5.

As for the shelf-scale cyclonic gyre, the SO GLOBEC broad-scale dynamic height calculations relative to a zero-velocity reference velocity at $400 \mathrm{~m}$ showed it to be centered off Adelaide Island, roughly at the mid-shelf point $\left(67^{\circ} \mathrm{S}\right)$, and it is a feature which is relatively persistent from the fall to the winter (Klinck et al., 2004). This gyre is consistent with the cyclonic, largely barotropic circulation described here from the

\footnotetext{
${ }^{4}$ Note, however, that the weak polarization implies calling an axis 'major' and the other 'minor' axis somewhat ambiguous.
} 
moored array data taken around the trough, although the predicted velocity from the dynamic height calculations underestimate the total velocity. Even near the coast of Adelaide Island, where the flow is largely baroclinic, the dynamic height calculations gave maximum velocities of the order of $3 \mathrm{~cm} / \mathrm{s}$ during the fall 2001 season, although the measured surface velocities at A1 were closer to $40 \mathrm{~cm} / \mathrm{s}$. This appears to be a direct consequence of the sampling grid being too coarse in the cross-shelf direction $(20 \mathrm{~km})$ to resolve the small dynamical scales (the internal radius of deformation is roughly $4 \mathrm{~km}$ ).

\subsubsection{Blocking Effects in the Mean Flow}

The above description of the flow highlights the obvious influence of the local topography on the alignment of both the mean and axes of variability around Marguerite Trough, where most of the moorings were located. However, much of the area of the shelf is occupied by small-scale bathymetric features which are also likely to have a profound effect on the circulation.

Consider, for example, the vertical structure of the mean flow at A1. The flow in the top $200 \mathrm{~m}$ is dominated by the APCC, a strongly baroclinic current. Downstream (to the southwest) from the mooring, there is a ridge extending from the coast which the flow below $300 \mathrm{~m}$ (the approximate sill depth) must negotiate. If the height of an obstacle in the path of a stratified, steady flow is relatively small, the flow will generate internal waves. If the obstacle is large enough, the fluid will instead be blocked upstream. This critical scale height is given by (Gill, 1982; Baines, 1995)

$$
h_{m}=\frac{U}{N}
$$

which can be compared to the height of the obstacle $h_{s}$. At A1, $h_{s}=200 \mathrm{~m}$, and a reasonable estimate for the velocity above the sill and the stratification are $U=5 \mathrm{~cm} / \mathrm{s}$ and $N=1.3 \cdot 10^{-3} \mathrm{~s}^{-1}$ respectively, which results in $h_{m} \approx 40 \mathrm{~m}$. Clearly, $h_{s}>h_{m}$ and the flow is expected to be blocked below the sill. This is evident in Figure 3-2, showing the mean velocities for the moored array. While the flow above the sill appears aligned 
with the coastline, the flow at $309 \mathrm{~m}$ (roughly at the sill depth) shows some offshore veering, and the deepest instrument shows a mean perpendicular to the coastline, and parallel to the orientation of the ridge located downstream of the mooring site. Notice that relatively small magnitude of the flow at and below the sill depth is not surprising given the baroclinic nature of the APCC. The orientation of the mean, however, appears consistent with the idea of blocking. As we will see later in this chapter, the tidal velocities have similar velocity amplitudes and the ridge also blocks their motion at depth 


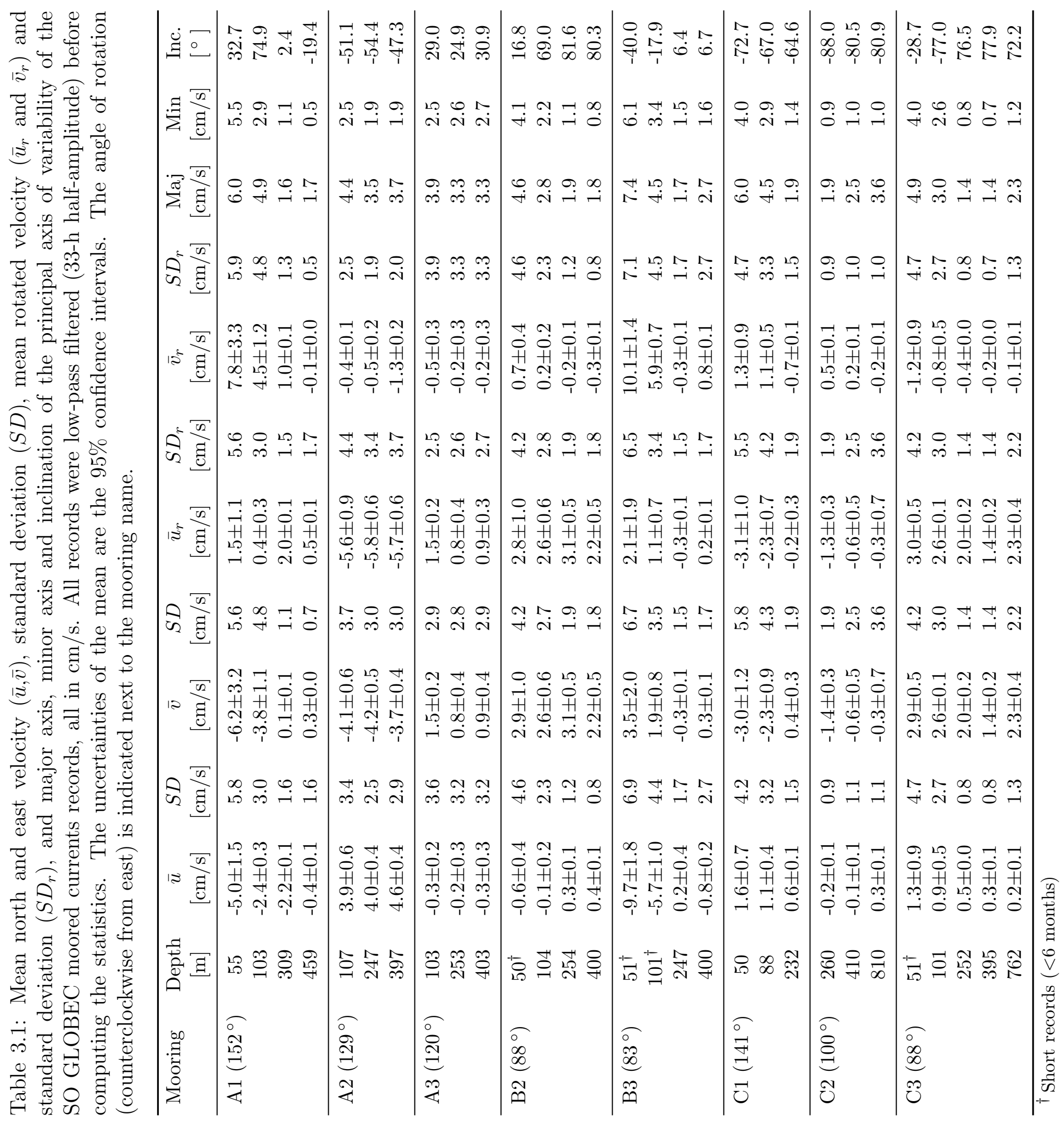



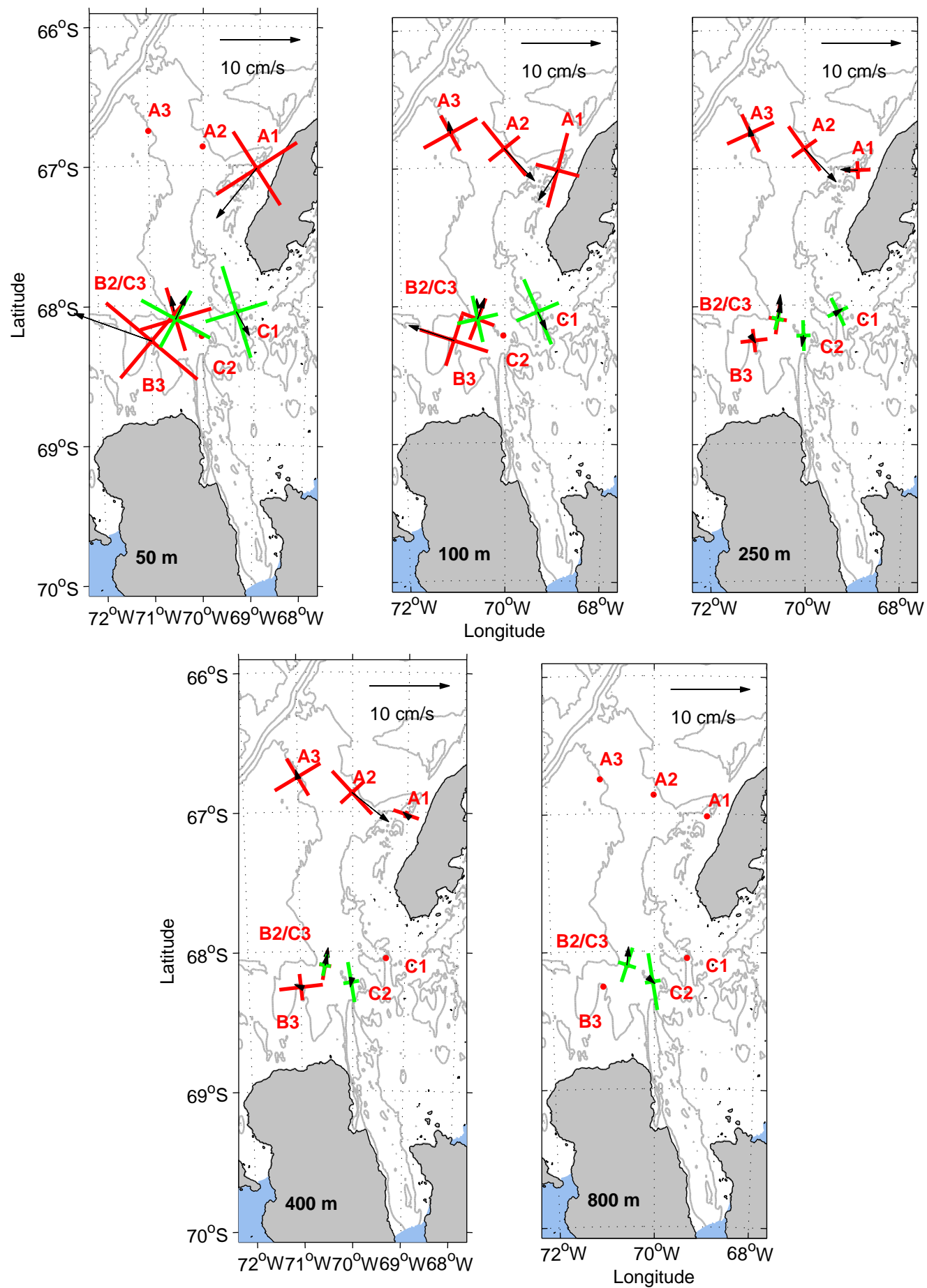

Figure 3-2: Mean and principal axes of the low-pass filtered (33-h half-amplitude) velocity records at 50, 100 and $250 \mathrm{~m}$ (top panels) and $400 \mathrm{~m}$ and $800 \mathrm{~m}$ (bottom panels). The red crosses indicate the 2001-2002 deployment (the A- and B-lines) and the green the 2002-2003 deployment (C-line). At A1, the instruments labeled 250 and $400 \mathrm{~m}$ were at 309 and $459 \mathrm{~m}$, respectively. 

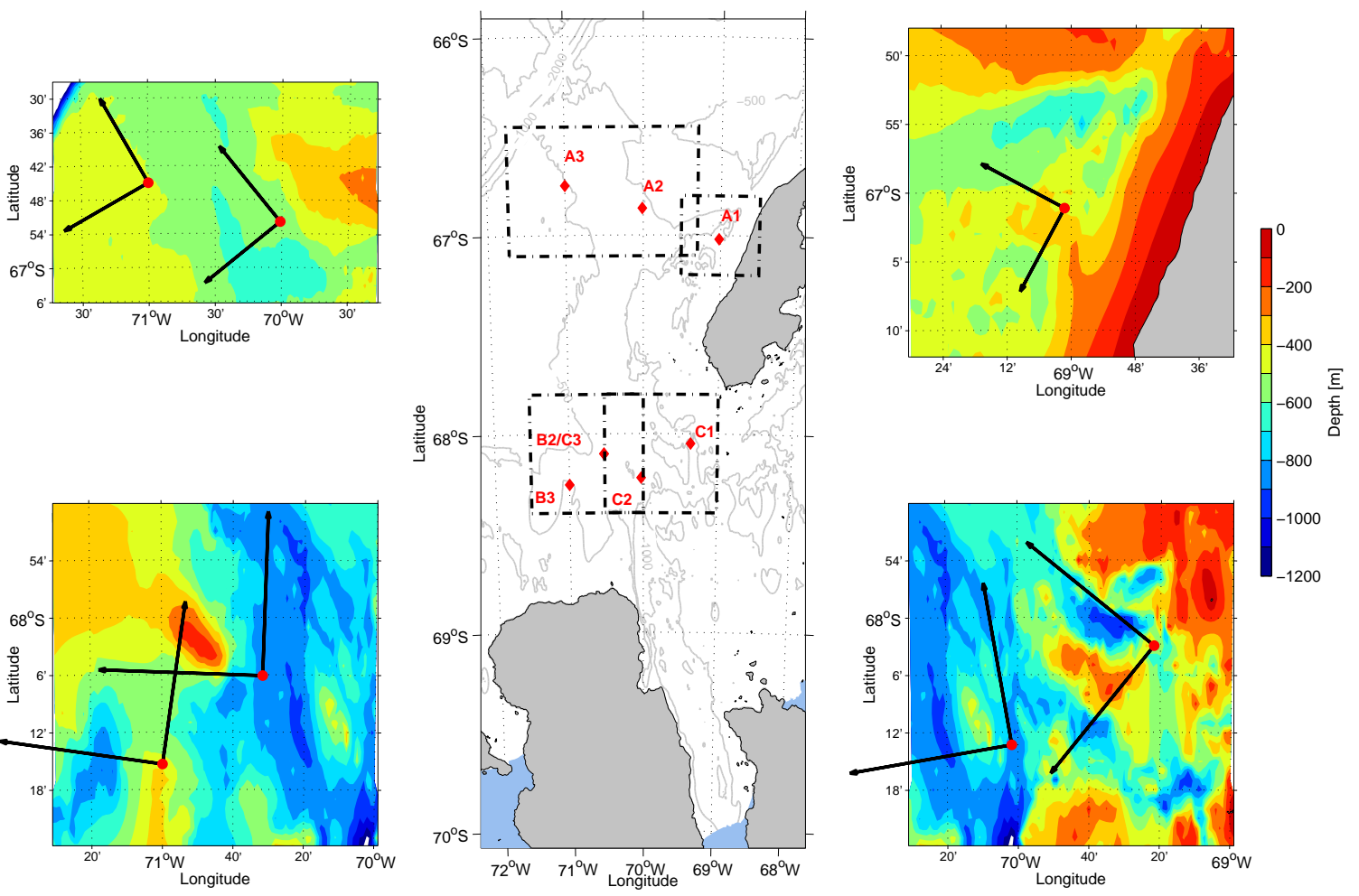

Figure 3-3: Bathymetry and orientation moored array current records. The center panel shows a map of the study area around Marguerite Trough, with the 500-, 1000-, 2000- and 3000-m isobaths plotted. The panels on either side show detailed maps of the bathymetry (with contours every $100 \mathrm{~m}$ ) in boxes around each mooring, indicated by the dashed lines in the center panel. At each site, the positive x-axis is aligned with the local isobaths and pointing towards the shelf-break, with the exception of A1, where the $y$-axis is aligned with the coastline, and B3, where the direction of the local isobaths is ambiguous (see text). 


\subsection{Tidal Variability}

In this section, an overview of the tidal current variability on the wAP shelf is presented. The analysis was carried out using a subset of the SO GLOBEC array velocity and pressure records using the T_TIDE toolbox for MATLAB (Pawlowicz et al., 2002). The toolbox is used to perform harmonic analysis of real (i.e. pressure) or complex (i.e. velocity) time series. The product of the analysis of a velocity time series is a pair of complex amplitudes $\left(a_{k}, a_{-k}\right)$ for each tidal constituent $k$, and they are converted to the standard tidal parameters reported here:

$$
\begin{aligned}
\operatorname{Maj}_{k} & =\left|a_{k}\right|+\left|a_{-k}\right| \\
\operatorname{Min}_{k} & =\left|a_{k}\right|-\left|a_{-k}\right| \\
\operatorname{Inc}_{k} & =\frac{\operatorname{ang}\left(a_{k}\right)+\operatorname{ang}\left(a_{-k}\right)}{2} \bmod 180 \\
\text { Phase }_{k} & =v_{k}-\operatorname{ang}\left(a_{k}\right)+\operatorname{Inc}_{k},
\end{aligned}
$$

which describe an ellipse with semi-major and semi-minor axes Maj and Min and inclination Inc, which is measured counter-clockwise from east. If Min is positive (negative), the ellipse is traced counter-clockwise (clockwise). The phase is given as "Greenwich phase", i.e. the phase of the response referenced to the equilibrium response at $0^{\circ}$ Longitude ( $v_{k}$ is the equilibrium phase). In the case of a pressure record, the values reported are the amplitude of the response and the Greenwich phase.

In order to separate neighbouring constituents separated in frequency by $\Delta f$, the time series must be of length

$$
|\Delta f| T \geq R
$$

where $T$ is the record length and $R$ (called the Raleigh criterion) is typically equal to unity (Emery and Thompson, 1998). For example, separation of the $K_{1}$ and $P_{1}$ diurnal components with $R=1$ requires a record length of

$$
T \geq \frac{1}{f\left(K_{1}\right)-f\left(P_{1}\right)}=\frac{1}{0.0418-0.0416} \frac{\mathrm{cpd}}{\mathrm{cpd}}=182 \text { days }
$$


For the analysis presented here, only long records of between 302 and 364 days were selected, which allows for the separation of the most energetic components observed. Notice also that at $67^{\circ} \mathrm{S}$, the inertial frequency is $0.0226 \mathrm{cpd}$, so that motions at this frequency can be separated from motions at the $M_{2}$ tidal frequency with a time series 11-days long or so, with the caveat that motions forced for example by the wind usually occupy a broad band near $f$.

The instruments recorded velocity and pressure at nominal depths of 100, 250, 400 and $800 \mathrm{~m}$. Significant components are defined as having a signal-to-noise (SNR) ratio of 2 or more. The SNR is calculated as the squared ratio of the amplitude to the amplitude error (Pawlowicz et al. 2002$)$. The results of the pressure record analysis are reported in centimeters of water, which were converted from pressure units assuming hydrostatic balance and a density of $1027 \mathrm{~kg} / \mathrm{m}^{3}$.

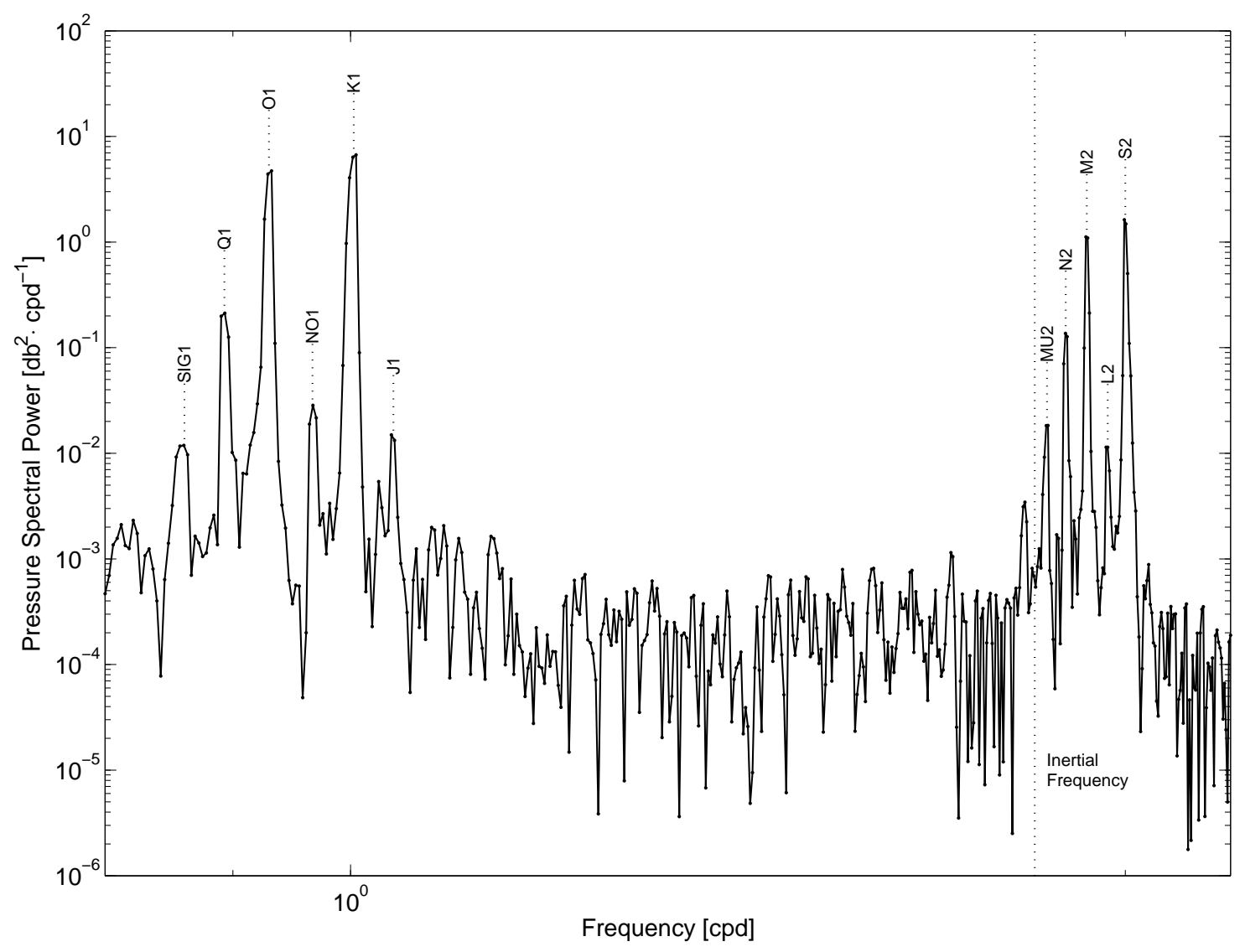

Figure 3-4: Spectrum of the pressure record at $47 \mathrm{~m}$ at A2 showing the main tidal constituents for the SO GLOBEC study region. 
Overall, the analysis reveals that tidal currents are typically less than $2 \mathrm{~cm} / \mathrm{s}$. The four largest tidal components are the semi-diurnal $M_{2}$ and $S_{2}$ and the diurnal $O_{1}$ and $K_{1}$ (Figure 3-4). These four components explain between 5 (at $100 \mathrm{~m}$ at A2) and $55 \%$ (at depth at B3) of the variance (18\% on average) of the velocity records.

In the following sections, the semi-diurnal and diurnal components are considered separately.

\subsubsection{Semi-diurnal Components}

\section{Velocity}

The semi-diurnal components show a few important similarities. Tidal currents are of the order of 1 to $2 \mathrm{~cm} / \mathrm{s}$ everywhere. On the mid- and outer-shelf at A2 and A3, the currents (Table 3.3 and Figures $3-5$ and $3-6$ ) are barotropic, while the rest of the locations show significant vertical structure. Overall, the $S_{2}$ component shows stronger polarization at all depths.

Down to $250 \mathrm{~m}$, the $M_{2}$ tidal ellipses are roughly aligned with the along-shelf direction north of Marguerite Bay (the clockwise rotation of the ellipses with offshore distance is not statistically significant), while at the B- and C-mooring lines they are roughly oriented east-west, in the direction of the mouth of the bay. For the same upper layer, the $S_{2}$ component, which in the nearshore mooring north of the bay (A1) is also strongly aligned with the coast, turns anti-clockwise with distance from the coast and is oriented perpendicular to the coast at A3. Across the mouth of the bay, at B3, C1 and C3, the $S_{2}$ ellipse is also roughly aligned with the $M_{2}$ components, while at B2/C3, the $S_{2}$ ellipses are oriented north-south. Given that B2/C3 and B3 are only $25 \mathrm{~km}$ apart, this suggests that there is significant spatial variability in the orientation of the semi-diurnal currents around Marguerite Bay.

At A1 and at the B- and C-mooring lines located across the mouth of Marguerite Bay, the semi-diurnal currents have a complicated vertical structure. At A1, the tidal currents at 100 and $250 \mathrm{~m}$ are roughly aligned with the coast of Adelaide Island, while the deepest instrument, located below the sill of the deep depression where the 
mooring was deployed (see Section 3.2.1 and Chapter 5), shows strong veering of the currents so that they are aligned perpendicular to the coast and roughly parallel to the orientation of the nearby sill (Figure $3-2$ ). There is also a roughly $100^{\circ}$ phase difference between the currents above and below the sill for both components, although the magnitude of the currents does not change significantly.

The strong influence of local bathymetry is also evident elsewhere on the shelf. At $\mathrm{C} 2$ and B2/C3, the currents at and below $400 \mathrm{~m}$ appear increasingly aligned with the local bathymetry with increasing depth, and also show phase differences of $60-150^{\circ}$ above and below $400 \mathrm{~m}$ (with the exception of the $M_{2}$ at B3). The magnitude of the velocity also is reduced with depth at $\mathrm{C} 2$, while at $\mathrm{B} 3$ the velocity increases with depth for both components.

The vertical structure of the semi-diurnal components is perhaps most interesting at B2/C3. The estimates are consistent from the first (B2) to the second (C3) year of the deployment, and show the velocity decreasing and turning anti-clockwise from 100 to $400 \mathrm{~m}$ at both moorings. However, the deepest instrument at C3, located at $800 \mathrm{~m}$, reveals that at depth the velocity increases again, so that the velocity magnitude shows a minimum at $400 \mathrm{~m}$.

\section{Sea-level Amplitude}

The tidal sea-level amplitude on the shelf (Table 3.5 and Figure 3-11, top panels) is maximum along the shelf-break for $M_{2}$ with a small $(1 \mathrm{~cm})$ drop in the $\approx 110 \mathrm{~km}$ covered by the A-mooring line. The phase estimations, which show larger errors, are not significantly different across the shelf. Across the mouth of the bay going from north to south, from C1 to B3 (Figure 3-12), the amplitude also drops by less than $1 \mathrm{~cm}$, with a relatively constant phase.

The $S_{2}$ tide show an opposite structure across the shelf, with a maximum near the coast and a 1-cm drop toward the outer mooring. The phase estimates also show an $8^{\circ}$ to $10^{\circ}$ increase in the phase from the coast to A3. Across the mouth of the bay, the structure is similar to the $M_{2}$ tide, with a 1-cm or so drop in sea-level from C1 to B3. The variability in the phase estimations, even at the $\mathrm{B} 2 / \mathrm{C} 3$ pair, is too large to 
detect any spatial patterns of variability, although the entire range is only $5^{\circ}$ (Table 3.5.

\subsubsection{Diurnal Components}

\section{Velocity}

The tidal ellipses and phases of the two most important diurnal components, $O_{1}$ and $K_{1}$, are shown in Figures $3-7$ and $3-8$ and Table 3.4 . The structure shares some characteristics with the semi-diurnal components. At the mid- and outer-shelf moorings of the A-line (A2 and A3) the diurnal components are barotropic, while at A1 the motion below the sill shows strong veering and a phase difference of $130^{\circ}$ or so with respect to the overlying water.

The $O_{1}$ currents have a similar spatial structure to $M_{2}$ north of Marguerite Bay. The tidal ellipses are strongly polarized near the coast and aligned with the coastline. The ellipses show clockwise rotation with distance from the coast (the uncertainties are in this case much smaller), with the ellipse becoming less polarized in the outer shelf. Across the mouth of Marguerite Bay, the tidal ellipses have a complex horizontal structure, with the currents near the northern edge of the entrance to the bay oriented along the axis of the mouth, while farther to the south-west at B2/C3, C2 and B3 the ellipses show markedly distinct structures, with relatively small $(1 \mathrm{~cm} / \mathrm{s})$ velocities with weak polarization at B2/C3 and strong $(3-4 \mathrm{~cm} / \mathrm{s})$ velocities at B3, oriented in the east-west direction. The above description applies also for the $K_{1}$ currents, with a few exceptions: the tidal ellipses across the A-mooring line are more similar to $S_{2}$ in that the ellipses show a strong $90^{\circ}$ clockwise rotation from the nearshore A1 mooring to the outer-shelf A3 mooring. Also, the B2/C3 moorings show stronger polarization of the diurnal ellipses.

The vertical structure of the diurnal constituents in the B- and C-mooring lines also shows some structure with depth, but is generally not as significant as that shown by the semi-diurnal components. At B3, where both the $O_{1}$ and $K_{1}$ are the largest on the shelf, diurnal currents increase significantly from 250 to $400 \mathrm{~m}$, although there 
is no significant veering and only a weak phase difference with depth. At B2/C3, a vertical structure resembling the semi-diurnal components is also evident, with a velocity minimum at $400 \mathrm{~m}$. Finally, the tidal ellipses at $\mathrm{C} 2$, which are roughly aligned with the bathymetry above the rim of Marguerite Trough, becoming more strongly polarized with depth but show little veering and phase changes.

\section{Sea-level Amplitude}

The diurnal sea-level components show a rather simple structure along the A-line, with both components showing a constant amplitude across the shelf. The phase estimations have too much spread to determine trends, but in both cases the phase changes are less than $5^{\circ}$.

Across the mouth of Marguerite Bay, the diurnal components resemble the semidiurnal components, with the highest amplitude on the northern edge of the mouth near Adelaide Island and the $O_{1}\left(K_{1}\right)$ tide showing a 1.5-cm (1-cm) drop in amplitude towards the southernmost mooring. The phase is nearly constant along this line.

\subsubsection{Comparison with the AntPen04.01 Tidal Model}

A regional context for the tidal analysis results provided in the previous section can be obtained from comparisons with the AntPen04.01 regional tidal model, developed by Laurie Padman and colleagues at Earth and Space Research (http://www.esr.org). The following sections provide a brief overview of the model and the first comparison between the model and moored currents observations for this region.

\section{A brief overview of the model}

The AntPen04.01 is a high-resolution $\left(1 / 30^{\circ}\right.$ Longitude x $1 / 60^{\circ}$ Latitude, roughly $2 \mathrm{~km}$ ), barotropic, and linear forward tidal model whose domain covers the entire Antarctic Peninsula. The model includes the best bathymetry available to date, including the high-resolution bathymetry for the SO GLOBEC study region (Bolmer et al. 2004). The model is forced at its lateral boundaries by CATS02.01, a circum- 
Antarctic, coarser-resolution forward model (Padman et al., 2002) and by astronomical forcing, and is based on the linearized shallow water equations.

\section{The main tidal constituents in AntPen04.01}

The model sea-level amplitude and phase of the main semi-diurnal and diurnal components are shown in Figures $3-9$ and 3-10. For all of the components, the tidal amplitude tends to be smaller and with larger horizontal scales on the western shelf of the peninsula than on the eastern shelf. The diurnal components are largest all along the coast except near the tip of the peninsula where $M_{2}$ becomes slightly larger. In and around Marguerite Bay, however, the tidal phase has a range of only a few degrees for each component.

Of the four components considered here, three $\left(S_{2}, O_{1}\right.$ and $\left.K_{1}\right)$ have a phase structure consistent with anti-clockwise propagation around the tip of the peninsula and southward along the coast. The diurnal components have phase fluctuations with long horizontal scales with changes of the order of $10^{\circ}$ along the $400 \mathrm{~km}$-long study region. The $S_{2}$ tide has a roughly $30^{\circ}$ phase change within the same region.

The $M_{2}$ tide propagates across the shelf, turning slightly north-eastward north of Alexander Island (the southern boundary of Marguerite Bay) and south-eastwards south of the bay, with the phase increasing by roughly $10^{\circ}$ from the shelf-break to the coast in the SO GLOBEC study area.

\section{Comparison with the observations}

To compare the model output to the moored array observations, the current and pressure observations were vertically averaged prior to performing the tidal analysis. The vertically-averaged velocity and pressure records are defined as:

$$
\bar{u}=\frac{1}{H} \int_{H}^{0} u d z
$$


and

$$
\overline{p^{\prime}}=\frac{1}{H} \int_{H}^{0} p^{\prime} d z
$$

where $u$ is the velocity, $p^{\prime}$ is the pressure anomaly (the pressure record with the time mean removed) and $H$ is the bottom depth. In order to calculate the average quantities, the velocity and pressure anomaly are assumed constant from the shallower (deepest) instrument in the water column to the surface (bottom). Several of the ADCP records in the top $50 \mathrm{~m}$ or so have long periods of time (in particular during the winter) with no data, and B2 and B3 had a few instruments change depth due to loss of buoyancy of their top instrument (B2) and flotation sphere (B3) (Moffat et al., 2005). The vertical averages were therefore computed using a subset of the data that provided measurements throughout the entire deployment and, in the case of the ADCP records, had at least $90 \%$ of data return during that period. Table 3.2 presents a list of the instrument records used to calculate the vertical averages.

Figures 3-5 to 3-8 show the tidal ellipses from the AntPen04.01 model together with the tidal analysis, and Table 3.6 presents the tidal ellipse parameters for each mooring site from both the model output and the vertically-averaged records. Let us consider first the tidal currents along the A-line. For the four components considered, the model predicts the semi-diurnal components well for all the sites, although it overestimates the magnitude of $M_{2}$ at A1. For $O_{1}$, the model tends to underestimate the magnitude of the velocity at the three moorings by $25 \%$ to $50 \%$. The $O_{1}$ inclination is predicted correctly at A1, but not at A2 and A3, and the phase is within error at A1 and A2 and is too small at A3 by $7^{\circ}$ (some 30 minutes). The model also slightly underestimates the $K_{1}$ currents at A1, and the inclination and phase is off by 70 and $100^{\circ}$ respectively. At A2 and A3, the model correctly predicts the magnitude and phase of the $K_{1}$ currents, while the predicted inclination is slightly outside the estimated errors.

Across the mouth of Marguerite Bay, the model shows mixed results in predicting the tidal currents. The observed $M_{2}$ tide current magnitude is overestimated by the 
Table 3.2: Depth of the current velocity and pressure records used to compute the vertical averages. ADCP records are given as a range, with the bin separation in parenthesis (97-165 (2) means from 97 to $165 \mathrm{~m}$ every $2 \mathrm{~m}$ ), and the instruments are separated by commas. Also given are the bottom depth at each mooring and the length of the record used.

\begin{tabular}{|c|c|c|c|c|}
\hline Mooring & $\begin{array}{c}\text { Velocity } \\
\text { Record Depth } \\
{[\mathrm{m}]}\end{array}$ & $\begin{array}{c}\text { Pressure } \\
\text { Record } \\
\text { Depth }[\mathrm{m}]\end{array}$ & $\begin{array}{c}\text { Bottom Depth } \\
{[\mathrm{m}]}\end{array}$ & Length [days] \\
\hline $\mathrm{A} 1$ & $\begin{array}{c}97-165(2), 309 \\
459\end{array}$ & 309,502 & 509 & 323 \\
\hline $\mathrm{A} 2$ & $107,247,397$ & $47,247,554$ & 561 & 319 \\
\hline A3 & $103,253,403$ & $103,253,480$ & 480 & 319 \\
\hline $\mathrm{B} 2$ & $\begin{array}{c}91.7-289.7(6) \\
400,811\end{array}$ & 804 & 811 & 321 \\
\hline B3 & 247,400 & 247,400 & & 322 \\
\hline $\mathrm{C} 1$ & $26-88(2), 232$ & 232 & $859^{a}$ & 368 \\
\hline $\mathrm{C} 2$ & $260,410,810$ & 260,852 & 859 & 367 \\
\hline C3 & $\begin{array}{c}13-109(2), 252 \\
395,762\end{array}$ & 252 & 806 & 364 \\
\hline
\end{tabular}

${ }^{a}$ The integration was conducted assuming $H=250 \mathrm{~m}$

model at B3 and underestimated at C1 (in both cases by $\approx 25 \%$ ) but is predicted correctly everywhere else. The $M_{2}$ phase is within the error at B3 and C1 but it is not predicted correctly at B2, C2 and B2/C3. The inclination from the model for the $M_{2}$ tide is outside the confidence intervals at B3 and C2. The amplitude of the $S_{2}$ tide is in general predicted correctly, with small (10\%-20\%) overestimations at B2 and $\mathrm{C} 2$ and a bigger underestimation (25\%) at C2. The inclination and phase tend to be off by 10 to $30^{\circ}$ (for phase, 20 minutes to one hour), with as much as $150^{\circ}$ of error in the phase at B3.

The diurnal components are also predicted reasonably well by the model. Dif- 
ferences between the model and the data larger than the confidence intervals are generally within $15 \%$ or so of the estimations from the observations. The only significant exception is at B3, where the model does the worst of all the mooring sites for the diurnal components, underestimating the amplitude of the velocity by around $67 \%$ and predicting the phase incorrectly.

Comparisons of the estimated tidal sea-level amplitudes and phases with the model predictions are shown together in Figures 3-11 and 3-12. At the A-line, the model underestimates the amplitude of the $M_{2}, O_{1}$ and $K_{1}$ constituents by $\approx 5 \%$ (0.5 to $1.5 \mathrm{~cm})$, while overestimating the $S_{2}$ amplitude by $1 \%(0.2 \mathrm{~cm})$ or so. The phase predictions are either within error or within a few degrees of the estimated values. This translates into an error of 2 to 4 minutes, which is in general larger than the clock drifts found upon instrument recovery, although a few instruments were found to have clock errors of a few minutes over the 1-year deployment (Moffat et al., 2005).

Across the mouth of Marguerite Bay, the model amplitudes also predict the observations well. The model consistently underestimates the $M_{2}$ and $K_{1}$ amplitude by 1-4\% (0.2 to $1 \mathrm{~cm})$ while errors in the other two components, where they are significant, are of the same magnitude. The phase estimates are significantly different than the model in a few locations, with the $K_{1}$ phase predictions being consistently too small across the bay by $1^{\circ}$ or so (4 minutes), but overall the errors are smaller than a few degrees.

\subsubsection{Discussion and Summary of the Tidal Analysis}

The analysis presented in the above sections shows the tidal velocities are small in the study region, with velocities as large as $4 \mathrm{~cm} / \mathrm{s}$ but in general less than $2 \mathrm{~cm} / \mathrm{s}$. The tidal currents are fairly barotropic on the mid- and outer-shelf off Adelaide Island, but the analyses in the above sections show that the tidal currents can have significant vertical structure.

At $\mathrm{C} 2$, for example, the semi-diurnal components are oriented at a significant angle with respect to the axis of Marguerite Trough, and shows strong veering and

phase shifts below the rim of the trough. The diurnal components, however, are 
roughly aligned with the axis of the trough and one of the effects of the bathymetry is to increase the polarization of these currents with depth. At A1, where all the tidal components are aligned with the coastline above the sill, the deepest instrument always show strong veering and phase shifts to align the deep currents along the direction of the nearby sill, oriented roughly perpendicular to the coastline.

Other properties of the tidal velocity field are more complex. At B2/C3, for example, the tidal velocities show a minimum at $400 \mathrm{~m}$, and although the firstyear deployment lacked a deep instrument, the vertical structure down to $400 \mathrm{~m}$ is consistent in both years, suggesting this mid-depth minimum is not due to instrument malfunction.

Some of the ideas about flow blocking discussed before (Section 3.2.4) also apply to oscillatory flows (Legg, 2004; Garrett and Kunze, 2007) and therefore blocking of the flow is also expected at A1. To understand the vertical structure at some of the mooring sites, simple dynamical scales based on models of flow past isolated obstacles are likely not appropriate and more complicated models of tidal, stratified flows will be required.

As the barotropic tide interacts with topography, internal gravity waves known as internal tides might be forced. The internal tides extract energy from the barotropic tide and this energy could be propagated away or be dissipated on the shelf. Although a detailed study of internal tides on the wAP shelf is beyond the scope of the basic description presented here, a brief exploration of the relevant scales of internal tide dynamics might shed some light on their relevance in the study region. Radiating waves can be expected for motions with frequencies $f<\omega<N$. For the wAP region, both the $M_{2}$ and $S_{2}$ semi-diurnal components, which would act as the forcing, are within this range and therefore radiation of internal waves at these frequencies can be expected. In fact, the diurnal components tend to be more barotropic than the semi-diurnal components, which suggest that the transfer of energy from the barotropic to the baroclinic tide might be more relevant for the semi-diurnal tides. If one assumes a simple, two-dimensional stratified ocean with sinusoidal topography, where there is a tidal flow with scale $u_{o}$, an important parameter of the flow is $u_{o} / \omega$, 
the tidal excursion. For the relatively small tidal velocities observed on the wAP shelf $(1-2 \mathrm{~cm} / \mathrm{s})$, the tidal excursion is only of the order of a kilometer or so for the semi-diurnal components. Moreover, the scale of the topography $k^{-1}$ can be much larger than the tidal excursion, so that the advective terms in the governing equations need to be retained and lee waves might be generated (Garrett and Kunze, 2007). Another parameter of importance is the topographic steepness, defined as

$$
\gamma=\frac{k h_{0}}{c},
$$

where

$$
c=\left(\frac{\omega^{2}-f^{2}}{N^{2}-\omega^{2}}\right)^{1 / 2},
$$

where $h_{0}$ is a height scale of the topography, and $c$ is the slope of the particle motions and of the internal wave rays with frequency $\omega$ propagating in a fluid of stratification $N$ (Baines, 1974). When the steepness parameter $\gamma$ is near 1, the topographic slope is said to be critical, and regions of near-critical slope have been shown to have enhanced baroclinic tidal motion (Leaman, 1980; Holloway, 1985; Garrett and Kunze, 2007).

On the wAP shelf, $c$ is roughly 0.03 for the $M_{2}$ tide (with $N=1.310^{-3} \mathrm{~s}^{-1}$ ). With the complicated bathymetry typical of the region (see Chapter 2), critical slopes are ubiquitous on the shelf. As an example, the side walls of Marguerite Trough (Figure 2-5. have scales $h_{0}$ of the order of 300 to $1000 \mathrm{~m}$ over lateral scales $k^{-1}$ of only 10 to $20 \mathrm{~km}$, which result in values for $\gamma$ of 3 to 22 , clearly supercritical. This simple analysis suggests that internal tides forced by the semi-diurnal barotropic tide might be important on the wAP region, and that even though the tidal currents are small, the strongly sloping bathymetry might provide an effective mechanism for the transfer of energy from the barotropic tide to internal waves, which might in turn enhance mixing on the shelf.

As for the diurnal tidal currents, which are of lower frequency than the local Coriolis frequency $f$, the evidence indicates they tend to be more barotropic everywhere, which is consistent with the absence of internal tide generation based on simple mod- 
els (Garrett and Kunze, 2007). However, some of the vertical structure which is observed at some sites might be due to the blocking effects by bathymetry discussed above.

Finally, a comparison of the tidal analysis results with the AntPen04.01 model output revealed that the model predicts reasonably well the amplitude and phase of the four major constituents considered here to within a few percent. However, the observed tidal currents have significant vertical structure at several of the mooring sites which appears to be influenced by the complicated bathymetry on the shelf. The model predicts reasonably well the tidal velocity at the A-mooring line, in particular the offshore moorings where the tides are barotropic, but it has mixed results across the mouth of Marguerite Bay, where the tidal currents have a more complex vertical structure. 


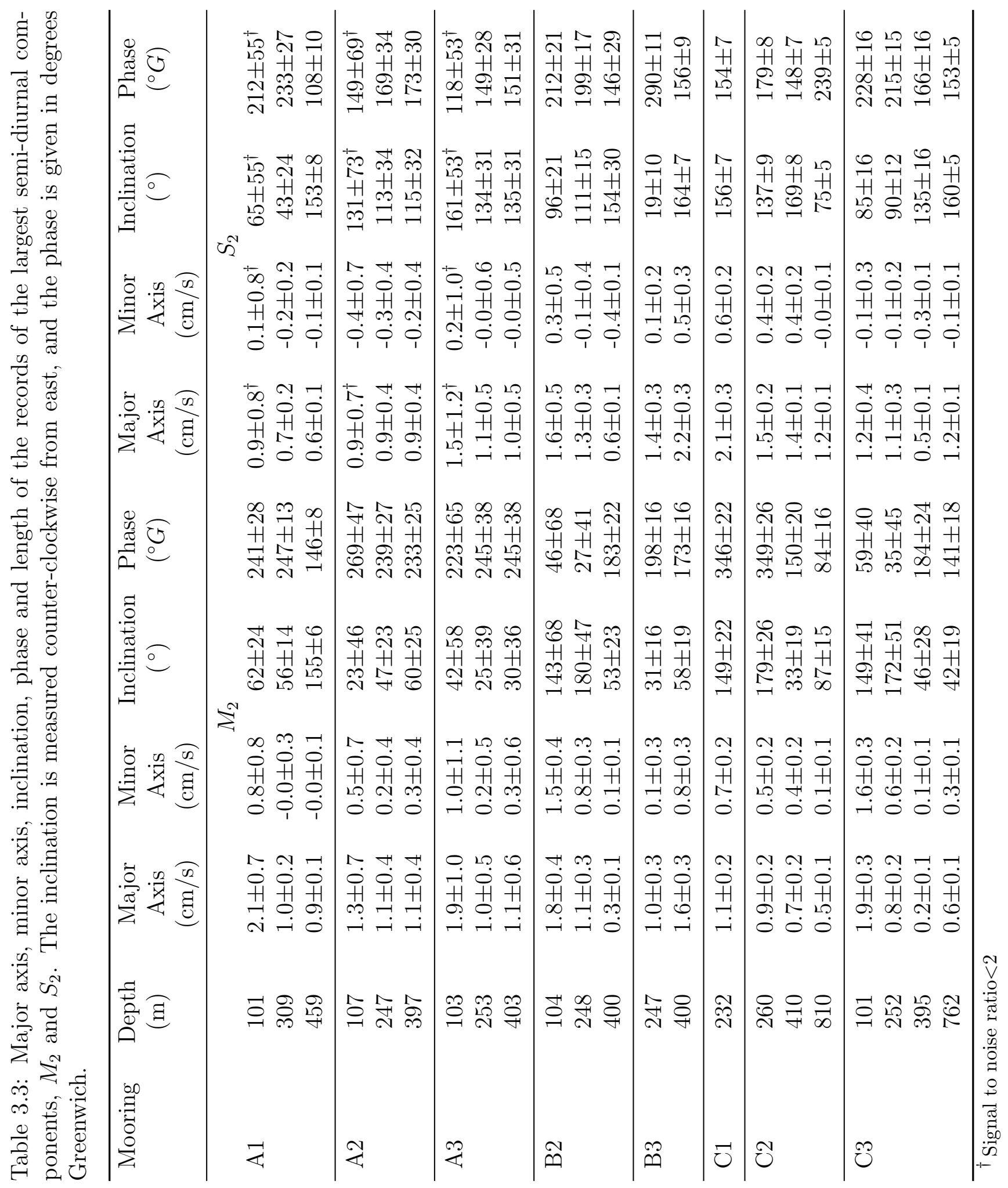




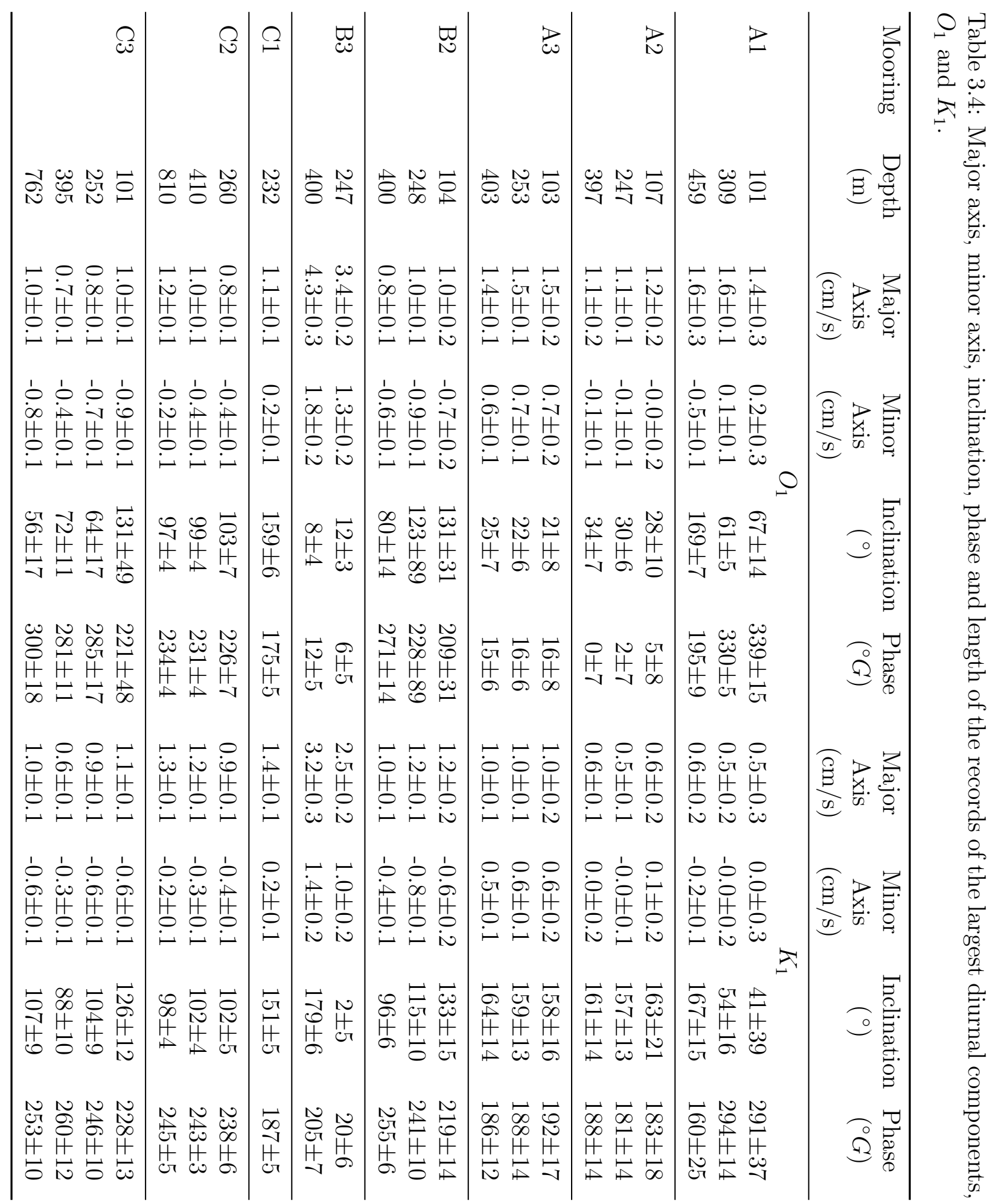




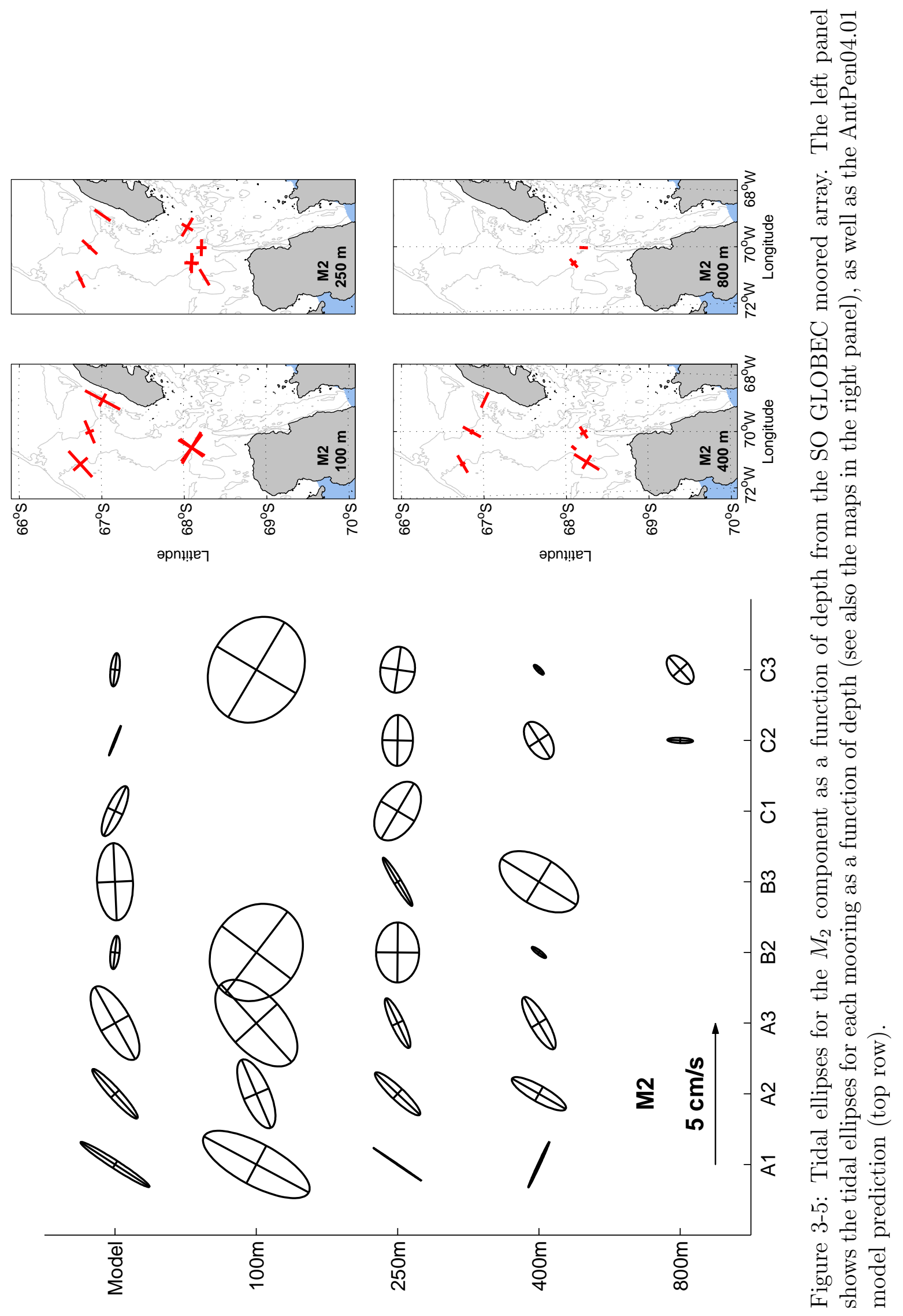




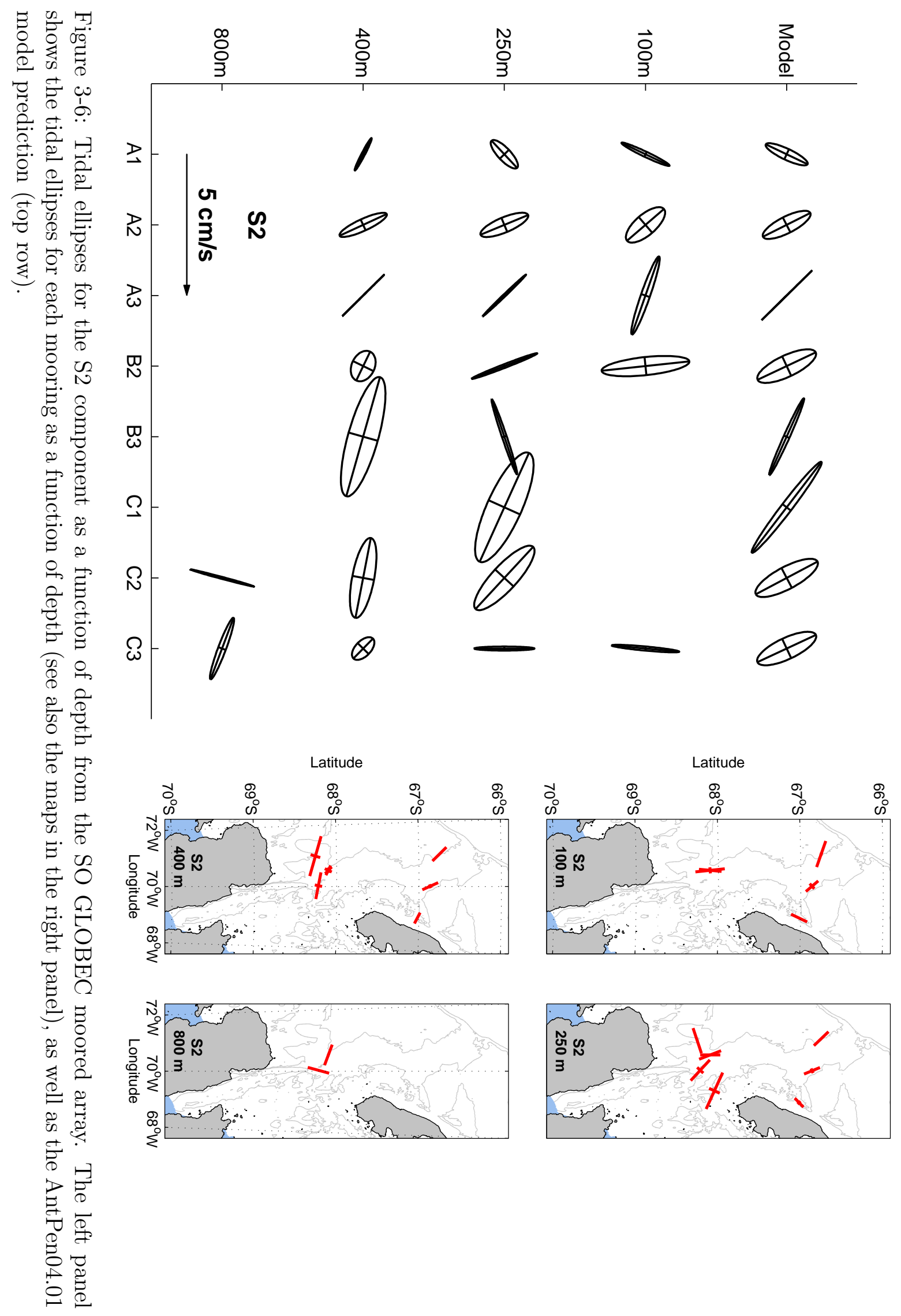



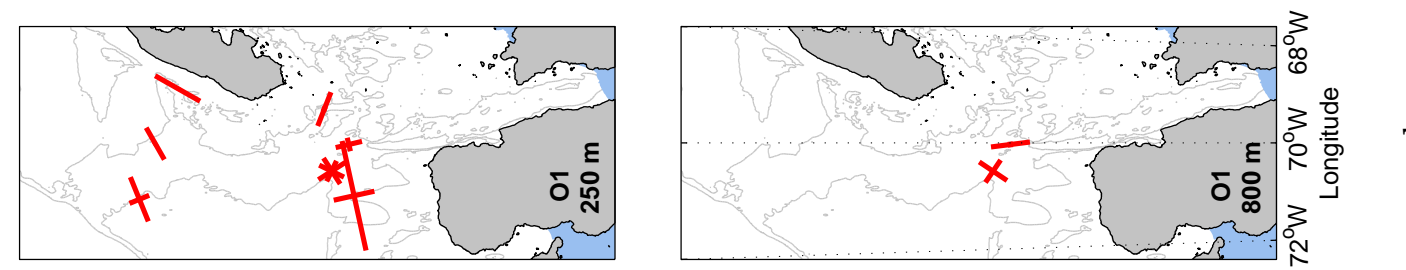

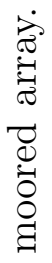

总
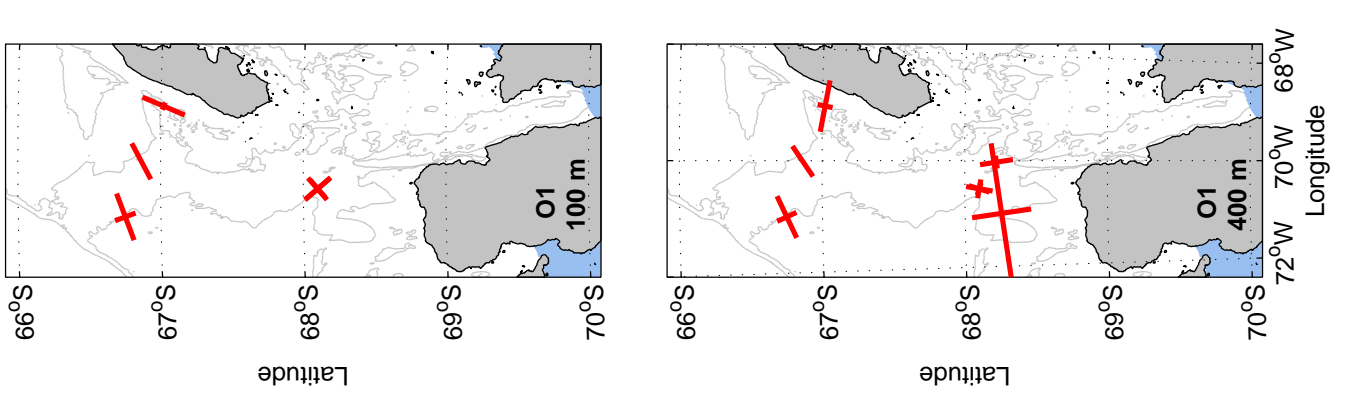

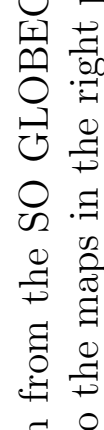

돈, $\frac{0}{2}$

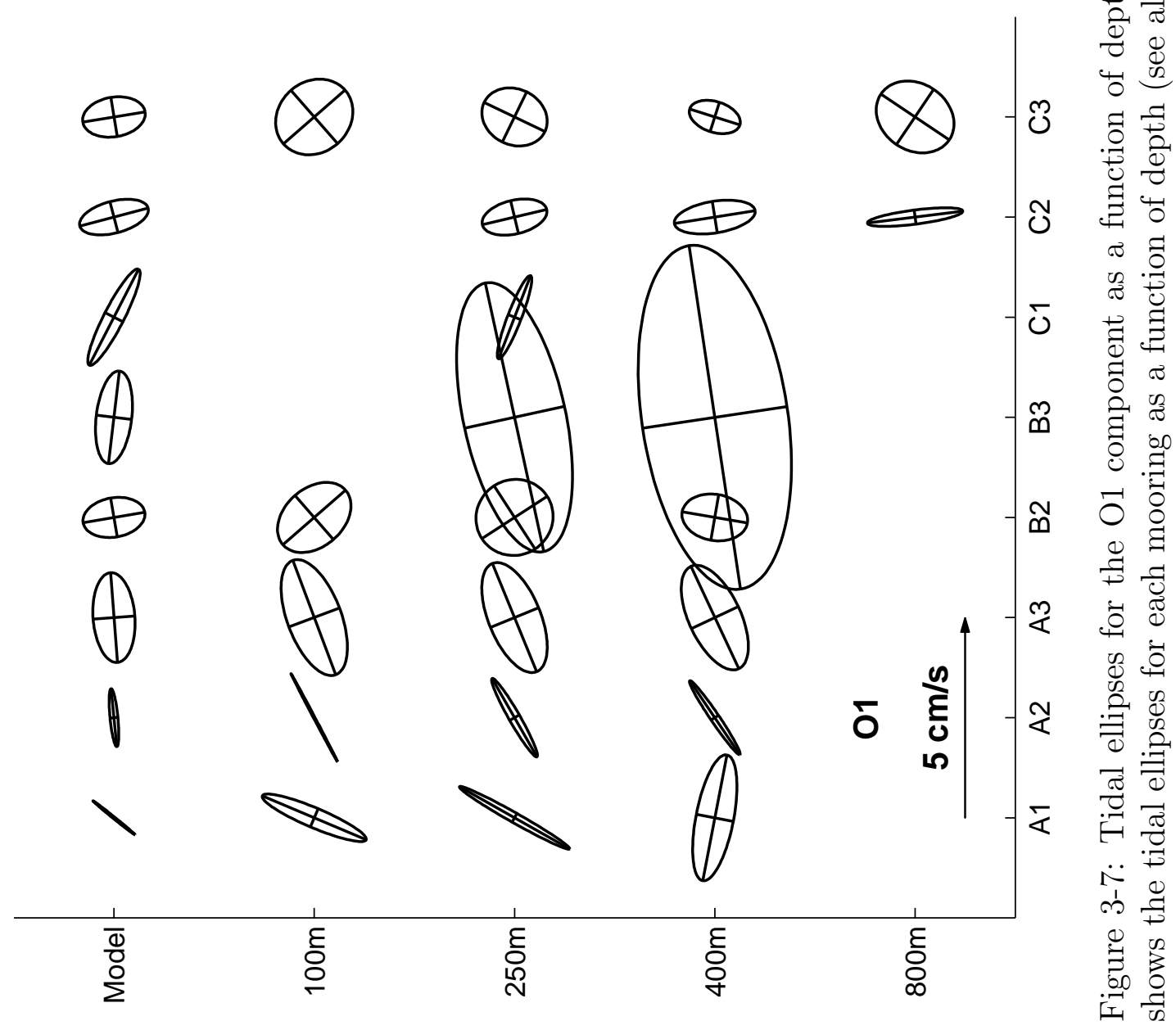




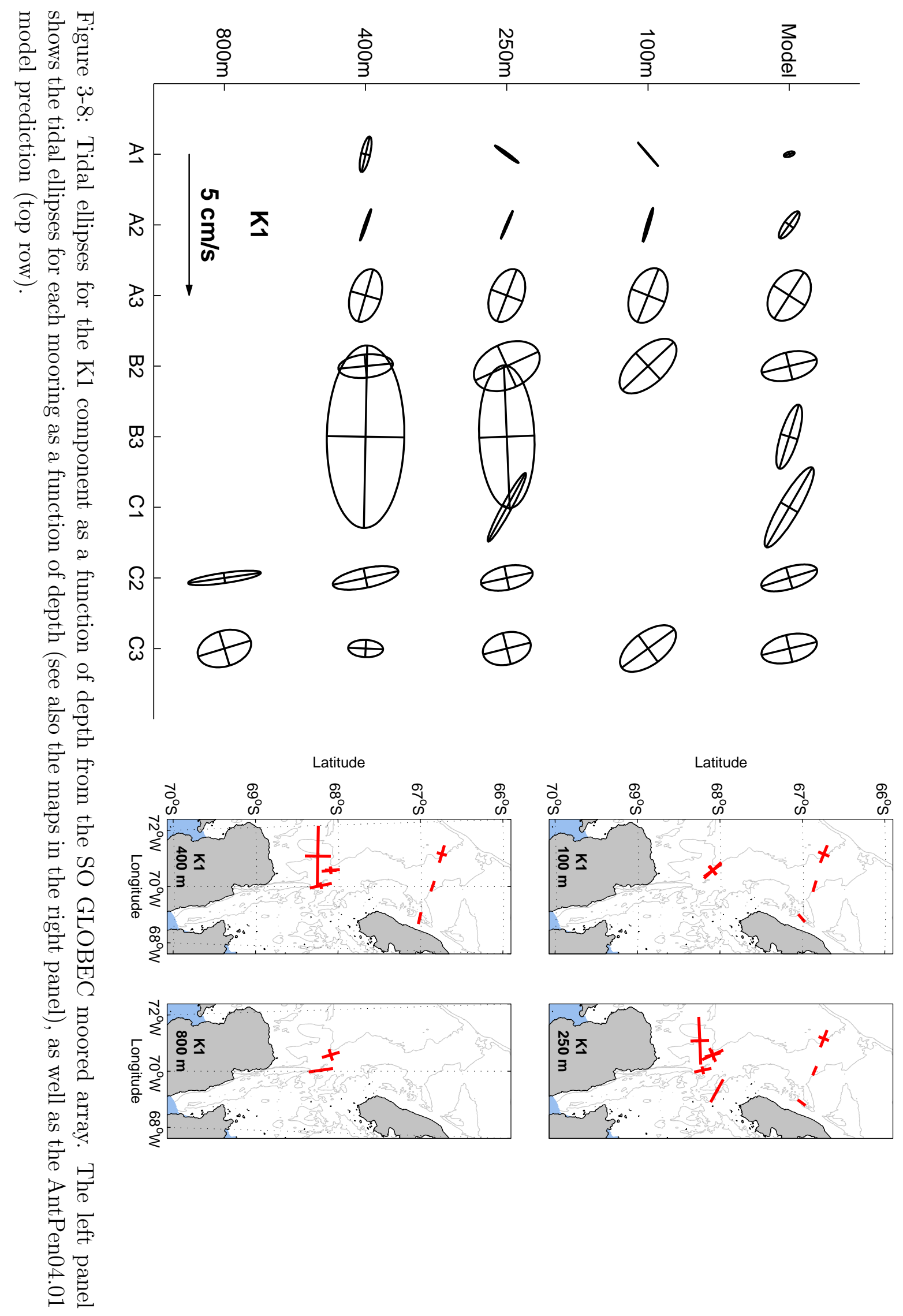



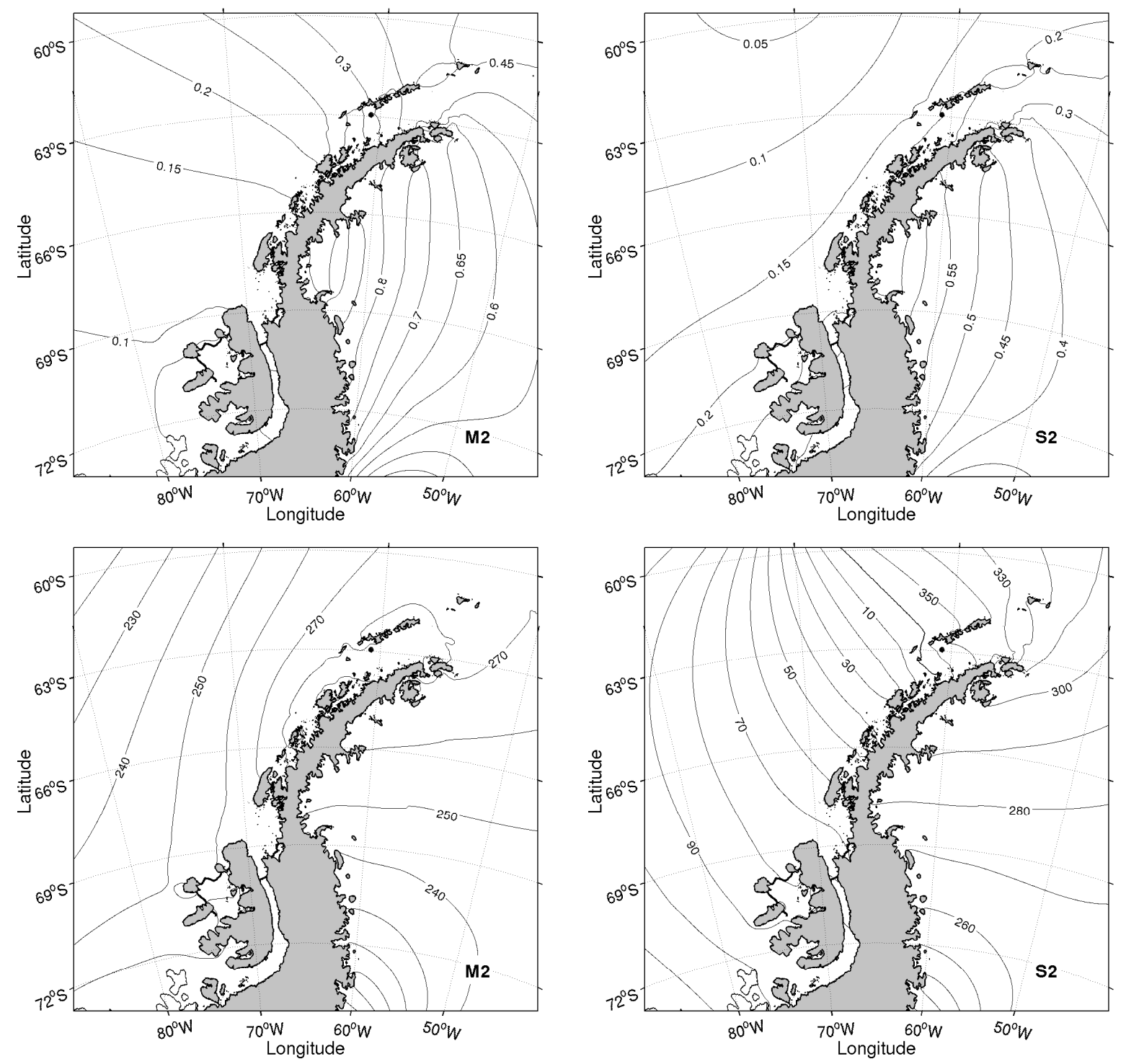

Figure 3-9: Tidal sea-level amplitude (in $\mathrm{cm}$, top panels) and Greenwich phase (bottom panels) of the largest semi-diurnal components from the AntPen04.01 tidal model. 

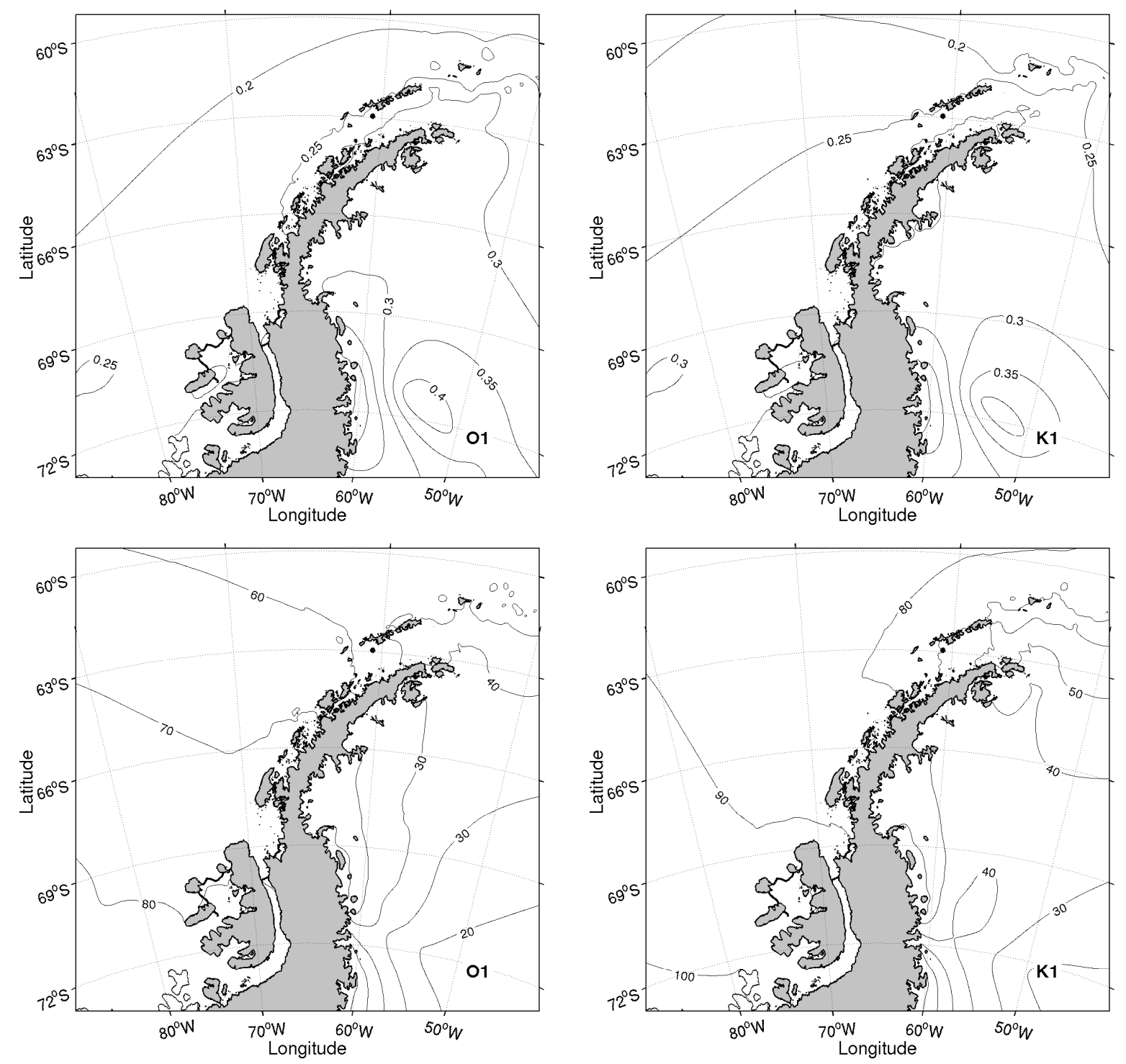

Figure 3-10: Tidal sea-level amplitude (in $\mathrm{cm}$, top panels) and Greenwich phase (bottom panels) of the largest diurnal components from the AntPen04.01 tidal model. 
Table 3.5: Estimated tidal sea-level amplitude $\left(A_{o b s}\right)$ and Greenwich phase $\left(\phi_{\text {obs }}\right)$, calculated from the SO GLOBEC array pressure records. The uncertainties correspond to the $95 \%$ confidence interval for each estimate (Pawlowicz et al., 2002).

\begin{tabular}{|c|c|c|c|c|c|}
\hline Mooring & $\begin{array}{c}\text { Depth } \\
{[\mathrm{m}]}\end{array}$ & $\begin{array}{l}A_{o b s} \\
{[\mathrm{~cm}]}\end{array}$ & $\begin{array}{c}\phi_{o b s} \\
{\left[\begin{array}{c}{ }^{\circ} \mathrm{G}\end{array}\right]}\end{array}$ & $\begin{array}{l}A_{o b s} \\
{[\mathrm{~cm}]}\end{array}$ & $\begin{array}{c}\phi_{o b s} \\
{\left[\begin{array}{ll}{ }^{\circ} \mathrm{G}\end{array}\right]}\end{array}$ \\
\hline & & \multicolumn{2}{|c|}{$M_{2}$} & \multicolumn{2}{|l|}{$S_{2}$} \\
\hline \multirow[t]{2}{*}{ A1 } & 309 & $11.5 \pm 0.3$ & $262 \pm 1$ & $15.5 \pm 0.3$ & $55 \pm 1$ \\
\hline & 502 & $11.5 \pm 0.4$ & $265 \pm 2$ & $15.5 \pm 0.4$ & $59 \pm 1$ \\
\hline \multirow[t]{3}{*}{ A2 } & 47 & $12.1 \pm 0.4$ & $263 \pm 2$ & $14.9 \pm 0.3$ & $59 \pm 1$ \\
\hline & 247 & $12.1 \pm 0.2$ & $266 \pm 1$ & $14.9 \pm 0.2$ & $63 \pm 1$ \\
\hline & 554 & $12.1 \pm 0.2$ & $266 \pm 1$ & $14.9 \pm 0.2$ & $63 \pm 1$ \\
\hline \multirow[t]{3}{*}{ A3 } & 103 & $12.4 \pm 0.4$ & $264 \pm 2$ & $14.4 \pm 0.4$ & $65 \pm 2$ \\
\hline & 253 & $12.5 \pm 0.2$ & $264 \pm 1$ & $14.5 \pm 0.2$ & $66 \pm 1$ \\
\hline & 480 & $12.4 \pm 0.2$ & $262 \pm 1$ & $14.3 \pm 0.2$ & $64 \pm 1$ \\
\hline \multirow[t]{2}{*}{ B2 } & 140 & $11.6 \pm 0.3$ & $263 \pm 1$ & $17.1 \pm 0.3$ & $70 \pm 1$ \\
\hline & 804 & $11.6 \pm 0.3$ & $263 \pm 1$ & $16.8 \pm 0.3$ & $70 \pm 1$ \\
\hline \multirow[t]{2}{*}{ B3 } & 247 & $11.2 \pm 0.3$ & $264 \pm 1$ & $16.9 \pm 0.3$ & $72 \pm 1$ \\
\hline & 440 & $11.4 \pm 0.2$ & $263 \pm 1$ & $16.7 \pm 0.3$ & $72 \pm 1$ \\
\hline $\mathrm{C} 1$ & 232 & $12.0 \pm 0.1$ & $263 \pm 1$ & $17.8 \pm 0.1$ & $71 \pm 0$ \\
\hline \multirow[t]{2}{*}{$\mathrm{C} 2$} & 260 & $11.9 \pm 0.1$ & $264 \pm 1$ & $17.6 \pm 0.1$ & $74 \pm 0$ \\
\hline & 852 & $11.5 \pm 0.2$ & $262 \pm 1$ & $17.2 \pm 0.2$ & $71 \pm 1$ \\
\hline \multirow[t]{2}{*}{ C3 } & 252 & $11.4 \pm 0.3$ & $264 \pm 2$ & $16.6 \pm 0.2$ & $74 \pm 1$ \\
\hline & & \multicolumn{2}{|l|}{$O_{1}$} & \multicolumn{2}{|l|}{$K_{1}$} \\
\hline \multirow[t]{2}{*}{ A1 } & 309 & $24.6 \pm 0.2$ & $71 \pm 1$ & $29.5 \pm 0.2$ & $86 \pm 0$ \\
\hline & 502 & $24.6 \pm 0.3$ & $73 \pm 1$ & $29.6 \pm 0.3$ & $88 \pm 1$ \\
\hline \multirow[t]{3}{*}{$\mathrm{A} 2$} & 47 & $24.7 \pm 0.5$ & $70 \pm 1$ & $29.5 \pm 0.5$ & $87 \pm 1$ \\
\hline & 247 & $24.7 \pm 0.2$ & $72 \pm 1$ & $29.3 \pm 0.2$ & $89 \pm 0$ \\
\hline & 554 & $24.6 \pm 0.2$ & $72 \pm 0$ & $29.4 \pm 0.2$ & $89 \pm 0$ \\
\hline \multirow[t]{3}{*}{ A3 } & 103 & $25.0 \pm 0.2$ & $71 \pm 0$ & $29.6 \pm 0.2$ & $89 \pm 0$ \\
\hline & 253 & $24.9 \pm 0.2$ & $71 \pm 0$ & $29.5 \pm 0.2$ & $89 \pm 0$ \\
\hline & 480 & $24.7 \pm 0.2$ & $70 \pm 0$ & $29.4 \pm 0.1$ & $88 \pm 0$ \\
\hline \multirow[t]{2}{*}{ B2 } & 140 & $23.9 \pm 0.3$ & $76 \pm 1$ & $29.5 \pm 0.2$ & $92 \pm 1$ \\
\hline & 804 & $23.8 \pm 0.2$ & $75 \pm 0$ & $29.5 \pm 0.2$ & $91 \pm 0$ \\
\hline \multirow[t]{2}{*}{ B3 } & 247 & $23.0 \pm 0.3$ & $76 \pm 1$ & $29.1 \pm 0.3$ & $92 \pm 1$ \\
\hline & 440 & $23.3 \pm 0.2$ & $76 \pm 1$ & $29.1 \pm 0.2$ & $92 \pm 0$ \\
\hline $\mathrm{C} 1$ & 232 & $24.5 \pm 0.1$ & $75 \pm 0$ & $30.1 \pm 0.2$ & $91 \pm 0$ \\
\hline \multirow[t]{2}{*}{$\mathrm{C} 2$} & 260 & $24.2 \pm 0.2$ & $77 \pm 0$ & $29.7 \pm 0.2$ & $92 \pm 0$ \\
\hline & 852 & $23.7 \pm 0.3$ & $75 \pm 1$ & $29.2 \pm 0.3$ & $91 \pm 1$ \\
\hline C3 & 252 & $23.4 \pm 0.2$ & $76 \pm 0$ & $28.8 \pm 0.2$ & $92 \pm 0$ \\
\hline
\end{tabular}


Table 3.6: Tidal ellipses parameters for each SO GLOBEC mooring sites. For each mooring, the tidal ellipses from the AntPen04.01 output (top row) and calculated from the vertically-averaged velocity records (bottom row) are presented. The semi-diurnal components are presented in the top half of the table, and the diurnal components on the bottom half. The inclination is measured anticlockwise from east and the phase is given in degrees Greenwich.

\begin{tabular}{|c|c|c|c|c|c|c|c|c|}
\hline Mooring & $\begin{array}{l}\text { Major } \\
(\mathrm{cm} / \mathrm{s})\end{array}$ & $\begin{array}{l}\text { Minor } \\
(\mathrm{cm} / \mathrm{s})\end{array}$ & Incl. $\left(^{\circ}\right)$ & $\begin{array}{l}\text { Phase } \\
\left({ }^{\circ} \mathrm{G}\right)\end{array}$ & $\begin{array}{l}\text { Major } \\
(\mathrm{cm} / \mathrm{s})\end{array}$ & $\begin{array}{l}\text { Minor } \\
(\mathrm{cm} / \mathrm{s})\end{array}$ & Incl. $\left(^{\circ}\right)$ & $\begin{array}{l}\text { Phase } \\
\left({ }^{\circ} \mathrm{G}\right)\end{array}$ \\
\hline & \multicolumn{4}{|c|}{$M_{2}$} & \multicolumn{4}{|c|}{$S_{2}$} \\
\hline \multirow[t]{2}{*}{ A1 } & 1.5 & 0.1 & 57 & 240 & 0.8 & -0.2 & 65 & 213 \\
\hline & $1.2 \pm 0.2$ & $0.0 \pm 0.2$ & $52 \pm 9$ & $249 \pm 10$ & $0.6 \pm 0.2$ & $-0.3 \pm 0.2$ & $47 \pm 27$ & $228 \pm 28$ \\
\hline \multirow[t]{2}{*}{$\mathrm{A} 2$} & 1.2 & 0.2 & 42 & 233 & 0.9 & -0.3 & 117 & 163 \\
\hline & $1.0 \pm 0.3$ & $0.2 \pm 0.3$ & $43 \pm 14$ & $248 \pm 16$ & $0.9 \pm 0.3$ & $-0.3 \pm 0.3$ & $118 \pm 19$ & $166 \pm 19$ \\
\hline \multirow[t]{2}{*}{ A3 } & 1.5 & 0.6 & 29 & 231 & 1.2 & 0.0 & 135 & 146 \\
\hline & $1.3 \pm 0.3$ & $0.5 \pm 0.4$ & $37 \pm 19$ & $233 \pm 20$ & $1.1 \pm 0.3$ & $-0.0 \pm 0.4$ & $147 \pm 18$ & $135 \pm 17$ \\
\hline \multirow[t]{2}{*}{$\mathrm{B} 2$} & 0.6 & 0.2 & 173 & 11 & 1.1 & -0.4 & 115 & 189 \\
\hline & $0.6 \pm 0.1$ & $0.3 \pm 0.1$ & $175 \pm 18$ & $44 \pm 18$ & $0.9 \pm 0.1$ & $-0.2 \pm 0.1$ & $108 \pm 7$ & $196 \pm 8$ \\
\hline \multirow[t]{2}{*}{ B3 } & 1.4 & 0.6 & 3 & 199 & 1.5 & 0.1 & 156 & 155 \\
\hline & $1.1 \pm 0.2$ & $0.3 \pm 0.2$ & $43 \pm 15$ & $187 \pm 13$ & $1.4 \pm 0.2$ & $0.0 \pm 0.2$ & $5 \pm 8$ & $308 \pm 10$ \\
\hline \multirow[t]{2}{*}{$\mathrm{C} 1$} & 1.0 & 0.3 & 156 & 357 & 2.0 & 0.2 & 143 & 173 \\
\hline & $1.3 \pm 0.2$ & $0.9 \pm 0.1$ & $157 \pm 14$ & $352 \pm 14$ & $2.7 \pm 0.1$ & $1.1 \pm 0.2$ & $153 \pm 4$ & $173 \pm 5$ \\
\hline \multirow[t]{2}{*}{$\mathrm{C} 2$} & 0.6 & 0.0 & 158 & 8 & 1.2 & -0.4 & 118 & 191 \\
\hline & $0.5 \pm 0.1$ & $0.2 \pm 0.1$ & $15 \pm 13$ & $158 \pm 14$ & $1.0 \pm 0.1$ & $-0.1 \pm 0.1$ & $145 \pm 6$ & $171 \pm 6$ \\
\hline \multirow[t]{3}{*}{ C3 } & 0.6 & 0.2 & 174 & 11 & 1.1 & -0.4 & 115 & 190 \\
\hline & $0.5 \pm 0.1$ & $0.3 \pm 0.1$ & $165 \pm 11$ & $36 \pm 12$ & $0.8 \pm 0.1$ & $-0.3 \pm 0.1$ & $108 \pm 5$ & $200 \pm 5$ \\
\hline & \multicolumn{4}{|c|}{$O_{1}$} & \multicolumn{4}{|c|}{$K_{1}$} \\
\hline \multirow[t]{2}{*}{ A1 } & 0.7 & 0.0 & 51 & 340 & 0.2 & -0.1 & 107 & 195 \\
\hline & $1.3 \pm 0.1$ & $-0.1 \pm 0.1$ & $53 \pm 6$ & $334 \pm 6$ & $0.4 \pm 0.1$ & $-0.1 \pm 0.1$ & $38 \pm 21$ & $296 \pm 18$ \\
\hline \multirow[t]{2}{*}{$\mathrm{A} 2$} & 0.7 & -0.1 & 6 & 1 & 0.6 & 0.2 & 144 & 192 \\
\hline & $1.2 \pm 0.1$ & $-0.1 \pm 0.1$ & $31 \pm 6$ & $2 \pm 6$ & $0.6 \pm 0.1$ & $0.0 \pm 0.1$ & $161 \pm 12$ & $185 \pm 13$ \\
\hline \multirow[t]{2}{*}{ A3 } & 1.1 & 0.5 & 4 & 7 & 1.0 & 0.7 & 147 & 190 \\
\hline & $1.5 \pm 0.1$ & $0.7 \pm 0.1$ & $22 \pm 6$ & $15 \pm 6$ & $1.0 \pm 0.1$ & $0.6 \pm 0.1$ & $160 \pm 12$ & $189 \pm 12$ \\
\hline \multirow[t]{2}{*}{ B2 } & 0.8 & -0.5 & 100 & 226 & 1.0 & -0.5 & 104 & 228 \\
\hline & $0.9 \pm 0.1$ & $-0.8 \pm 0.1$ & $95 \pm 30$ & $256 \pm 29$ & $1.0 \pm 0.1$ & $-0.5 \pm 0.1$ & $108 \pm 5$ & $244 \pm 5$ \\
\hline \multirow[t]{2}{*}{ B3 } & 1.2 & 0.4 & 173 & 152 & 1.2 & 0.3 & 163 & 162 \\
\hline & $3.7 \pm 0.2$ & $1.4 \pm 0.2$ & $11 \pm 3$ & $8 \pm 4$ & $2.7 \pm 0.2$ & $1.1 \pm 0.1$ & $1 \pm 5$ & $21 \pm 5$ \\
\hline \multirow[t]{2}{*}{$\mathrm{C} 1$} & 1.3 & 0.3 & 153 & 184 & 1.6 & 0.4 & 150 & 196 \\
\hline & $1.0 \pm 0.1$ & $0.1 \pm 0.1$ & $179 \pm 4$ & $166 \pm 5$ & $1.1 \pm 0.1$ & $0.0 \pm 0.1$ & $171 \pm 4$ & $181 \pm 4$ \\
\hline \multirow[t]{2}{*}{$\mathrm{C} 2$} & 0.9 & -0.4 & 105 & 225 & 1.0 & -0.4 & 107 & 229 \\
\hline & $1.0 \pm 0.1$ & $-0.3 \pm 0.0$ & $99 \pm 3$ & $231 \pm 3$ & $1.1 \pm 0.1$ & $-0.3 \pm 0.0$ & $100 \pm 3$ & $242 \pm 3$ \\
\hline \multirow[t]{2}{*}{ C3 } & 0.8 & -0.5 & 99 & 226 & 1.0 & -0.5 & 103 & 228 \\
\hline & $0.8 \pm 0.1$ & $-0.7 \pm 0.0$ & $69 \pm 15$ & $284 \pm 16$ & $0.8 \pm 0.1$ & $-0.5 \pm 0.0$ & $105 \pm 7$ & $249 \pm 9$ \\
\hline
\end{tabular}



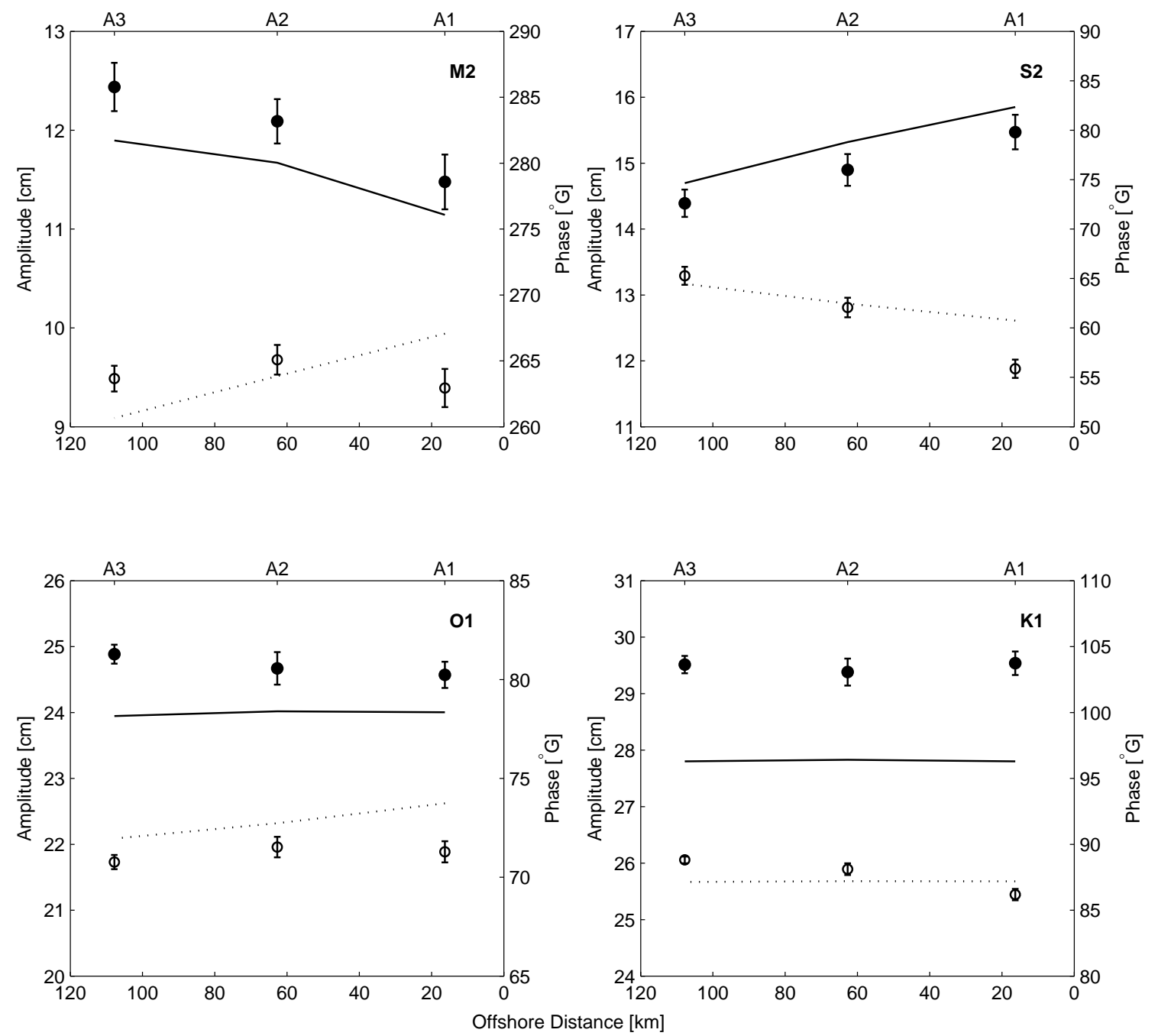

Figure 3-11: Tidal sea-level amplitudes and Greenwich phase for the A-line moorings. The solid (hollow) dots are the amplitude (phase) calculated from the verticallyaveraged pressure anomaly records, and the error bars are the $95 \%$ confidence limits for the estimates. The solid (dotted) line shows the amplitude (phase) from the AntPen04.01 model output. 

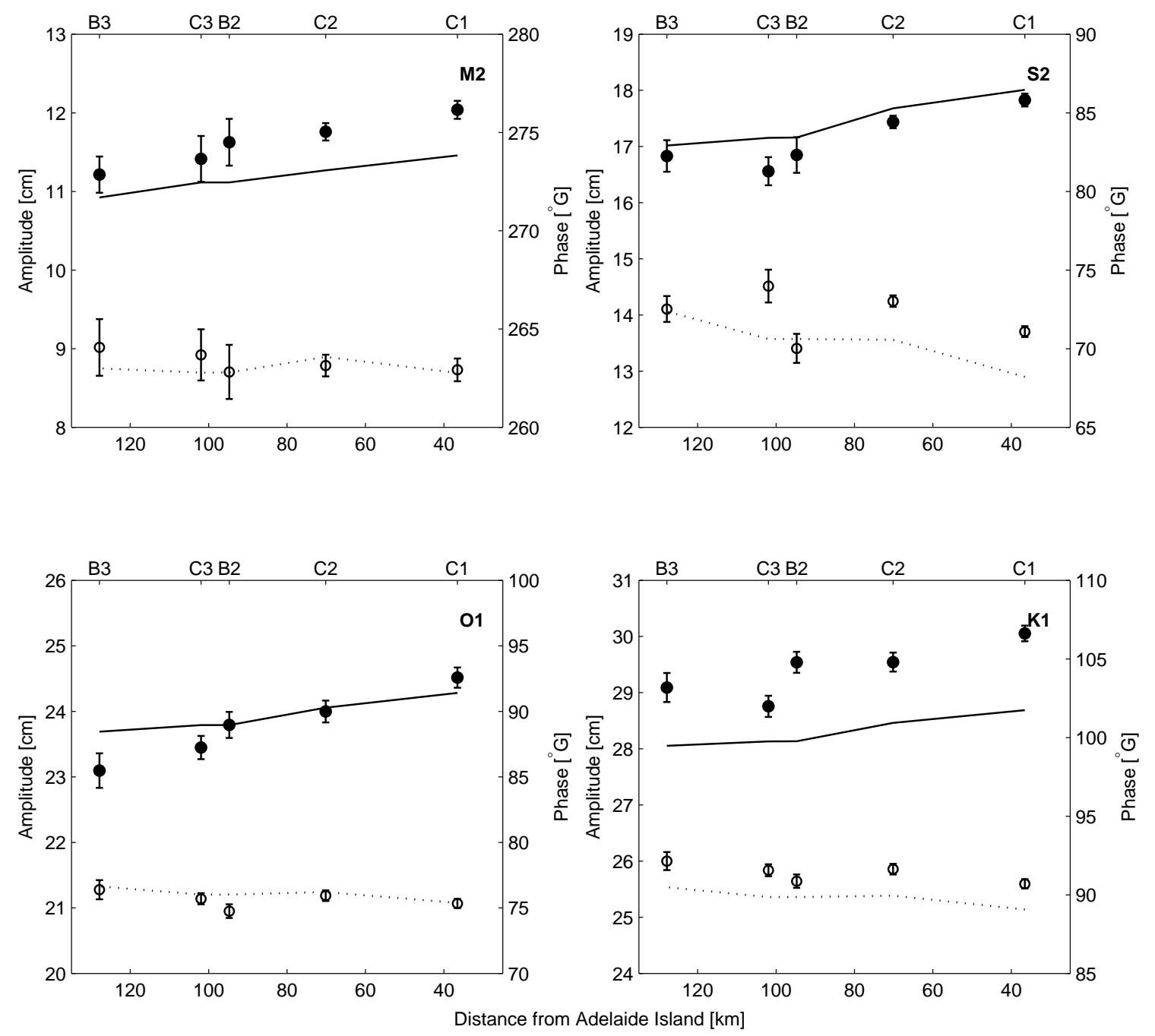

Figure 3-12: Tidal sea-level amplitudes and Greenwich phase for the B- and C-line moorings. The solid (hollow) dots are the amplitude (phase) calculated from the vertically-averaged pressure anomaly records, and the error bars are the $95 \%$ confidence limits for the estimates. The solid (dotted) line shows the amplitude (phase) from the AntPen04.01 model output. 


\subsection{Near-inertial Motions}

Examination of the spectra of the moored array current records over the wAP shelf reveal a large, broad peak at or near the inertial frequency (e.g. Figure 3-1). Some of the specific issues mentioned here, like the dynamics of wind, ice, and near-inertial currents, are treated in Hyatt (2006). The following section provides a basic description of the horizontal, vertical, and temporal variability of the near-inertial motions over the shelf.

\subsubsection{Rotary Spectra}

Rotary spectra of the velocity records show strong counterclockwise energy at nearinertial frequencies (Figure 3-13 shows one typical spectra, for $100 \mathrm{~m}$ at A2), which is expected for inertial-internal waves in the southern hemisphere (e.g. Kundu and Allen, 1976). The ratio of counterclockwise to clockwise power spectral density at the near-inertial peak for each record is between 10 and 1000 for all the records except for the deepest instrument at A1, where there is no significant near-inertial energy peak and the ratio is only 1.7 .

The anticlockwise components of the rotary spectra of the detided velocity records at nominal depths ${ }^{5}$ of 100, 250, 400 and $800 \mathrm{~m}$ reveal the basic structure of the nearinertial motions on the shelf (Figure 3-14). Across the shelf at the A-line, the energy at the spectral peak increases from the nearshore A1 mooring to the A3 mooring, where the energy is the highest measured at $100 \mathrm{~m}$ on the shelf. At depth, the structure is similar at A2 and A3, with the energy at the spectral peak diminishing significantly between the top $(100 \mathrm{~m})$ and the bottom two instruments (250 and $400 \mathrm{~m})$, which have inertial peaks of comparable size. At A1, the vertical energy distribution is quite different. The energy decays markedly between $100 \mathrm{~m}$ and $309 \mathrm{~m}$, and at $459 \mathrm{~m}$, there is no distinguishable inertial peak. As with the mean flow and the tides, the steep bathymetry and sill around A1 appears to be blocking the near-inertial motions.

Across the mouth of Marguerite Bay, the near-inertial energy also decays with

\footnotetext{
${ }^{5}$ Note the depths of the A1 mooring instruments are $\approx 100,309$ and $459 \mathrm{~m}$
} 


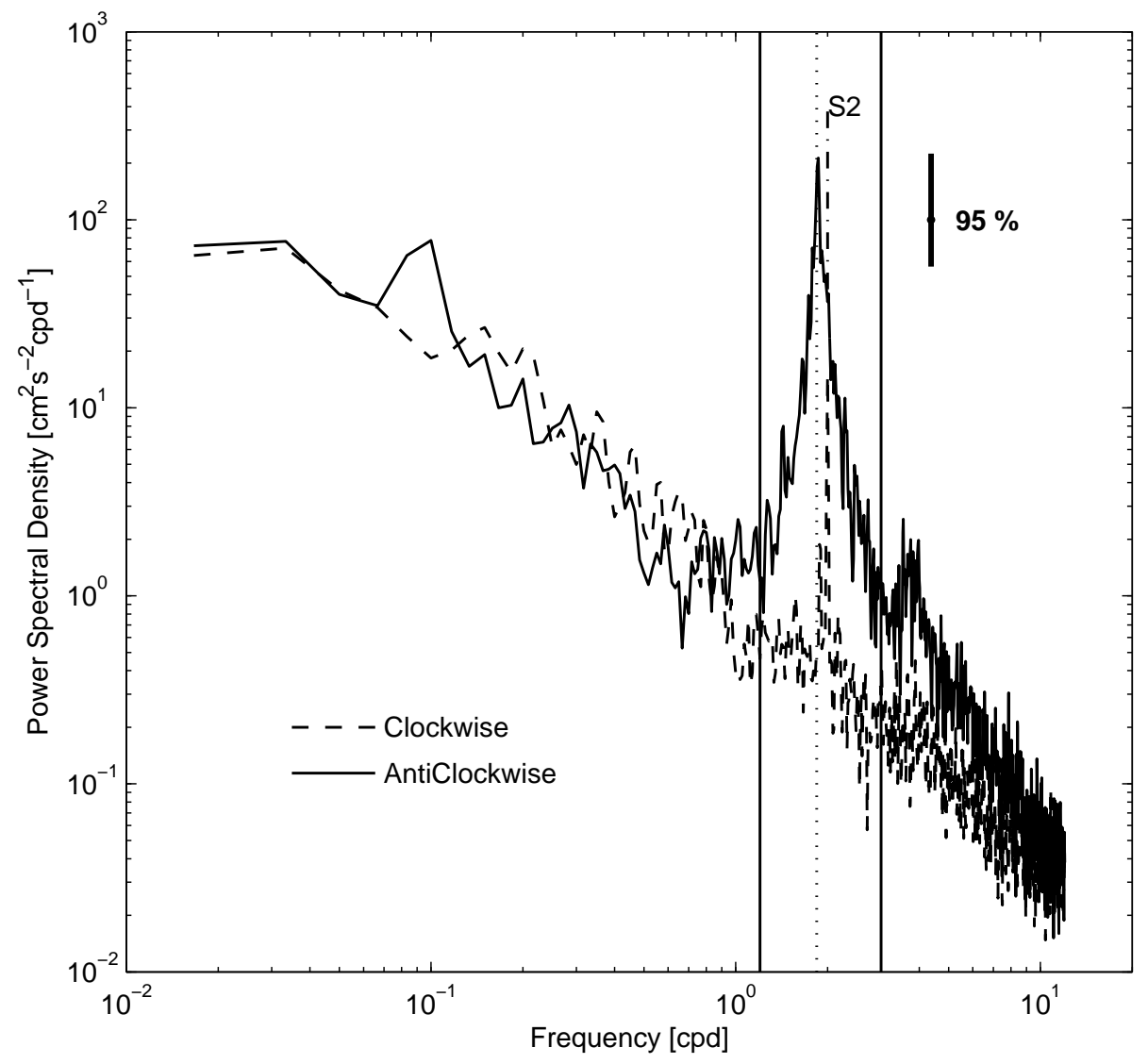

Figure 3-13: Rotary spectra of the de-tided current record at $100 \mathrm{~m}$ from A2. The vertical dotted line indicates the inertial frequency $(1.84 \mathrm{cpd}, \approx 13-\mathrm{h})$ and the solid lines the half-amplitude periods for the bandpass filter $(1.2 \mathrm{cpd}$ and $3 \mathrm{cpd})$ used to filter the current records. For this record, the ratio of anticlockwise to clockwise energy at the inertial frequency is 391 . Notice also the residual of tidal energy at the $S_{2}$ frequency.

depth but all of the records show a significant inertial peak, including the deepest instruments at $\mathrm{C} 2$ and $\mathrm{C} 3$. While most moorings show either a decrease of nearinertial energy with depth, or a lower layer (below $200 \mathrm{~m}$ ) with nearly constant energy, C3 shows a significantly higher peak at $800 \mathrm{~m}$ than at $400 \mathrm{~m}$. As with the tidal analysis presented earlier in this chapter, the structure at C3 is consistent with the co-located B2 down to $400 \mathrm{~m}$, the deepest current meter on B2. 


\subsubsection{Band-pass Filtering}

In order to compute basic statistics of the near-inertial motions, the hourly current meter and ADCP data were filtered with a cosine-lanczos filter (Emery and Thompson, 1998) with 100 weights to band-pass variability between 8 to 20 -h. The filter was applied to the de-tided time series, as the semi-diurnal tidal components are close to the inertial frequency and cannot be easily filtered out. The choice of 8 -h to 20 -h for the band-pass filter retains the broad near-inertial variability while filtering out any remnants of diurnal tidal variability (Figure 3-13).

\subsubsection{Near-inertial Currents}

Basic statistics of the near-inertial band motions are listed in Table 3.7 for a subset of the current records. Overall, RMS velocity magnitudes are $\approx 3$ to $\approx 7.5 \mathrm{~cm} / \mathrm{s}$ for the top 100-m records and around $1 \mathrm{~cm} / \mathrm{s}$ for the deepest. The largest velocities are found on the outer shelf, at A3, where the largest velocity recorded was $26.1 \mathrm{~cm} / \mathrm{s}$. Near-inertial band motions explain a minimum of 10 to $15 \%$ percent of the total current variance $^{6}$ at the deepest instruments across Marguerite Bay (B- and C-lines) and as much as $65 \%$ of the variance at $103 \mathrm{~m}$ at A3. Notice that even at $400 \mathrm{~m}$ in the mid- and outer-shelf, the near-inertial frequency variability explains $25-30 \%$ of the variance.

The principal axis of the band-pass velocity shows that the polarization (the ratio between the major and minor axis) is very small almost everywhere, with the exception of $\mathrm{A} 1$ at $459 \mathrm{~m}(\mathrm{Maj} / \mathrm{Min}=1.8)$, which also shows the weakest inertial peak (see previous section). This is dynamically consistent with the Wentzel-Kramers-Brillouin (WKB) solutions for horizontal currents for near-inertial waves (Kundu and Allen, 1976; Pedlosky, 2003):

$$
u=\mp A \frac{m^{1 / 2}}{k} \cos \left(k x \pm \int m d z\right)
$$

\footnotetext{
${ }^{6}$ At most instruments, the variance explained is similar for both velocity components, so only an average is presented.
} 


$$
v= \pm A\left(\frac{f}{\omega}\right) \frac{m^{1 / 2}}{k} \sin \left(k x \pm \int m d z\right)
$$

where $A$ is the amplitude, $k$ is the x-wavenumber, $m$ is the vertical wavenumber, $\omega$ is the frequency, and the $\mathrm{x}$-coordinate is aligned with the direction of horizontal propagation. At $\omega=f$, there is no polarization in the velocity, and as the frequency of the waves increases, the principal axis becomes increasingly ellipsoidal. This relationship is not very consistent in our velocity records (Figure 3-15), but the near-circular motions are generally consistent with the idea of near-inertial waves.

\subsubsection{Vertical Structure}

In order to study the vertical structure of the near-inertial motions, complex empirical orthogonal functions (cEOF, Emery and Thompson, 1998; Shearman, 2005) were calculated for each mooring using all the available data that covered the entire deployment period (with the exception of B3, where only the first 78 days while the ADCP at $150 \mathrm{~m}$ was sampling were used).

The first cEOF explains between 44 and $82 \%$ of the variability of the band-pass filtered detided data. On the mid- and outer-shelf (Figure 3-16, top panel), the A2 and A3 moorings have a similar vertical structure resembling a first baroclinic mode, with the velocity at $100 \mathrm{~m} 180^{\circ}$ out of phase with the velocities at depth. Consistent with results mentioned earlier, the first cEOF has a larger amplitude at A3 than at A2. Near the shore at A1, the deepest instruments show near-zero amplitude, and the structure in the top $160 \mathrm{~m}$ is complicated, with a maximum amplitude of $4.4 \mathrm{~cm} / \mathrm{s}$ at around $125 \mathrm{~m}$ and counterclockwise veering with depth of $0.6-1.5^{\circ} / \mathrm{m}$ over the top $165 \mathrm{~m}$.

Across the mouth of Marguerite Bay (Figure 3-16, bottom panel), the structure of the first cEOF is complicated. The moorings that include data in the top $100 \mathrm{~m}$ (B3, C1 and C3) show counterclockwise veering with depth, and velocity amplitudes of the order of $3-5 \mathrm{~cm} / \mathrm{s}$, while velocities below $250 \mathrm{~m}$ in all the moorings are less than $1 \mathrm{~cm} / \mathrm{s}$. Unlike the clear first-mode baroclinic structure observed at A2 and 
A3, the overall vertical structure at B3 and C3 is complicated, with the small bottom velocities showing a $\approx 90^{\circ}$ phase difference with the surface velocities.

\subsubsection{Horizontal Scales}

Complex correlation at zero lag (Kundu and Allen, 1976) between pairs of eigenvectors of the first cEOF modes were computed in order to get an order of magnitude estimate of the horizontal scales of the near-inertial motions ${ }^{7}$. The largest correlation $(0.38)$ is between the A2 and A3 records, but neither of them shows significant correlation with A1, nor with the B-line records. The B2 and B3 records are significantly correlated (0.35), although no significant correlation was found between the C-line moorings. This is surprising, as B2 and B3 are separated by roughly the same distance as the C-line moorings and located roughly in the same area. Notice, however, that the bathymetry separating the C-line mooring sites is quite complicated, with at least one large sea mount between $\mathrm{C} 1-\mathrm{C} 2$ and C2-C3. Comparatively, the flow has less restrictions between B2/C3 and B3 (Figure 3-3).

\subsubsection{Seasonal Evolution}

A rough idea of the time variability of near-inertial motions on the shelf can be obtained by calculating monthly averages of the kinetic energy per unit mass (e.g. Shearman, 2005):

$$
\bar{K} E=\frac{1}{2}\left(\sigma_{u}^{2}+\sigma_{v}^{2}\right)
$$

where $\sigma^{2}$ is the variance for a given near-inertial velocity component (calculated from the band-pass filtered detided data). Figure $3-17$ (top panel) shows $\bar{K} E$ for all the available current records at $100 \mathrm{~m}$. The variability from month to month is largest on the mid- and outer-shelf and smallest across Marguerite Bay, especially in 2002. The largest values of $\overline{K E}$ were registered during the spring of 2001 and well into the summer of 2002, with values as large as three times the ones for the fall and winter,

\footnotetext{
${ }^{7}$ One could use different methods here, like calculating correlation indices for individual velocity components, or calculating the coherence between velocity pairs. Those methods result in the same qualitative results presented here.
} 
but spatially limited to the A-line moorings, with no significant increase at B2, some $150 \mathrm{~km}$ to the south. In March of both years, $\overline{K E}$ is relatively high everywhere.

The middle panel of Figure 3-17 shows the SSM/I satellite-derived ice-concentration (see Chapter 5 for more information) for A2 and B2/C3. Large spatial and interannual changes are evident. In 2001, the ice remained in Marguerite Bay long after it had retreated from the open shelf, and there were only brief periods of no ice before the next winter arrived. The interannual changes are also large, with the ice arriving roughly two months earlier in 2002 than 2001, and covering a larger extent of the shelf.

The evidence of suppression of near-inertial motions by the ice cover is mixed. In 2002 the largest $\bar{K} E$ values occurred when the shelf was either ice-free (April) or a clear opening occurred in the ice (October). In 2001, the highest values also occurred during relatively ice-free conditions, but there are also relatively high values in August (although notice the simultaneous drop in ice concentration in both sites).

The standard deviation of monthly averages of the eastward and northward windstress at Kirkland Island (Figure 3-17, bottom panel) shows that the wind is highly variable on the shelf, with no clear seasonal signal in these two years, and with strong month-to-month variability. The correlation between the wind variability and the $\overline{K E}$ in the upper ocean is low, which is particularly evident in the spring of 2001, when the wind variability was low but the energy in the A-line moorings was highest.

\subsubsection{Discussion and Summary of Near-inertial Variability}

The brief description of the near-inertial motions presented above suggest they are an important component of the wAP circulation. On average, the near-inertial motions tend to be larger than the most energetic tides, and single events can have velocities an order of magnitude larger.

Several of the moorings also show a shift of the highest peak towards frequencies larger than $f$ (Figure 3-14), with the shift increasing with depth at some sites. If one 
considers the vertical component of the group velocity

$$
C_{g z}=\frac{\left(N^{2}-\omega^{2}\right)\left(f^{2}-\omega^{2}\right)}{m \omega\left(N^{2}-f^{2}\right)} .
$$

In an idealized ocean with no lateral boundaries where where the winds force inertial motions, one would expect no vertical propagation $(\omega=f)$. The presence of a coast, or wind forcing with a finite horizontal scale, for example, can generate vertically propagating near-inertial waves. The shift in the near-inertial peak with depth is thus consistent with the dominant waves having a larger vertical component. Notice, however, that these shifts, both towards frequencies larger and smaller than $f$, have been observed when the waves propagate through flows with significant relative vorticity (Weller, 1982; Shearman, 2005).

These results also highlight the small dynamical scales and strong spatial variability characteristic of this area. In the relatively open region where A2 and A3 are located, the near-inertial motions are well correlated, suggesting scales of $45 \mathrm{~km}$ (the mooring separation) or more for the near-inertial motions. However, across Marguerite Bay, the C-line moorings show little correlation among them, suggesting horizontal scales of less than $25 \mathrm{~km}$. The correlation between the first cEOF at B2 and B3 is high, which seems strange considering the results for the C-line moorings, which show small correlation among them.

The evolution of the 100-m monthly-mean near-inertial kinetic energy shows very high values for the spring of 2001 and early summer of 2002. This might be connected with anomalous atmospheric conditions with strong northwesterly winds (as seen from pressure maps) which helped create the high ice concentration conditions shown here (Massom et al. 2006), and highlights the need for wind measurements in the open shelf region.

The forcing mechanism of the near-inertial motions remains unclear. On monthly to yearly time-scales, the wind forcing does not seem well correlated, although further exploration of the dataset is needed. Moreover, the discussion of the tidal current variability (Section 3.3.4) suggest that internal tides might be common on the wAP 
shelf. These internal waves can have a broad spectral response to the barotropic tidal forcing, and therefore the band-pass filtering used to calculate statistics (Section 3.4.2) would not remove this motions. Therefore, the variability discussed here is likely to be a mixture of wind- and tidally-driven near-inertial motions.

Overall, near-inertial motions are an important component of the flow on the wAP shelf. Because these motions have a significant decay of energy in the vertical (which results in vertical shear) and are a relatively important component of the circulation, near-inertial motions might be an important candidate to provide the mixing necessary to close the property budgets. 
Table 3.7: Statistics of near-inertial band motions on the wAP shelf. The columns show the root mean square (RMS), maximum band-pass velocity measured (Max), the variance explained by the band-pass filtered time series (Var - see text), the major (Maj), minor (Min) and inclination (Inc) of the principal axis of the band-pass time series, and the record length.

\begin{tabular}{lcccccccc}
\hline Mooring & $\begin{array}{c}\text { Depth } \\
{[\mathrm{m}]}\end{array}$ & $\begin{array}{c}\text { RMS } \\
{[\mathrm{cm} / \mathrm{s}]}\end{array}$ & $\begin{array}{c}\text { Max } \\
{[\mathrm{cm} / \mathrm{s}]}\end{array}$ & $\begin{array}{c}\text { Var } \\
{[\%]}\end{array}$ & $\begin{array}{c}\text { Maj } \\
{[\mathrm{cm} / \mathrm{s}]}\end{array}$ & $\begin{array}{c}\text { Min } \\
{[\mathrm{cm} / \mathrm{s}]}\end{array}$ & $\begin{array}{c}\text { Inc } \\
{\left[{ }^{\circ}\right]}\end{array}$ & $\begin{array}{c}\text { Length } \\
{[\text { days }]}\end{array}$ \\
\hline A1 & 103 & 5.3 & 17.4 & 38 & 3.8 & 3.7 & 18 & 318 \\
& 309 & 1.8 & 7.8 & 29 & 1.3 & 1.2 & 3 & 318 \\
& 459 & 1.3 & 8.6 & 19 & 1.1 & 0.6 & -21 & 318 \\
\hline A2 & 107 & 5.3 & 17.3 & 48 & 3.9 & 3.7 & 83 & 318 \\
& 247 & 2.7 & 8.3 & 27 & 1.9 & 1.8 & -77 & 318 \\
& 397 & 2.6 & 8.8 & 24 & 1.8 & 1.8 & -53 & 318 \\
\hline A3 & 103 & 7.4 & 26.1 & 65 & 5.3 & 5.1 & 2 & 318 \\
& 253 & 3.1 & 11.1 & 31 & 2.2 & 2.2 & 9 & 318 \\
& 403 & 3.2 & 10.4 & 31 & 2.3 & 2.2 & 15 & 318 \\
\hline B2 & 122 & 3.8 & 15.9 & 37 & 2.7 & 2.7 & -6 & 318 \\
& 254 & 2.3 & 6.8 & 33 & 1.6 & 1.6 & 75 & 318 \\
& 400 & 0.9 & 3.5 & 15 & 0.7 & 0.6 & 85 & 318 \\
\hline B3 & 51 & 4.7 & 11.9 & 13 & 3.5 & 3.2 & -26 & 79 \\
& 101 & 5.7 & 14.6 & 40 & 4.0 & 4.0 & -79 & 79 \\
& 247 & 2.3 & 8.1 & 22 & 1.7 & 1.5 & 23 & 318 \\
& 400 & 2.2 & 8.1 & 15 & 1.7 & 1.4 & -20 & 318 \\
\hline C1 & 50 & 3.4 & 12.7 & 14 & 2.5 & 2.4 & -47 & 365 \\
& 88 & 3.5 & 13.9 & 21 & 2.5 & 2.4 & 33 & 365 \\
& 232 & 1.9 & 7.0 & 20 & 1.3 & 1.3 & -15 & 365 \\
\hline C2 & 260 & 1.6 & 5.7 & 23 & 1.1 & 1.1 & -30 & 365 \\
& 410 & 1.2 & 4.1 & 13 & 0.9 & 0.8 & -75 & 365 \\
& 810 & 1.0 & 8.0 & 11 & 0.8 & 0.6 & -80 & 365 \\
\hline C3 & 51 & 4.6 & 18.2 & 25 & 3.3 & 3.2 & -78 & 365 \\
& 101 & 3.1 & 10.4 & 27 & 2.2 & 2.1 & 73 & 365 \\
& 252 & 1.7 & 8.3 & 35 & 1.2 & 1.2 & -85 & 365 \\
& 395 & 0.8 & 2.9 & 15 & 0.6 & 0.5 & 87 & 365 \\
& 762 & 1.0 & 3.6 & 10 & 0.7 & 0.7 & 41 & 289 \\
\hline \multirow{4}{*}{} & & & & & & & &
\end{tabular}



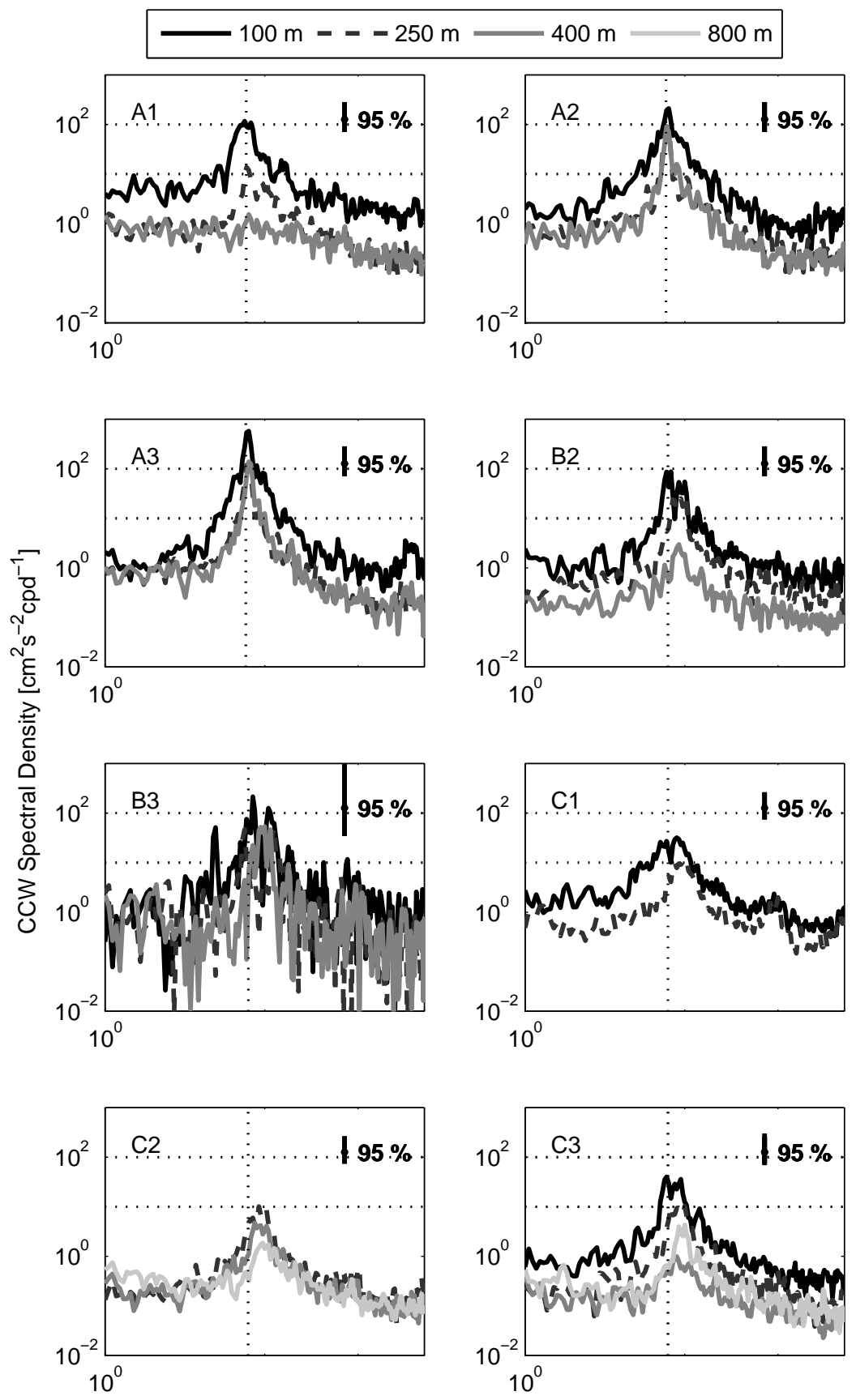

Frequency [cpd]

Figure 3-14: Counterclockwise component of the rotary spectra for the SO GLOBEC moored array records, calculated from the de-tided (not band-passed) data. In each panel, the vertical dotted line is the local inertial frequency, and two horizontal lines are plotted as reference. The horizontal axis spans the 1-4 cpd frequency range. 


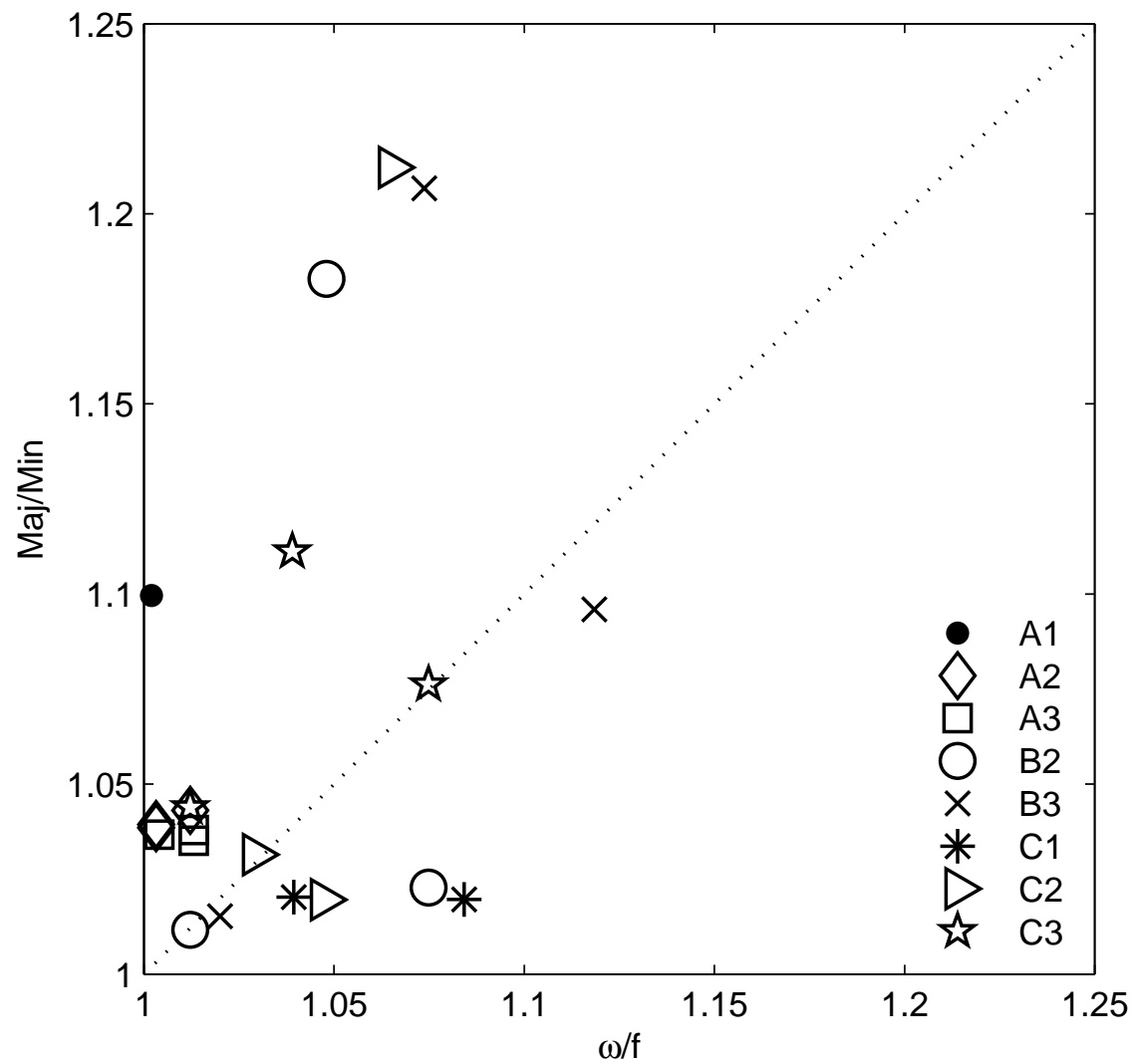

Figure 3-15: Ratio of major to minor axis of variance of the band-pass velocity records as a function of the ratio of the frequency of the maximum counterclockwise spectral peak to the inertial frequency. The point corresponding to the deepest instrument at A1 $(\omega / f=1.01, \mathrm{Maj} / \mathrm{Min}=1.88)$ is omitted. The dotted line is the 1:1 relationship. 

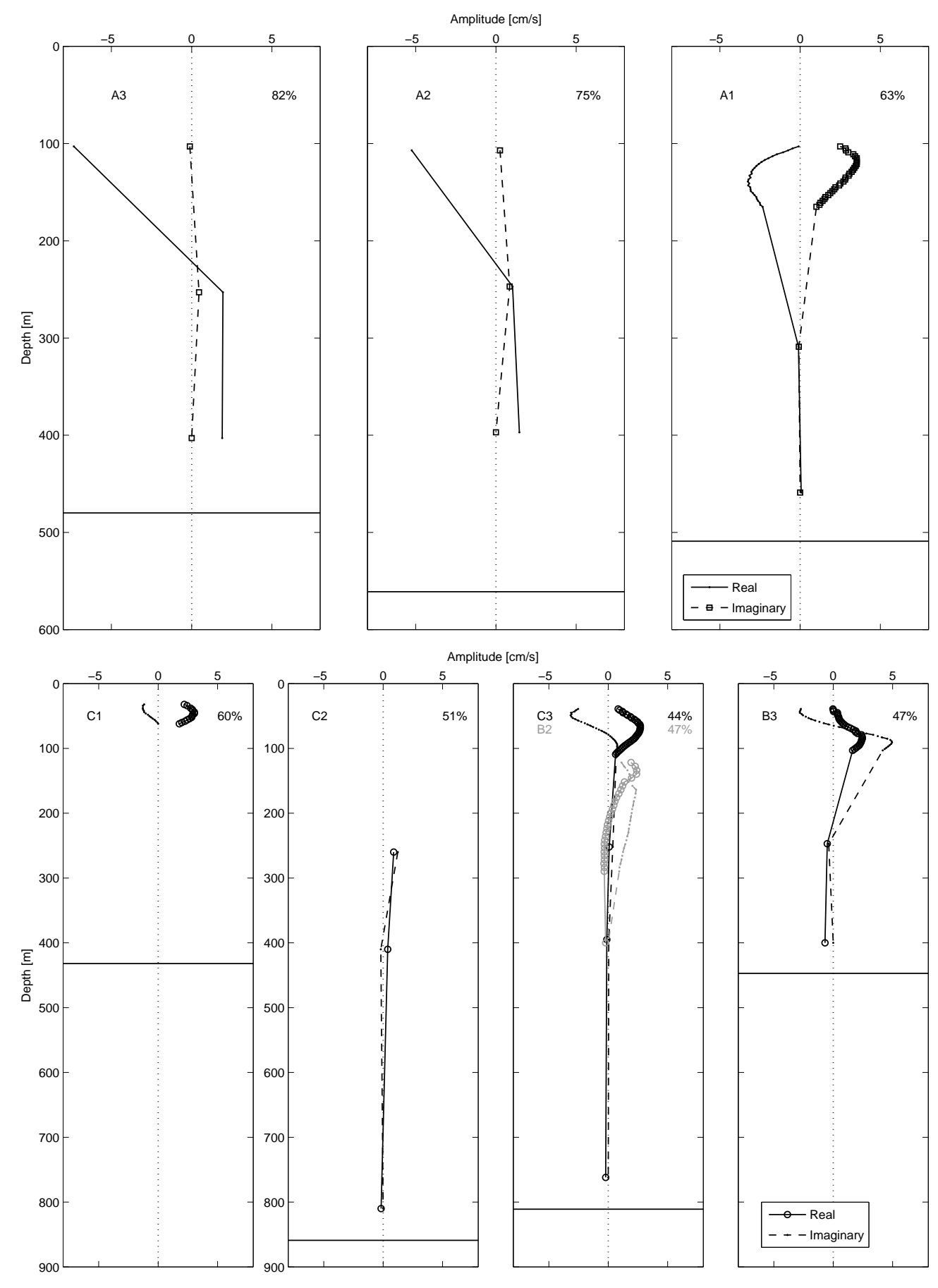

Figure 3-16: First cEOF for the A-line moorings (top panels) and the B- and C-line moorings (bottom panels). The horizontal line indicates the bottom depth at each mooring. For each mooring, the percentage of the variance of the band-passed records is indicated. 

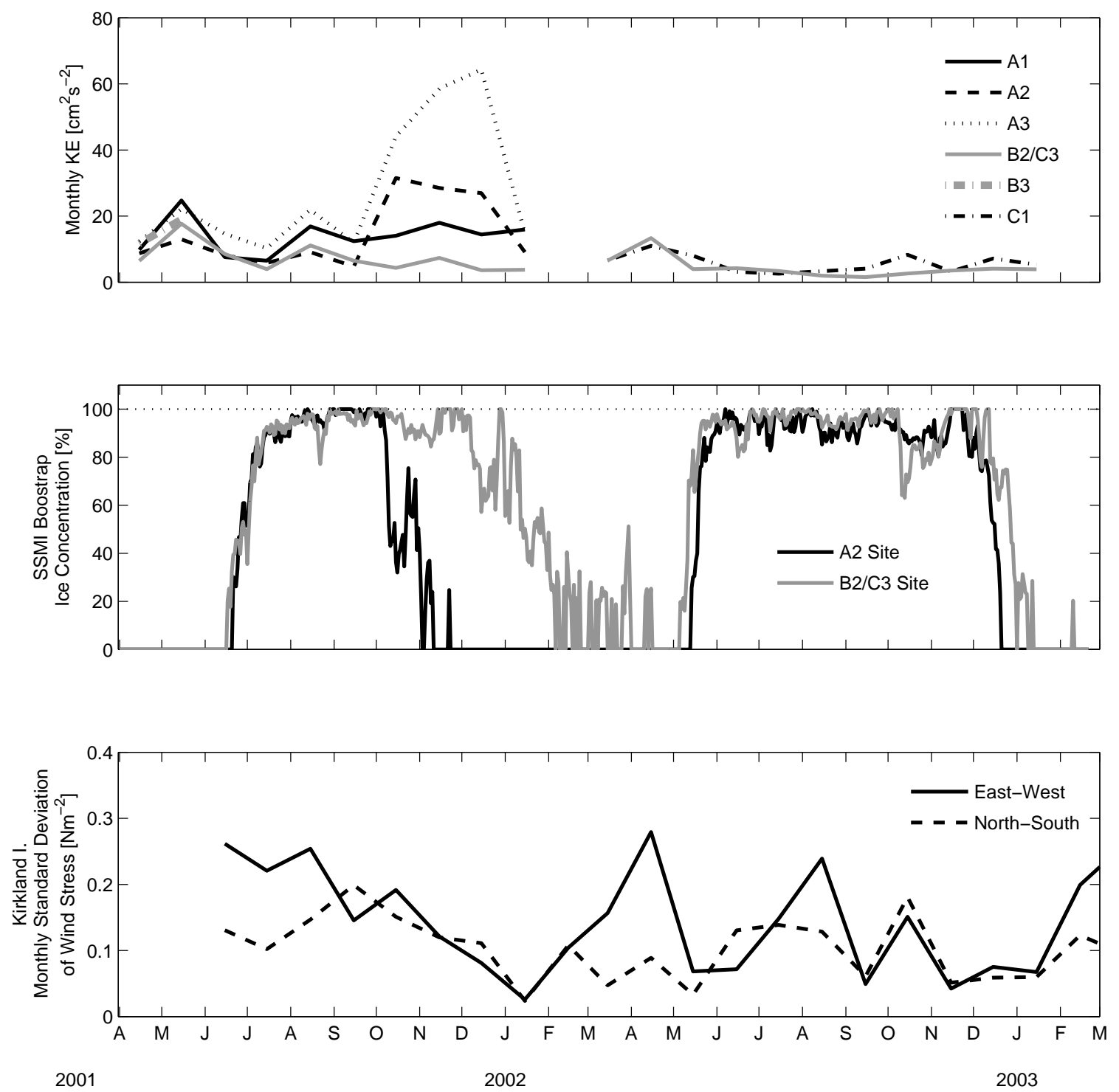

Figure 3-17: Monthly averaged kinetic energy at $100 \mathrm{~m}$ (top panel), sea-ice concentration (middle panel) and standard deviation of the monthly averaged wind-stress at Kirkland Island (bottom panel). 


\subsection{Bottom-trapped Topographic Waves in Mar- guerite Trough}

Examination of the vertical structure of the current records revealed in some of the moorings bottom-intensified subtidal motions in scales of a few days to two weeks or so. Figure 3-18 shows the power spectra of the along- and cross-slope currents for two of these moorings, A2 and C2 (the third, B3, shows a similar structure). At A2, there is consistently more energy at the deepest instrument $(397 \mathrm{~m})$ than at $247 \mathrm{~m}$ in subtidal scales of a few days and longer than 9 days or so, with a gap in this pattern around seven days. The surface-most instrument, at $107 \mathrm{~m}$ is less consistent, and shows significantly more energy, in particular in the cross-slope direction. At C2, all the records show energy increasing with depth (notice this mooring had a failure in its surface-looking ADCP so no records of the surface currents were recovered). Because the presence of the relatively strong bottom slope in Marguerite Trough together with the deep stratification can sustain baroclinic vorticity waves (e.g. Rhines, 1970; Thompson and Luyten, 1976; Auad et al., 1998), we speculated that these motions could be due to bottom-trapped topographic Rossby waves (TRWs).

In the following sections, I use the A2 mooring records to explore this hypothesis. The results at $\mathrm{C} 2$ are qualitatively similar, but the applicability of the simple model outlined below is at best questionable: simple theories which can be tested with a single mooring assume, a simplified bathymetry, and the C2 mooring site, surrounded by the walls of Marguerite Trough and a large sea mount, means one must make arbitrary decisions about the coordinate system and direction of propagation. The A2 mooring site, instead, provides a more straight-forward test of the hypothesis.

\subsubsection{Dynamics}

In the context of linear, unforced quasi-geostrophic dynamics in the presence of a small bottom slope and constant stratification, the leading order horizontal velocity 
field can be rewritten using a streamfunction (e.g. Rhines, 1977):

$$
\Psi=\Psi_{0} \cdot e^{i(k x+l y-\omega t)} \cosh (\kappa N z / f)
$$

where $N$ is the buoyancy frequency, $\kappa$ is the magnitude of the wavevector, $f$ is the Coriolis parameter and $z$ is measured positive upward from the bottom. This function is a solution to the quasi-geostrophic potential vorticity equation with boundary conditions:

$$
\begin{array}{r}
w=0 \quad \text { at } \quad z=H \\
w=u \cdot \frac{d h}{d y} \quad \text { at } \quad z=0
\end{array}
$$

where $h$ is the bottom bathymetry and $y$ is the upslope direction. The dispersion relation for these bottom trapped modes is given by (for a complete derivation, see Rhines, 1970):

$$
\omega=N \alpha \sin \phi \operatorname{coth}(\kappa N H / f), \quad \sin \phi=\frac{k}{\left(k^{2}+l^{2}\right)^{1 / 2}}
$$

where $\alpha$ is the bottom slope, $H$ is the water depth, $\phi$ is the orientation of the wavevector with respect to the upslope direction (and, as $\vec{\kappa} \cdot \vec{u}=0$, also the orientation of the velocity vector to the isobaths). In the short-wave limit, where the internal radius of deformation is larger than the scale of the motion, $\operatorname{coth}(\kappa N H / f) \approx 1$ and the dispersion relation becomes:

$$
\omega=N \alpha \sin \phi
$$

that is, independent of the wavevector magnitude. In this case, the highest possible frequency is given by $\omega=N \alpha$. Notice that both the phase speed and group velocity propagate to the right facing shallow water in the southern hemisphere:

$$
C_{x}=\frac{N \alpha}{\left(k^{2}+l^{2}\right)^{1 / 2}} \quad, \quad C_{y}=\left(\frac{k}{l}\right) \frac{N \alpha}{\left(k^{2}+l^{2}\right)^{1 / 2}}
$$




$$
C_{g x}=\frac{N \alpha l^{2}}{\left(k^{2}+l^{2}\right)^{3 / 2}} \quad, \quad C_{g y}=-\frac{N \alpha k l}{\left(k^{2}+l^{2}\right)^{3 / 2}}
$$

In the case of Marguerite Trough, both phase and energy would therefore propagated clockwise, towards the coast on its northern side and towards the ocean on its southern side. Figure 3-19 depicts the vertical structure of a single wave packet and the orientation of the wave structure.

In summary, the assumptions involved in the derivation of the above dispersion relation and derived quantities, are:

- small slope $(L=1 / \kappa): \delta=\alpha L / H \ll 1$

- linear: $R_{o} / \delta=U H /\left(f L^{2} \alpha\right) \ll 1$

- topographic beta larger than planetary beta: $\alpha / \delta=\beta_{o} /(f \alpha / H) \ll 1$

- short waves $^{8}: \lambda_{i} / L=N H /(f L) \ll 1$

- low frequency motions: $\omega / f=O(\delta)$

- Constant stratification

A few properties of the dispersion relation and velocity field can be used to evaluate the dynamics described above with single mooring data (Thompson and Luyten, 1976). From Equation (3.16), the ratio of kinetic energy at depths $z_{1}$ and $z_{2}$ is given by:

$$
R=\left[\frac{\cosh \left(N / f \kappa z_{1}\right)}{\cosh \left(N / f \kappa z_{2}\right)}\right]^{2}
$$

where $R$, if significant, can be evaluated from observations to obtain the horizontal scale of the waves $\kappa$. As the dispersion relation for the short-wave limit (Equation 3.18 is independent of the magnitude of the wavevector, it provides a prediction for its orientation (and thus, for the orientation of the velocity vector) as a function of frequency for a given stratification and bottom slope. This theoretical estimate can

\footnotetext{
${ }^{8}$ Not strictly required unless one wants to use 3.17 as the dispersion relation.
} 
be compared to the orientation of the principal axis of the velocity records (again, as function of frequency). Finally, the density field and the up-slope velocity component are expected to be in quadrature, with the velocity leading.

\subsubsection{Topographic Waves at A2}

As described in section 3.5.1, linear quasi-geostrophic theory predicts that on time scales longer than $(\alpha N)^{-1}$, bottom intensified modes can be excited in the presence of stratification and a bottom slope. The power spectra shown in Figure 3-18 show several frequency bands with such vertical decay in kinetic energy. Although the vertical decay is not significant in the spectra plotted (based on the $95 \%$ confidence F-distribution test, see Emery and Thompson, 1998), band-averaging of the spectral estimates over synoptic time-scales ( 7 to 20 days) to increase the number of available degrees of freedom showed that the decay is significant on average over that frequency band.

The ratio of the variance for the along-slope velocity component of the bottom two instruments is 0.71 , which can be used to estimate the horizontal scale of the waves using Equation (3.19). A reasonable estimate of the lower-layer stratification at A2 can be obtained from the density records collected on the mooring (which are not significantly different from CTD casts collected at or near the mooring site) and is, on average, $N=1.3 \cdot 10^{-3} \mathrm{~s}^{-1}$. The local bottom slope $\alpha$ is uncertain, but a reasonable value is 0.02 over a scale of $50 \mathrm{~km}$ or so. With $f=1.35 \cdot 10^{-4} \mathrm{~s}^{-1}$, the horizontal scale of the waves is $\kappa=2 \cdot 1 \cdot 10^{-4} \mathrm{~m}$.

Consider now the orientation of the velocity vector. At low frequencies, motion is predicted to be mainly along isobaths, with the velocity slowly turning at higher frequencies until we reach the highest allowable frequency, $\alpha N$, when motions are purely up and down the slope. In order to compare the observations to the theoretical prediction, the velocity records at the A2 mooring were band-pass filtered around a central period that was varied from around 60 days to $(\alpha N)^{-1}$. Figure 3-20 shows the orientation of the band-passed velocity records at the three measurement depths. Also plotted is the theoretical estimate of the orientation from Equation 3.18 using 
local values for $N$ and $\alpha$.

The results are encouraging for the bottom two instruments, which are the pairs that shows consistent variance decay from the bottom. The misfit of the theoretical estimate and the 100-m velocity record suggests that the waves have a vertical scale of less than $400 \mathrm{~m}$, or more likely, that the large increase in $N$ associated with the permanent pycnocline found centered near $150 \mathrm{~m}$ reduces the wave amplitude in the surface layer above the maximum stratification. The flow is highly coherent between $250 \mathrm{~m}$ and $400 \mathrm{~m}$, with zero temporal phase lag between the band-pass currents currents at 250 and $400 \mathrm{~m}$ (not shown), as is predicted by linear theory.

An independent test of the presence of this waves comes from the relation between the density and the upslope velocity. At A2, the density field and the upslope velocity are roughly in quadrature for periods around 10 days (Figure 3-21), as expected from the theory, with significant but low (0.4) coherence.

\subsubsection{Discussion and Summary of Bottom-trapped Topographic Waves}

Several assumptions are made in the derivation of the theory used here. A number of them can be revisited a posteriori and are shown in Table 3.8. The horizontal scale of the waves is not much larger than the radius of deformation, so in this analysis the short-wave assumption is the weaker one.

Table 3.8: Values of the non-dimensional parameters relevant to the derivation of the linear quasi-geostrophic vorticity waves. All values should be much less than 1 .

\begin{tabular}{llllll}
\hline Site (Period/Scale) & $\delta$ & $R o / \delta$ & $\alpha / \delta$ & $L / \lambda_{i}$ & $\omega / f$ \\
\hline $\mathrm{A} 2(10.9 \mathrm{~d} / 30 \mathrm{~km})$ & 0.17 & 0.43 & $1.8 \cdot 10^{-3}$ & 0.88 & 0.05 \\
\hline $\begin{array}{l}a \\
\text { Period: Center of the band where significant decay of power was } \\
\text { found (see text). Scale: For the given period, } L=1 / \kappa, \text { as calculated } \\
\text { from Eq. }\end{array}$
\end{tabular}

Two further assumptions are made, namely constant stratification and bottom 
slope. The latter is somewhat broken in the study area as the slope changes significantly in the WKB sense. A derivation of TRW theory relaxing this assumption or pursuing a numerical solution is required to determine the effects of a variable slope on these waves. As for the constant stratification assumption, this can be explored by solving the vertical structure of the quasi-geostrophic potential vorticity equation numerically for a given stratification function. The result (not shown) indicates that in the study region one should expect the TRW modes to decay extremely fast and not to penetrate the pycnocline, found at $150 \mathrm{~m}$ or so.

The above results assume that the spectral properties do not change in time. An idea of the evolution of the velocity field can be obtain by performing a wavelet analysis of the A2 records (Torrence and Compo, 1998). The wavelet transform allows for the energy (or variance) to be decomposed both in the time and frequency domains. Figure 3-22 shows the wavelet variance for the along-isobath components of the velocity at A2, averaged over periods from 7 to 20 days, which corresponds closely to the band used to calculate $R$. The result is interesting because Figure $3-22$ shows the bottom-intensified events to be highly episodic. There is one large event in mid-August to mid-September and another one the first few weeks of November. Moreover, there are clearly other dynamics acting at these frequency bands. There is a high-energy period during June, and another period during October that shows some interesting vertical structure. This complexity is not too surprising, as the $10 \mathrm{~d}$ time-scale is some of the most energetic in the atmospheric forcing.

In summary, the results shown here are consistent with the presence of bottomtrapped topographic Rossby waves in Marguerite Trough. At A2, the waves have a wavelength of $30 \mathrm{~km}$ or so and a vertical scale spanning several hundred meters from the bottom, although the pycnocline prevents their penetration into the surface-most layer. 

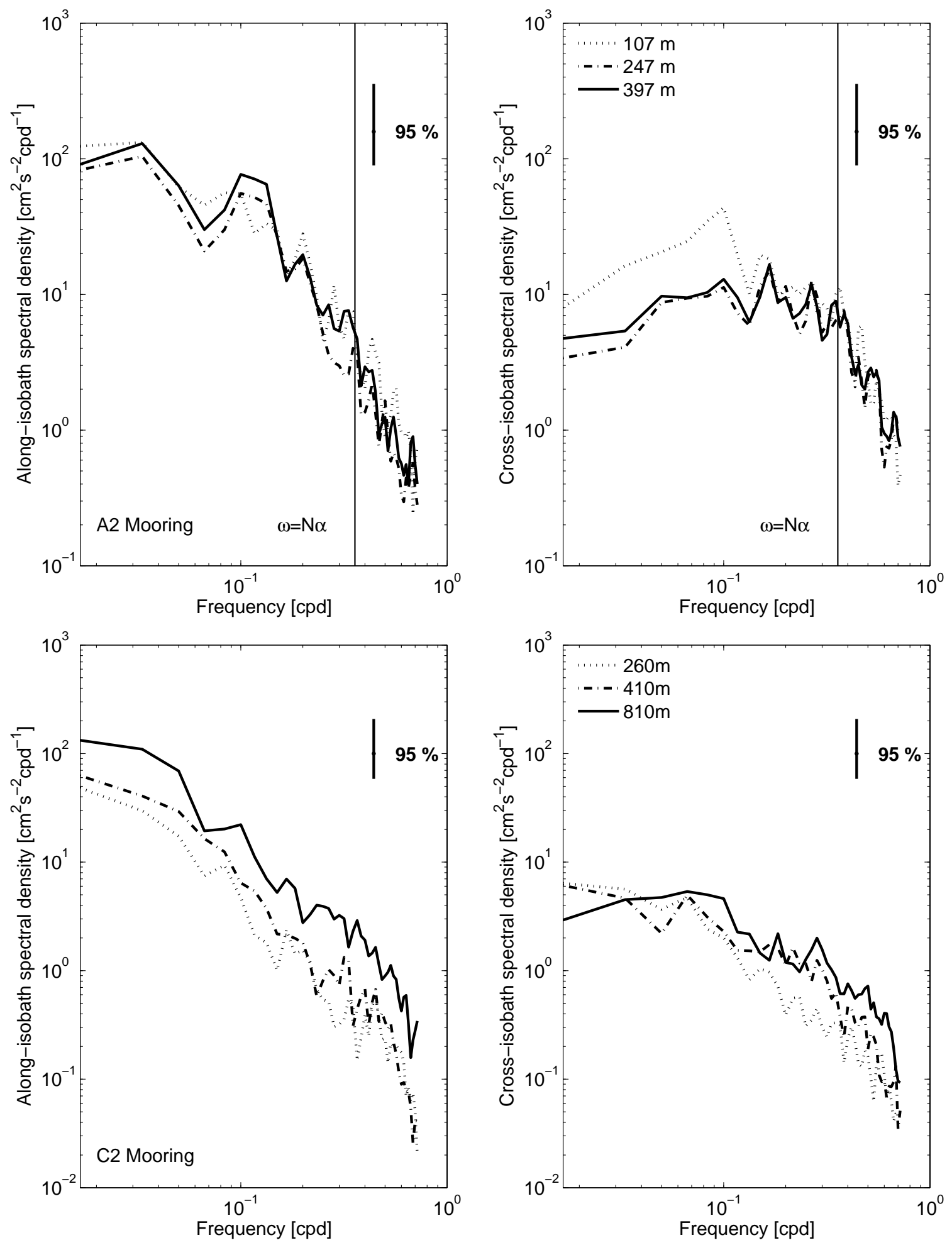

Figure 3-18: Power spectra of the along-slope velocity (left panel) and the crossslope velocity (right panel) for the A2 (top panels) and C2 (bottom panels) mooring records. 


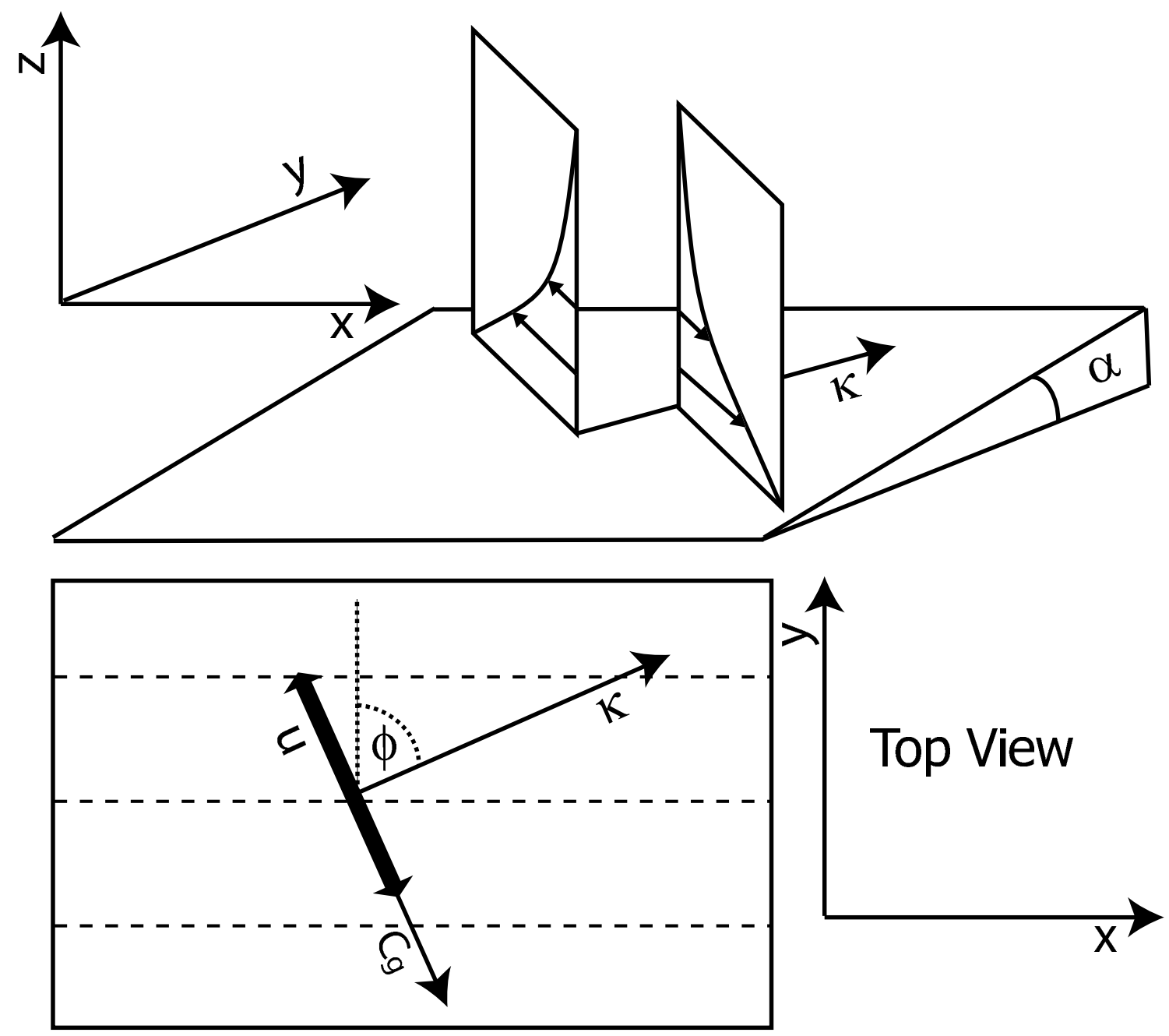

Figure 3-19: Schematic showing the structure of a bottom-trapped topographic Rossby wave. The top panel shows the velocity structure of a wave over a bottom slope $\alpha$, and with a vertical velocity structure decaying with distance from the bottom. The bottom panel shows the velocity vector $u$ with respect to the wavevector $k$ and the group velocity $C_{g} . \phi$ is the angle between the upslope direction and the wavevector. Modified from Rhines (1970) 


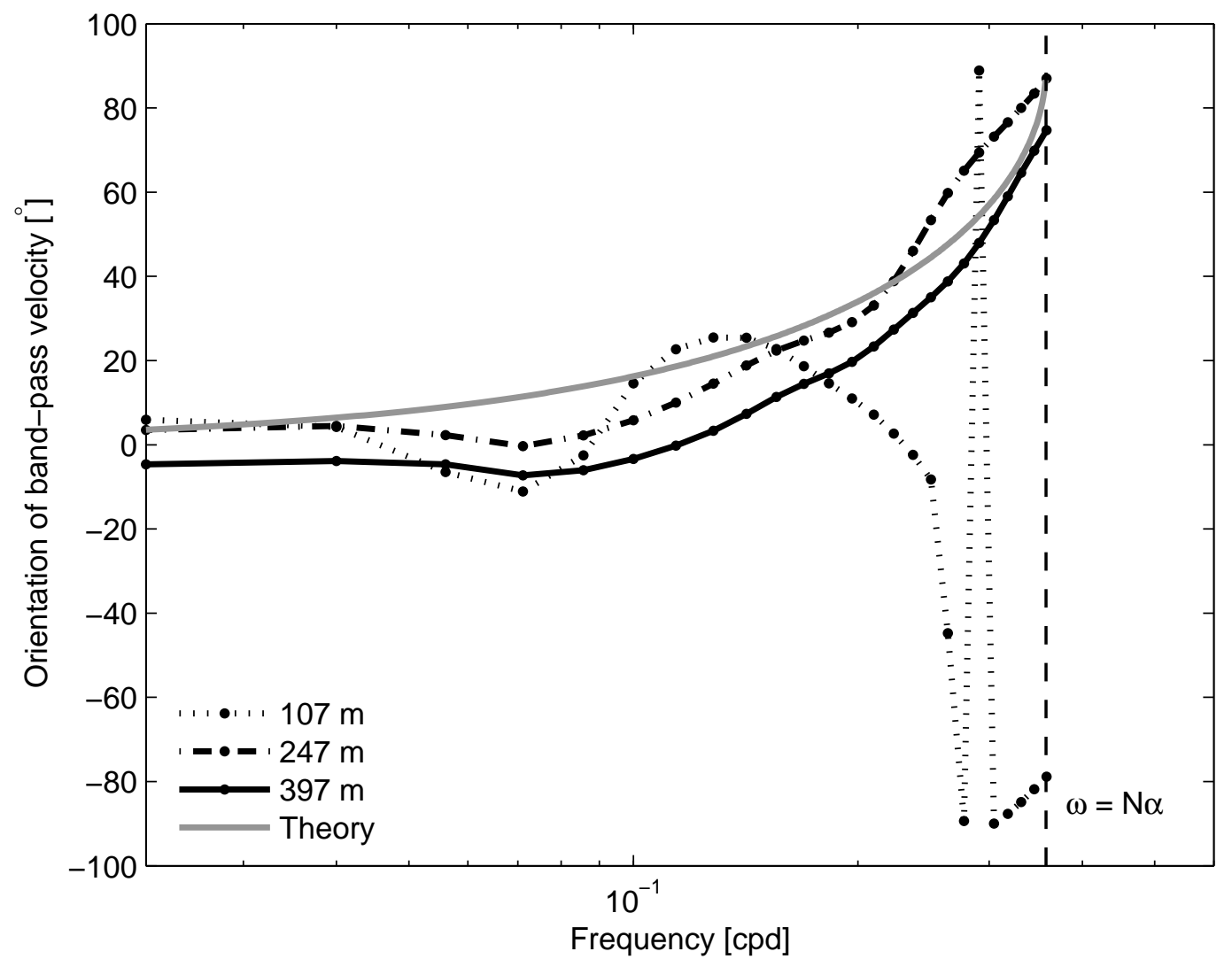

Figure 3-20: Orientation of the band-pass velocity as a function of filter frequency for the 107 (dotted), 247 (dashed) and 397 (solid black) A2 velocity records. The angle is positive (negative) in the upslope (downslope) direction. The prediction of the orientation of the currents records from wave theory (solid gray) is also plotted. The vertical line corresponds to the maximum frequency possible for the short-wave limit considered (See text). 

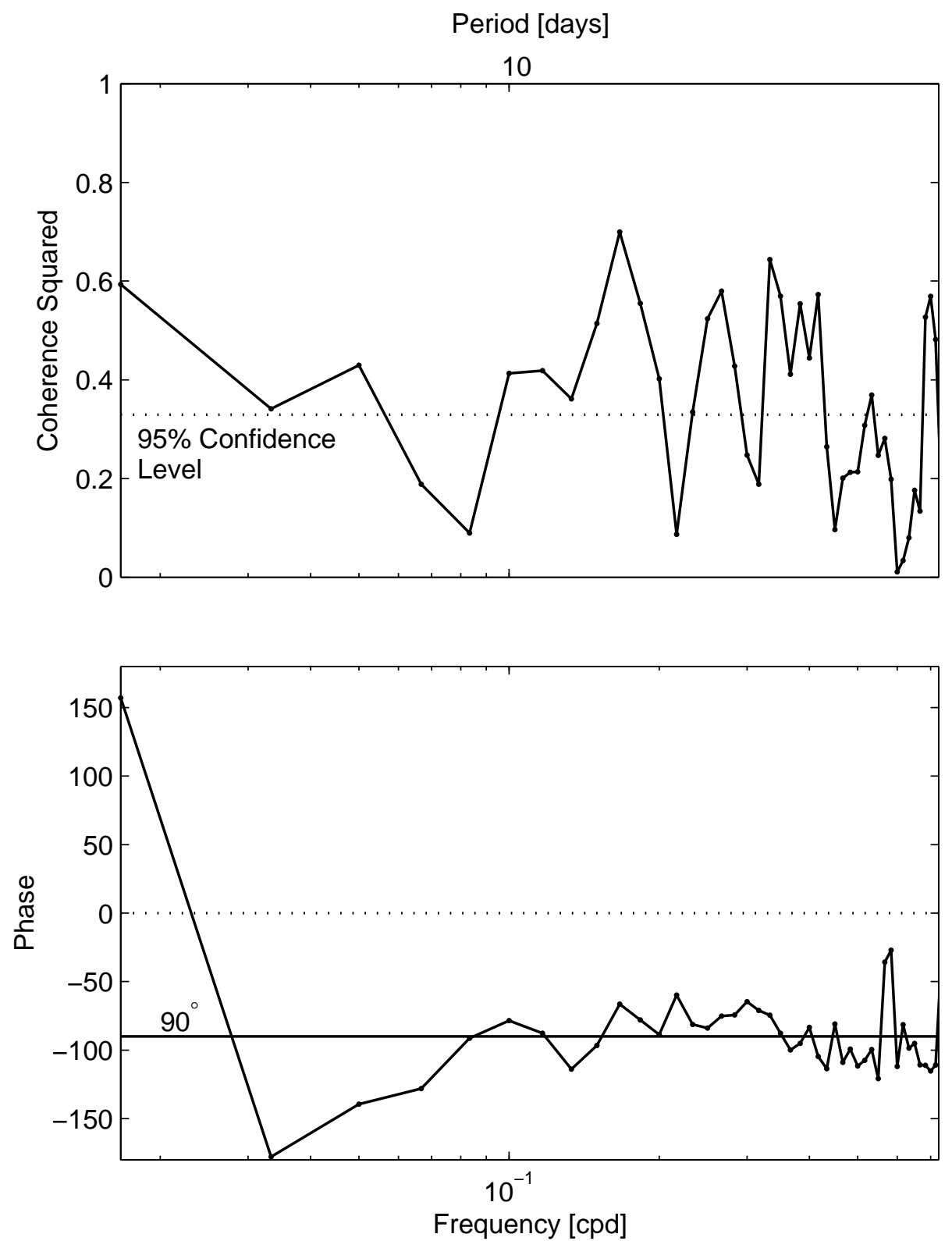

Figure 3-21: Coherence (top panel) and phase (bottom panel) between the downslope velocity $v$ and the density $\rho$ at $247 \mathrm{~m}$ at the A2 mooring. A phase value of $-90^{\circ}$ indicates that the density lags the velocity by $90^{\circ}$, as predicted by the theory discussed in the text. The horizontal dashed line is the $95 \%$ confidence level for the coherence. 


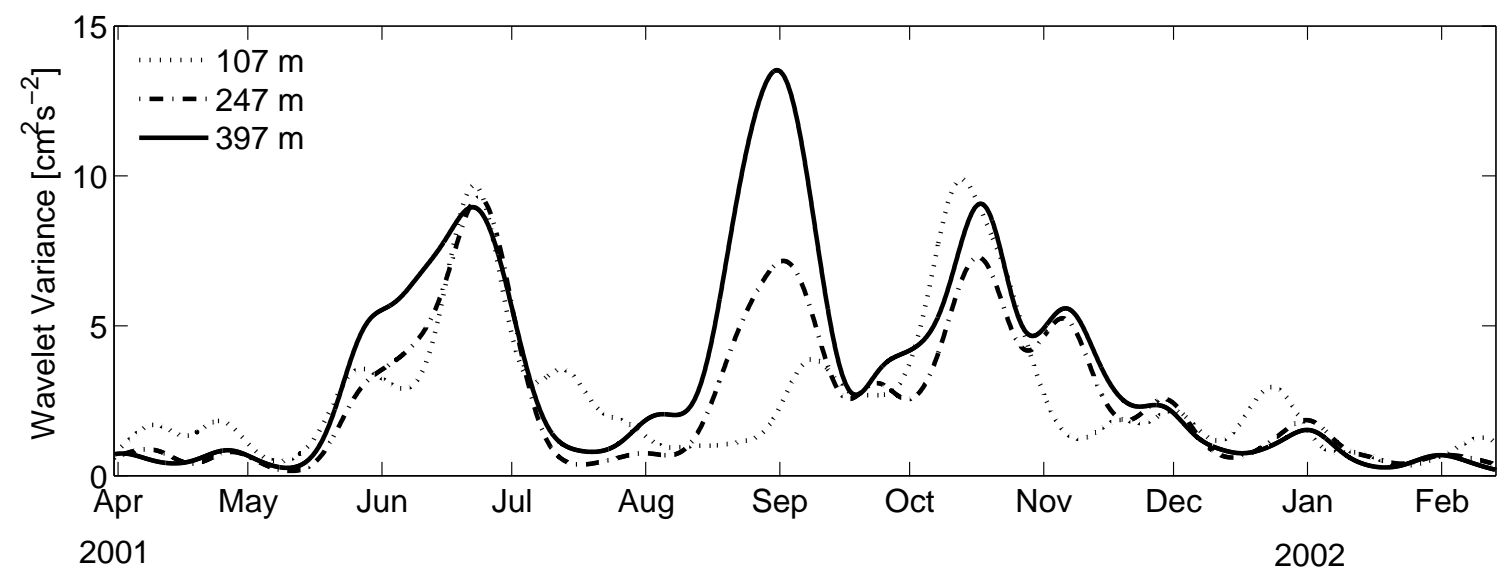

Figure 3-22: Wavelet variance averaged over periods of 7 to 20 days for the alongisobath current records at A2. 


\subsection{Alongshore Wind Response in Marguerite Trough}

The relationship between ocean circulation and wind forcing in this region has not been investigated until recently, when the relationship between ice motions, wind, and the surface ocean at near-inertial frequencies were studied (Hyatt et al., 2006). The subtidal circulation, on the other hand, has not been studied. This section aims at providing a lowest-order description of the subtidal current wind response in Marguerite Trough.

\subsubsection{Wind Data}

As part of SO GLOBEC, two automatic weather stations (AWSs) were deployed on Kirkland and Dismal Islands, in Marguerite Bay (see Chapter 2 for details). The AWS were not deployed until late May of 2001, almost two months after the beginning of the 2001 mooring deployment. The wind speed and direction were used to calculate the wind stress following Large and Pond (1981).

Figure 3-23 shows the mean and principal axes of the wind stress at the two AWSs, which are separated by roughly $30 \mathrm{~km}$. The wind stress has a mean vector roughly parallel to the direction of the main landmass of the Peninsula, and both these measurements and atmospheric model results suggest this is the general direction of the mean throughout this region (van Lipzig et al., 2004), making the winds downwelling-favorable for most of the region ${ }^{9}$. The wind stress at the two sites is highly correlated. Complex correlation at zero lag (Kundu and Allen, 1976) between the wind-stress time series at Dismal at Kirkland Islands is 0.86 with a phase angle of $7.3^{\circ}$. The wind stress at Dismal has principal axes which are markedly more polarized than at Kirkland, and a mean wind almost twice as large (Table 3.9). This variability suggests the influence of the surrounding topography and of the complicated coastline of Marguerite Bay, which appear to steer the wind and thus implies that the AWS wind measurements might not represent the wind-field in the open shelf. Also, the two instruments were located at different heights on small islands (see Chapter 2).

\footnotetext{
${ }^{9}$ Naturally, along the southwest coast of Marguerite Bay, the winds are upwelling-favorable
} 
These two factors might also contribute to the observed differences between the two AWS records.

Table 3.9: East and north means and principal axes of the wind stress from the two SO GLOBEC automatic weather stations on Kirkland and Dismal Islands and from the Polar MM5 model output at the A2 mooring site (statistics from 05/25/02 to $02 / 13 / 02)$.

\begin{tabular}{lccccc}
\hline Location & $\begin{array}{c}\tau_{x} \\
\mathrm{Nm}^{-2}\end{array}$ & $\begin{array}{c}\tau_{y} \\
\mathrm{Nm}^{-2}\end{array}$ & $\begin{array}{c}\mathrm{Maj} \\
\mathrm{Nm}^{-2}\end{array}$ & $\begin{array}{c}\mathrm{Min} \\
\mathrm{Nm}^{-2}\end{array}$ & $\begin{array}{c}\text { Inc. } \\
\circ\end{array}$ \\
\hline Kirkland I. & -0.01 & -0.05 & 0.12 & 0.09 & 20 \\
Dismal I. & 0.02 & -0.09 & 0.17 & 0.09 & -62 \\
MM5.A2 & -0.02 & -0.06 & 0.12 & 0.09 & 39 \\
\hline
\end{tabular}

The apparent local effects of coastal topography on the AWS winds and the lack of wind during the first few months of the mooring deployment led us to find other sources of wind information for the area. Output from the lowest level of the Polar MM5 atmospheric model, run by the Polar Meterology Group at The Ohio State University (Guo et al., 2003), were obtained by M. Caruso at WHOI. The model produces a 3-day forecast of the wind field every 12 hours, with a temporal resolution of three hours, on a grid with a horizontal resolution of $60 \mathrm{~km}$. Comparisons of the model output with the available shipboard wind data, AWS data, and the scarce satellite data were good (M. Caruso, personal communication). Figure 3-23 shows the mean and principal axes calculated from the model output at the A2 mooring site (MM5.A2), for the same period, and calculating the stress using the same formulation as with the AWS data. The model wind stress show a magnitude and variability similar to Kirkland Island (with complex correlation 0.75), but it is more closely aligned with the coastline of Adelaide Island (Table 3.9) and are also downwellingfavorable on average, although the variability is high compared to the mean at all the sites. Based on the reasonable agreement found between model and the observations by M. Caruso, we therefore assume that the MM5.A2 time series is an appropriate 
representation of the wind stress on the shelf off Adelaide Island.

In the rest of this section, the response of the currents at the B- and C-line moorings is briefly described using the model wind-stress in the along-shelf direction at A2. The orientation of the principal axis differs from the local coastline orientation $\left(\approx 62^{\circ}\right.$ counterclockwise from east), which is the direction where one would expect the maximum response in the along-shelf flow in the case of a much simpler twodimensional coastal ocean domain. The MM5.A2 wind-stress was therefore rotated into the coastline orientation, which is then called 'along-shelf wind-stress'. The mooring data will be kept in the same along- and cross-isobath directions defined in Section 3.2.1, and the current response will be described in that coordinate system.

\subsubsection{Correlations with the Wind-stress}

Overall, cross-correlation between the along-shelf wind-stress and the mooring velocities is low, but statistically significant in several locations. The $95 \%$ significance level for most of the records is 0.13-0.15, and the cross-correlation is highest at A2 and C2 and $\mathrm{B} 3$ in the along-isobath direction $(0.40,0.23$ and 0.20 respectively) with phase lags (wind leading) of $30-$ to $50-\mathrm{h}$ (1 to 2 days). The correlation at all these moorings is roughly equal with depth. The other moorings show no significant correlation with the along-shelf wind-stress in the along-isobath direction. For the cross-isobath velocity, the highest correlation is found at B2 (0.30), C1 (0.23), A2 and A3 ( $\approx-0.20)$, with phase lags of the same order as for the along-shelf flow.

\subsubsection{Magnitude and Structure of the Response}

To illustrate the response of the circulation in Marguerite Trough, the along- and cross-isobath subtidal currents records were bin-averaged as a function of the alongshelf wind-stress. For all the data falling into a given wind range, the average alongisobath and cross-isobath velocity are calculated, together with a $95 \%$ confidence level based on the total number of data points in the bin and the integral time-scale of the wind for the entire period $(\approx 45 \mathrm{~h})$. A minimum of 20 events must be contained in 
each bin for statistics to be calculated (the usual trade-off is to lose binning data at more extreme, but rarer, wind-stress magnitudes).

Figures 3-24 and 3-25 show the response of the circulation in the along- and cross-isobath direction in Marguerite Trough. The range of along-shelf wind-stress magnitudes for which enough events were found is -0.2 to $0.2 \mathrm{Nm}^{-2}$. Somewhat consistent with the cross-correlation results, the response is evident in a subset of the moorings only. For downwelling-favorable wind-stress (positive in the coordinate system used), the flow is forced towards the shelf-break (Figure 3-24) and downslope (Figure 3-25) at A2 and only along the isobath at C2 (the northern side of the trough), with maximum velocities of $2-4 \mathrm{~cm} / \mathrm{s}$ at A2 and $1-2 \mathrm{~cm} / \mathrm{s}$ at the deeper $\mathrm{C} 2$. Notice that there is a hint of a baroclinic structure at A2, with the vertical shear increasing with the wind-stress magnitude (the uncertainties, however, are too large for this tendency to be significant). All of the velocity records at $\mathrm{C} 2$ are from well below the pycnocline and the response to the wind is barotropic to within our error estimates. For upwelling-favorable wind-stress, the opposite is true, with both of the moorings showing shoreward (negative) flow and a tendency for upslope flow at A2.

The results at A3 have large uncertainties, and there is no clear response in the along-isobath direction, but downwelling-favorable wind-stress tends to generate positive flow, which is roughly in the along-shelf direction and surface intensified. The steering of the flow in the along-isobath direction seen at A2 does not affect the flow at A3, most likely because the slope is much gentler on the southern side of the trough where A3 was deployed (see Figures 3-3 and 2-5). For upwelling-favorable wind-stress, the tendency is for the flow to be downslope (to the north-east), although the uncertainties are too large to make a definitive statement about this.

\subsubsection{Summary of the Subtidal Current Wind Response in Marguerite Trough}

When the winds are downwelling-favorable, the results indicate that the circulation is anticyclonic along the northern side of Marguerite Trough and southwestwards 
at A3 (roughly in the along-shelf direction). Upwelling-favorable wind-stress causes shoreward, upslope flow at A2 and into Marguerite Bay at C2. The response is of the scale of 1 to $4 \mathrm{~cm} / \mathrm{s}$, which is comparable to the mean flow at several moorings (See section 3.2). Most of the long records considered here were located deep in the water column, although the surface-most instruments both at A2 and A3 show some tendency for baroclinicity. At C2, however, instruments spanning $550 \mathrm{~m}$ (all below the pycnocline) show a clear barotropic response.

Interestingly, the mean flow in the canyon was shown (See section 3.2) to be strongest at A2 and cyclonic around the canyon, that is, in the opposite sense of what would be expected from a mean downwelling-favorable wind-stress as shown here. 


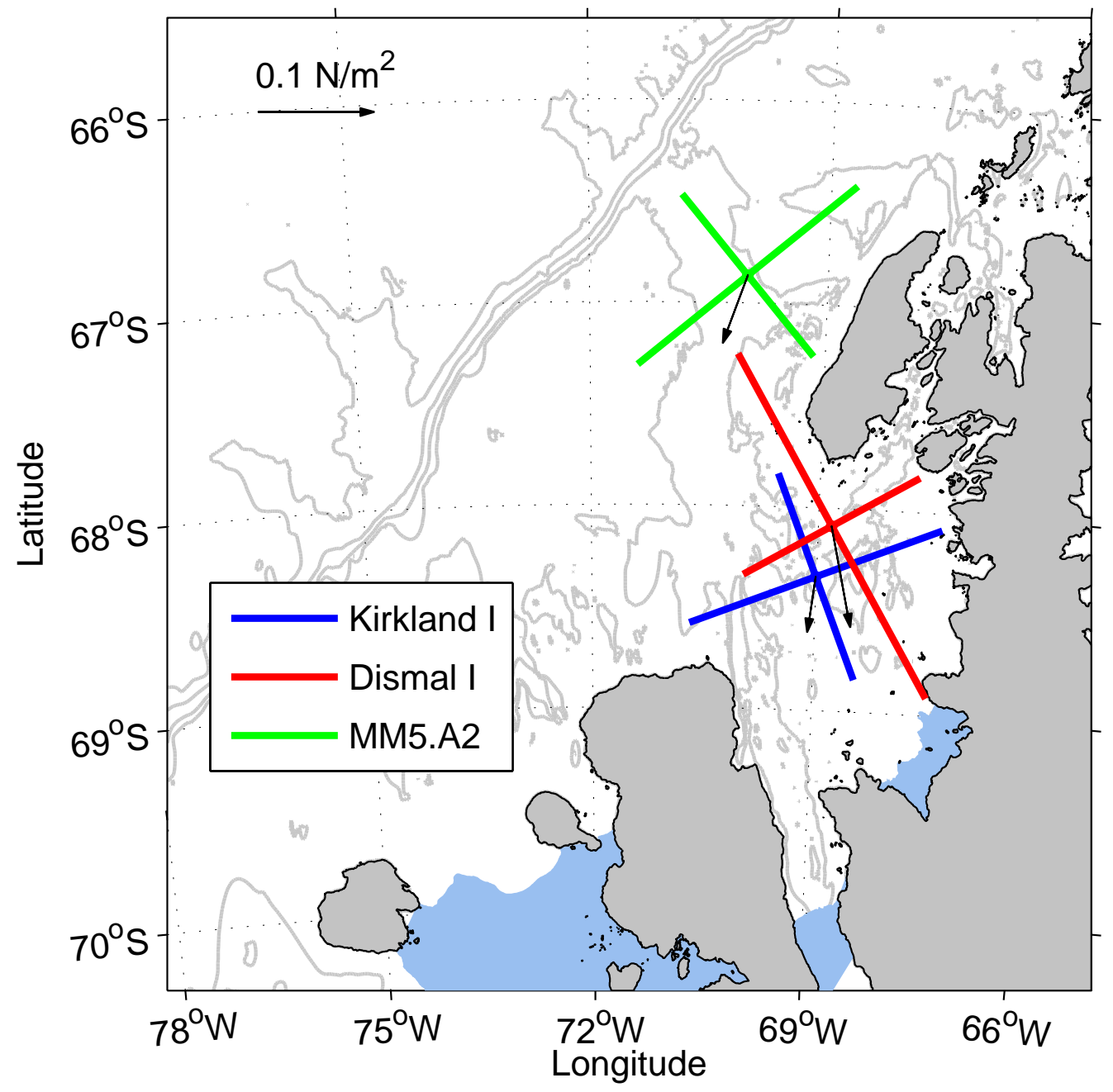

Figure 3-23: Mean and principal axes of the wind stress from the AWSs at Kirkland and Dismal Island and from the output of the Polar MM5 model at the A2 mooring site. The statistics are calculated for the period starting 05/25/02 (the beginning of the AWS time-series) until 02/13/02 (when the A- and B-line moorings were recovered). 

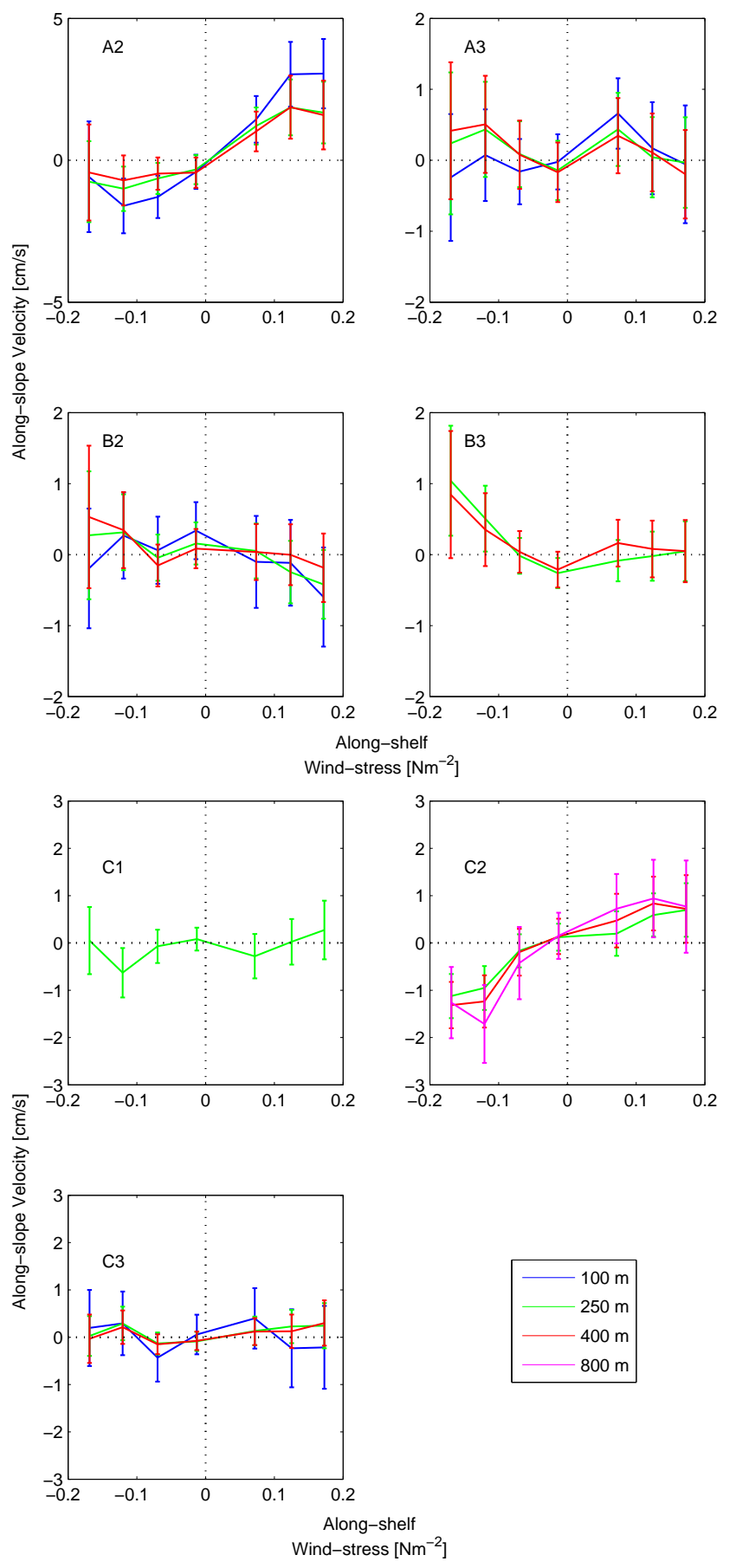

Figure 3-24: Along-isobath current response to along-shelf wind-stress in Marguerite Trough. The vertical axis is the along-isobath velocity binned as a function of the along-shelf wind stress. The error bars are the $95 \%$ confidence intervals for each bin. Downwelling-favorable wind-stress is positive. 

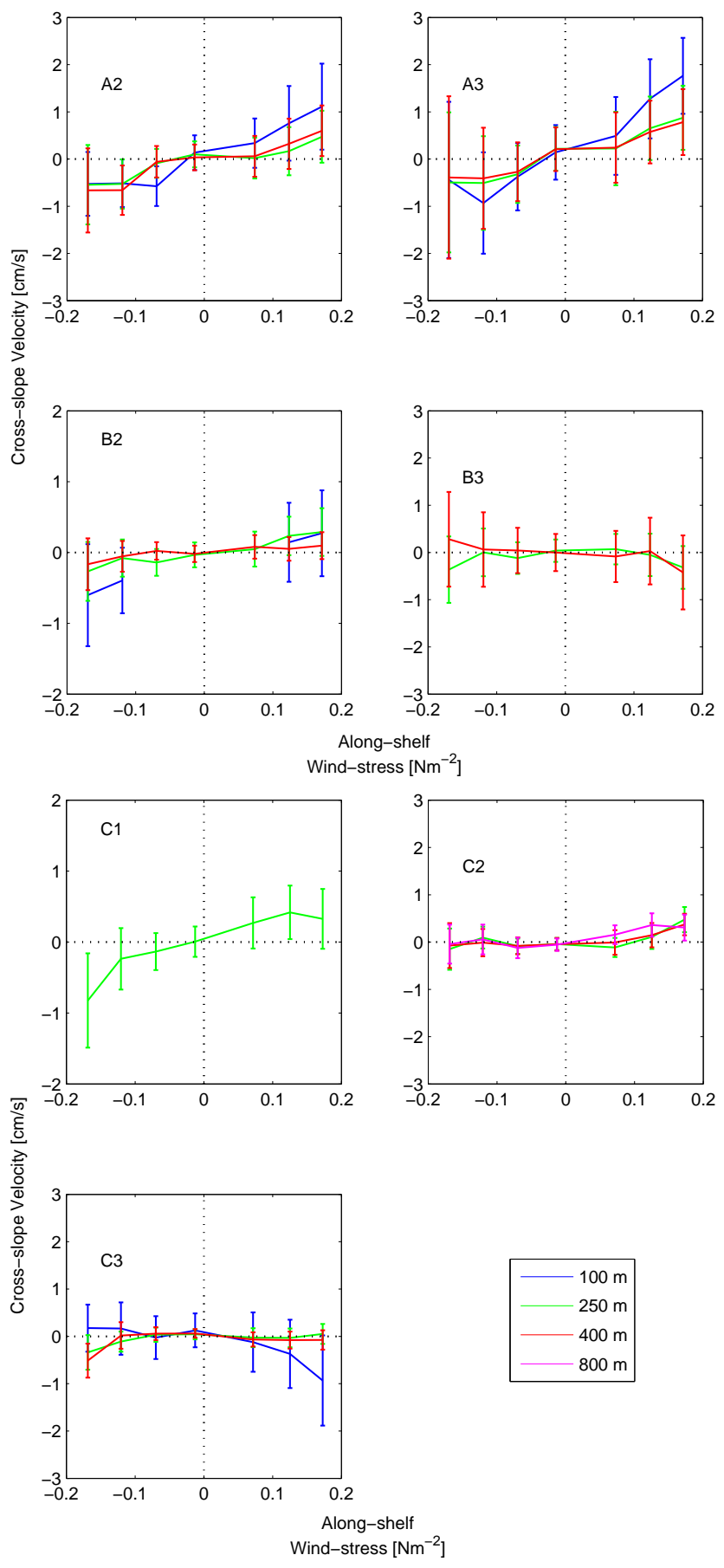

Figure 3-25: Cross-isobath current response to along-shelf wind-stress in Marguerite Trough. The vertical axis is the cross-isobath velocity binned as a function of the along-shelf wind stress. The error bars are the $95 \%$ confidence intervals for each bin. Downwelling-favorable wind-stress is positive. 


\section{Chapter 4}

\section{Circumpolar Deep Water Intrusions}

\subsection{Background}

Early studies of the western Antarctic Peninsula (wAP) shelf revealed a complex hydrographic structure with a strong seasonal cycle. The surface layer is occupied by Antarctic Surface Water (AASW), a relatively fresh and cold water mass that is usually found all around the Antarctic continent (Figure 4-1). During the late fall and winter, the surface mixed layer is deepened by surface cooling and by brine rejection as a result of ice formation. The resulting mixed layer is roughly at freezing temperatures and reaches a depth of $100 \mathrm{~m}$ or so. As the air temperature increases at the end of winter, the ice breaks up, melt water from the coast increases and a positive heat flux into the ocean all lead to restratification of the deep mixed layer, leaving a layer of cold water at $100 \mathrm{~m}$ or so called Winter Water (WW). Below the WW, the shelf is occupied by a warm and salty water mass called modified Circumpolar Deep Water (mCDW), a slightly colder and fresher version of the oceanic Circumpolar Deep Water, found along the shelfbreak of the wAP.

Although precise estimates of the heat budget are lacking, hydrographic surveys and modeling studies suggest that the integrated heat budget for the surface layer results in a net heat loss to the atmosphere. As heat is readily available in the lower 


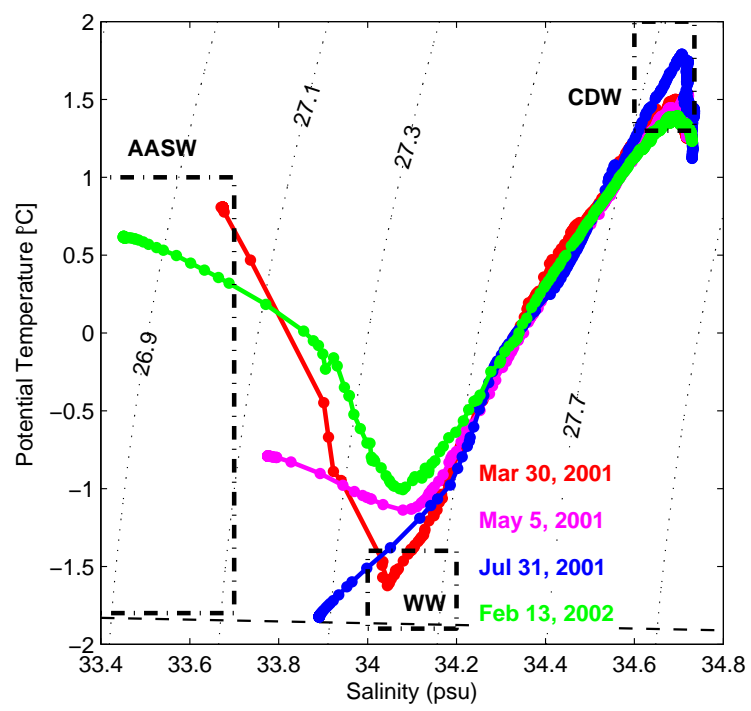

Figure 4-1: Evolution of the hydrographic structure on the mid-shelf of the wAP (A2 mooring site). The panel shows a $\theta$-S diagram of profiles taken throughout 2001 and 2002. The black boxes illustrate the typical range of the Antarctic Surface Water (AASW), Winter Water (WW) and Circumpolar Deep Water (CDW). The dashed blue line indicates the freezing point of seawater. Notice that CDW is composed of a warm branch (UCDW, with temperatures $>1.5^{\circ} \mathrm{C}$ ) which is evident in the July profile, and a lower, saltier branch (salinities larger than 34.72 or so).

layer of the shelf in the form of $\mathrm{mCDW}$, and because this water mass has clearly lost heat after moving onto the shelf, it has been hypothesized that a vertical flux from the lower layer is responsible for balancing the net heat loss to the atmosphere. The magnitude of this upward flux has been estimated from observations using a simple two-dimensional model equating lateral to vertical fluxes, resulting in an estimate of $1.5 \mathrm{~W} / \mathrm{m}^{2}$ (Klinck, 1998), and from a 1-D mixed-layer/ice model which resulted in an estimate closer to $5 \mathrm{~W} / \mathrm{m}^{2}$ (Smith and Klinck, 2002).

In order to close the heat budget, an onshore flux of heat must compensate the cooling of the lower layer of the shelf. Hydrographic data from a summer cruise conducted in 1993 suggested that CDW intruded in four specific locations along the shelf, two of which are within the SO GLOBEC study region (Prézelin et al. 2000: Prézelin et al., 2004). Remnants of CDW were found along Marguerite Trough during the SO GLOBEC cruises, which also suggested that this bathymetric feature, connecting the shelfbreak to Marguerite Bay, provides a path for CDW intrusions to move across 
the shelf (Klinck et al., 2004). On the basis of these hydrographic surveys, it has been suggested that CDW moves into Marguerite Trough and across the shelf into Marguerite Bay four to six times a year (Klinck et al., 2004).

In this chapter, the questions of the spatial scales, frequency and circulation of CDW intrusions onto the shelf are addressed using the SO GLOBEC broad-scale hydrographic cruises and moored array (See Chapter 2 for details on the dataset). In the next sections, I provide a characterization of the source waters for the intrusions, a definition for the intrusions, a characterization of their spatial scales, frequency, and intensity, and a rough estimation of their contribution to the horizontal heat flux. Finally, the implications of this work for the wAP system and biological communities are discussed.

\subsection{Characteristics of Oceanic Waters}

A hydrographic section conducted in the austral summer of 1992 along the S04P World Ocean Circulation Experiment (WOCE) line illustrates the key hydrographic structure of the region. The section was conducted starting in the mid-shelf region and moving offshore, with four relatively close CTD casts across the shelfbreak (Figure 4-2). Figure 4-3 shows the potential temperature $(\theta)$, salinity and potential density $\left(\sigma_{\theta}\right)$ sections from the cruise. Away from the shelf, the vertical structure is characterized by a deep temperature maximum at $500 \mathrm{~m}$ or so, corresponding to the core of the Upper Circumpolar Deep Water (UCDW). The colder and saltier water mass below, with densities $>27.8$ and salinity maximum around 34.72 corresponds to Lower Circumpolar Deep Water (LCDW), which is also characterized by higher dissolved oxygen values. Both branches of Circumpolar Deep Water are carried by the Antarctic Circumpolar Current (ACC) along the shelfbreak, and as is characteristic of the southern boundary of the ACC around Antarctica, both the isotherms and isohalines shoal towards the continent (Sievers and Nowlin, 1984; Orsi et al., 1995).

Because the Circumpolar Deep Water is carried by ACC fronts (see Chapter 1 for a brief description of the regional circulation) that lack a distinctive upper layer 


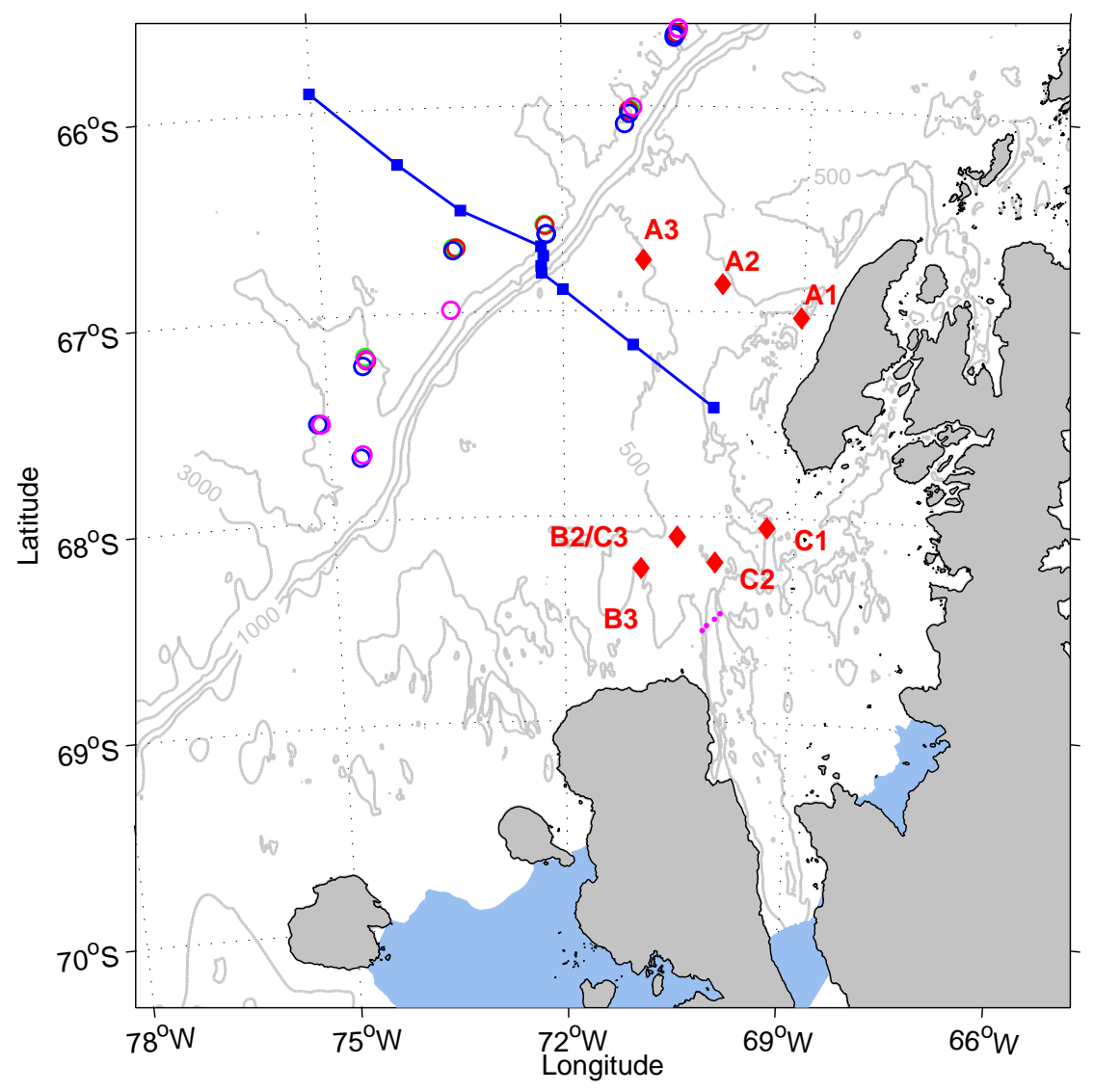

Figure 4-2: Location of the first ten CTD casts conducted during the S04P cruise (blue squares), the SO GLOBEC moorings (red diamonds), CTD stations conducted off the shelf during the SO GLOBEC broad-scale cruises (open circles) and location of CTD casts from the cross-isobath section conducted by the L. M. Gould during the fall of 2001 (magenta dots).

signature that can be used to trace its presence on the shelf, surface data - including satellite images - are of little use in determining the boundary of water masses carried by the ACC near the wAP shelf, and therefore of the UCDW intrusions of interest here. Below, we use the hydrographic survey data from the SO GLOBEC cruises to provide a suitable definition of an UCDW intrusion.

\subsubsection{Definition of an Oceanic Intrusion}

Although the SO GLOBEC sampling grid included only a handful of CTD casts in the open ocean during each of the broad-scale surveys, together they provide a good 


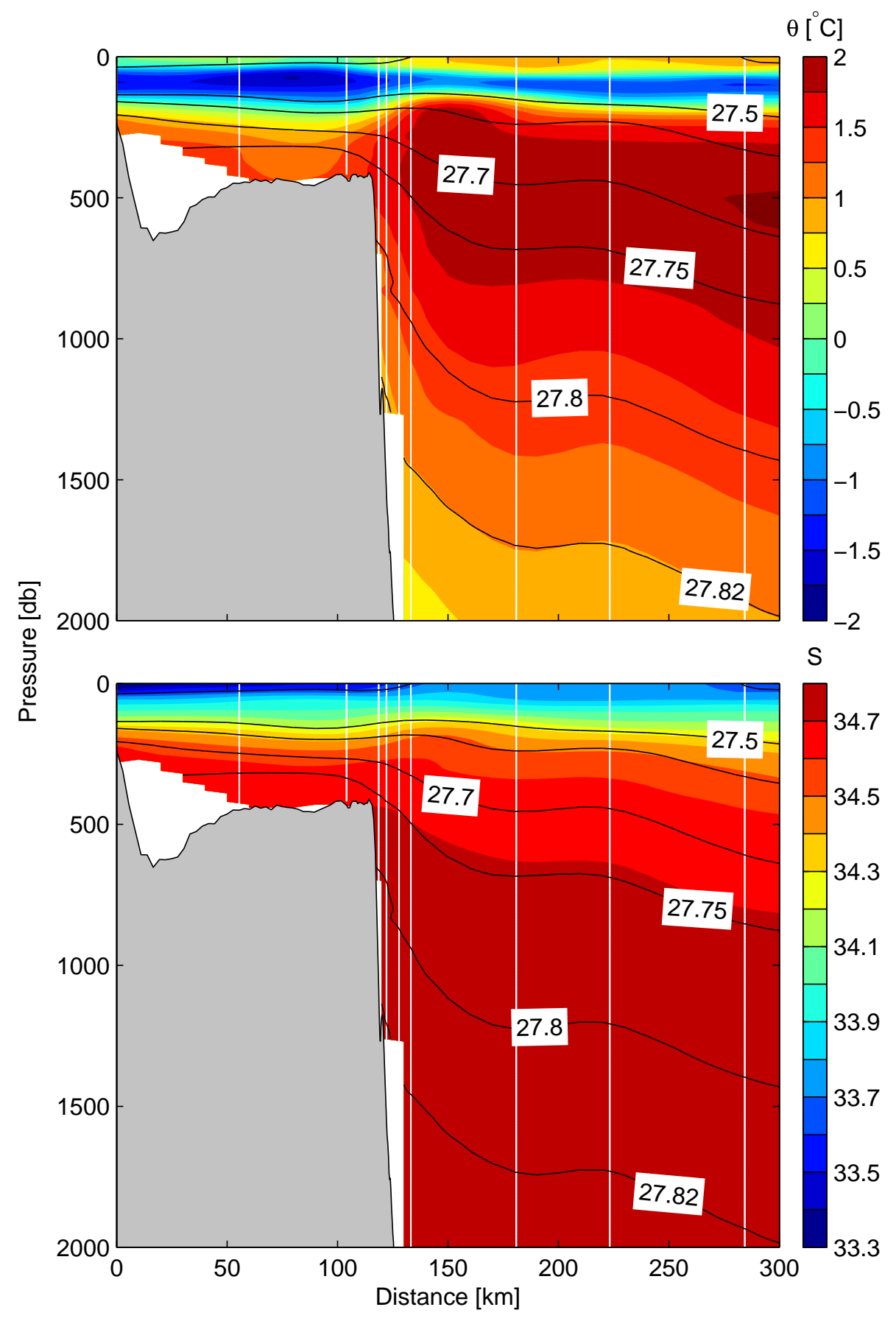

Figure 4-3: Color contours of potential temperature (top panel) and salinity (bottom panel) for the S04P section, conducted between February 22 and 24, 1992. Contours of $\sigma_{\theta}$ (black) are superimposed in both panels. The white vertical lines represent where CTD stations were taken. 
picture of the variability of the source water for the deep water intrusions. Figure 4-4 shows a $\theta$-S diagram of all the CTD casts collected off the shelf and shelf-break at locations deeper than $2000 \mathrm{~m}$. The figure reveals the basic features of the seasonal changes in the region. The relatively warm and fresh water found in the surface layer during the fall is replaced by cold (near freezing) and salty water during the winter. At depth, the variability is not seasonal but mostly spatial. The mid-depth potential temperature maximum corresponding to the core of the UCDW (Figure 4-4. right panel) is characterized by a relatively wide range of temperatures (from 1.55 to $2.1^{\circ} \mathrm{C}$ ) and salinities of 34.62 to 34.68 . Below UCDW, the $\theta$-S properties tend to collapse as the salinity increases and temperature decreases. The maximum salinity of around 34.72 and temperatures of $1.2{ }^{\circ} \mathrm{C}$ or so corresponds to the core of the other branch of CDW, Lower Circumpolar Deep Water (LCDW).

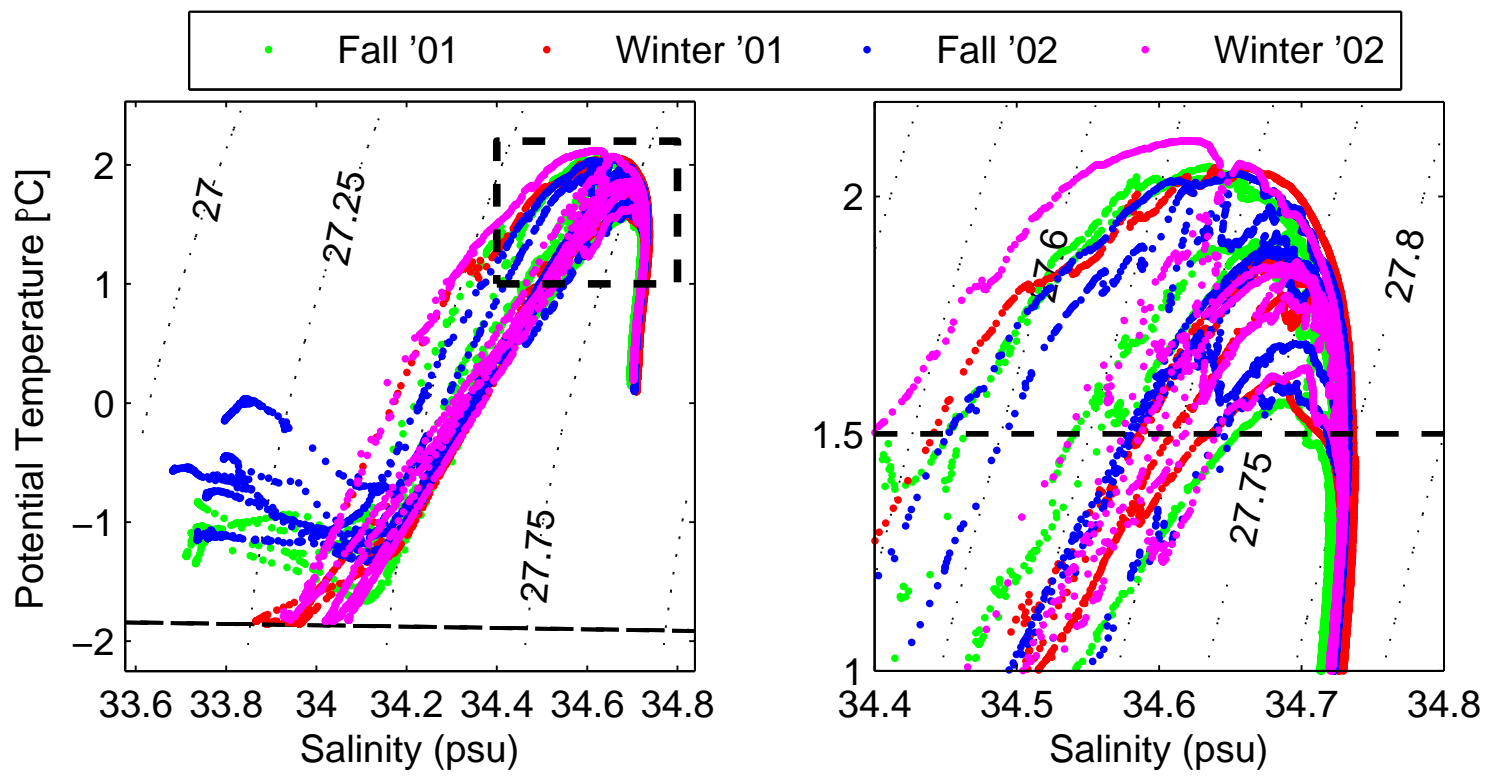

Figure 4-4: $\theta$-S diagram of all the CTD casts from open ocean locations collected during the fall 2001 (green dots), winter 2001 (red), fall 2002 (blue) and winter 2002 (magenta) SO GLOBEC broad-scale cruises. Open ocean is defined as locations deeper than $2000 \mathrm{~m}$. The left panel shows the full depth (the dashed line is the freezing temperature) and the right panel is a detail of the $\theta-\mathrm{S}$ space associated with Circumpolar Deep Water (the dashed line marks $1.5^{\circ} \mathrm{C}$ ).

The vertical hydrographic structure on the shelf is qualitatively similar to the 
open ocean, except for a weaker subsurface temperature maximum as a result of the modification of UCDW into mCDW and also the absence of LCDW from most of the shelf, although it has been reported as a thin deep layer in Marguerite Trough (Klinck et al., 2004). Therefore, a reasonable detection criteria for UCDW intrusions on the shelf is water with potential temperature of $1.5^{\circ} \mathrm{C}$ or more below the mixed layer. This is consistent with what is known about the source waters carried by the ACC close to the shelfbreak from observations (Figure 4-4), and with historical characterizations of the ACC water mass structure and boundaries as seen in Figure 4-3 and in the literature (Orsi et al., 1995; Smith et al., 1999).

To characterize the intrusions, we first look for evidence of warm water in the hydrographic cruises and the moored array, with the objective of determining their amplitude, spatial scale, frequency and circulation.

\subsection{Spatial Distribution of UCDW Events}

\subsubsection{UCDW in the Hydrographic Surveys}

Evidence of UCDW on the shelf can be found in the four SO GLOBEC cruises. The maximum $\theta$ below the mixed layer (Figure 4-5) shows water of $1.75^{\circ} \mathrm{C}$ or more along the shelfbreak, except for the southern half of the study region during the fall 2001 survey, when no stations were conducted there. The $1.5^{\circ} \mathrm{C}$ isotherm, representing relatively unmixed UCDW, was found all along the shelfbreak and on the outer shelf for all cruises. UCDW was found penetrating onto the shelf at two locations: during both of the 2001 survey and the fall 2002 survey around $67.5^{\circ} \mathrm{S}$, and in all of the cruises around $67^{\circ} \mathrm{S}$, along the eastern side of Marguerite Trough. Warm water at these two sites was also reported in previous work examining data collected during hydrographic surveys conducted in 1993 and 1994, which also identified two other intrusion sites to the north of the SO GLOBEC study region (Prézelin et al., 2000; Prézelin et al., 2004).

Broad-scale hydrographic surveys sampling the shelf with a typical horizontal 

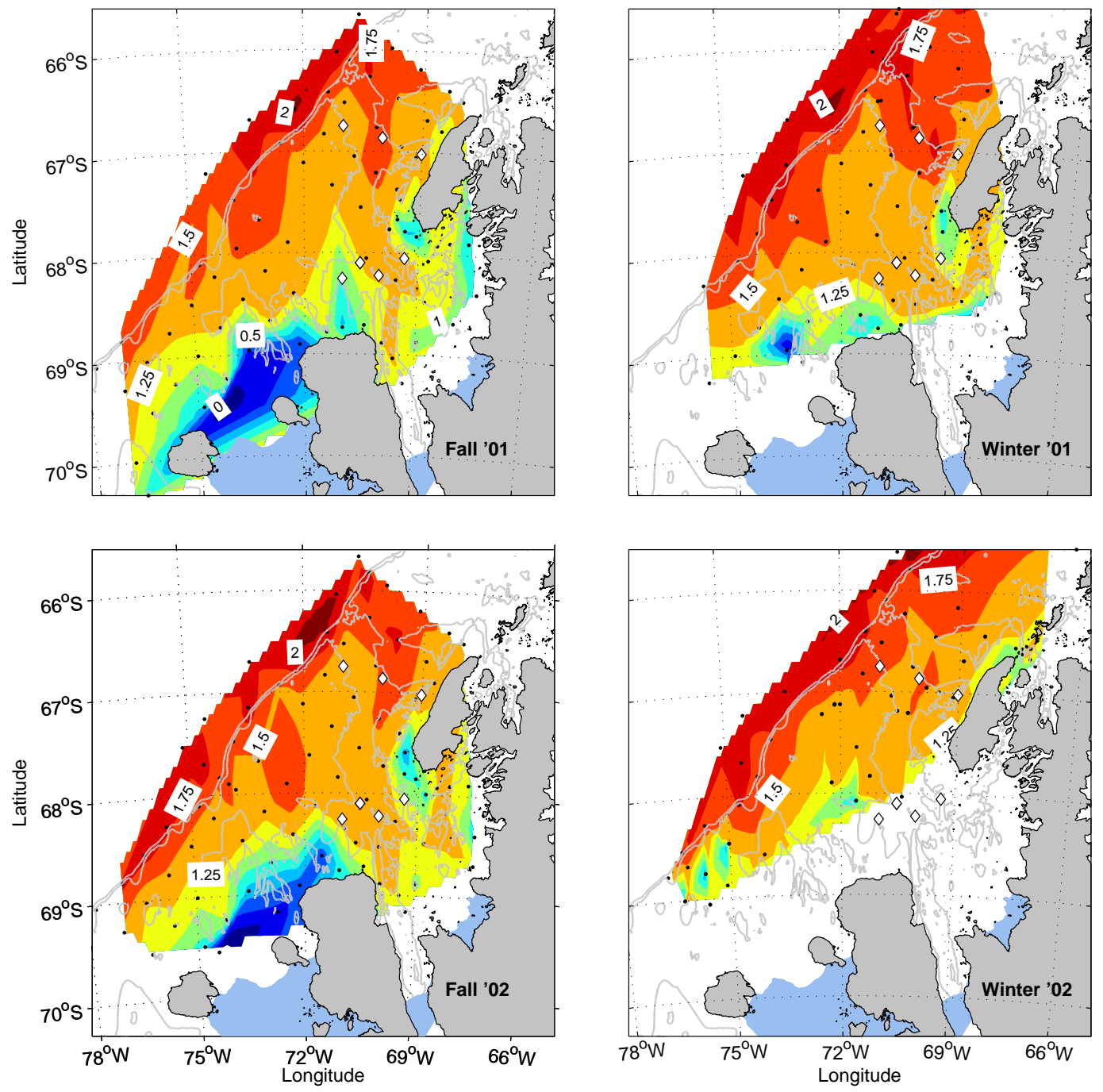

Figure 4-5: Maximum potential temperature $\theta$ below the mixed layer for the four broad-scale SO GLOBEC cruises. The nominal CTD horizontal resolution is $20 \mathrm{~km}$. The isotherms separation is $.25^{\circ} \mathrm{C}$. Notice the figure is meant to show presence or absence of UCDW (defined here as $\theta \geq 1.5$ ), and should not be interpreted as representing contiguous warm intrusions on the shelf (see text for details).

resolution of $20 \mathrm{~km}$ and showing the presence of UCDW on the shelf as shown in Figure 4-5 must be considered carefully. Figure 4-6 shows a detail of $\theta$-S space for the CTD casts on the shelf, showing the stations where UCDW was found. In most of them, the signal is relatively weak, with temperatures between 1.5 and $1.6^{\circ} \mathrm{C}$. In the fall of 2001 , for example, the only station where water warmer than $1.6^{\circ} \mathrm{C}$ 
was recorded was located some $20 \mathrm{~km}$ from the shelf-break on the eastern side of Marguerite Trough. During the winter 2001 cruise, the highest temperature recorded $\left(>1.8^{\circ} \mathrm{C}\right)$ on the shelf was also located on the eastern side of the trough, between the A1 and A2 mooring sites. Another isolated patch of warm water can also be seen in the winter 2002 cruise (Figure 4-5), as well as in the 1993 survey reported by Prézelin et al. (2004).

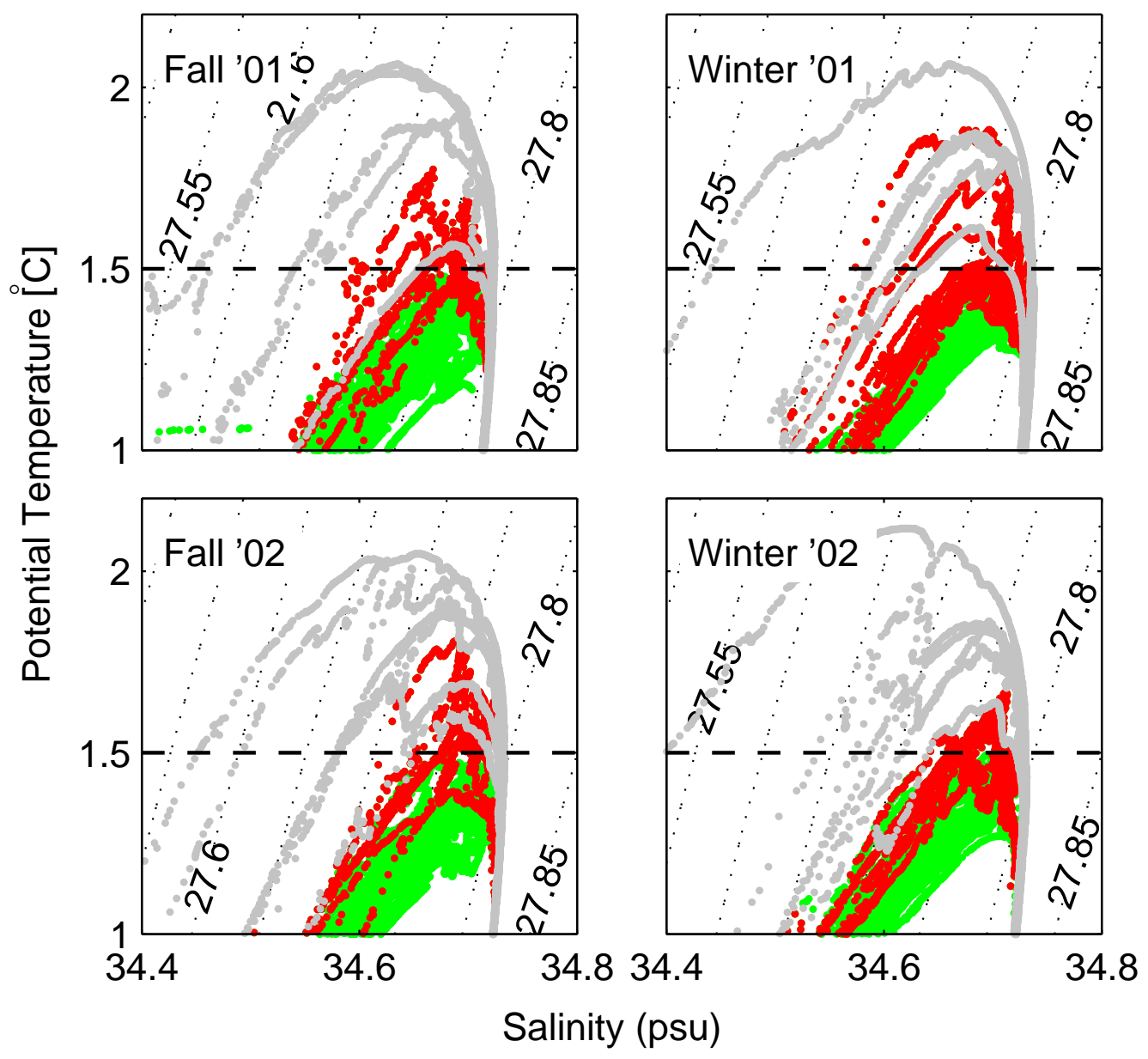

Figure 4-6: $\theta$-S diagram of the hydrographic data for all four broad-scale hydrographic cruises. The colors represent CTD casts collected off-shelf (gray), on the shelf showing UCDW (red), and all other casts on the shelf (green).

Although UCDW was not found in Marguerite Bay, there is more evidence Marguerite Trough is a path for the intrusions. Four CTD stations collected across the 
trough by the L. M. Gould during her fall 2001 cruise show slightly warmer (though colder than $1.5^{\circ} \mathrm{C}$ ) and salty water on the eastern side of the trough (Figure 4-7), which is consistent with the advection of warm UCDW and LCDW by the cyclonic flow in the trough (see Chapter 3). This is consistent with the finding of LCDW in the deepest part of Marguerite Trough - and within Marguerite Bay - reported by Klinck et al. (2004) using the SO GLOBEC broad-scale hydrographic data.
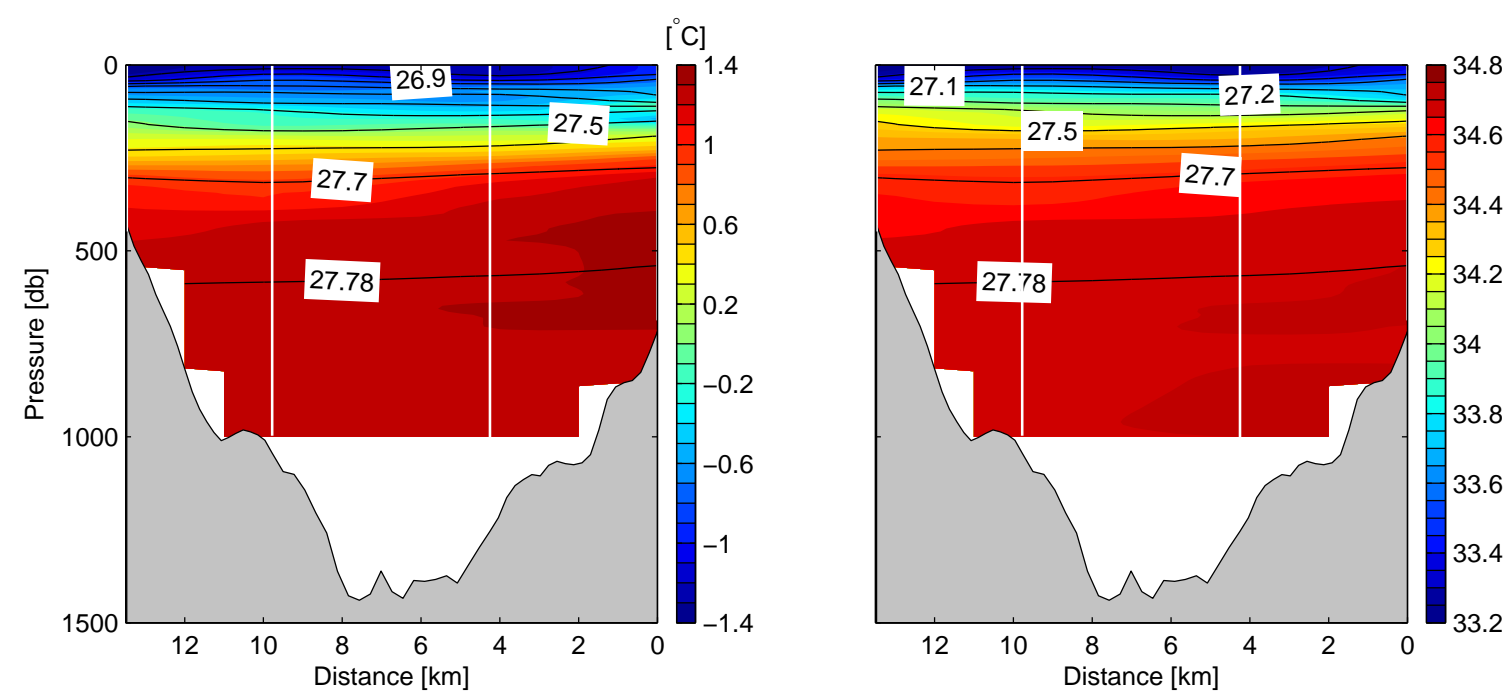

Figure 4-7: Color contours of potential temperature (left panel) and salinity (right panel) for a section across Marguerite Bay, conducted in the fall of 2001. Contours of $\sigma_{\theta}$ (black) are superimposed on both panels. The figure is oriented so that the eastern edge of the trough is on the right.

\subsubsection{UCDW in the Moored Array}

The SO GLOBEC moored array (diamonds in Figure 4-5) is well located to test the hypothesis that Marguerite Trough is one of the locations for UCDW to move onto the shelf. The A3 mooring is located $38 \mathrm{~km}$ onshore of the shelfbreak, on the western side of Marguerite Trough (Figure 4-2). A2 is located $45 \mathrm{~km}$ farther onshore (83 km from the shelfbreak), on the eastern side of the Trough, a location which Figure 4-5 suggests is a path for the intrusions. The analysis shown below reveals this is indeed the case. 
Inspection of the detided temperature records revealed intense, high-frequency events of warm water at the A2 and A3 mooring sites. As many of the events have a duration around the 33-hr half-amplitude period used to low-pass filter the mooring records elsewhere in this thesis, the time series are treated differently here. All of the mooring data were first de-tided using T_TIDE (Pawlowicz et al., 2002) and subsequently low-pass filtered with a 100-weight cosine-lanczos filter with a 20-hr halfamplitude period to filter out the inertial frequency variability (Emery and Thompson, 1998). 20-hr is a good compromise between filtering the broad inertial peak centered at 12.9-hr while keeping most of the variability associated with the warm-water events. Although there is no significant tidal signal at $250 \mathrm{~m}$ in the temperature records at either mooring, the shallower instruments did have a tidal signal removed prior to the filtering. All of the records here are for the entire deployment except for the $200 \mathrm{~m}$ temperature record at A3, which is 246 days long as the temperature recorder failed on $12 / 03 / 01$.

At $\mathrm{A} 2$ and $\mathrm{A} 3$, water warmer than $1.5^{\circ} \mathrm{C}$ was detected in instruments located from $200 \mathrm{~m}$ to $400 \mathrm{~m}$. Histograms of potential temperature for the instruments where intrusions where detected (Figure 4-9) clearly show a higher prevalence of warmer than $1.5^{\circ} \mathrm{C}$ observations at the $\mathrm{A} 2$ mooring at all depths. The colder anomalies at A2, particularly at $200 \mathrm{~m}$, are typical of the moorings closer to the coast. At $250 \mathrm{~m}$, where the mid-depth temperature maximum is usually found on the shelf, temperature higher than $1.5^{\circ} \mathrm{C}$ was recorded $2 \%$ of the time at $\mathrm{A} 3$, compared to $15 \%$ at A2. At A1, two brief events were recorded at the end of July, when the APCC is absent (see Chapter 2), but the rest of the time series shows no evidence of UCDW. None of the remaining moorings (the B- and C-lines) recorded waters warmer than $1.5^{\circ} \mathrm{C}$ at depth.

In order to calculate the statistics of the events, individual events were defined as follows. For each instrument recording temperature at each mooring, times when the potential temperature was $1.5^{\circ} \mathrm{C}$ or more were found. The beginning (end) of the event at each depth was defined as the time when the temperature started (finished) increasing (decreasing). An example of one such event is shown in Figure 4-8, If 


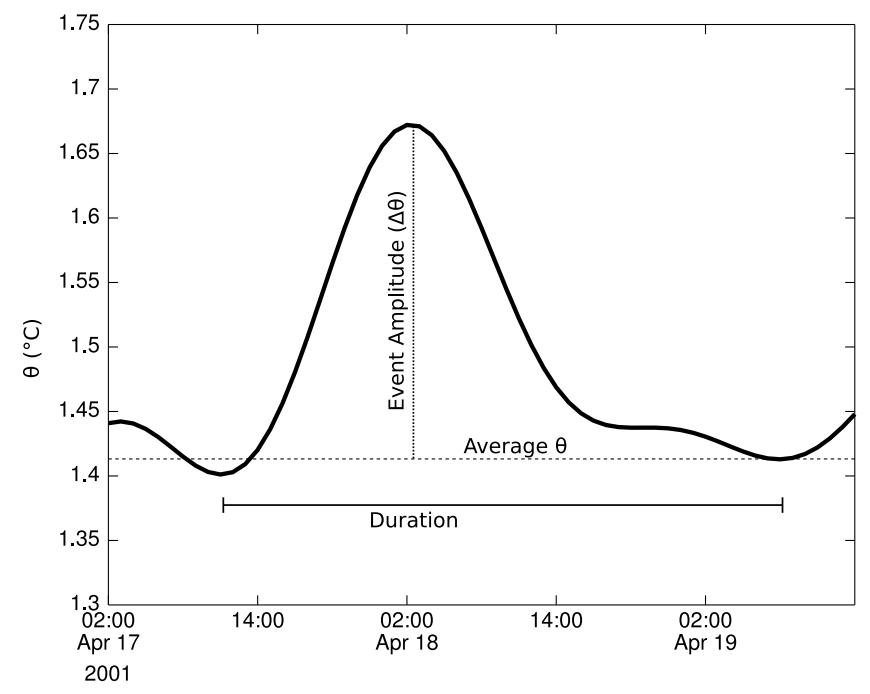

Figure 4-8: Example of a UCDW intrusions as recorded at the A2 mooring at $250 \mathrm{~m}$. The horizontal dotted line indicates the mean potential temperature for the entire record, and the basic scales $(\Delta \theta$, Duration) are also indicated.

those times overlapped with events recorded at another instrument, it was assumed they corresponded to one event spanning the entire depth range covered by those instruments.

\subsection{Frequency and Duration of Warm Events}

Statistics of the events reveal the basic features of the intrusions of UCDW onto the shelf. At A2, 40 events were recorded in the 10.5-month time series, compared to only 11 events at A3. At both moorings sites, the events were relatively short, typically lasting 1 to 3 days, with events as long as 7 days at A2 (Figure 4-10). There does not seem to be a significant seasonal signal in the occurrence of events. At A2, there are as few as zero events per month (in October) to seven (in May), with an average of four events per month (Figure 4-11). At A3, all the events occur during the first few months of the deployment, from April to June, resulting in a similar average of events for the fall season as at A2. From July on, no events of warm UCDW were recorded at A3. However, it must be noted that during the winter 2002 cruise, UCDW was found at the location of the A3 mooring (Figure 4-5), which suggest that intrusions 

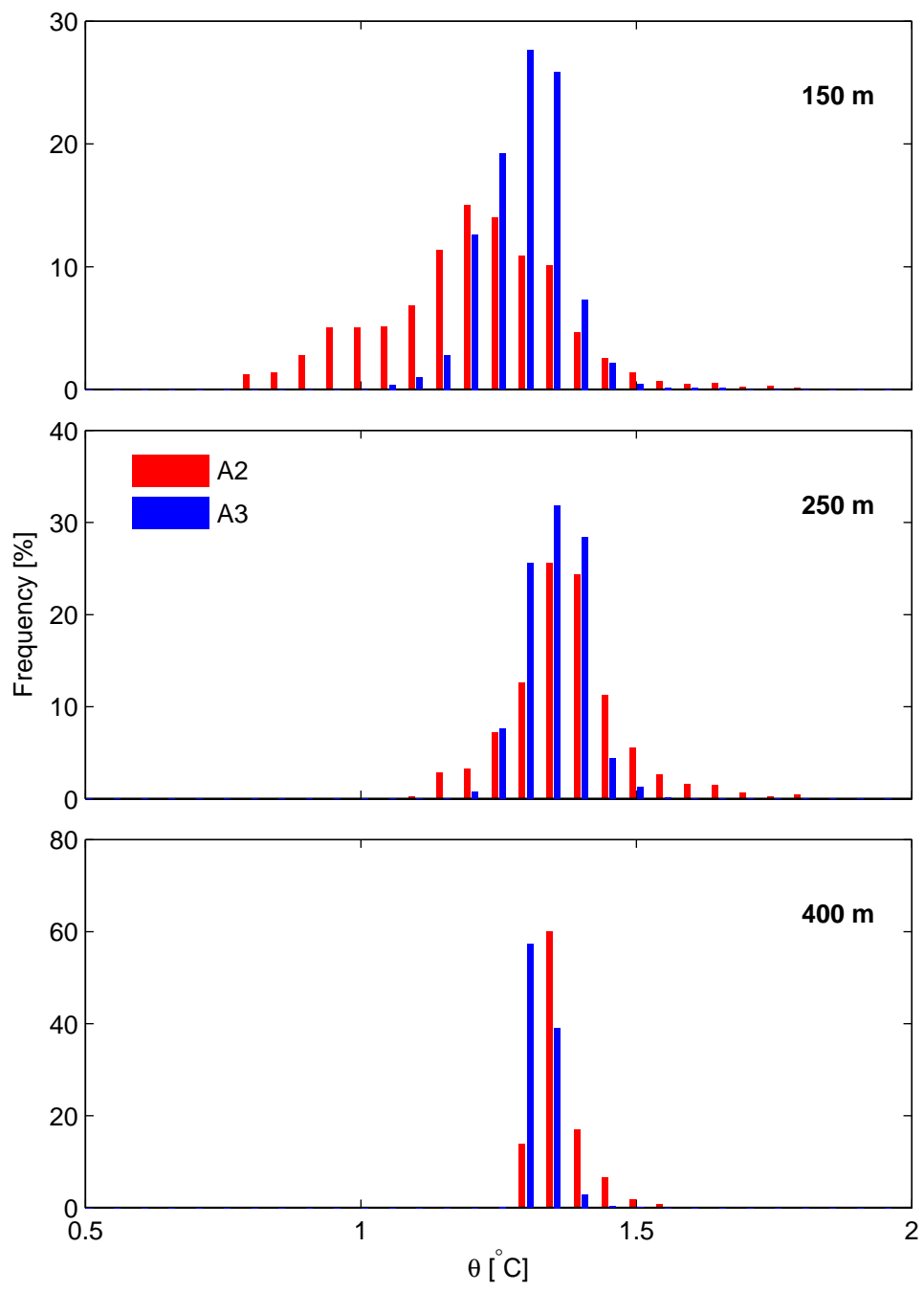

Figure 4-9: Histogram of potential temperature for the A2 (red) and A3 (blue) moorings at approximately $200 \mathrm{~m}$ (top panel), $250 \mathrm{~m}$ (middle panel) and $400 \mathrm{~m}$ (bottom panel). The $200 \mathrm{~m}$ temperature record at A3 is 246-d long (the instrument failed on $12 / 03 / 01$ ) and the rest are $\approx 318$-d long.

at this location, although less frequent than at A2, can also occur during different seasons.

\subsection{Circulation Associated with the Warm Events}

The A2 mooring recorded currents at 100, 250 and $400 \mathrm{~m}$. Figure 4-12 shows time series of potential temperature at $250 \mathrm{~m}$ (where the signal of the warm events is 


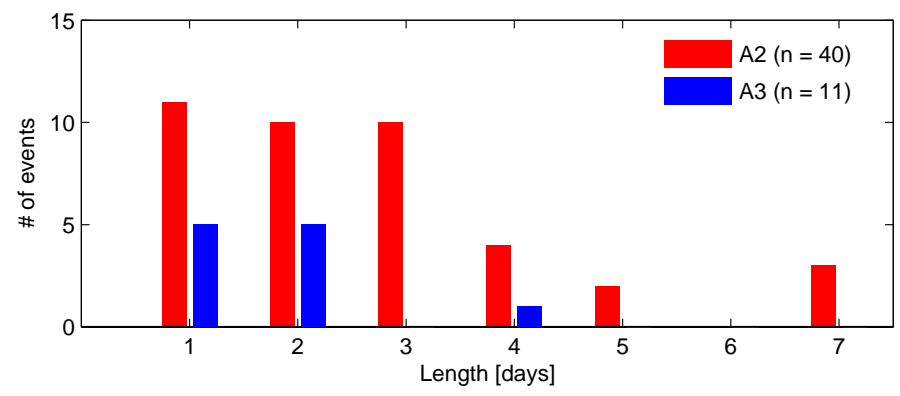

Figure 4-10: Histogram of the UCDW-event duration for the A2 (red) and A3 (blue) moorings. Also indicated are the total number of events (n) for each mooring.

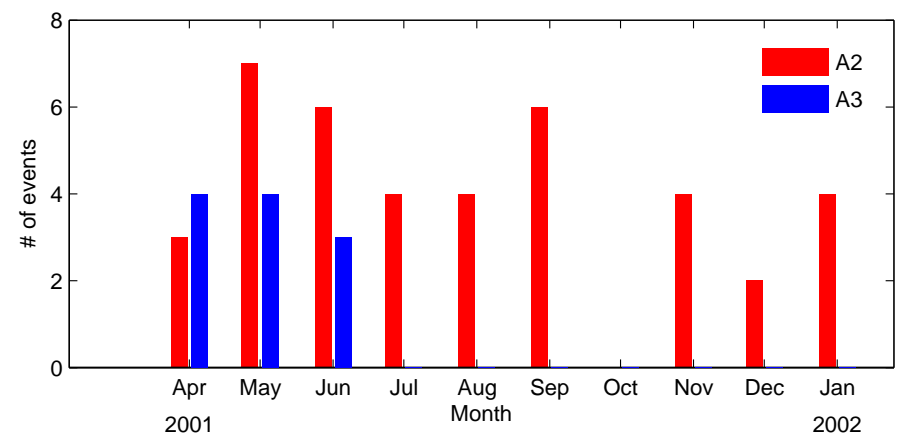

Figure 4-11: Number of intrusions per month at A2 (red) and A3 (blue) throughout the 2001/2002 SO GLOBEC mooring deployment (March 31, 2001 to February 12, 2002).

strongest) and along-isobath and cross-isobath velocity records. Times when intrusions were detected at any depth are marked in red. There is not a clear relationship between the velocity field and the occurrence of warm events. At both moorings, correlations between $u$ or $v$ and $\theta$ are small (maximum $<0.20$ with lags of one to two days) and statistically not significant at the 95\% confidence level. The subtidal current variability has its strongest component in the 5-10 days band (see Chapter 3) and the coherence with temperature oscillations in the 1-3 day band where the intrusions occur is not significant. However, it is important to remember that both cross-correlation and coherence analysis average the variability over the entire time series, and might not be appropriate when studying relatively isolated events.

Average velocities during the warm events are shown in Figure 4-13. All but three (93\%) of the events have a mean average along-isobath velocity toward the coast, with 

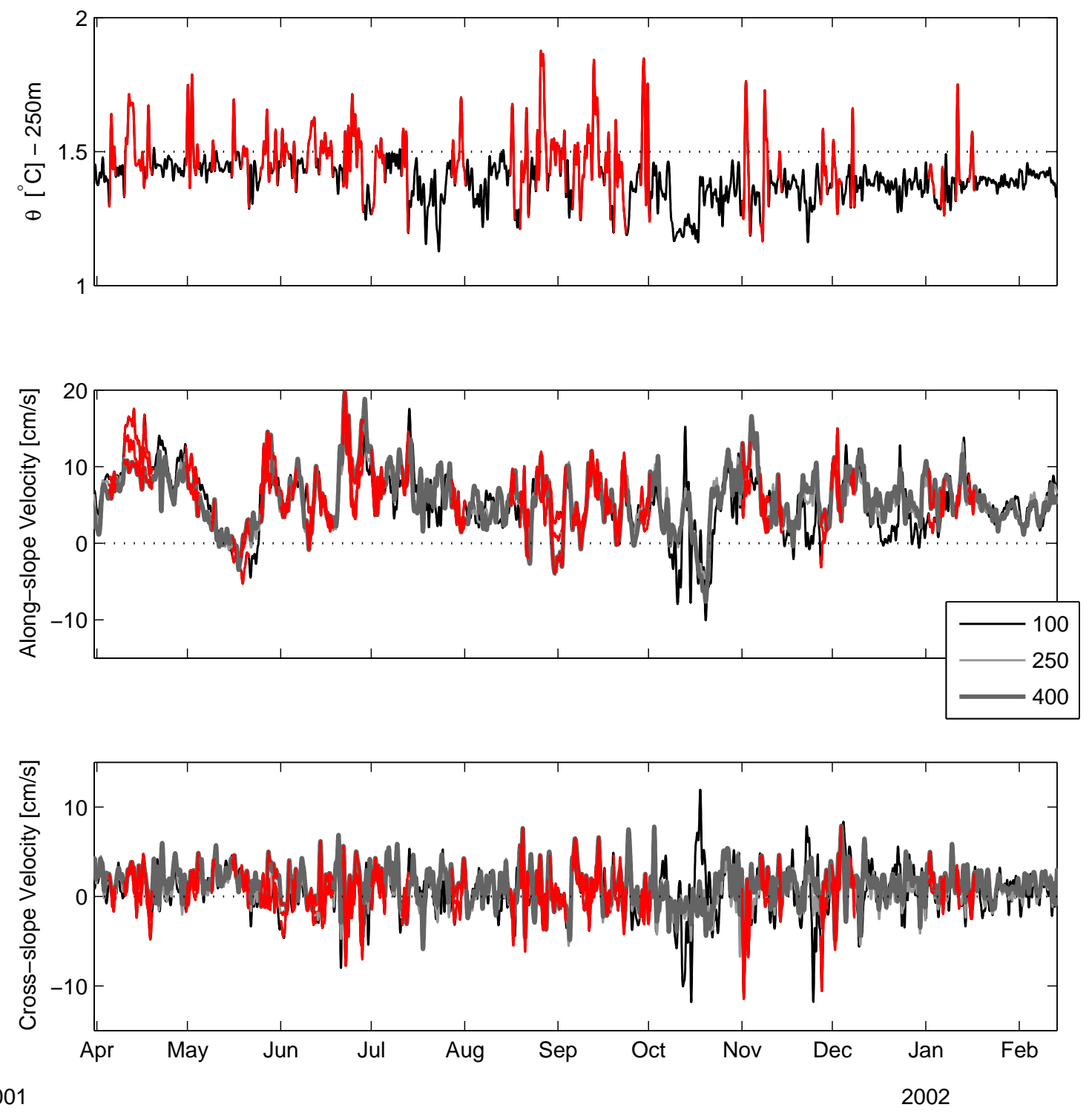

Figure 4-12: Time series of detided, low-pass filtered time series of potential temperature (top panel), along-isobath velocity (middle panel) and cross-isobath velocity (bottom panel). The warm UCDW events are indicated in red.

an overall mean of around $5.8 \pm 2.7 \mathrm{~cm} / \mathrm{s}$ ( \pm 1 standard deviation). The magnitude and vertical structure of the velocity during the events are very similar to the average structure during the remaining part of the records. The mean velocity during the events has very small vertical shear with a total of $10^{\circ}$ counterclockwise veering with depth. For all the intrusions, the flow is dominated by the low-frequency component and the velocities in the frequency band of the UCDW events are typically less than 
$10 \%$ of the low-frequency flow.

The velocity and temperature records from the moored array are illuminating when interpreting the broad-scale survey data (Figure 4-5). The time series indicate that warm events occur frequently and are short-lived. This is consistent with the survey data if one considers some important aspects of the survey resolution and the resulting hydrographic fields. First, the warm water found during the survey is associated with different density surfaces at different sites, and therefore the results of Figure 4-5 should be interpreted as presence of UCDW, not a contiguous warm intrusion. Second, the UCDW signal is generally weak when found on the shelf, with temperatures slightly over $1.5^{\circ} \mathrm{C}$ in thin layers, with a few exceptions where the CTD cast shows a very strong $\theta-\mathrm{S}$ signature (Figure 4-6). Third, in the five days or so that it takes to conduct the CTD survey over the northern part of the study region where the warm water was found, one or two distinct events lasting 1 day or so each were registered at the A2 mooring. This is inconsistent with the idea of a large-scale intrusion moving onto the shelf, because typical velocities on the shelf are of the order of 5 to $10 \mathrm{~cm} / \mathrm{s}$, which results in an advective time-scale of 8 to 20 days for an intrusion moving across the shelf as far as is typically observed in Figure 4-5.

These results suggest that the UCDW is intruding as frequent, short events, and not as large-scale intrusions. These events might be instead eddies moving onshore, and leaving, as they mix away on the shelf, the broad regions of weak UCDW signature which are typically observed in the mid-shelf. In the next section, I explore this hypothesis using a simple model applied to the A2 mooring data.

\subsubsection{Eddies Advected Pass a Mooring}

Let us assume the UCDW events are eddies carried by the shelf circulation across the shelf via Marguerite Trough. The flow as observed by the mooring would be given by (i.e. Lilly and Rhines, 2002):

$$
\vec{u}=\vec{U}+\overrightarrow{u_{e}}
$$



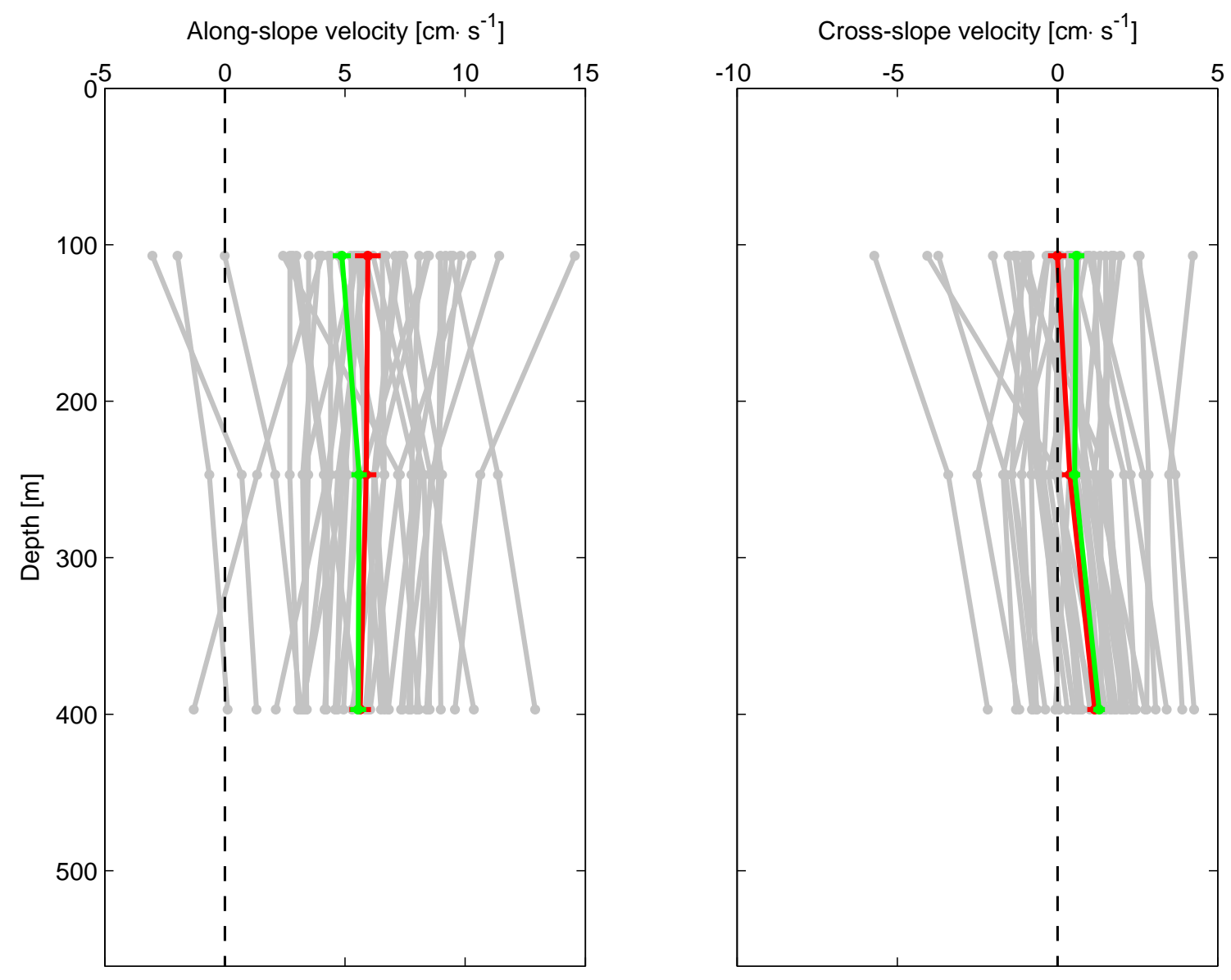

Figure 4-13: Average along-isobath (left panel) and cross-isobath (right panel) velocity for each of the 40 UCDW intrusions recorded at the A2 mooring site. The red lines are the ensemble averages for the along- and cross-slope velocity components, and the green lines the average velocity for times when no intrusions were recorded.

where $\vec{u}$ is the observed flow, $\vec{U}$ is the background flow, which will be assumed to be spatially uniform but slowly evolving in time, and $\overrightarrow{u_{e}}$ is the flow of the eddy being advected by the background flow pass the mooring. A sensible option for the eddy flow is given by a Rankine vortex, where the core is in solid body rotation, and outside of which the radial velocity decays with distance from the center of the eddy. In polar coordinates the azimuthal velocity is given by

$$
v(r)= \begin{cases}V r R^{-1}, & r<R \\ V r^{-1} R, & r>R\end{cases}
$$


where $r$ is the distance from the center of the eddy, $V$ is the maximum azimuthal velocity (at $r=R$ ), and $R$ is the radius of the eddy. $V$ is taken here to be positive for an anticyclonic eddy. The velocity field associated with an anticyclonic eddy is
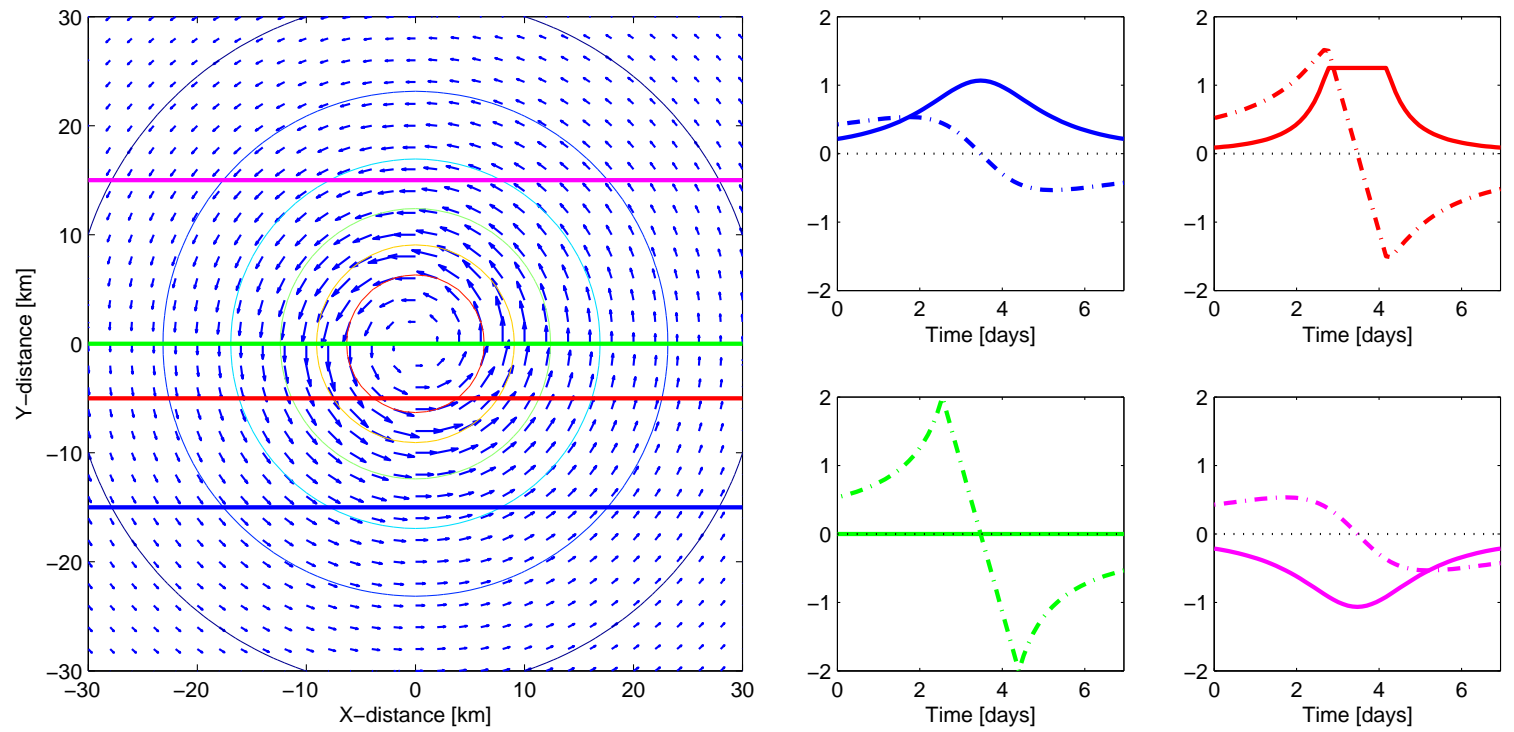

Figure 4-14: A Rankine vortex. The left panel shows the horizontal flow associated with an eddy of $R=8 \mathrm{~km}$ and $V=2 \mathrm{~cm} / \mathrm{s}$. The contours are the pressure field. The four panels on the right show the zonal (solid) and meridional (dashed) velocity as would be recorded by a fixed mooring as the eddy is advected along the horizontal lines shown in the left panel by a constant flow of $10 \mathrm{~cm} / \mathrm{s}$ from left to right.

shown in Figure 4-14. In this example, the eddy has a radius of $8 \mathrm{~km}$ and a maximum azimuthal velocity $V$ of $2 \mathrm{~cm} / \mathrm{s}$. The four panels on the right show the velocity components as they would be seen by a mooring at different y-locations represented by the horizontal lines on the left panel, assuming the eddy is advected by a constant $10 \mathrm{~cm} / \mathrm{s}$ zonal (from left to right) flow . The zonal eddy velocity is symmetric and it goes from negative values south of the center of the eddy to positive north of it. The meridional velocity is antisymmetric and always positive first when measured at our hypothetical moorings and it decreases (increases) linearly in time (space) inside the core of the eddy. The opposite is true in the case of cyclonic eddies.

If the UCDW events are eddies being advected past the moorings, one would expect the "cross-stream" velocity, the component perpendicular to the direction of advection, to have the characteristic signature shown in Figure 4-14 early positive 
(negative) velocities for an anticyclone (cyclone). However, the example above has the eddy advected by a constant zonal velocity. This is bound to be poor assumption in most realistic flows, and therefore one must estimate the velocity and direction of the advecting flow $U$ as it evolves. The eddy flow then becomes

$$
\overrightarrow{u_{e}}=\left(\vec{u}-\overrightarrow{U_{l f}}\right) e^{-i \phi(t)}
$$

where $U_{l f}$ is the low-pass velocity (5-day half-power lanczos filter) with direction $\phi$. $\overrightarrow{u_{e}}=u_{e}+i v_{e}$ is therefore rotated so that $v_{e}$ is the cross-stream component equivalent to the meridional velocity in Figure 4-14. Any small linear trends remaining in $v_{e}$ are removed.

There is an important caveat to keep in mind as the results are presented in the next sections: a single mooring recording passing eddies would necessarily tend to underestimate the intensity and size of the eddies as chances are that the "sampling" is off-center. Therefore, the average properties over many events are biased and do not represent the true properties of the eddy "population", even under the assumption that A2 is recording all the eddies moving through Marguerite Trough.

\subsubsection{Eddy-like Events in the A2 Records}

In order to test the simple model outlined above, the events must be relatively isolated. As was described above, the A2 records contain 40 warm events; inspection of the records reveal that most of the longer ( $>3$ days) events appear to be closely spaced short events. Several temperature peaks larger than $1.5^{\circ} \mathrm{C}$ are evident at each depth in those cases, and individual events are difficult to separate.

For the analysis below, 24 warm events which appear to be reasonably isolated in time were selected. Of those, $19(79 \%)$ had a velocity signature consistent with an anticyclonic eddy, four (17\%) with a cyclonic eddy and one was not consistent with either. Examples of a cyclonic and anticyclonic event are shown in Figure 4-15.

Both of them have a strong temperature anomaly at $250 \mathrm{~m}$ and a velocity structure spanning the 300-m depth range of the velocity records. The events have scales of a 

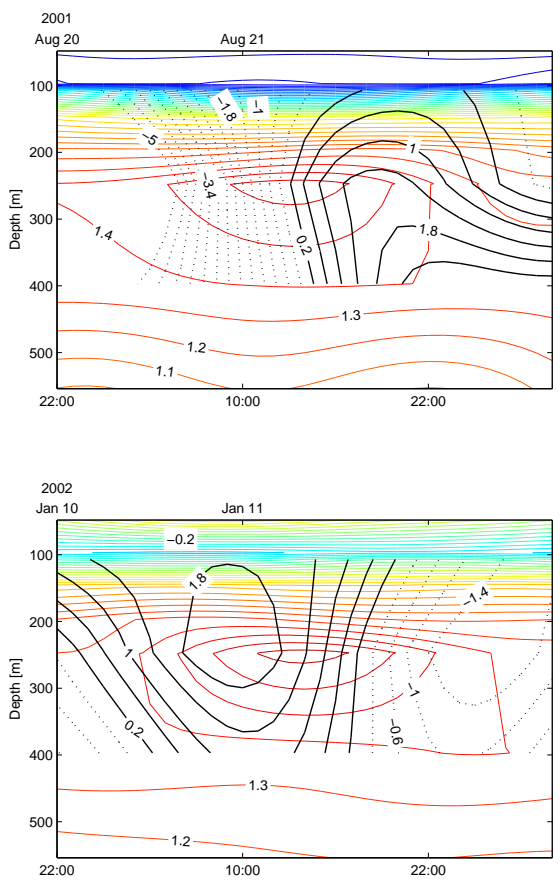

Figure 4-15: Potential temperature (color contours), and cross-stream $\left(v_{e}\right)$ velocity records (black contours) for a cyclonic (top panel) and an anticyclonic (bottom panel) event recorded at A2. Positive (negative) cross-stream velocities are shown as solid (dotted) contours.

day or so and average cross-stream velocities of 1 to $5 \mathrm{~cm} / \mathrm{s}$.

Figure 4-16 shows the potential temperature and velocity records for the 23 events with a consistent "eddy" signature. In order to compare events of different duration, the time coordinate is normalized using the 250-m records, where the temperature signal is strongest, as

$$
t^{\prime}=\left(t-t_{m}\right) / T_{\text {vmax }}
$$

where $t$ is the time, $t_{m}$ is the center time between the two absolute maximum $v_{e}$ during an event (which corresponds to the limits of the eddy chord), and $T_{\text {vmax }}$ is the time period between those velocity maximums.

On average, the anticyclonic events have a maximum temperature signal of $1.6 \pm 0.09^{\circ} \mathrm{C}( \pm 1$ standard deviation $)$, with a weak, but consistent, circulation with 
maximum velocities as large as $4 \mathrm{~cm} / \mathrm{s}$ at $250 \mathrm{~m}$ or so but only slightly over $0.9 \pm 0.7 \mathrm{~cm} / \mathrm{s}$ on average. The eddies have, on average, a significant velocity structure at 250 and $400 \mathrm{~m}$, with stronger velocities at mid-depth. The velocity signal at $100 \mathrm{~m}$ is not very consistent. The cyclonic events have a circulation and temperature signal of comparable magnitude, although because they are rarer their statistics are less certain. Also, notice that the velocity does not tend to diminish at the beginning and end of the period sampled (Figure 4-16), which is inconsistent with the simple ranking eddy model (Figure 4-14).

\subsection{Events Intensity and Depth Scale}

A measure of the intensity of the eddies can be obtained from:

$$
\langle\Delta \theta(z)\rangle=\left\langle\theta_{\text {in }}(z)-\theta_{r f}(z)\right\rangle
$$

where $\theta_{\text {in }}$ is the maximum potential temperature during an event at depth $z$ and $\theta_{r f}$ is

a profile of reference potential temperature calculated from averages of the time series in times when no intrusions were detected. The \langle\rangle indicate an ensemble average of all the events. The same procedure is used to calculate equivalent profiles for salinity $(\langle\Delta S\rangle)$ and potential density $\left(\left\langle\Delta \sigma_{\theta}\right\rangle\right)$.

Figure 4-17 shows the averaged vertical profiles of $\langle\Delta \theta\rangle,\langle\Delta S\rangle$ and $\left\langle\Delta \sigma_{\theta}\right\rangle$ for the same events plotted in Figure 4-16. On average, the anticyclonic events have a temperature signature at mid-depth with intensities of $0.26 \pm 0.03^{\circ} \mathrm{C}$ and salinity of $0.03 \pm 0.003$ at $250 \mathrm{~m}$. The slightly lower $\theta$ associated with the events in the bottom instrument, though small, is consistent with the hydrographic structure offshore, which has the colder LCDW located below UCDW.

Despite having a significant temperature and salinity signature, these warm and salty events have, on average, a significant density signal only at $100 \mathrm{~m}$, where the difference is $0.02 \pm 0.01$. This signature is consistent with the anticyclonic velocity signature shown in Figure 4-16. The weak density signal is clearly shown in the $\theta-\mathrm{S}$ 

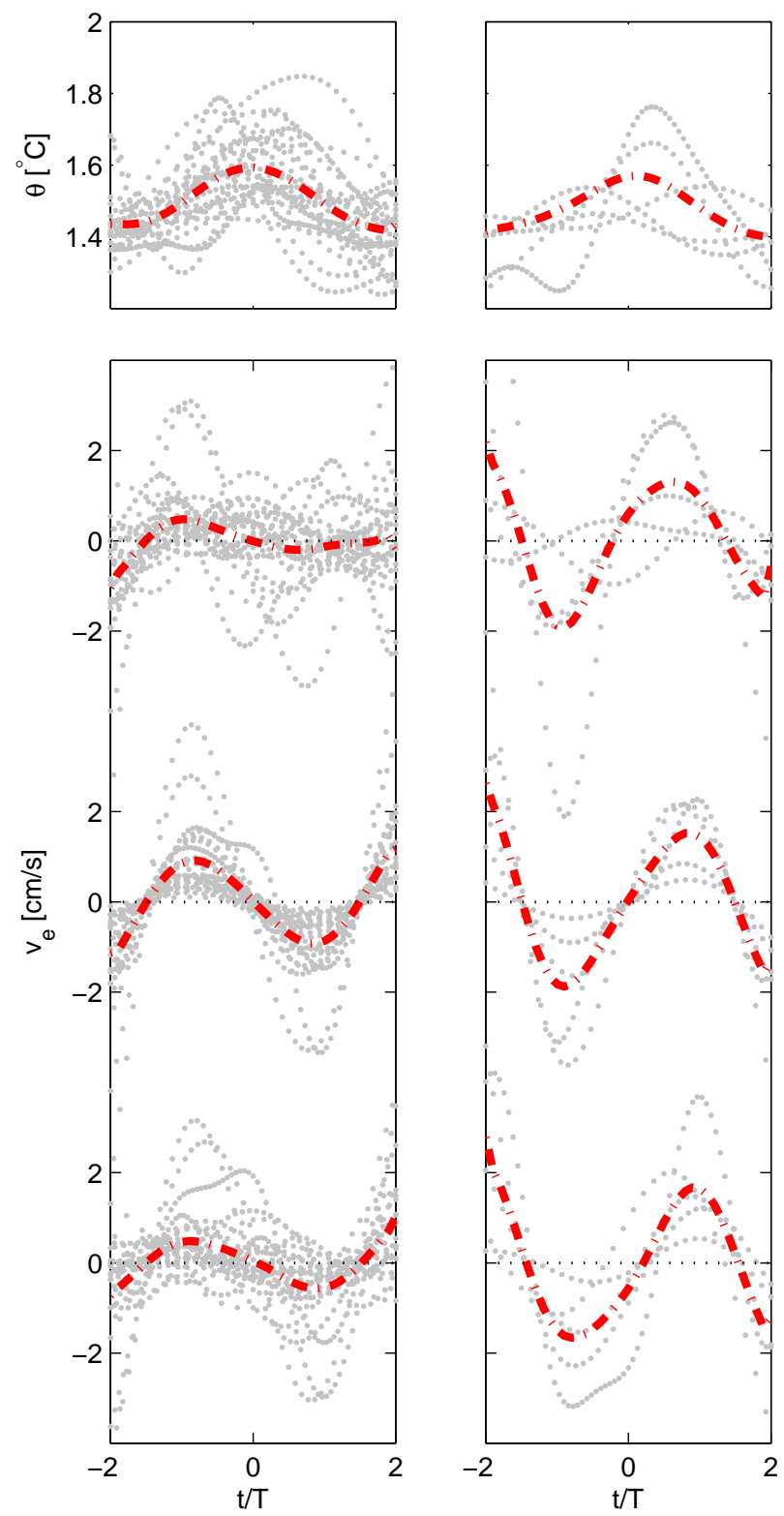

Figure 4-16: Potential temperature (top panel) and cross-stream $\left(v_{e}\right)$ velocity records at 100, 250 and $400 \mathrm{~m}$ (bottom panel) for warm eddy-like events at A2. The left panels show the anticyclonic events and the right panel the cyclonic events. The gray dots indicate individual records, and the red dashed lines are ensemble averaged for all the events. The time is normalized using equation 4.4 .

diagram for the events shown in Figure 4-18, The average density at $250 \mathrm{~m}$ is roughly 27.75 regardless of the presence of the intrusions.

For the cyclonic events (bottom panels in Figure 4-17), the hydrographic structure is more ambiguous. They also show a stronger temperature signal at mid-depth, with 
the salinity and temperature anomalies nearly compensating there. And although the density signature is, on average, negative at $100 \mathrm{~m}$, the errors are large (there are only 4 events being averaged here), and therefore no firm conclusions can be reached about their vertical structure.

The depth scale of the events is harder to study using the moored array data. In both A2 and A3, there are only a few instruments in the 300-m depth range where UCDW was detected. However, the vast majority of the events were recorded at $250 \mathrm{~m}$ in both moorings (Figure 4-19), with only a handful being detected only at $200 \mathrm{~m}$ (2 at A2 and none at A3) or at $400 \mathrm{~m}$ (2 at A2 and 1 at A3). Also, 12\% of the events (5) at A2 were detected at both $200 \mathrm{~m}$ and $400 \mathrm{~m}$. For the events detected by at least two instruments, the results indicate that $20 \%$ of the events have a minimum thickness of $150 \mathrm{~m}-200 \mathrm{~m}$ and a maximum of $\approx 400 \mathrm{~m}$, as the temperature records at $147 \mathrm{~m}$ and $554 \mathrm{~m}$ at A2 did not register UCDW.

\subsection{Horizontal Scale of the Eddies}

An estimate of the horizontal scale of the eddies can be obtained from

$$
\langle L\rangle=\left\langle\int_{-T_{v \max }}^{T_{v \max }} U_{l f} d t\right\rangle
$$

Horizontal scales for the intrusions are roughly $4.2 \pm 2.5 \mathrm{~km}$ and $4.3 \pm 3.5 \mathrm{~km}$ for the anticyclonic and cyclonic events, respectively. A rough estimate of the internal radius of deformation for the deep layer using $N=1.3 \cdot 10^{-3} \mathrm{~s}^{-1}, H=400 \mathrm{~m}$ and $f=$ $1.35 \cdot 10^{-4} \mathrm{~s}^{-1}$ results in $\lambda=3.9 \mathrm{~km}$. Notice that because the "sampling" of the eddies by the moorings is biased towards underestimating their size and intensity, this estimate appears to be rather reasonable and dynamically consistent with the idea that the UCDW events are indeed eddies recorded by the mooring. 


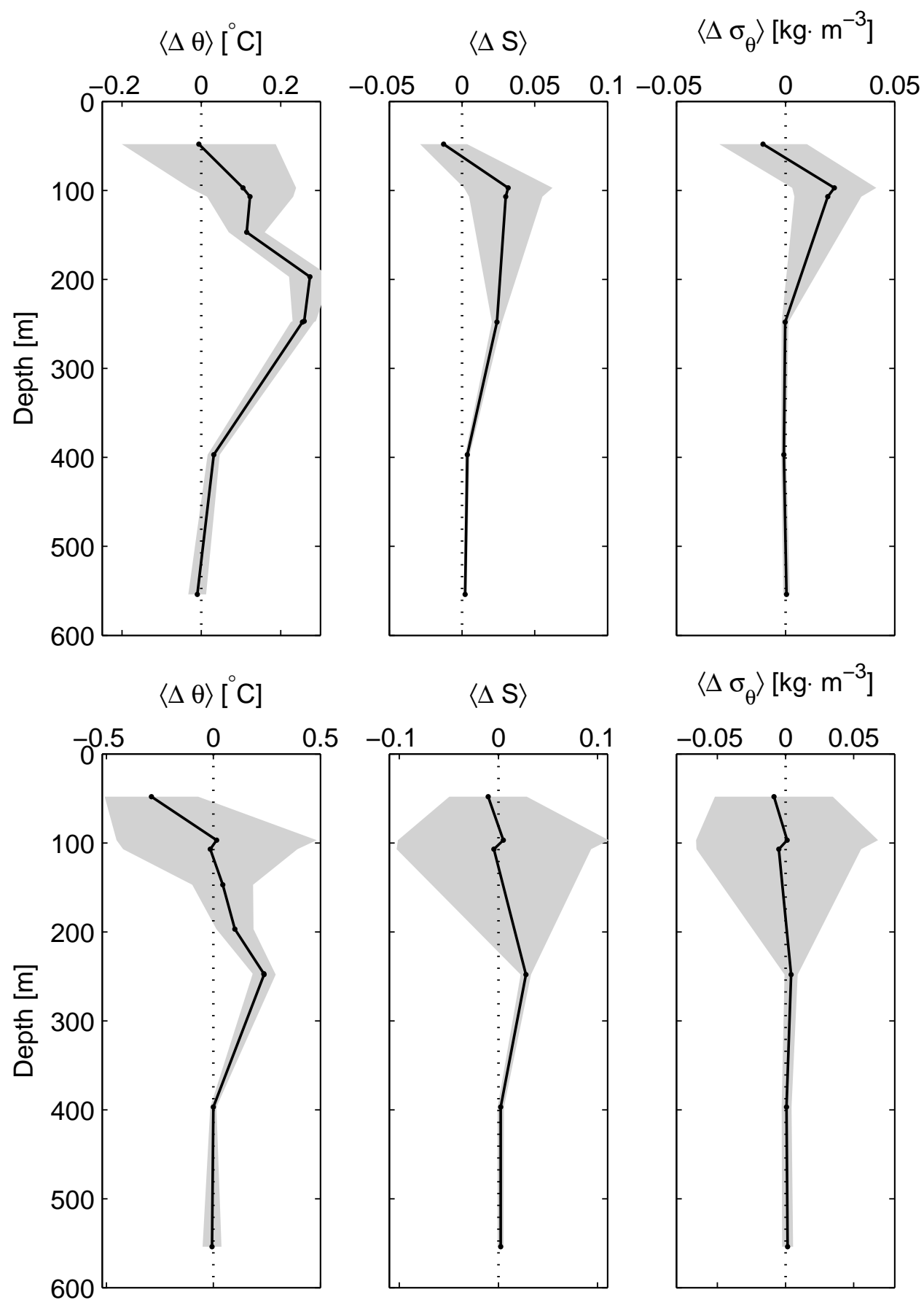

Figure 4-17: Vertical profiles of $\langle\Delta \theta\rangle,\langle\Delta S\rangle$ and $\left\langle\Delta \sigma_{\theta}\right\rangle$ for the A2 mooring. The top panels correspond to 19 events identified as anticyclones, and the bottom panel the 4 events identified as cyclones. The gray shading indicates the $95 \%$ confidence interval for the ensemble averages. 


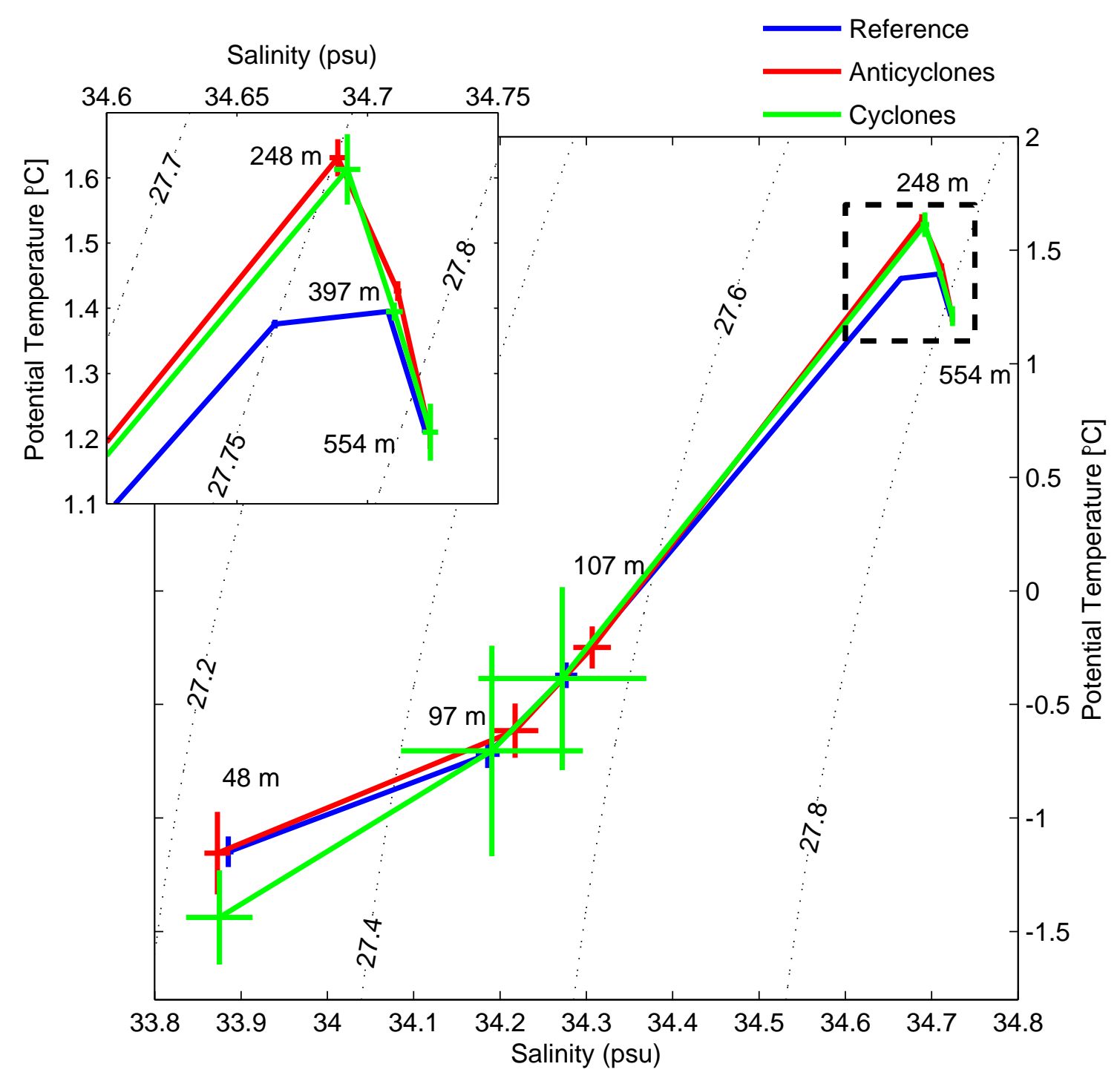

Figure 4-18: $\theta$-S diagram of average A2 mooring records during times in the absence of UCDW intrusions (blue), when UCDW was detected and the velocity signal was anticyclonic (red) and when the velocity signal was cyclonic (green). Also indicated are the instrument depths (in meters).

\subsection{Heat Content}

As mentioned previously, estimates from hydrographic surveys and modeling studies for the region suggest that a vertical heat flux of $1.5-5 \mathrm{~W} / \mathrm{m}^{2}$ is necessary to close the heat budget on the shelf in the SO GLOBEC study region (Klinck, 1998; Smith and Klinck, 2002). Making an estimation of the heat flux due to the warm UCDW 


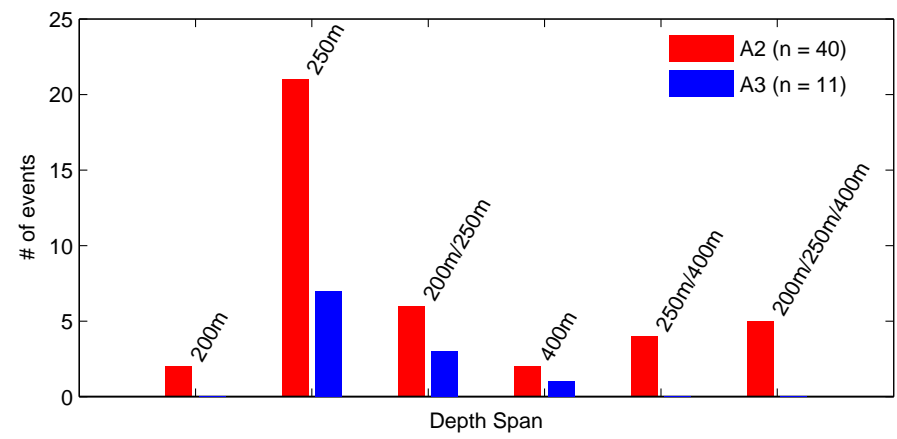

Figure 4-19: Depth span of intrusions at A2 (red) and A3 (blue). Events are grouped by the instruments at which single events were recorded.

intrusions studied here provides at best an order of magnitude estimate for only one of the locations for cross-shelf exchange of heat, but it is important even to have a rough idea of the contribution of these processes to the overall heat budget.

To make this calculation, I will assume that each warm eddy is advected onto the shelf and is mixed away, and that when it moves onto the shelf, an equivalent volume of water with some reference temperature characteristic is advected away from the region of interest (Lilly and Rhines, 2002). Consider first the heat content of a warm event:

$$
H_{e v}=\rho_{o} c_{p} \int_{-h}^{0} \theta d z
$$

where $\rho_{o}$ is a reference density, $c_{p}$ is the specific heat capacity, $h$ is the bottom depth and $\theta$ is the potential temperature. On average, the heat gained with respect to a reference temperature profile is $\langle\Delta H\rangle=\left\langle H_{e v}-H_{r f}\right\rangle$. Using the vertical profiles of potential temperature for the times with and without events (the profile of the difference is shown in Figure 4-17), $\langle\Delta H\rangle=1.72 \pm 0.35 \cdot 10^{8} \mathrm{~J} / \mathrm{m}^{-2}$. For this calculation, both profiles are extrapolated to the surface and the bottom using the closest available value.

To estimate the contribution over the entire shelf from this single average event, a ratio of the area of a single "eddy" to the entire shelf is calculated. For the event, we consider a circle of radius $r=4.2 \pm 2.5 \mathrm{~km}$, which is the lateral scale for the eddies 
we calculated in the previous section. For the area of the entire shelf, we consider the study area of the SO GLOBEC program (the same used for the published estimates of the vertical heat flux), that is, from the northern tip of Adelaide Island to roughly the southern tip of Charcot Island, an area of around $1 \cdot 10^{5} \mathrm{~km}^{2}$. The ratio of both areas is $R=0.001 \pm 0.0005$, which results in an average for the heat gain on the shelf of $\langle\overline{\Delta H}\rangle=1.72 \pm 0.93 \cdot 10^{5} \mathrm{~J} / \mathrm{m}^{2}$.

The equivalent vertical heat flux associated with these events is

$$
Q_{e v}=\langle\overline{\Delta H}\rangle E
$$

where $E$ is the number of events per year. Assuming there are 46 events a year (40 in 10.5 months $), Q_{e v}=0.25 \pm 0.15 \mathrm{~W} / \mathrm{m}^{2}$. With all uncertainties considered, the recorded

events could contribute between $5 \%$ to $15 \%$ of the required heat flux to balance the heat budget.

The above number is probably a lower bound for a number of reasons. First, it is likely that there is more than one location between Adelaide Island and Charcot Island where UCDW intrusions occur. Second, Marguerite Trough is some 80-km wide where A2 is located, so eddies with an horizontal scale of 5-10 km can be easily missed if the advective flow scales with the bathymetric scales. Third, because of the dependence of $R$ on the square of $r$, the sensitivity to the horizontal scale of the intrusions is rather critical. For example, an "average eddy" with a horizontal scale of $2 \lambda$ would contribute $Q_{e v}=0.50 \mathrm{~W} / \mathrm{m}^{2}$. Finally, events counted as a single eddy here tend to group together several eddies, which has a direct effect on $E$ above.

\subsection{Discussion and Conclusions}

In this chapter, I have characterized intrusions of warm, salty water onto the wAP shelf which are thought to strongly influence the heat budget. A number of conclusions can be drawn from this work.

First, the analysis presented here suggests that Marguerite Trough, and in partic- 
ular its eastern side, is a path for warm water to move across the shelf. Almost four times as many warm-water events were recorded on the eastern side of Marguerite Trough (at A2) compared to the west side (at A3).

Second, the events are much smaller in scale and more frequent than had been thought previously on the basis of large-scale hydrographic surveys. The sampling bias introduced by the $20-\mathrm{km}$ or so CTD cast separation typical of the SO GLOBEC and other seasonal surveys in this area suggested that intrusions had large horizontal scales (significantly larger than the internal radius of deformation) and with a frequency of six or so per year. The results presented here suggest otherwise. The UCDW intrusions have a thickness of a few hundred meters, and they occur roughly four times a month on average. A simple model of an isolated eddy being advected pass a mooring was shown to be somewhat consistent with the observations at A2, and results in eddies with an horizontal scale of 4 to $5 \mathrm{~km}$ and a associated currents of 1 to $2 \mathrm{~cm} / \mathrm{s}$. A caveat relating to the band-pass filtering of the velocity data needs to be taken into account when considering the results presented here. Figure 4-20 shows a synthetic velocity time-series of a Rankine eddy (see Section 4.5.1) being advected pass a mooring. The eddy has a velocity scale of $2 \mathrm{~cm} / \mathrm{s}$ and the event lasts for a few days, which is of the same order as the events recorded at A2. The solid lines in Figure 4-20 are the original modelled time-series, and the dashed lines are the modelled velocity records band-pass filtered using the same method used for the moored observations. The filtering appears to affect the original signal, although the basic scales of the eddy as seen from the cross-stream velocity remain roughly the same in the example. However, it must be noted that in the case of the synthetic time-series we know what the along-stream and cross-stream directions are. In the case of the moored observations, this direction was determined by rotating the velocity in the direction of the low-pass filtered velocity, and thus the effect of the filtering might be more pronounced. Other methods for isolating the eddies, and observations which resolve the spatial scales of the intrusions might be required to resolve the question of their circulation.

Although this work does not attempt to answer the question of the formation 
process of the intrusions, it does help to provide some constraints for the spatial and temporal scales involved. This has straightforward implications for the wAP ecosystem. Prézelin et al. (2000) noted that diatom populations on the mid- and outer-shelf depend on the renewal of the silica-rich UCDW. The work presented here suggests that this renewal is frequent and more or less continuous throughout the year, which has important implications for the continuous success of the biological community.

Finally, the contribution of the warm-water events considered here to the heat budget of the shelf has been estimated. The results suggest that Marguerite Trough could contribute at least $5 \%$ to $15 \%$ of the heat flux required to close the heat budget. However, it must be noted that the surface net ocean heat loss to the atmosphere on the shelf is a poorly constrained quantity, that the rough estimation of the contribution of Marguerite Trough is based on observations from a single mooring, and that the choice of a reference temperature profile, though reasonable, is not necessarily the correct one. All of these caveats must be addressed in future studies of the heat and nutrients budgets on the wAP shelf.

Overall, these results suggest that the circulation and property budgets of the wAP shelf, are heavily influenced by the ACC and the complicated bathymetry, are fully three-dimensional, and that many of the important processes, including the UCDW intrusions, have time and spacial scales small enough that would require process or modeling studies resolving horizontal distances of 1 to $2-\mathrm{km}$ and time scales of a day or so. 

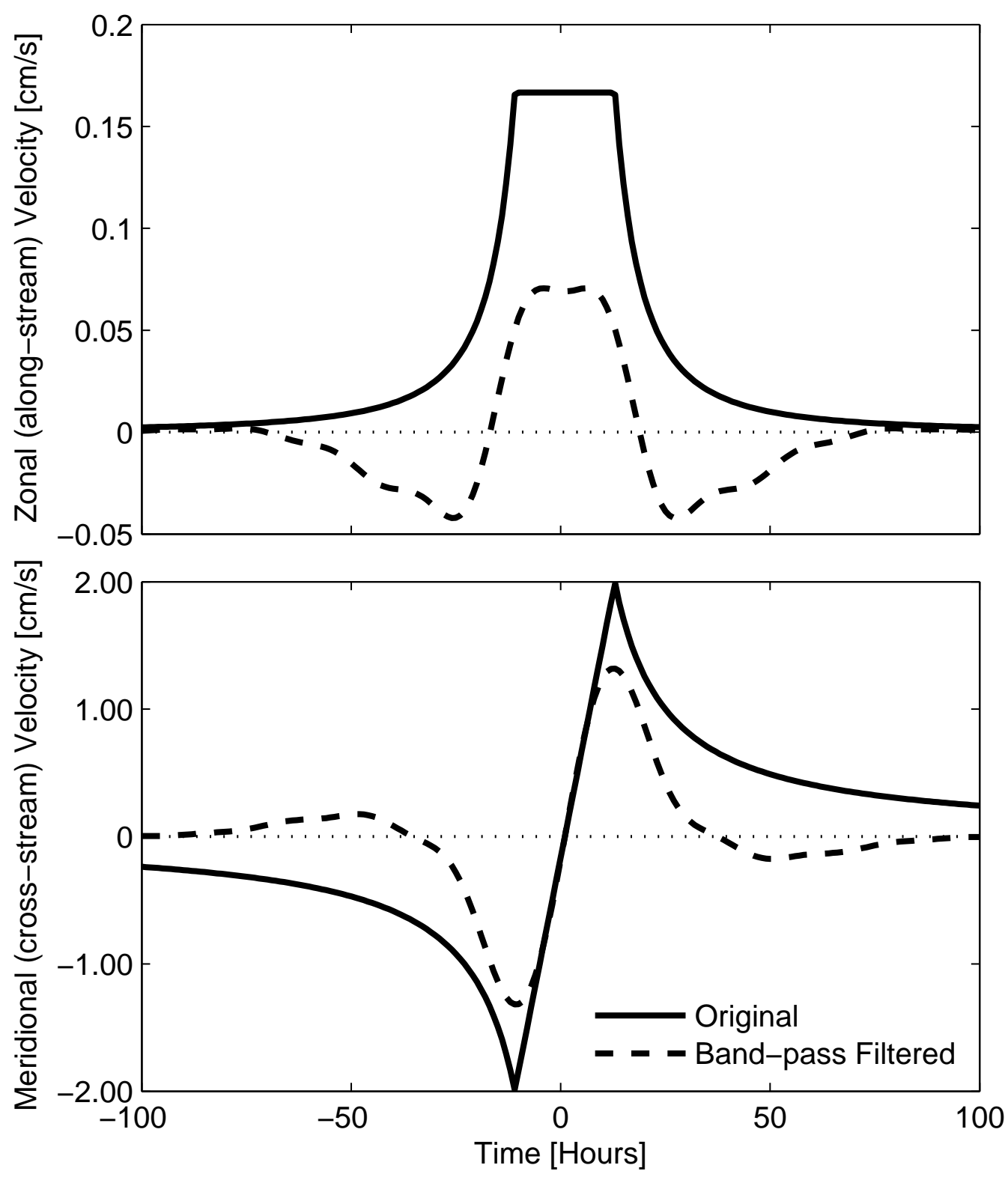

Figure 4-20: Effect of the band-pass filtering of the velocity records. The top (bottom) panel shows the along-stream (cross-stream) velocity records from a synthetic time series using the Rankine eddy model described in Section 4.5.1. The solid lines are the original time-series of an eddy with a maximum velocity of $2 \mathrm{~cm} / \mathrm{s}$, and the dashed lines are the band-pass filtered time series (half-power of 20 -h and 5 days). 


\section{Chapter 5}

\section{A First Description of the Antarctic Peninsula Coastal}

\section{Current}

\section{$5.1 \quad$ Introduction}

The west Antarctic Peninsula (wAP) continental shelf hosts a rich biological community centered around Antarctic krill (Euphasia superba). The region has been hypothesized to act as a source for krill populations elsewhere in the Southern Ocean (Murphy et al., 1998; Hofmann and Klinck, 1998, Fach and Klinck, 2006), as well

as to sustain a number of higher trophic levels in the peninsula's food web Costa and Crocker, 1996; Fraser and Trivelpiece, 1996). Additionally, multiple studies of the regional climate have found that the surface air temperature of the peninsula is rising at one of the highest rates in the world and causing rapid changes in the region (Vaughan and Doake, 1996; Cook et al., 2005). Ocean dynamics of the wAP shelf are expected to play an important role in these processes, but they remain poorly understood. The Southern Ocean Global Ecosystem Dynamics (SO GLOBEC) field program, conducted between 2001 and 2003, was aimed at understanding the dominant physical and biological processes in Marguerite Bay and the adjacent wAP shelf 
region (Hofmann et al., 2002, 2004).

Prior to SO GLOBEC, the shelf circulation had been addressed by only a handful of studies, mostly involving observations of the hydrographic fields during austral summer. In a review paper, Hofmann and Klinck (1998) describe the circulation in the SO GLOBEC study area (Figure 5-1) as a slow, cyclonic gyre composed of a north-eastward branch flowing along the shelf break and a southward flow along the inner shelf. The shelf-break circulation is dominated by the large-scale Antarctic Circumpolar Current (ACC), while the near-shore southward flow was thought to be part of a shelf-scale gyre. However, two recent studies hint at the presence of an independent southward inner shelf circulation. Tracks of drifters released during the summer of 2001 and 2002 (as part of SO GLOBEC) show a southward current flowing along Adelaide Island and into Marguerite Bay, and then exiting on the south side of the Bay along Alexander Island (Beardsley et al., 2004). The SO GLOBEC regional surface dynamic topography for the fall (April-June) of 2001 is consistent with those results, and the low salinity water found on the inner shelf suggests the flow is a buoyancy-forced coastal current (Klinck et al., 2004).

Here we use the SO GLOBEC data set, including broad-scale hydrographic data and mooring observations, to provide a first description of this nearshore coastal current. We will refer to it as the Antarctic Peninsula Coastal Current (APCC). We discuss the vertical structure, transport, along-shelf variability, and seasonal evolution of the APCC. We also explore the possible forcing mechanisms and the implications of our results for the distribution of freshwater on the shelf.

The paper is organized as follows: we summarize the available data and processing (Section 5.2), followed by brief descriptions of the study area and background oceanographic and meteorological conditions (Section 5.3), results (Section 5.4), and discussion (Section 5.5). A final summary is presented in Section 5.6. 


\subsection{Data Sources}

During 2001, two hydrographic cruises were conducted off the west coast of the Antarctic Peninsula aboard the RV/IB N. B. Palmer as part of the SO GLOBEC field program (Table 5.1). These broad-scale cruises attempted to cover the entire study region, and provided CTD (conductivity for salinity, temperature and pressure for depth) profile observations on a grid with a nominal cross-shelf resolution of 20 $\mathrm{km}$ (Figure 5-1). The fall survey (April $24^{\text {th }}$ to June $5^{\text {th }}$ ) provided a larger spatial coverage than the winter survey (July $24^{\text {th }}$ to August $31^{\text {st }}$ ), in which weather conditions and sea-ice coverage impeded navigation. Sea surface temperature (SST) and sea surface salinity (SSS) as well as wind speed and direction data were also collected throughout the cruises using the $R V / I B N$. B. Palmer continuous sampling systems. Details of the processing of the data set can be found in Wiebe et al. (2001) and Klinck et al. (2004).

As part of these broad-scale cruises, conductivity, temperature and pressure data from depths of roughly $15 \mathrm{~m}$ to $250 \mathrm{~m}$ were also collected using the Bio-Optical Multi-frequency Acoustical and Physical Environmental Recorder (BIOMAPER-II), a towed undulating multi-sensor system (Wiebe et al., 2002). A subset of these data collected on June $1^{\text {st }}, 2001$ (during the fall cruise) were used to construct a highresolution, cross-shelf hydrographic section off Adelaide Island (Figure 5-1, Section I) by merging a near-shore CTD station (Station 101), the BIOMAPER data, and the underway SST and SSS data.

Velocity data were obtained during the cruises with a shipboard-mounted RD Instruments (RDI) 150-kHz narrow-band Acoustic Doppler Current Profiler (ADCP) sampling from 31 to $431 \mathrm{~m}$. The ADCP was configured with fifty eight-meter bins, an eight-meter pulse length, and five-minute ensemble averages. During most of the cruise, the ADCP operated in bottom-tracking mode. The data processing was initially done during the cruise using the Common Oceanographic Data Access System (CODAS). Final processing and quality control were done by by J. Hummon (University of Hawaii) and S. Howard (Earth Systems Research) (Klinck et al., 2004). ADCP 
data return during the winter cruise was greatly reduced while the N. B. Palmer was moving through sea-ice and data from those times are not considered here. For the fall cruises, the small $\left(<0.02 \mathrm{~m} \mathrm{~s}^{-1}\right)$ barotropic tidal currents were removed from the data set using the Antarctic Peninsula tide model, version 04.01 (AntPen04.01), a high-resolution barotropic model based on the linearized shallow water equations (L. Padman, personal communication - See Chapter 3).

Velocity, salinity, and temperature observations were also collected at the A1 mooring, located $16.3 \mathrm{~km}$ off the west coast of Adelaide Island at a water depth of $509 \mathrm{~m}$ (Figure 5-2). The A1 mooring was deployed and recovered by the $R / V$ Laurence M. Gould and collected data from March 2001 to February 2002 (Table 5.1). The mooring was equipped with SeaBird Electronics (SBE) temperature recorders at 134, 209 and $259 \mathrm{~m}$ depth, SBE MicroCATs measuring both temperature and salinity at 159 and $309 \mathrm{~m}$, and a conductivity and temperature sensor set attached to a Vector-Averaging Current Meter (VACM) at 459 m. A SBE SeaGauge pressure sensor at $502 \mathrm{~m}$ recorded pressure and additional temperature and conductivity data. Velocity measurements included an upward-looking, RDI 300-kHz broadband WorkHorse ADCP located at $169 \mathrm{~m}$ depth and configured with sixty two-meter bins (ranging from 47 to $165 \mathrm{~m}$ ) and half-hour ensemble averages. Four bins (107, 109, 159 and $161 \mathrm{~m}$ ) were replaced by linear interpolation due to contamination by the acoustic reflection from other instruments farther up on the mooring line. Finally, two VACMs also recorded currents averaged over fifteen minutes intervals at 309 and $459 \mathrm{~m}$. For details of the moored array design and data, see Moffat et al. (2005).

Ice concentration data for the study region were obtained from the Special Sensor Microwave/Imager (SSM/I) data set derived from the bootstrap passive microwave algorithm and distributed by the National Snow and Ice Data Center (NSIDC). The sea-ice data grid has a cell size of $25 \times 25 \mathrm{~km}$, and data are provided as daily averages (Comiso, 1999, updated 2005). Ice thickness data were also obtained at a series of ice stations during the winter cruise (Perovich et al., 2004), and throughout the SO GLOBEC mooring deployment (March 2001 to February 2002) at the A2 mooring (Figure 5-1 and Table 5.1), which was equipped with an Ice Profiling Sonar (IPS) 
deployed at the top of the mooring line. The IPS measured the acoustic range to the surface (the sea surface or ice bottom when present) every two seconds, which was then converted to distance (and thus, ice draft) using in situ sound speed and density calculated from a nearby sensor (Moffat et al., 2005). All mooring time series data shown here were low-pass filtered using a 33-hr half-amplitude filter (Flagg et al., 1976; Limeburner et al., 1983) to remove tidal and inertial band variability. All salinities are given in the practical salinity scale.

\subsection{Background}

The SO GLOBEC study area extends nearly $500 \mathrm{~km}$ from the northern tip of Adelaide Island to Latady Island (Figure 5-1). The wAP shelf is relatively wide $(\approx 130 \mathrm{~km})$, deep and characterized by complex bathymetry that includes shallow plateaus and deep depressions, with mean and maximum depths of $\approx 450 \mathrm{~m}$ and $1600 \mathrm{~m}$, respectively (Bolmer et al., 2004). This complexity is also evident inside Marguerite Bay, where small islands, subsurface reefs and troughs are ubiquitous.

The general features of the shelf hydrographic structure have been described in previous studies (Hofmann and Klinck, 1998; Smith et al., 1999; Klinck et al., 2004), and are illustrated by the potential temperature-salinity $(\theta-\mathrm{S})$ diagram and vertical profiles in Figure 5-3. The data were collected using a shipboard CTD at the A2 mooring site during the 2001 mooring deployment, the fall and winter cruises, and the 2002 mooring recovery (Table 5.1). The surface waters of the wAP region are occupied by Antarctic Surface Water (AASW), a water mass with temperatures ranging from -1.8 to $1^{\circ} \mathrm{C}$ and relatively low salinities of 33.0 to 33.7 (Smith et al., 1999). By the end of the austral fall (end of June), strong surface heat loss leads to the formation of a deep winter mixed layer and a sea-ice cover over the entire shelf. As the sea-ice retreats and later during the ice-free season, the surface mixed layer is partially restratified by surface heating and freshening by sea-ice melt and runoff. The remnant of that cold winter mixed layer, called Winter Water (WW), is found at roughly 80- to 100-m

depth during the ice-free season, with temperatures of $-1^{\circ} \mathrm{C}$ or less. Subpycnocline 
waters, below 150 to $200 \mathrm{~m}$, are dominated by a modified version of the Circumpolar Deep Water $(\mathrm{CDW})$, a warm $\left(1.5^{\circ} \mathrm{C}\right)$ and salty $(34.6$ to 34.73$)$ water mass, a source of heat and nutrients for the upper layer of the shelf (Smith et al., 1999; Serebrennikova and Fanning, 2004).

\subsection{Structure and Dynamics of the APCC}

\subsubsection{Spatial Structure}

During the fall cruise, maps of SSS and SST (Figure 5-4) show the fresher end of the AASW near the coast, where salinities are typically lower than 33.25. These fresher waters are found along Adelaide Island and particularly in the region off Alexander Island and Charcot Island, where the surface salinity is at its minimum. SST (Figure 5-4) is above zero in the northern half of the study region, and the coolest temperatures are found off Alexander and Charcot Islands, and along the shelf break. The north-south temperature gradient is likely a combination of the shelf-wide cooling during the four-week cruise, which proceeded from north to south (Klinck et al., 2004), and a mean gradient reflecting the regional climate (Stammerjohn et al., 2003).

Potential temperature-salinity $(\theta-\mathrm{S})$ diagrams (Figure 5-5) illustrate the crossshelf hydrographic structure during the fall cruise. Far offshore, the vertical structure of the water column resembles the structure characteristic of the outer shelf and open ocean as described in Section 5.3 (black solid lines in Figure 5-5). Near the coast, however, salinity anomalies of the order of 0.3 to 0.7 extend down to 100-200 m (red dashed lines in Figure 5-5. Also, the subsurface temperature minimum that is the signature of the Winter Water (WW) is much weaker near the coast than offshore. At Section C, WW is completely absent and temperature increases monotonically with depth. This absence of the WW during the fall is unique to the nearshore areas and Marguerite Bay (not shown).

A detailed hydrographic and velocity section (Figure 5-6) taken off the coast of Adelaide Island (Section I, Figure 5-1) shows the vertical and cross-shelf structure 
of the APCC. As suggested by the fall broad-scale CTD survey, freshwater is concentrated near the coast. The front separating the fresh coastal current from the shelf waters is centered $20 \mathrm{~km}$ off the coast. The salinity anomaly is of the order of 0.6 at the surface, and extends below $100 \mathrm{~m}$ and to $30 \mathrm{~km}$ off the coast. Unlike the shelf waters, which show a well-mixed surface layer 50 to $70 \mathrm{~m}$ deep, the surface stratification of the APCC is relatively strong, and the temperature structure differs markedly from the temperature structure of the shelf waters. Winter Water, typically found at 80 to $100 \mathrm{~m}$ depth during the ice-free season (Figure 5-3), is absent from the nearshore waters, and is replaced by a tongue of warm water out to $10 \mathrm{~km}$ offshore of the front. This is consistent with the absence of WW near the coast described above in the broad-scale CTD survey data (Figure 5-5).

The frontal structure of the salinity field is typical of coastal buoyant plumes, and is reflected in the velocity field, which shows a well-defined coastal current co-located with the salinity front (Figure 5-6). In order to obtain the velocity field above the shallowest ADCP bin (31 m, Section 5.2), we used the thermal wind (geostrophic) shear calculated from the hydrographic fields to extrapolate the ADCP velocity to the surface. A comparison of the mean vertical shear observed by the ADCP and the thermal wind shear averaged across the current (Figure 5-7) confirms that the vertical structure of the along-shelf velocity is largely determined by the cross-shelf density gradient and validates the use of geostrophic shear to extrapolate the ADCP data vertically. Inertial motions and other wind-forced currents could strongly contaminate the characterization of the low-frequency motions we are addressing here. However, measurements from the N. B. Palmer indicate wind forcing was low $\left(<2 \mathrm{~m} \mathrm{~s}^{-1}\right)$ while Section I was occupied. A wavelet analysis (not shown) of the A1 mooring velocity records showed negligible inertial frequency energy during this period.

Section I data show surface velocities approaching $0.4 \mathrm{~m} \mathrm{~s}^{-1}$ (Figure 5-66), which decays vertically with a scale of approximately $80 \mathrm{~m}$ and have a horizontal scale $(L)$ of only $5 \mathrm{~km}$. The Rossby number for the current is $R_{o} \sim V / f L$, where $f$ is the Coriolis parameter and $V$ is a typical velocity. With the observed scales $R_{o}$ is $\approx 0.6$, an indication that nonlinear effects may be important in the along-shelf momentum 
balance.

Evidence of a velocity front can be found elsewhere on the shelf. Other ADCP sections off Adelaide and Alexander Islands (Figure 5-8) also show nearshore flow moving with the coast to the left (Figure 5-9). Although none of these sections have concurrent high-resolution hydrography that would allow examination of the dominant frontal features, freshwater fluxes and/or dynamical balances, the structure and scales observed in Sections II and III, with surface velocities of $0.15-0.40 \mathrm{~m} \mathrm{~s}^{-1}$ and depth scales of $\approx 100 \mathrm{~m}$ are similar to those from Section I. Section IV is different in that the velocity front is much wider and weaker, and is also located farther offshore, a displacement perhaps forced by the shallower bathymetry of the region. Although all these observations suggest a continuous current along the shelf, it must be noted that the APCC front could not be traced within Marguerite Bay, and given the presence of other sources of freshwater within the bay, more data are required to determine the path of the APCC along the coast.

\subsubsection{Volume and Fresh Water Transports}

The volume transport of the APCC was determined by integrating the ADCP velocity from Section I shown in Figure 5-6. As a lower vertical limit for the integration, we used the 34.4 isohaline. This choice captures the frontal structure seen in the velocity field, and is also a reasonable choice for the freshwater transport. Offshore of the front, the 34.4 isohaline is typically located in the upper pycnocline, above $150 \mathrm{~m}$, and is deeper than $200 \mathrm{~m}$ near the coast (Figure 5-6). The integration from the 34.4 isohaline to the surface and from the coast offshore to $24 \mathrm{~km}$ results in a total transport of $0.32 \pm 0.13 \mathrm{~Sv}$. The associated freshwater transport of the APCC in Section I is given by

$$
F W T=\int_{A} \frac{S-S_{r}}{S_{r}} v d A,
$$

where $v$ is the along-shelf velocity, $S$ is the observed salinity, $S_{r}$ is a reference salinity (chosen here as 34.4), and $\mathrm{A}$ is the total area enclosed by the isohaline and an offshore limit of $24 \mathrm{~km}$. This results in a value of $F W T$ of approximately $126 \pm 50 \mathrm{~km}^{3} \mathrm{yr}^{-1}$ 
for Section I (For convenience, we take both the volume and freshwater transports as positive quantities). This value is obtained by assuming the APCC is present on the shelf for seven months of the year. The work presented in the discussion section provides the basis for this assumption.

The uncertainty in the two transport estimates (about 40\%) can be explained as follows. Systematic instrumental errors have been removed during post-processing of the data (see Section 5.2 and references therein), and other instrumental errors are assumed to be negligible when the data are integrated over the entire section. Tidal currents are small (as discussed before), and have been removed using a regional tidal model. The A1 mooring data provide a good estimate of the synoptic variability of the APCC during the fall season. This variability might be due to temporal variability in the transport, as well as cross-shelf displacements of the front of the APCC. An estimate of both effects can be calculated from the ratio of the mean velocity to the standard deviation of the fall along-shelf velocity, which is of the order of $35 \%$. As we are unable to separate temporal variability from horizontal displacements of the front, we assume all of this uncertainty is due to temporal variability. An additional source of uncertainty is the vertical extrapolation of the ADCP data using the thermal wind shear. Apart from this calculation, we attempted two other methods of extrapolation: linear extrapolation and assuming a constant velocity from the shallowest ADCP bin to the surface. The resulting spread added an additional $5 \%$ or so of uncertainty to the transport calculation, giving a total uncertainty of about $40 \%$.

\subsubsection{Comparison with Theoretical Scales}

Several studies have explored the processes and dynamics that determine the relevant scales of a geostrophically-balanced coastal buoyant plume (Yankovsky and Chapman, 1997; Fong and Geyer, 2001; Lentz and Helfrich, 2002). Using the data from Section I, we can compare some simple theoretical scalings to those observed in the APCC. Among those scales are the along-shelf volume transport $(Q)$, the total width of the current $\left(W_{p}\right)$, and the width of the front $\left(W_{s}\right)$. Assuming a buoyant plume in geostrophic balance over a motionless deep layer, the volume transport as a function 
of the distance offshore can be estimated from

$$
Q(x)=\frac{g^{\prime}}{2 f}\left(h_{p}^{2}-h(x)^{2}\right)
$$

where $g^{\prime}$ is the reduced gravity $g \Delta \rho / \rho, \Delta \rho$ is the density difference between the plume and the ambient water, $g$ is the gravitational acceleration, $h_{p}$ is the depth at which the front touches the bottom, and $h$ is the depth of the front at a distance $x$ offshore of the foot of the front. If the isopycnal chosen to characterize the front outcrops and the integration is carried out over the entire region enclosed by that isopycnal, $h$ becomes zero and the volume transport $Q$ becomes independent of $x$. The width of the front scales with the internal radius of deformation $\left(W_{s}=\sqrt{g^{\prime} h_{p}} / f\right)$, and the total width of the current is then $W_{p}=W_{s}+W_{b}$, where $W_{b}$ is the horizontal distance from shore to the isobath $h_{p}$ (Figure 5-10; modified from Lentz and Helfrich, 2002).

Using the same 34.4 isohaline used in the previous section provides a meaningful comparison with the observed along-shelf transport, as the velocity below the chosen isohaline is reasonably close to zero (a basic assumption in the derivation of Equation 5.2). This isohaline touches the bottom at $h_{p}=220 \mathrm{~m}$, and the depth $h$ at the offshore limit of the front is $\approx 170 \mathrm{~m}$. The reduced gravity is computed using the observed density difference across the density front. Using either the density difference at the surface or the average density difference above the 34.4 isohaline results in $\Delta \rho \sim 0.45$ and $g^{\prime} \approx 4.310^{-3} \mathrm{~m} \mathrm{~s}^{-2}$. Using $f=1.3410^{-4} \mathrm{~s}^{-1}$, the theoretical volume transport $Q$ is $\approx 0.31 \mathrm{~Sv}$ and the front width $W_{s}$ is $\approx 7 \mathrm{~km}$.

The width of the front is estimated from the observations as the decay scale of the along-shelf velocity maximum on the surface layer, and is approximately $5 \pm 2 \mathrm{~km}$. Both the width and the volume transport calculated from the data in Section I are in good agreement with the theoretical scales (0.31 Sv and $7 \mathrm{~km}$ respectively), suggesting that the observed current is a coastal plume in geostrophic balance to lowest order. However, the observations show the total width $\left(W_{p}\right)$ of the APCC is larger than expected from the model sketched in Figure 5-10. In the model, the buoyant plume adjusts to a final state where the near-bottom velocity is zero and the front can 
be found attached to depth $h_{p}$. Our observations suggest that the front is farther offshore than expected, so that the total width is greater than $W_{b}+W_{s}$. This can also be observed in the hydrographic data, which show nearly flat isopleths in the upper $120 \mathrm{~m}$ or so of the water column onshore of $10 \mathrm{~km}$. This is a possible result of the APCC adjusting to some upstream bathymetric feature or local forcing, or the violation of some of the assumptions of the simple theoretical model used here.

\subsubsection{Temporal Evolution: The Winter Shutdown}

As the winter approaches, heat loss from the ocean to the atmosphere increases significantly, eventually leading to the formation of sea-ice on the shelf. As a result, SST during the winter months (Figure 5-4) is nearly at the freezing point everywhere. SSS is also strongly modified, showing higher values (partially explained by brine rejection), and dramatically reduced horizontal gradients compared to those for the fall.

Due to the sea-ice and harsh weather conditions, no high-resolution shipboard ADCP or BIOMAPER-II survey data were collected during the 2001 winter cruise. However, the surface fields (Figure 5-4) suggest the horizontal density gradients are greatly diminished when the shelf is ice-covered. This is confirmed by the winter CTD $\theta /$ S diagrams (Figure 5-5, right-hand panels), which show reduced horizontal gradients of properties during the winter cruise when the surface layers have become colder and saltier. Although a freshwater anomaly can still be found near the coast in winter, it is much smaller than that found during the fall cruise.

Despite the lack of detailed cross-shelf sections of hydrography or velocity during winter, the A1 mooring, deployed $16.3 \mathrm{~km}$ offshore of Adelaide Island (Figure 5-1), was favorably located to explore how the changing hydrographic structure and sea-ice conditions affect the evolution of the coastal current throughout the year. Low-pass filtered ADCP and VACM velocities from the A1 mooring, sampling the water column from 65 to $459 \mathrm{~m}$, are plotted in Figure 5-11. During the fall, the mooring data reflect the strongly baroclinic structure evident in the hydrographic and velocity sections off Adelaide Island (Section 5.4.1). Velocities in the shallowest depth bin $(65 \mathrm{~m})$ are 
typically 0.15 to $0.20 \mathrm{~m} \mathrm{~s}^{-1}$, and deep velocities remain small throughout the year. The A1 site mooring was located in a deep depression with a downstream (in the sense of the APCC flow) sill depth of around $320 \mathrm{~m}$ (the mooring depth is $509 \mathrm{~m}$. Figure 5-2, which might explain the small near-bottom velocities observed. These near-bottom velocities are not unlike others found elsewhere on the shelf in the SO GLOBEC study area where sills and deep depressions are ubiquitous (Moffat et al., 2005).

The SSM/I satellite ice-concentration time series clearly show the rapid onset and slow retreat of ice cover typical of the wAP region (Figure 5-11, Stammerjohn et al., 2003). As the shelf transitions from ice-free to mostly ice-covered at the beginning of July 2001, the along-shelf current is abruptly reduced (Figure 5-11). The ice-draft time series from the A2 mooring is consistent with the satellite data and also shows gradual growth in thickness of the sea-ice cover, reaching a draft of $2 \mathrm{~m}$ by midSeptember. By the time the 2001 winter cruise was conducted, there is little sign of a coherent along-shelf flow at A1, suggesting that the APCC has completely shut down. Velocities during the ice-covered period rarely exceed $0.05 \mathrm{~m} \mathrm{~s}^{-1}$, and northeastward flow $(v<0)$, virtually non-existent during the fall, is frequent during the winter.

This evolution is also evident in the seasonally-averaged mooring records (Figure 512), which show a strong along-shelf velocity profile during the fall (defined here until June, before the onset of the sea-ice on early July), with velocities in the shallower bins of $0.20 \mathrm{~m} \mathrm{~s}^{-1}$ or more and a depth scale exceeding $100 \mathrm{~m}$. The winter profile shows significant variability in the top $90 \mathrm{~m}$, but the seasonal mean is small throughout most of the water column. After the sea-ice retreats from the region in early November, a significant along-shelf flow reappears with a smaller seasonal mean, reflecting the reduction of the velocity and brief flow reversal in mid-December. Although the seasonal change may be due to cross-shelf displacements of the front, the broad-scale CTD surveys during the winter (discussed above) show significant reduction of the cross-shelf density gradients, consistent with the shutdown of the coastal current. Ice breakup and retreat starts in mid- to late-October 2001 and is evident both in the satellite ice concentration data as well as in the A2 ice-draft time series. As the sea- 
ice retreats, a coherent southward along-shelf flow reappears, and is only interrupted in mid- to late-December, when a strong reduction of the along-shelf velocity was observed.

\subsection{Discussion}

The freshwater sources which force the APCC are difficult to quantify due to the lack of reliable, continuous observations of freshwater inputs to the shelf. We will attempt to enumerate and quantify these sources and discuss their relative importance in the context of a freshwater budget for a coastal region upstream of Section I. We finish with a brief discussion of the effects of wind forcing on the APCC.

\subsubsection{Fresh water budget}

Unlike buoyant plumes formed by riverine outflow (e.g., Yankovsky and Chapman, 1997: Whitney and Garvine, 2005, Lentz and Largier, 2006), where most of the freshwater can be traced back to a single upstream source, the inputs for the APCC are multiple and are distributed along the coast. A freshwater budget for the APCC upstream of Section I can be written as

$$
F W T=U+\langle R\rangle+\langle P-E\rangle_{\text {ocean }}+\left\langle M_{i c e}\right\rangle+\langle O\rangle,
$$

where $F W T$ is the freshwater transport measured at Section I and $U$ is the freshwater transport at some point upstream of Section I. The other terms refer to the influx of freshwater between that upstream point and Section I: $R$ is the runoff from land, $P-E_{\text {ocean }}$ is the precipitation minus evaporation that occurs over the ocean, and $M_{i c e}$ is the sea-ice melt. Other sources or sinks of freshwater, such as cross-shelf Ekman transport, eddies, etc. are represented by $O$ and are not considered further, as we have no information about them. Integration of the terms over a given region upstream of Section I is represented by brackets $(\langle\rangle)$. Because there are no simultaneous observations of the terms on the right-hand-side of the freshwater budget 
above, we assume instead that $F W T$ from Section I is a reasonable estimation of the climatological freshwater transport of the APCC, and use both published data and results from an atmospheric regional model to estimate the right-hand-side terms of Eq. 5.3.

\section{Evidence for the APCC upstream of Section I}

A brief review of the available literature on the circulation north of Section I can shed light on the approximate size of the upstream region influencing the nearshore freshwater budget at Section I, and the size of $U$. Near the tip of the Antarctic Peninsula, the Antarctic Coastal Current (Fahrbach et al., 1992) has been observed to flow northwards and to continue counter-clockwise around the tip and then westwards into the Bransfield Strait (Heywood et al., 2004). Carrying water with T/S properties similar to those of the APCC, the Antarctic Coastal Current was found to transport $\approx 1 \mathrm{~Sv}$ into Bransfield Strait, although its path after it entered the strait could not be determined (Heywood et al. 2004).

Studies of the surface circulation in the Bransfield and Gerlache Straits, using drifter observations and hydrographic data, suggest the dominant feature in this region is flow crossing from the northern section of Gerlache Strait to the southern coast of the South Shetland Islands, although meanders and recirculations are common elsewhere in this area (Niiler et al., 1990; Huntley and Niiler, 1995; Zhou et al., 2002). This northward circulation from Gerlache Strait to Bransfield Strait suggest that the path of the Antarctic Coastal Current might retroflect within this region rather than continue along the shelf and towards the SO GLOBEC study region. This is consistent with summertime observations from the Palmer Long Term Ecological Research (LTER) program, which show minimal amounts of mixing between Bransfield Strait waters and the waters farther south (Capella et al., 1992; Smith et al., 1999).

For the region south of Bransfield Strait, a few published observations show a southward circulation between Anvers Island and Section I. A drifter released in Gerlache Strait on December 1991 moved to the southwest along the coast (Huntley and Niiler, 1995), and another drifter passing by Anvers Island also moved to the south- 
west in the last few months of 1979 (Hofmann et al., 1996). This is consistent with LTER observations, which showed the presence of a cross-shelf density gradient and geostrophic flow to the southwest near the coast south of Anvers Island (Smith et al., 1999). In summary, there is little observational evidence of a continuous southward circulation from Bransfield Strait to the shelf south of Anvers Island, suggesting that the APCC has a relatively local origin somewhere between Anvers Island and Section I. Thus, we take $U$ to be zero and consider the freshwater budget

$$
F W T=\langle R\rangle+\langle P-E\rangle_{\text {ocean }}+\left\langle M_{\text {ice }}\right\rangle
$$

for the region from Anvers Island to Section I (Figure 5-13).

\section{Runoff from land}

The mass budget of the land ice on the Antarctic Peninsula is given by

$$
\frac{d M}{d t}=\langle P-E\rangle_{l a n d}-\langle R\rangle-\langle C\rangle
$$

where $M$ is the mass of the land ice, $\langle P-E\rangle_{\text {land }}$ is the precipitation minus evaporation over the land ice, $R$ is the net runoff, and $C$ represents iceberg calving into the ocean. Although there is no quantitative information about the size of $C$, icebergs that melt locally are a net input of freshwater to the nearshore ocean. Lacking better information, we assume $R>>C$ (or equivalently, we assume icebergs melt primarily near the coast), and we estimate the runoff from land as

$$
\langle R\rangle=\langle P-E\rangle_{l a n d}-\frac{d M}{d t}
$$

Thus, net runoff from land is understood here to represent the net precipitation minus evaporation over land $\left(\langle P-E\rangle_{\text {land }}\right)$ minus long-term land ice change $d M / d t$. Note that downstream of Section I, the George VI ice shelf is expected to make a significant contribution to the budget, as studies suggest there are $53 \mathrm{~km} \mathrm{yr}^{-1}$ of basal melt for the entire ice shelf (Potter and Paren, 1985), and therefore the runoff term would 
include such contribution.

Both the mountainous topography of the peninsula and a consistently westerly atmospheric flow contribute to the wAP having the largest precipitation rate in Antarctica (van Lipzig et al., 2004). Since in situ measurements are sparse, van Lipzig et al. (2004) used a regional atmospheric mesoscale model to quantify the spatial variability in surface precipitation minus evaporation $(P-E)$. This Regional Atmospheric Climate MOdel (RACMO14), using a horizontal grid spacing of $14 \mathrm{~km}$, was integrated for the period 1987-1993. The annually averaged model output (Figure 5-13) shows $P-E$ values in excess of $2 \mathrm{~m} \mathrm{yr}^{-1}$ along most of the west drainage basin of the peninsula north of Marguerite Bay. In the SO GLOBEC study region, high values are found along the west coast of Adelaide Island, the north-east coast of Marguerite Bay, Wordie Bay and the northern coast of Alexander Island.

In order to calculate the annually averaged input of freshwater to the ocean from the land $\langle P-E\rangle_{\text {land }}$, we need to define the eastern boundary of the region between Anvers Island and Section I where the integration will be carried out. We used the RACMO14 topography to find the spine of the peninsula, i.e. the limit of the western drainage basin (Figure 5-13). The integration of the 7-year average $P-E$ over the land, integrated from Anvers Island to Section I and from the spine of the peninsula to the coast, results in a influx of $68 \pm 20 \mathrm{~km}^{3} \mathrm{yr}^{-1}$ ( \pm 1 standard deviation). Here, we assume the freshwater accumulated over land during the winter is discharged to the ocean preferentially during the ice-free season, as is suggested by the results of Meredith et al. The uncertainty above includes only one standard deviation of the monthly averaged model output, and not the differences with observations or other sources of error.

The Antarctic Peninsula is one of the fastest-warming regions in the world, with mean surface atmospheric warming of 2.5 to $3^{\circ} \mathrm{C}$ since 1951 , accompanied by a $1^{\circ} \mathrm{C}$ warming of the ocean's surface (King, 1994; Vaughan and Doake, 1996; Meredith and King, 2005). Of the 244 glaciers draining the Antarctic Peninsula ice sheet, $87 \%$ have retreated in the period between 1940 and 2004, and retreat rates are accelerating (Cook et al., 2005). Although few published estimates exist of the secular freshwater 
flux resulting from this process, an extrapolation of the retreat rates of glaciers melting into Wordie Bay (a small bay within Marguerite Bay, Figure 5-1) to a region including the west basin of the peninsula from its tip to Wordie Bay suggests $20 \pm 6 \mathrm{~km}^{3}$ of freshwater may be lost to the ocean every year (Rignot et al. 2005). A separate study estimated the runoff as a result of the increasing number of melting days on the peninsula to be between 2.9 to $20 \mathrm{~km}^{3} \mathrm{yr}^{-1}$ (For comparison purposes, we convert this range to an average of $11.5 \pm 8.5 \mathrm{~km}^{3} \mathrm{yr}^{-1}$ ). This estimate included the entire peninsula (including west and east drainage basins) for the year 2000 (Vaughan, 2006). Assuming the same rates for the $\approx 19200 \mathrm{~km}^{2}$ region used in our budget, and averaging the estimates of the two studies cited, we obtain a $d M / d t$ of $-6 \pm 4 \mathrm{~km}^{3} \mathrm{yr}^{-1}$. Adding the estimate of $\langle P-E\rangle_{\text {land }}$ north of Section I and the size of $d M / d t$ discussed above, our estimate for $\langle R\rangle$ is therefore $74 \pm 20 \mathrm{~km}^{3} \mathrm{yr}^{-1}$.

\section{Precipitation minus Evaporation over the Ocean}

Uplift of air occurs upstream of the mountains of the Antarctic Peninsula, resulting in high precipitation rates over the nearshore ocean of the wAP van Lipzig et al. 2004), as illustrated in Figure 5-13. Cross-shelf profiles of $P-E$ upstream of Section I suggests this input decays from the coast with an offshore scale of $\approx 25 \mathrm{~km}$. In order to quantify the importance of this component, the $P-E$ field over the ocean is integrated from Anvers Island to Section I and from the coast offshore to the $1 \mathrm{~m} \mathrm{yr}^{-1} P-E$ isopleth (some $20-50 \mathrm{~km}$ off the coast). This results in $27 \pm 7 \mathrm{~km}^{3} \mathrm{yr}^{-1}$ of freshwater input to the nearshore ocean from $\langle P-E\rangle_{\text {ocean }}$. This integration only includes the influx during the seven ice-free months of the year (from November to June), and not during the winter months (July to October), consistent with Section 5.5.1 (see below) and the freshwater transport calculation at Section I.

\section{Sea Ice Melt}

Sea-ice is formed at the end of the fall and throughout the winter, creating a seasonal cover that slowly retreats during the spring (Stammerjohn et al., 2003). Sea-ice samples collected during the 2001 SO GLOBEC winter cruise had an average thick- 
ness of $62 \pm 44 \mathrm{~cm}$ (Perovich et al. 2004). Relative to other places in the Southern Ocean, the wAP shelf region has high precipitation rates and relatively thin sea-ice (Perovich et al., 2004; van Lipzig et al., 2004). This leads to proportionally deep snow and negative sea-ice freeboard, setting the conditions for significant surface flooding, refreezing and snow-ice formation.

Quantifying the contribution of sea-ice melt $M_{i c e}$ to the freshwater budget of the APCC is particularly difficult. Ice formed from sea-water and melted in the same location does not generate, over a yearly cycle, a net input of freshwater. Other dynamics, however, are potentially important. Below, we discuss two mechanisms to input freshwater near the coast related to sea-ice: shoreward sea-ice drift and precipitation near the shore stored throughout the winter as snow and snow-ice.

Evidence for sea-ice drift has been reported in several regional studies of seaice dynamics. The meridional atmospheric circulation plays an important role in determining the extent and composition of the sea-ice cover, both by advecting the existing sea-ice and opening and closing leads where sea-ice production is enhanced (Stammerjohn et al., 2003; Massom et al., 2006; Harangozo, 2006). In nearshore areas, wind forcing can result in a significant amount of compaction and rafting of the sea-ice. This process was especially dramatic during the 2001-2002 season, when anomalously strong north-westerly winds were reported to cause rafting of sea-ice near the shore, reaching a thickness of 10 to $15 \mathrm{~m}$ during an October cruise in midMarguerite Bay (Massom et al., 2006).

High snowfall rates, another source of freshwater input, are also evident in the SO GLOBEC sea-ice measurements. A mass balance buoy was deployed on August 6, 2001, on sea-ice initially $0.65 \mathrm{~m}$ thick with $0.25 \mathrm{~m}$ of snow on top. The buoy functioned through November 10, mostly within $100 \mathrm{~km}$ or so from the northern shore of Alexander Island and measured an increase of snow thickness of approximately $1 \mathrm{~m}$ (see Figure 10 in Perovich et al., 2004). Although the accumulation for the rest of the year is unknown and the density of the snow cover was not recorded, these rates of snowfall are an indication that the rates of 1 to $2.5 \mathrm{~m} \mathrm{yr}^{-1}$ of water equivalent suggested by the atmospheric model's climatology for approximately the same region 
are reasonable (Figure 5-13). Using the same region as in Section 5.5.1, the model output results in $37 \pm 12 \mathrm{~km}^{3} \mathrm{yr}^{-1}$ of mean freshwater accumulation over the winter months (July to October).

As the sea-ice retreats and melts throughout the spring (and into summer), the freshwater input from both shoreward advection of ice and precipitation will contribute to the observed APCC freshwater transport. The resulting meltwater will presumably leave the region of interest. An estimate of the timescale for this signal to propagate alongshore away from the region can be obtained by estimating the propagation speed of a buoyant plume of finite along-shelf length trapped against the coast. In the absence of any other forcing, the leading and trailing edges (the "nose") of the plume will propagate at a speed given by:

$$
c_{p} \sim \frac{c_{w}}{1+W_{b} / W_{w}}
$$

where $c_{p}$ is the nose speed of the plume and $c_{w}=\left(2 g^{\prime} Q f\right)^{1 / 4}$ is the nose speed of a plume if it were moving along a vertical wall (Lentz and Helfrich, 2002). The ratio $W_{b} / W_{w}$ (Figure 5-10) describes the importance of a bottom slope in the dynamics, with surface-trapped plumes having ratios closer to zero. Using $W_{b} / W_{w}$ from 0.1 to 10 and the observed transport and density anomaly from Section I, Eq. 5.7 gives $c_{p}$ of $\sim 0.7 \mathrm{~m} \mathrm{~s}^{-1}$ to $\sim 0.07 \mathrm{~m} \mathrm{~s}^{-1}$, respectively. With this scaling, which assumes the density anomaly generated by sea-ice melting would be as large as the observed one, the freshwater signal would propagate through the $\sim 270-\mathrm{km}$ long stretch from Anvers Island to Adelaide Island in 5 days to 6 weeks. Even at the slowest estimate, it would seem that sea-ice, which decays to a minimum extent during the summer (Stammerjohn et al., 2003), would have a maximum impact on the freshwater budget considered here during the spring and early summer, and not during the fall, when the data discussed here were taken.

A few other datasets address the relevance of sea-ice to the nearshore freshwater budget. Hydrographic data taken off Anvers Island from 1991 to 1999 suggest the summer nearshore freshwater is largely explained by runoff detected as pulses of fresh- 
water in nearshore stations throughout the summer, and not melted sea-ice (Dierssen et al. 2002). Also, $\delta^{18} \mathrm{O}$ measurements collected close to the British Antarctic Survey Rothera Station in Marguerite Bay during 2002 and 2003 were used to quantify the relative contributions of sea-ice and freshwater runoff from land to the local uppercolumn freshwater content. These observations suggest runoff from land is largely responsible for the freshwater found in the surface layer, and that this runoff has a significant seasonal signal, with maximum input from February to June (Meredith et al.). However, it must be noted that the oxygen isotope samples were collected on the leeward side of Adelaide Island, so snow and snow-ice accumulation over the sea ice is not expected to be as large as on the windward side, where Section I is located (Figure 5-13).

In summary, we expect sea-ice melt to play a potentially important role in the freshwater budget of the APCC, in particular as the sea-ice melts during the spring and the $37 \pm 12 \mathrm{~km}^{3} \mathrm{yr}^{-1}$ that the model output suggest have accumulated on the ice start melting. The details of how this freshwater is discharged to the ocean, and quantification of the sea-ice drift contribution are difficult to determine at this point, but sea-ice is likely not relevant to the discussion of the freshwater budget when using observations taken in June. At the end of the fall, we expect most of the seaice to have melted and the associated freshwater anomaly to have propagated away from the region considered here. We therefore assume this component to be zero, with the important caveat that our reasoning here must be tested using new field measurements and high-resolution models of this region.

\section{Total Freshwater Input Upstream of Section I}

The sum of runoff from land $\left(\langle P-E\rangle_{\text {land }}\right.$ and $\left.\langle d M / d t\rangle\right)$ and precipitation over the ocean $\left(\langle P-E\rangle_{\text {ocean }}\right)$ could contribute $101 \pm 22 \mathrm{~km}^{3} \mathrm{yr}^{-1}$ of freshwater to the coastal ocean from Anvers Island to Section I (Eq. 5.3), with an unknown contribution from sea-ice and other sources and sinks. Given our estimates of the freshwater upstream of Section I (126 $\pm 50 \mathrm{~km}^{3} \mathrm{yr}^{-1}$ - Section 5.4.2, this suggests $\langle R\rangle$ and $\langle P-E\rangle_{\text {ocean }}$ are the primary sources of freshwater for the APCC. In the previous section, we argued 
that sea-ice is of secondary importance to the forcing of the APCC during summer and fall. The freshwater budget is certainly affected by sea-ice formation and melting, although near the coast, it is the runoff from land that appears to play a dominant role (Meredith et al. this issue). In this scenario, the driving factor is the reduction of air temperature as winter arrives. This causes both sea-ice formation and reduction of freshwater input from the land, but it is the latter that would be responsible for the shutdown of the APCC (Section 5.4.4). However, our estimation of the transport (based on a single shipboard ADCP section), the sources for our estimation of the freshwater influx, and our knowledge of the local sea-ice distribution and dynamics are subject to significant uncertainty, so additional observations are necessary to better determine the relative contributions of the different freshwater sources to the forcing of the APCC.

\subsubsection{Wind Effects}

While on June 1st, 2001 when the data in Section I were collected, the winds were rather weak $\left(<2 \mathrm{~m} \mathrm{~s}^{-1}\right)$, strong downwelling-favorable winds are prevalent in this region near the coast. They are expected to significantly affect the structure and dynamics of the APCC. Although the response of coastal buoyant currents to downwellingfavorable winds is not well understood, it is known that it will force a cross-shelf Ekman transport near the surface and an additional along-shelf, geostrophically balanced flow that can increase the observed transport of the current (Fong and Geyer, 2001; Whitney and Garvine, 2005; Lentz and Largier, 2006).

Assuming a simple model with linear bottom stress balancing the wind stress, the wind-driven along-shelf transport is $Q_{w}=\tau /\left(\rho_{o} r\right) A$, where $\tau$ is the along-shelf wind stress, $\rho$ is a reference density, $A$ is the cross-sectional area of the plume and $r$ is a bottom drag coefficient, taken here as $510^{-4} \mathrm{~m} \mathrm{~s}^{-1}$ (Lentz and Largier, 2006). Wind measurements collected in Marguerite Bay (Moffat et al., 2005) from June of 2001 to April of 2003 have a mean along-shelf wind stress of $-0.04 \pm 0.14 \mathrm{~N} \mathrm{~m}^{-2}( \pm 1$ standard deviation), and a maximum value of $-1.71 \mathrm{~N} \mathrm{~m}^{-2}$ (Here, the coordinate system is the same used for Section I, so negative values indicate downwelling-favorable winds). 
Over the same area enclosed by the 34.4 isohaline and a $24-\mathrm{km}$ offshore limit, which resulted in a volume transport of $0.32 \mathrm{~Sv}$ (Section 5.4.1), $Q_{w}$ is $0.28 \mathrm{~Sv}$ for the mean wind stress. Although this model is very simple, it illustrates the sensitivity of our transport calculations to wind forcing, and highlights the importance of concurrent atmospheric measurements on the wAP shelf when considering the dynamics of the APCC.

\subsection{Summary and Open Questions}

Observations collected during 2001-2002 as part of the Southern Ocean GLOBEC program reveal the presence of a buoyancy-forced, geostrophically-balanced coastal current along the west coast of the Antarctic Peninsula, from Adelaide Island to Alexander Island. The Antarctic Peninsula Coastal Current (APCC) is strongly seasonal and forms during the spring/summer when the shelf is ice-free. The APCC is characterized by a surface density anomaly of $\sim 0.6 \mathrm{~kg} \mathrm{~m}^{-3}$ and surface velocities of the order of $0.30-0.40 \mathrm{~m} \mathrm{~s}^{-1}$. One high-resolution hydrographic and velocity section off the coast of Adelaide Island suggests the volume transport of the APCC is of order $0.32 \pm 0.13 \mathrm{~Sv}$ with a freshwater transport of order $126 \pm 50 \mathrm{~km}^{3} \mathrm{yr}^{-1}$. Three additional ADCP sections along the coast show a velocity front consistent with a coastal buoyant current off Adelaide and Alexander Islands (Figure 5-14).

Moored observations show the virtual disappearance of the APCC during the winter months, after sea-ice forms on the shelf and the melt-water fluxes from the coast are drastically reduced. As the sea-ice breaks up and melts with increasing insolation and air temperature, the APCC reappears. Output from a regional atmospheric model and a review of the literature suggest runoff from land and precipitation over the ocean, when integrated from Anvers Island south, can provide roughly enough freshwater to the nearshore ocean to explain the observed freshwater transport of the APCC off Adelaide Island. Other sources and sinks, like ice-melt, wind-driven Ekman transport and eddies were not considered, but may play an important role. Previous studies reviewed here suggest the wAP region presents particularly favorable 
conditions (high $P-E$, retreating glaciers, downwelling-favorable winds) for the formation of a coherent seasonal coastal buoyant current.

Many questions remain. Although it is likely that the continuous freshwater influx along the peninsula makes the APCC a ubiquitous feature along the coast of the wAP south of Anvers Island, more detailed observations are required to determine its path in the SO GLOBEC study region. Of particular interest is the path (or paths) of the APCC inside Marguerite Bay, which could not be determined with our data set.

An important point that needs to be investigated is the interannual variability of the APCC. Researchers have found significant interannual variability in upper-ocean characteristics (Dierssen et al., 2002; Meredith et al., 2004) and sea-ice (Stammerjohn et al., 2003; Perovich et al., 2004; Harangozo, 2006) among others, and much of that variability is likely to directly impact the APCC. Observations designed to monitor its strength and along-shelf variability seem necessary to gauge the overall importance of the APCC on the wAP system.

Also, we have not addressed the connections of the APCC to the rich biological communities present on the wAP. Several recent studies of the biological communities in this region have observed strong cross-shelf gradients in biogeochemical variables. Chlorophyll (Dierssen et al., 2002), nutrient deficits (Serebrennikova and Fanning, 2004) and plankton concentrations (Ashjian et al., 2004; Lawson et al., 2004 Lawson, 2006) are high along the coast. This suggests that the APCC might be key to providing a favorable environment for biological production. This might be due to a variety of reasons: a coastal buoyant current like the APCC retains freshwater and nutrients (like trace metals) contained therein near the shore, it has relatively high stratification, and could be host to a biological community well adapted to the cold and low-salinity water maintained by the current. Also, the APCC provides a path for the along-shelf transport of biogeochemical tracers during the ice-free season. The ongoing synthesis effort of the SO GLOBEC data sets and further research into these and other questions should help address some of the many issues raised here. 


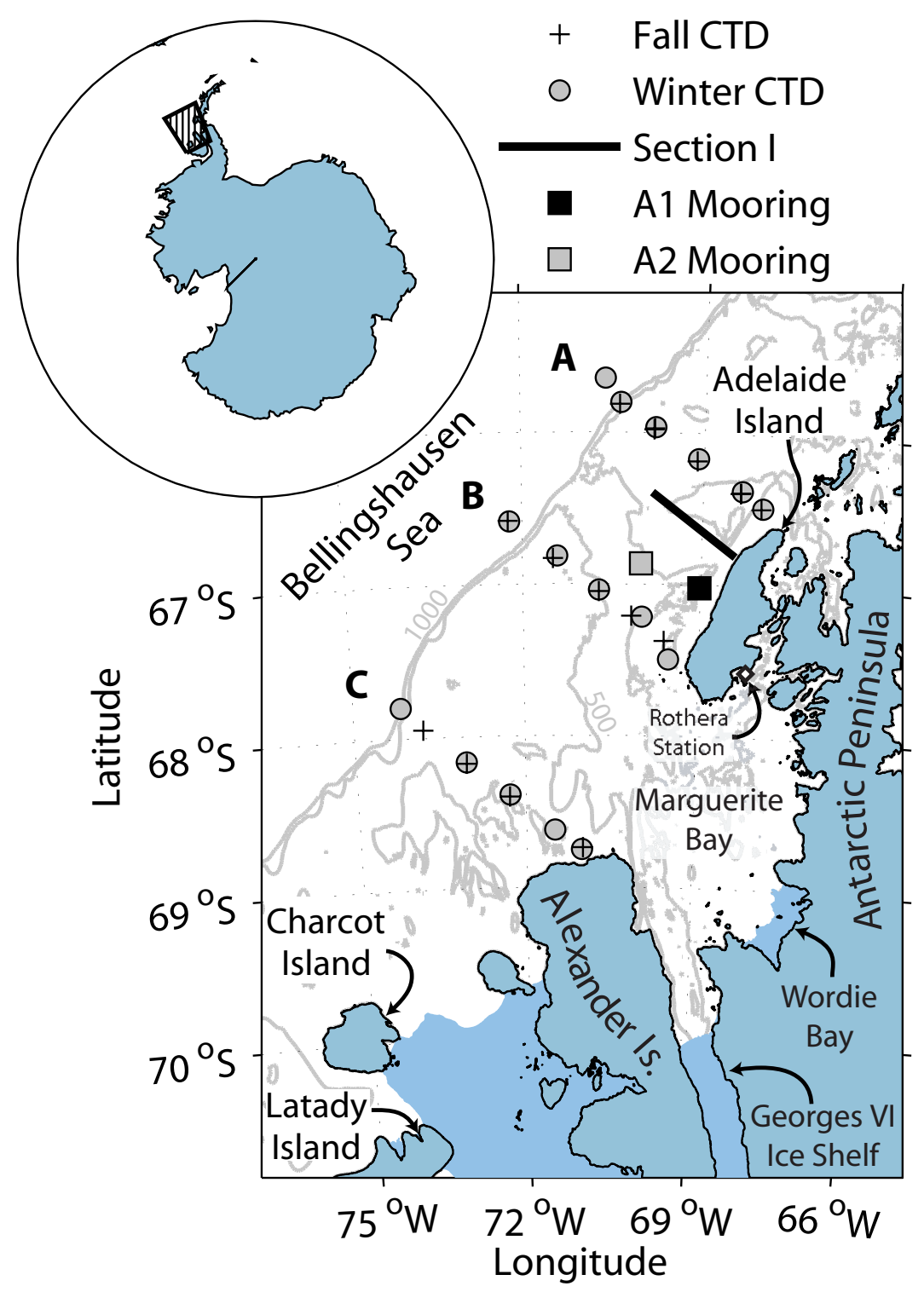

Figure 5-1: The west Antarctic Peninsula (wAP) contintental shelf. The gray lines indicate the 500- and 1000-m isobath, and the permanent ice-shelf cover is indicated by light blue. Also shown are the A, B and C CTD lines visited during the fall and winter survey cruises of 2001, the high-resolution Section I, the locations of the 2001 A1 and A2 Moorings and of the British Antarctic Survey Rothera Station. 


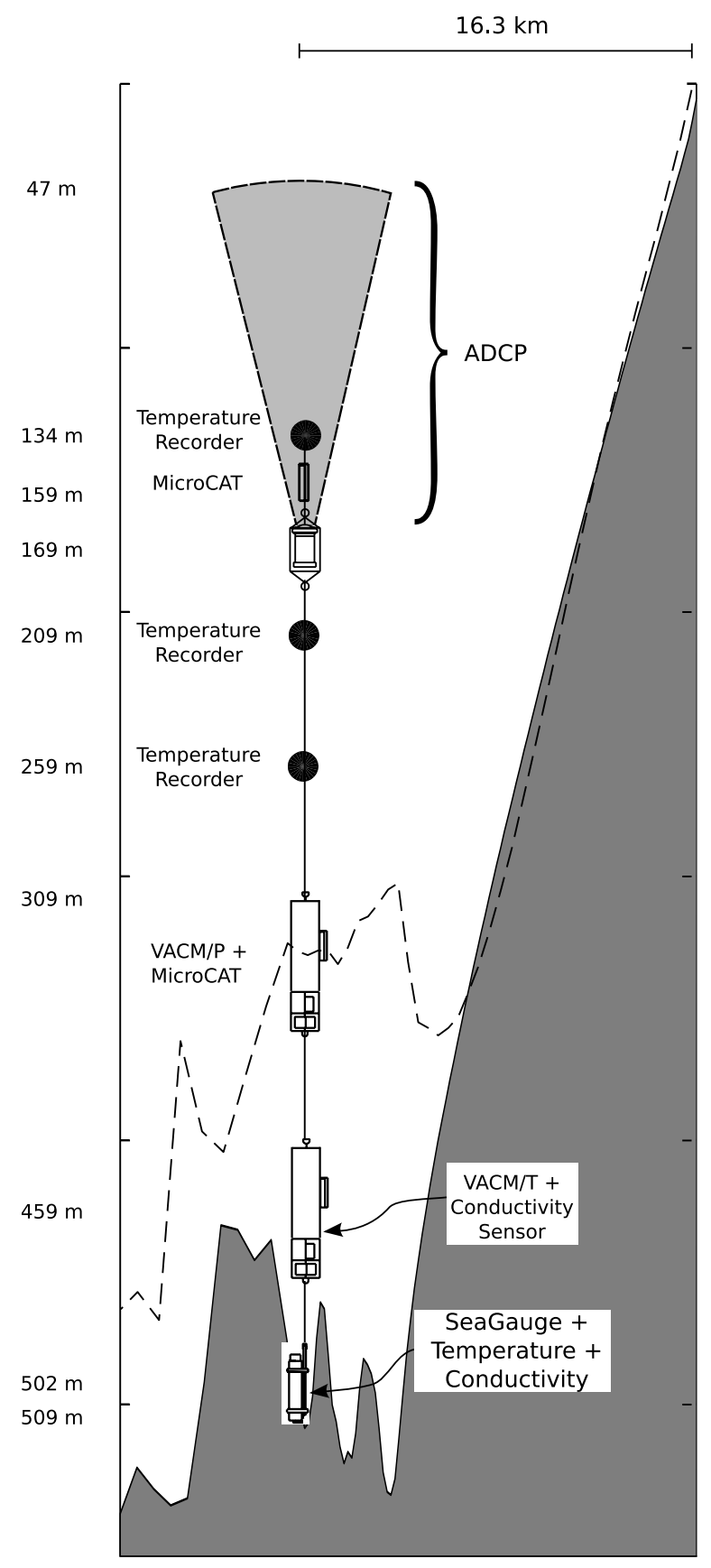

Figure 5-2: Schematic of the A1 mooring, deployed during 2001 and early 2002 off Adelaide Island. One of the VACMs had a temperature recorder (VACM/T) and the other a pressure recorder (VACM/P). The dashed line shows a profile of the cross-shelf bathymetry $\sim 3 \mathrm{~km}$ southwest of the mooring site. 


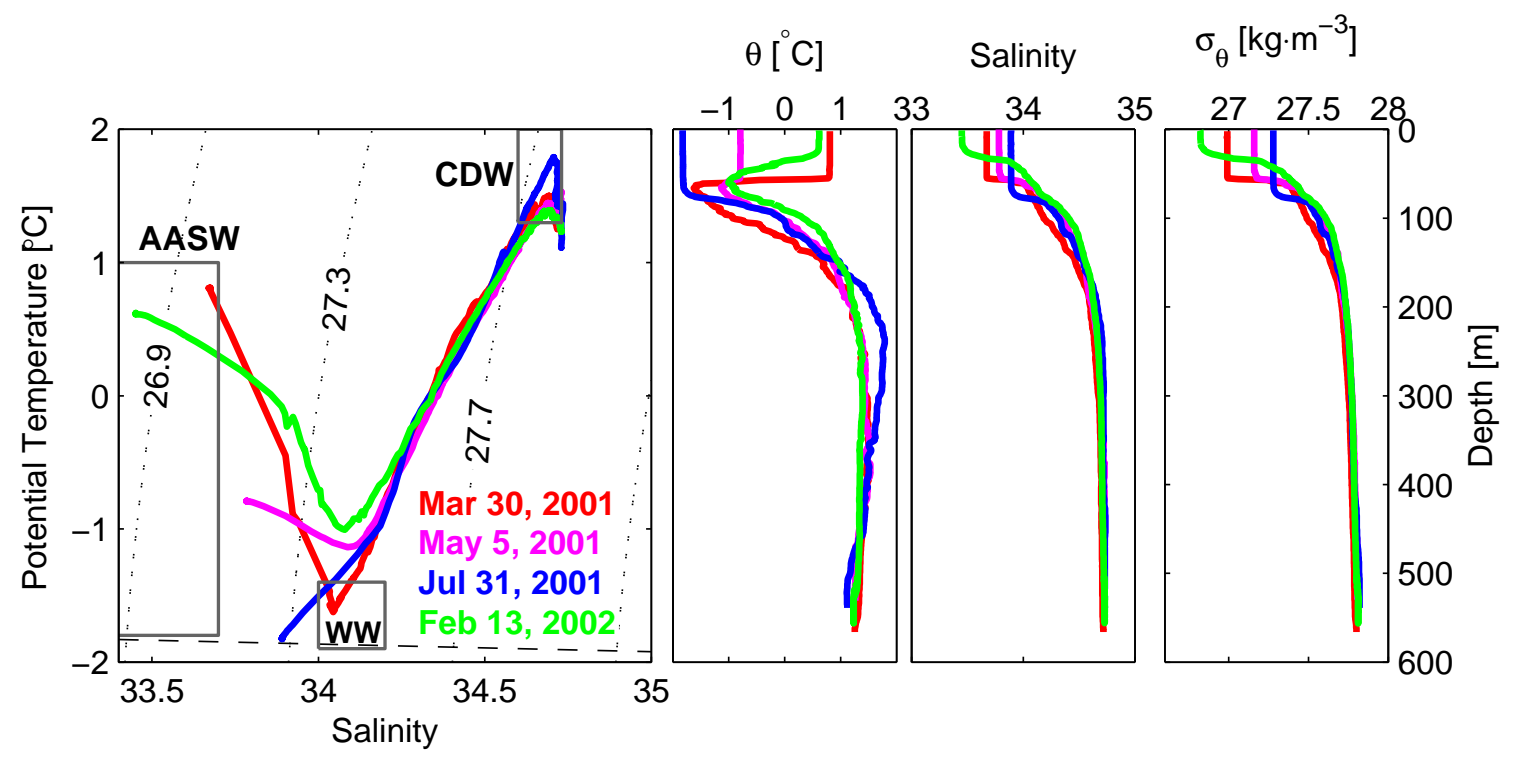

Figure 5-3: Evolution of the hydrographic structure on the mid-shelf of the wAP (A2 mooring site). The left panel shows a $\theta$-S diagram of profiles taken throughout 2001 and 2002. The gray boxes illustrate the typical range of the Antarctic Surface Water (AASW), Winter Water (WW) and Circumpolar Deep Water (CDW). The dashed line indicates the freezing point of seawater. The right panels show the corresponding potential temperature $(\theta)$, salinity, and potential density $\left(\sigma_{\theta}\right)$ profiles. 


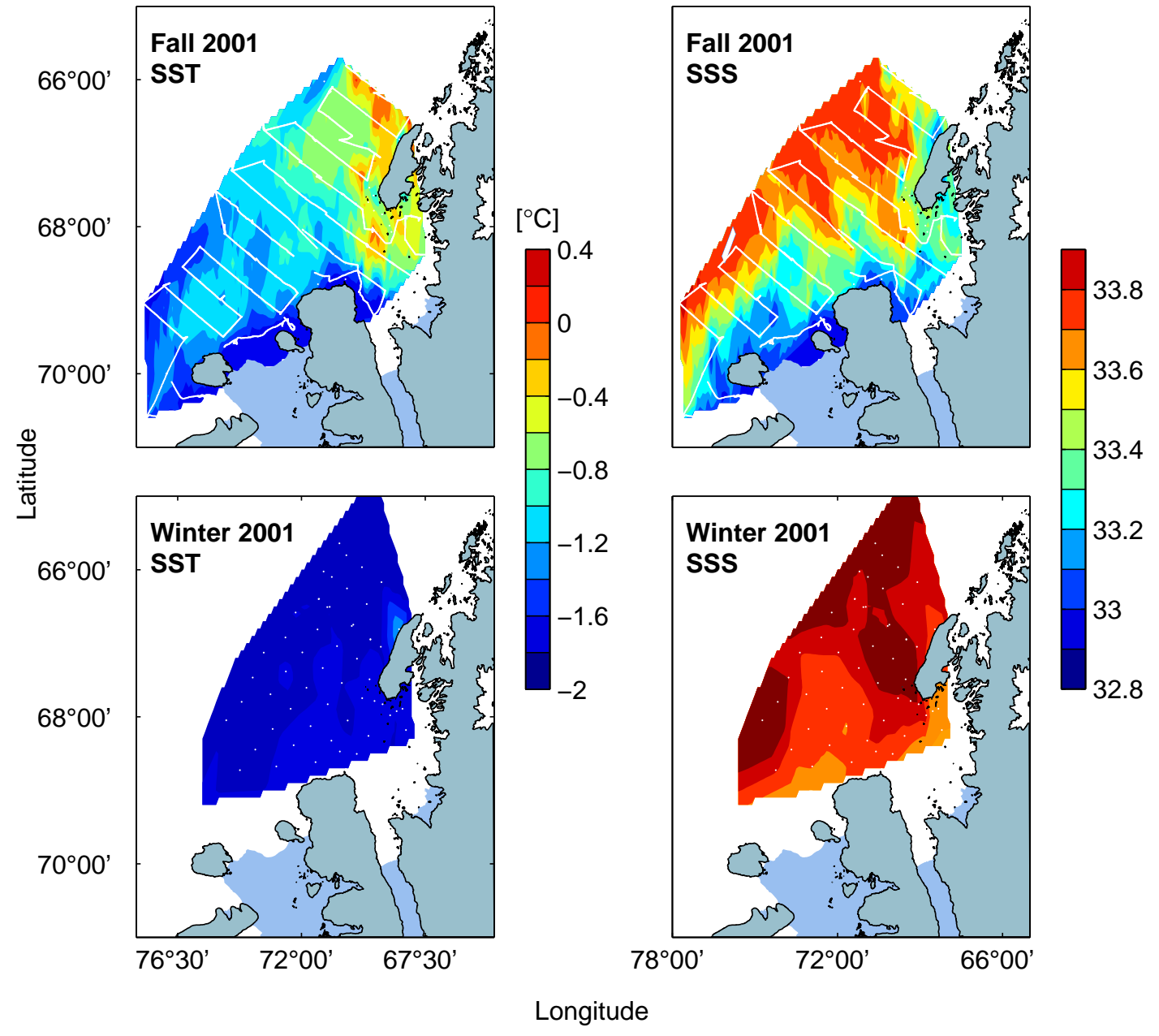

Figure 5-4: Sea surface salinity (SSS) and sea surface temperature (SST) for the fall (CTD and underway data, top panels) and winter (CTD data, bottom panels) of 2001 , collected during the SO GLOBEC broad-scale cruises on board the $R V / I B N$. B. Palmer. 

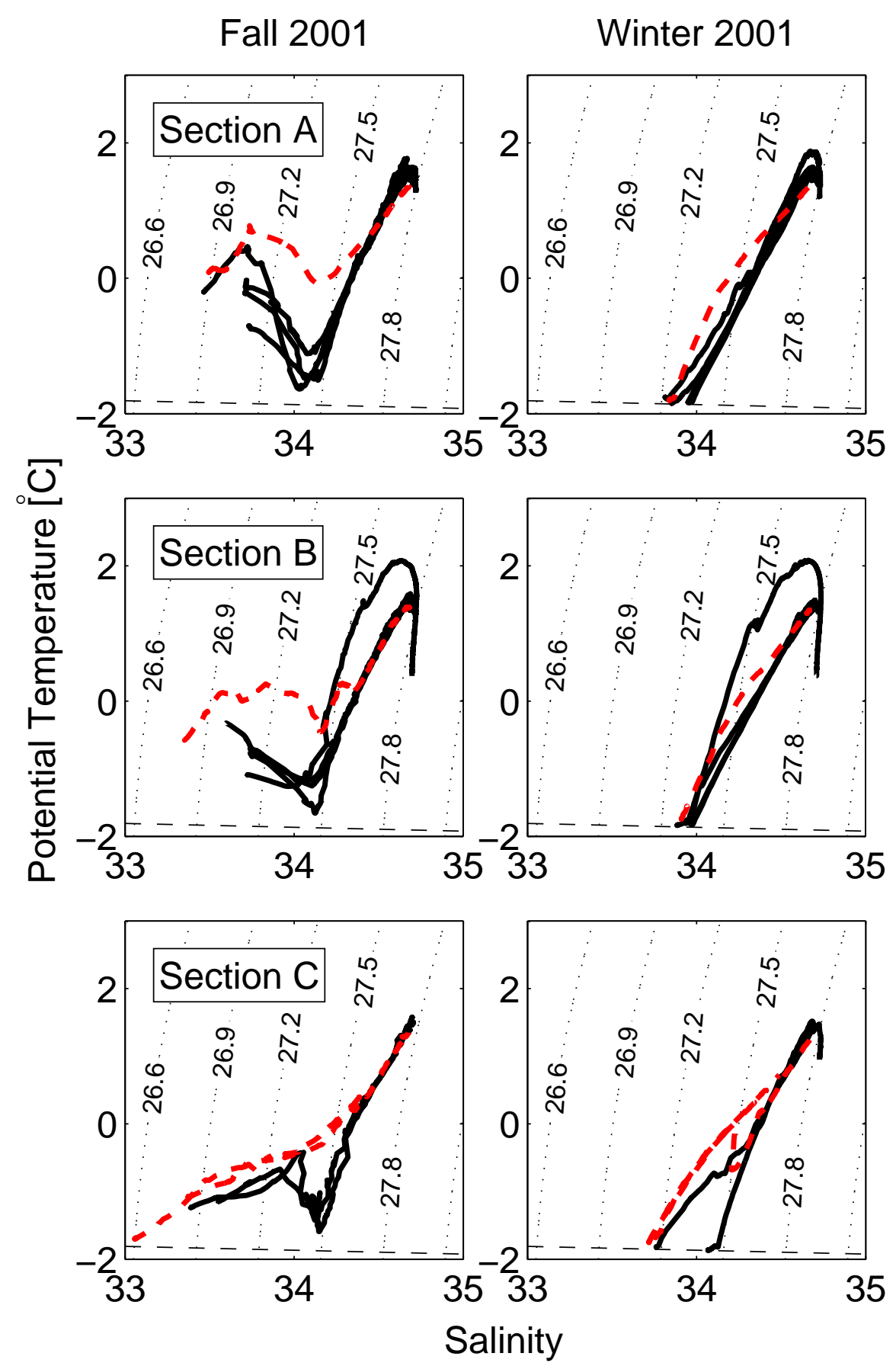

Figure 5-5: Potential temperature-Salinity $(\theta-\mathrm{S})$ diagrams from line A (top panels), $\mathrm{B}$ (middle panels) and C (bottom panels) for the fall of 2001 (left column) and winter of 2001 (right column). The solid black lines are stations from the mid- and outer shelf, and the dashed red lines are nearshore stations. The dashed line in each panel indicates the freezing point of sea-water. Station locations are plotted in Figure 5-1. 


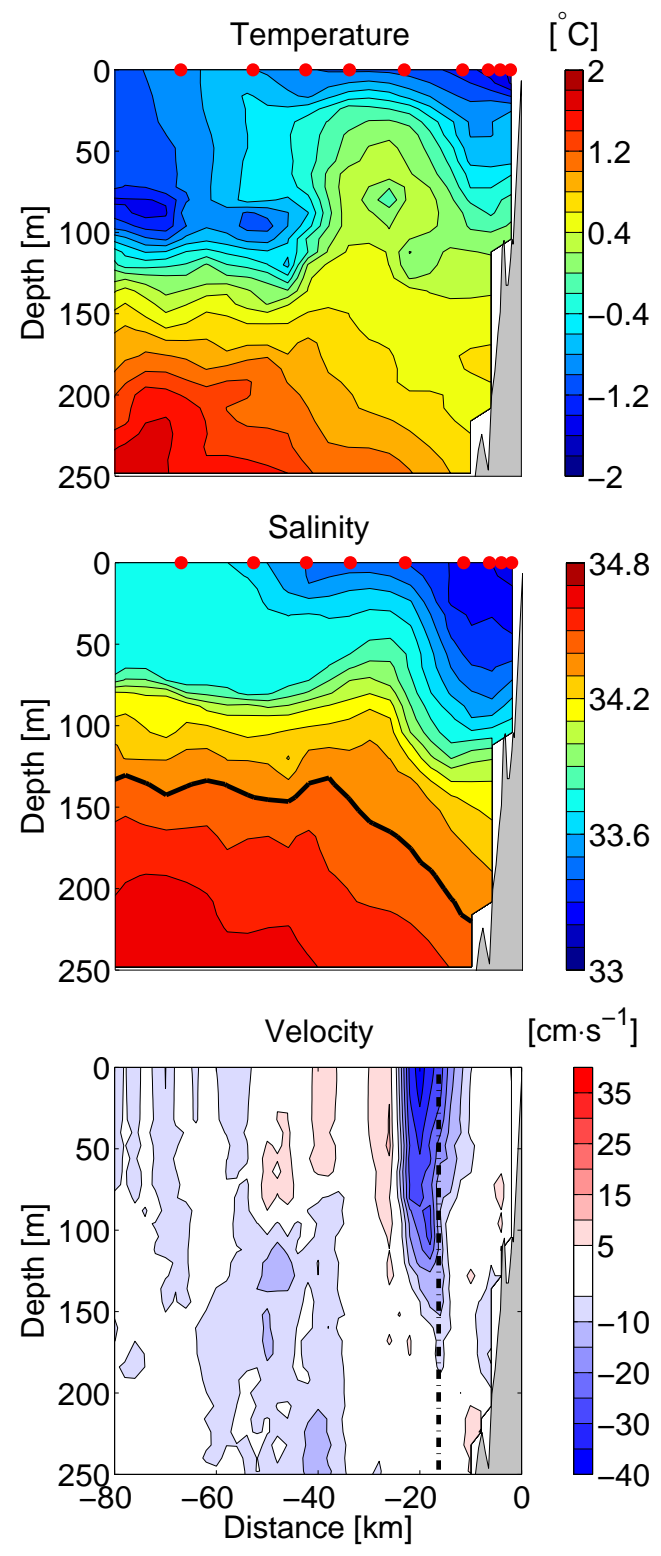

Figure 5-6: Gridded temperature, salinity and along-shelf velocity (ADCP) data from cross-shelf Section I, occupied on June $1^{\text {st }}, 2001$. The red dots indicate the approximate location of BIOMAPER-II dives (top and middle panels) and the ADCP 5-min averages (bottom panel). The thick black line in the middle panel indicate the 34.4 isohaline. The dashed black line in the bottom panel indicates the approximate crossshelf position of the A1 mooring. The along-shelf velocity is defined as the component perpendicular to the section shown in Figure 5-1, with negatives values denoting flow to the southwest. 


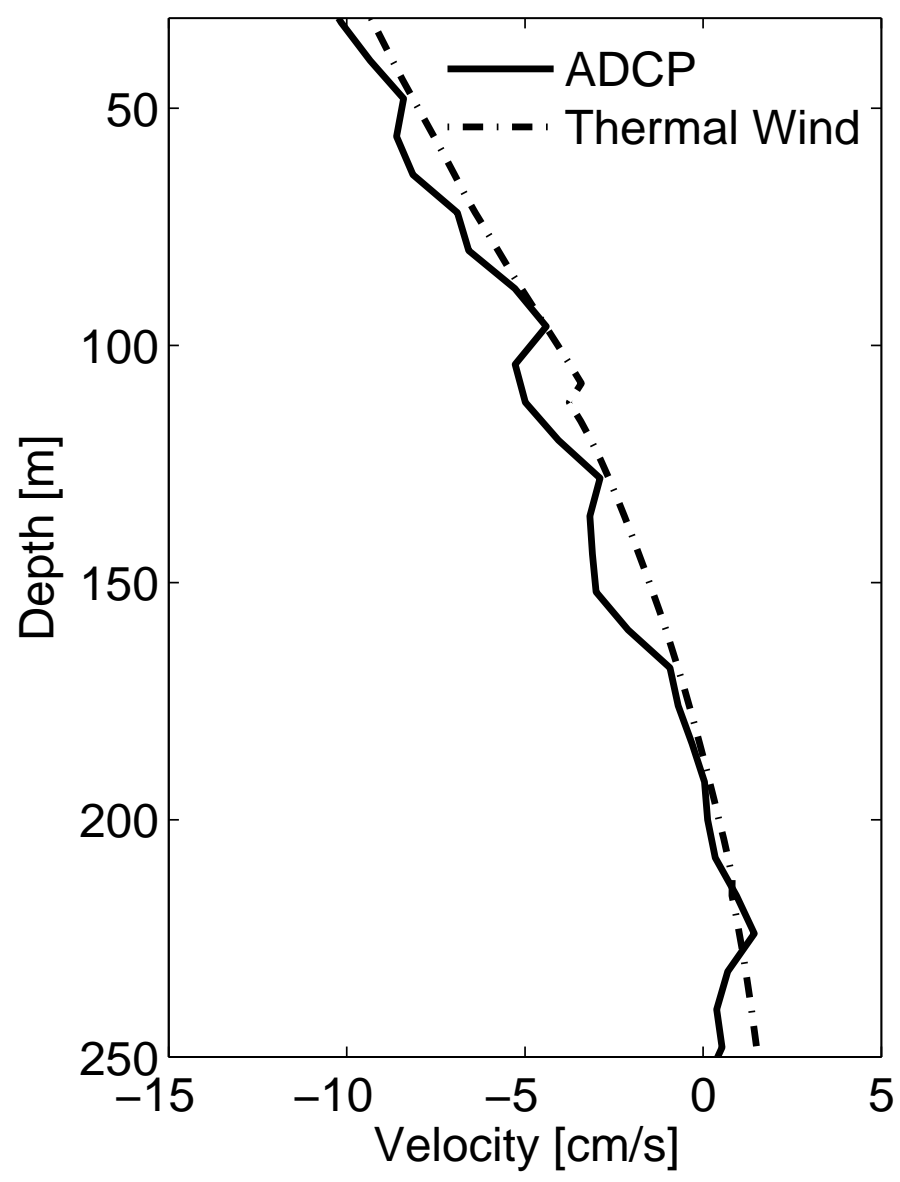

Figure 5-7: Mean ADCP velocity profile for the velocity front depicted in Figure 5-6 (solid) and mean velocity calculated from thermal wind shear (with an arbitrary offset) over the same cross-shelf region (4 to $32 \mathrm{~km}$ from the coast). 


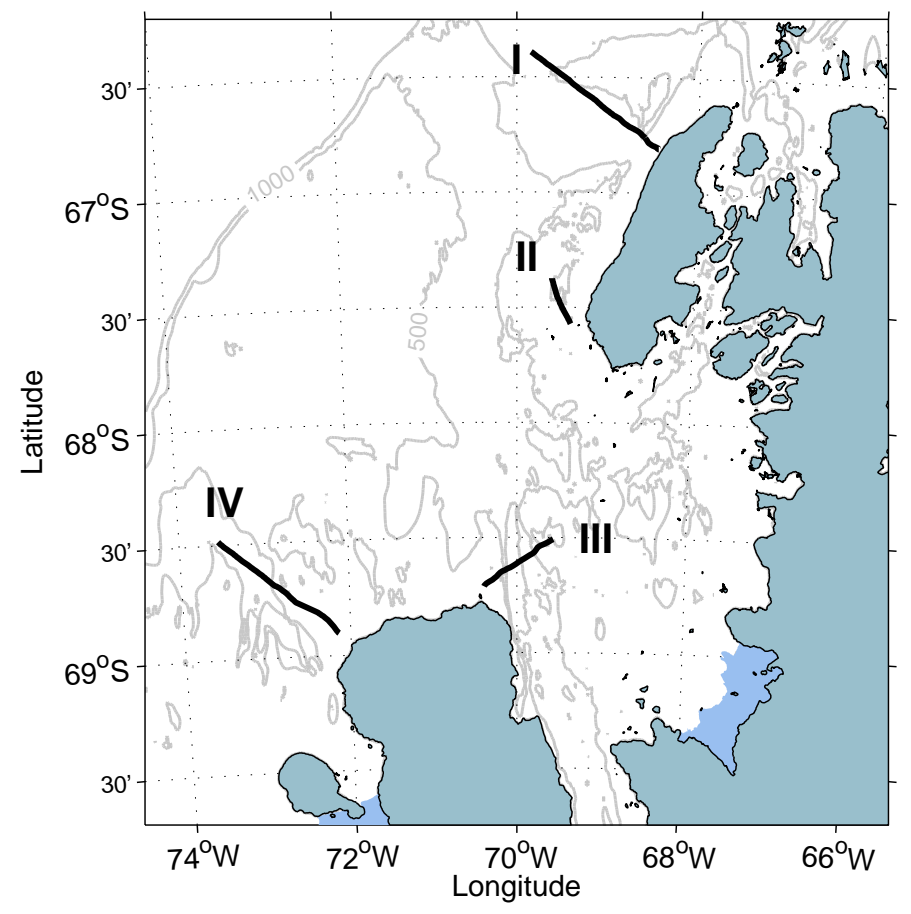

Figure 5-8: Cross-shore ADCP sections collected during the fall 2001 SO GLOBEC Cruise. The lines indicate the location of Section I, and sections conducted off the southern coast of Adelaide Island (II), and off the northern (III) and western (IV) coast of Alexander Island. 

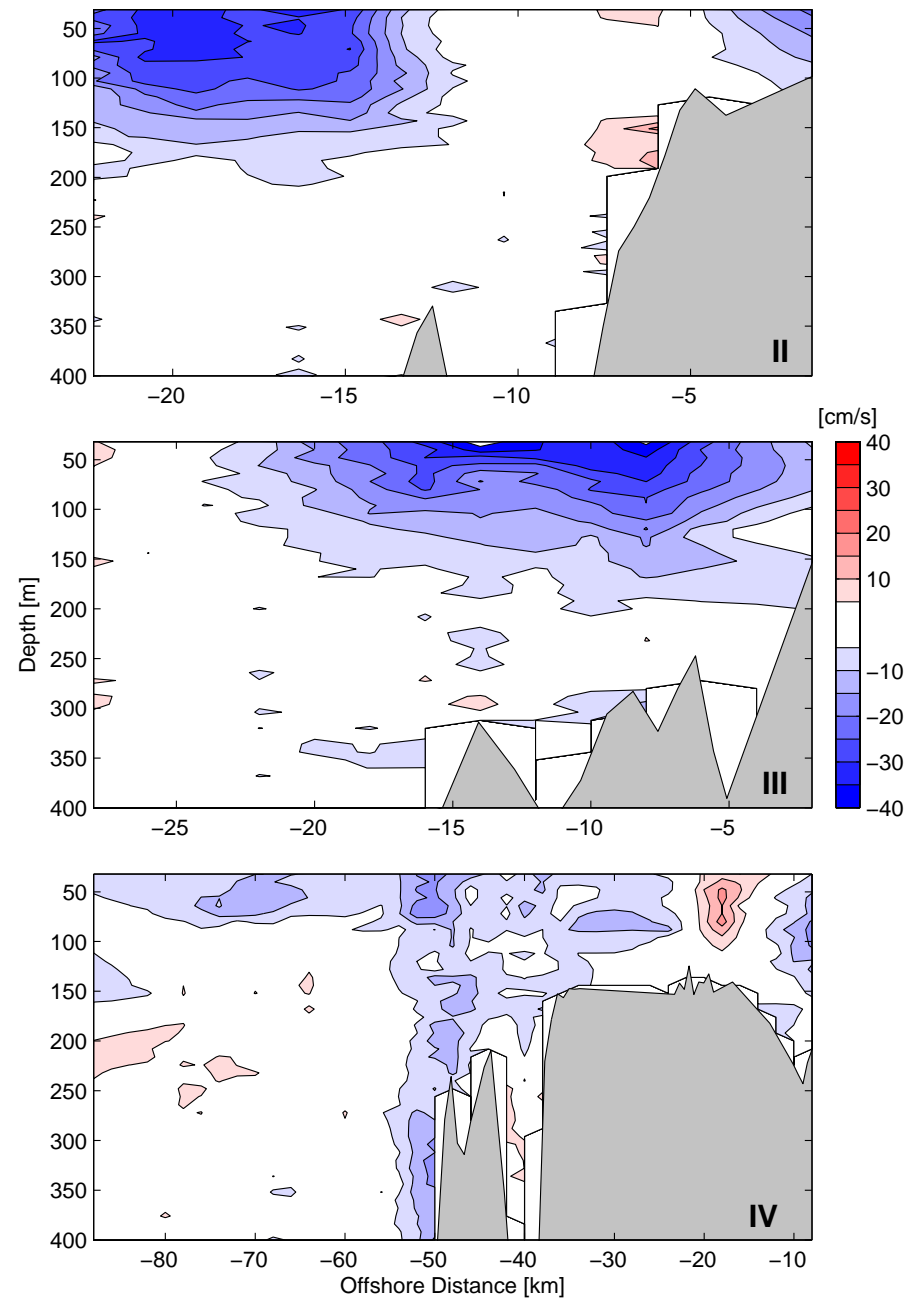

Figure 5-9: Along-shelf velocity ADCP sections, with negative values indicating flow with the coast to the left. The locations of Section II (top Panel), III (middle panel) and IV (bottom panel) are shown in Figure 5-8. The thin solid lines near the topography delineate the boundary for the velocity estimates. 


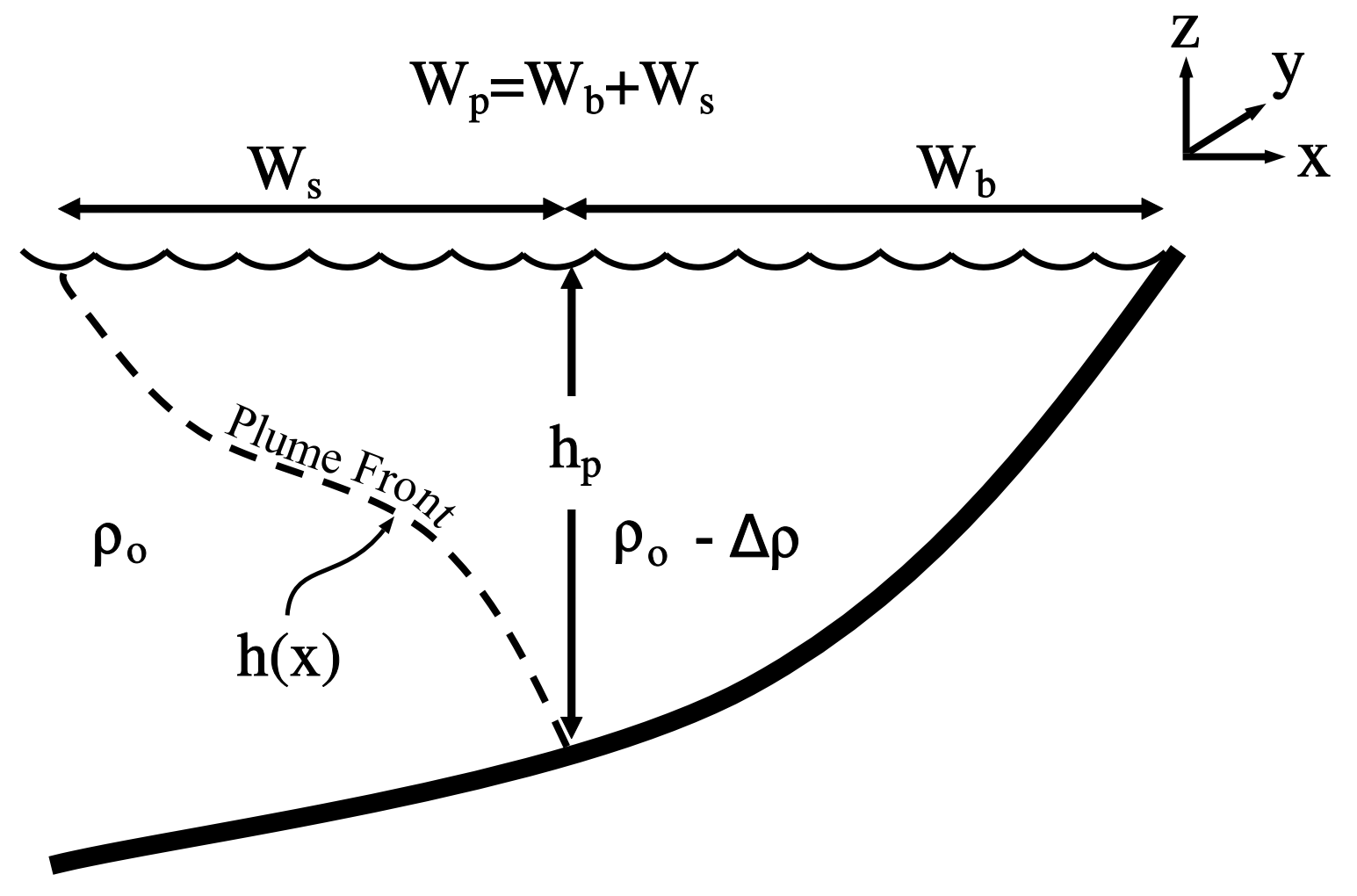

Figure 5-10: Schematic of the relevant scales of a coastal buoyant plume. The plume front, of width $W_{s}$, separates the shelf water of density $\rho_{o}$ from the lighter (by $\Delta \rho$ ) nearshore water. The front depth is $h$ and the front touches the bottom at $h_{p}$ and a distance from the coast $W_{b}$ (modified from Lentz and Largier, 2006). 


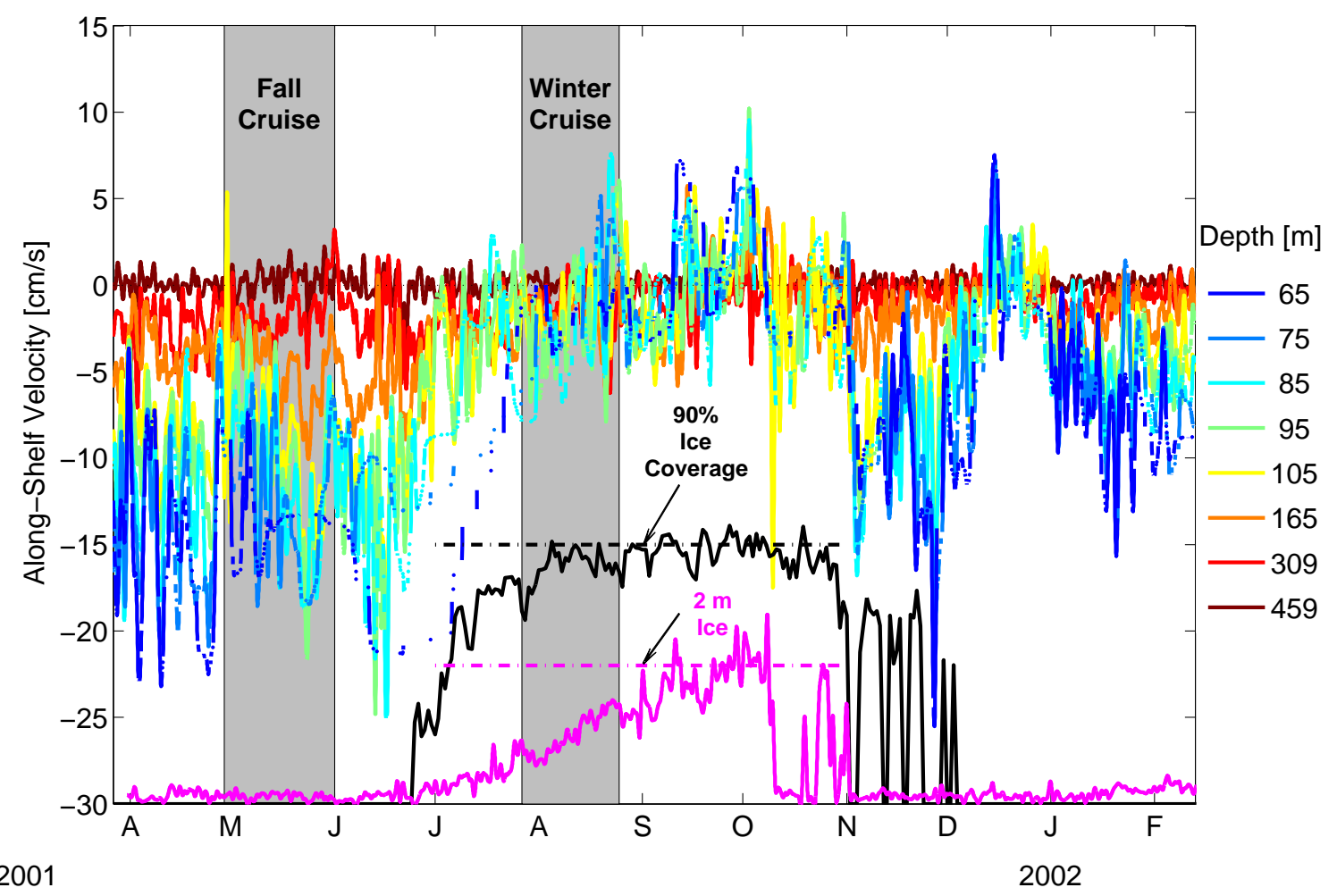

Figure 5-11: Time series of along-shelf (positive north-eastwards) velocity at the A1 mooring $\left(68^{\circ} 01.217^{\prime} \mathrm{W}, 67^{\circ} 01.134^{\prime} \mathrm{S}\right)$. The colored lines show velocity at different depths from the upward-looking ADCP (65 to $165 \mathrm{~m}$ ) and VACMs (309 and 459 $\mathrm{m})$. The shaded areas indicate periods when the fall and winter broad-scale cruises were conducted. The black line shows the sea-ice concentration (in percent) for the nearest grid point to the A1 mooring site from the Special Sensor Microwave/Imager (SSM/I) Satellite data (Comiso, 1999, updated 2005). The magenta line shows the sea-ice draft (in meters) measured with the IPS at the A2 mooring. 


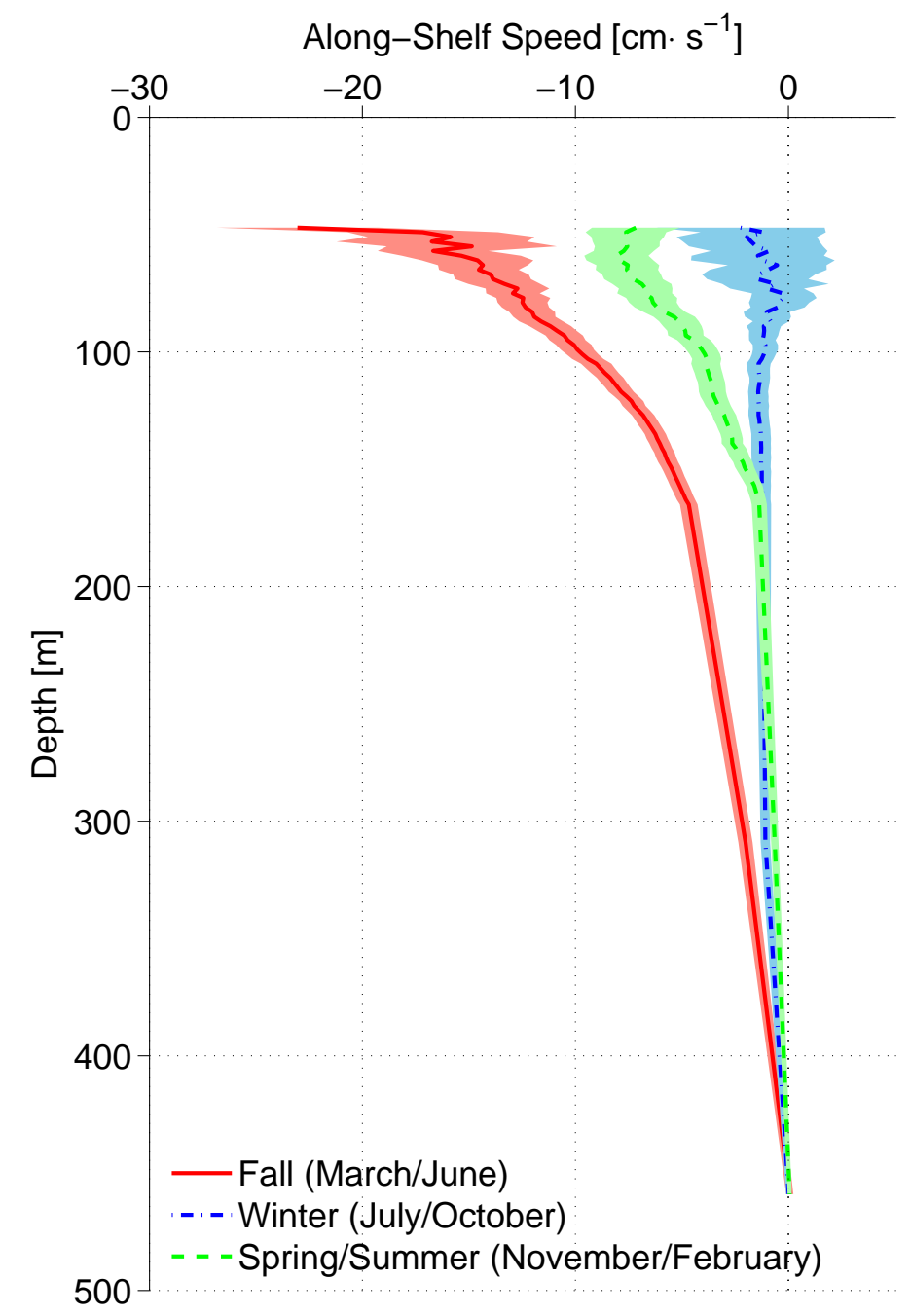

Figure 5-12: Average of along-shelf velocities from the A1 mooring records for the fall (February to June), winter (here defined as the ice-covered season, from July to October) and spring/summer (From November to the end of the deployment, in February) shown in Figure 5-11. The lines indicate the mean values for the season, and the shading the standard error. 

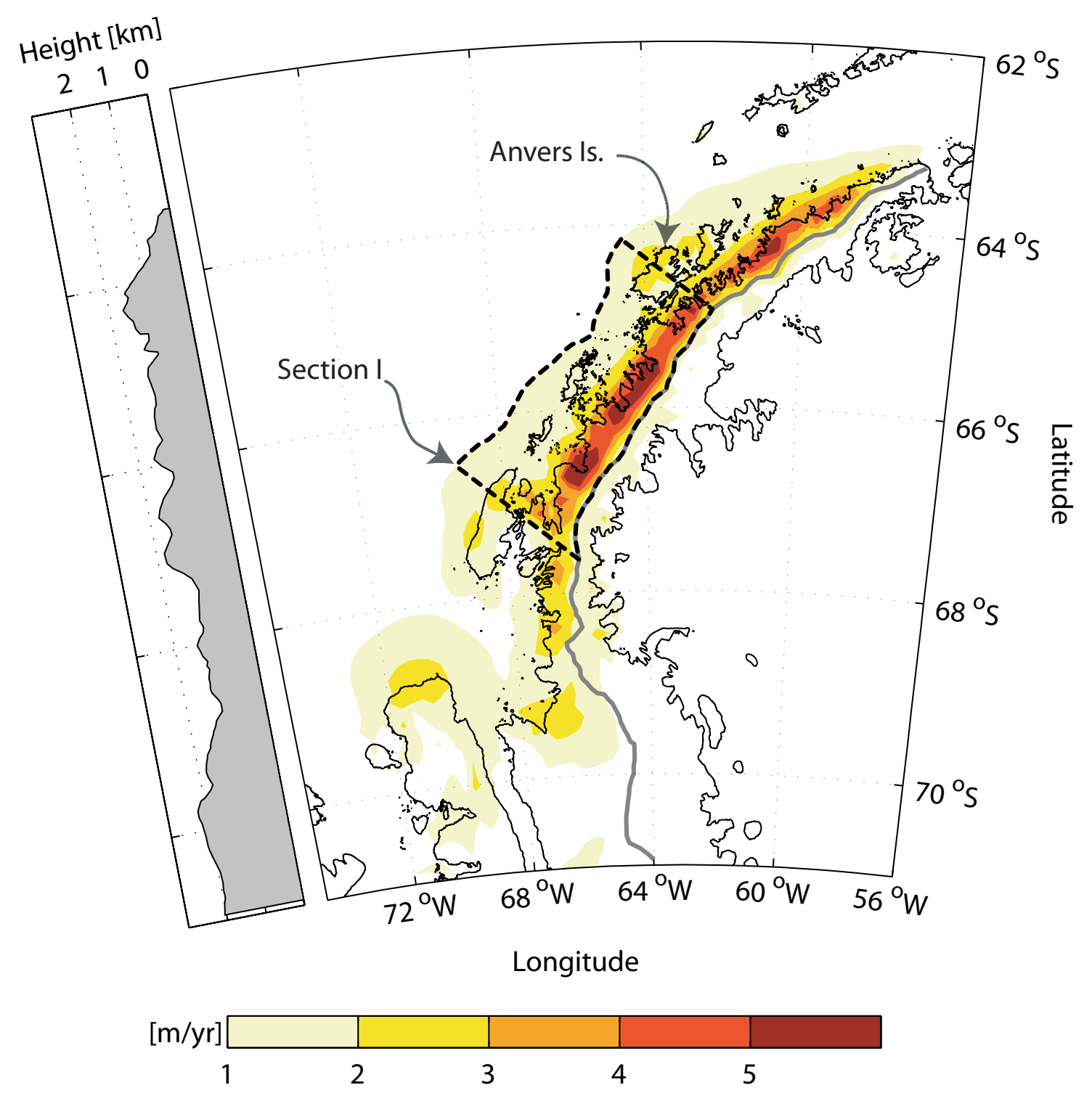

Figure 5-13: Modeled precipitation minus evaporation $(P-E)$ map for the wAP region (data from van Lipzig et al., 2004). The thick gray line indicate the location of the spine of the peninsula (from the RACMO14 topography), and the height of the topography along the spine is plotted on the left panel. The dashed black line indicates the region upstream of Section I used to compute the freshwater budget. 


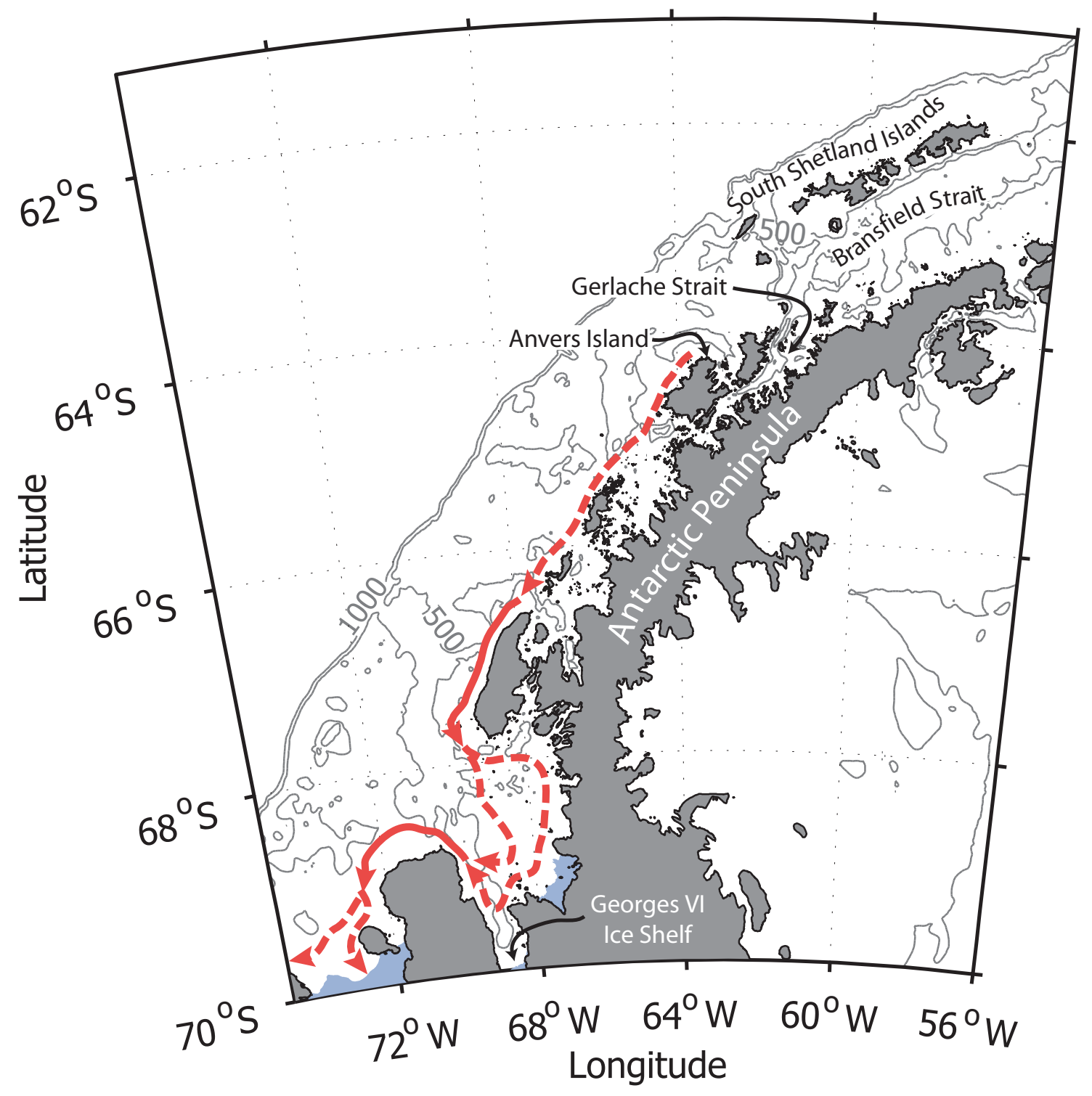

Figure 5-14: Schematic of the path of the APCC. The solid lines indicate sections along the coast where the velocity front and a cross-shelf density gradient was observed. The dashed lines are suggested paths, not derived from observations. 
Table 5.1: Summary of the cruise dates and number of CTD stations conducted, and of the dates, location and local depth of the moorings deployment.

\begin{tabular}{|c|c|c|c|c|}
\hline Cruise & Objective & Start & End & ETD Stations \\
\hline LMG01-03 & Mooring Deployment & $03 / 18 / 01$ & $04 / 13 / 01$ & 6 \\
\hline NBP01-03 & Fall 2001 Survey & $04 / 24 / 01$ & 06/05/01 & 84 \\
\hline NBP01-04 & Winter 2001 Survey & $07 / 24 / 01$ & 08/31/01 & 70 \\
\hline LMG02-1A & Mooring Recovery & 02/06/02 & 03/03/02 & 9 \\
\hline Mooring & Deployment & Longitude & Latitude & Depth $[\mathrm{m}]$ \\
\hline A1 & $03 / 26 / 01$ & $69^{\circ} 01.217^{\prime}$ & $67^{\circ} 01.134^{\prime}$ & 509 \\
\hline A2 & $03 / 31 / 01$ & $70^{\circ} 00.683^{\prime}$ & ' $\quad 66^{\circ} 51.883^{\prime}$ & 561 \\
\hline
\end{tabular}




\section{Chapter 6}

\section{Discussion and Summary}

Research presented in this thesis has substantially increased our knowledge of the circulation and dynamics on the western Antarctic Peninsula continental shelf, the study site of the Southern Ocean GLOBEC program.

In Chapter 3, the basic properties of the circulation are described. The results suggest that the correlation scales are relatively large for tidal and near-inertial motions on the mid- and outer-shelf off Adelaide Island, while across the mouth of Marguerite Bay, where the bathymetry and the coastline are significantly more complicated, the scale of the motion appears to be smaller than the mooring separation (25 km or so). Also, it is shown that Marguerite Trough has a strong influence on the circulation, determining the orientation of the mean flow, steering the tides, and sustaining vorticity waves. Circulation in the trough also shows a significant wind-driven response, with downwelling- (upwelling-) favorable wind-stress generating a anticyclonic (cyclonic) response in the northern side of the canyon and at A3. In the exploration of the warm-water intrusion hypothesis (Chapter 4), the trough also plays a role in the cross-shelf advection of heat.

Chapter 4 revealed some surprising results. Before this research, it was thought that the UCDW intrusions on the western Antarctic Peninsula continental shelf were of relatively large scale and that they happened 5 to 6 times a year (Klinck et al. 2004). The mooring observations, however, show otherwise. The warm UCDW intrusions are short, frequent (four per month at a fixed site, on average) and have an 
apparent horizontal scale of 3-5 km. They are advected in Marguerite Trough by the low-frequency cyclonic flow, although they are not observed in the mooring near the mouth of Marguerite Trough. It is unclear whether they mix away before reaching the deeper part of the trough in Marguerite Bay, or whether the Lagrangian circulation is such that the intrusions are advected elsewhere on the shelf.

Further investigation is necessary to understand the underlying dynamics of the intrusions. No attempt was made here to explain the generation process, although their properties indicate they originate in the ACC. Also, their horizontal scales and velocity structure were inferred using simple dynamical models and scaling arguments, not by direct observations. A moored array similar to the one used by SO GLOBEC, but consisting of more closely spaced moorings across the northern edge of Marguerite Trough (at the A2 site) could help resolve many of the questions left open by the research presented here.

Chapter 5 provided the first description of the Antarctic Peninsula Coastal Current (APCC). Although the uncertainties are large, observations and modelling results from the region suggest that during the ice-free season, the intense precipitation and melt water from the coast results in the formation of a coastal buoyant current in the study region. The current is roughly in geostrophic balance, and is the most coherent and energetic structure observed on subtidal time-scales.

The SO GLOBEC moored array has provided tremendous amounts of new information about the circulation on the wAP shelf. Some basic ideas about the general circulation and scales of variability are now in place, there are also implications from these results that should be tested more extensively with new observations.

One can speculate on what those new efforts might include. On the structure and origin of the APCC, an important question is what is the origin of the fresh water, which was addressed here with model output which itself needs further testing with observations. A relatively straightforward way to make progress on this question would be to make extensive measurements of oxygen isotopes during the ice-free season on the shelf, which would determine the relative importance of sea-ice vs glacier melt-water since they have distinctive isotopic signatures (e.g. Meredith et al. 
2006).

The APCC is also interesting in that our scarce observations indicate the structure of the front is not exactly what one would expect from the theories dealing with the evolution of coastal buoyant currents on the shelf: the prediction is that the foot of the front will move across isobaths (across the shelf) until the near-bottom velocity is zero (Lentz and Helfrich, 2002). The data presented here shows the front of the APCC to be located several kilometers farther offshore than expected (i.e., there is a region of relatively flat isopycnals between the coast and the front). This suggest than other processes (along-shelf topographic variations, wind-forcing, etc) are acting on the APCC front, apart from interactions with a relatively constant bottom slope.

The APCC is also similar to other coastal buoyant currents in the northern hemisphere, like the East Greenland Coastal Current and the Alaskan Coastal current, that are relatively large (compared to their small counterparts forced by river outflows in mid-latitudes) and subjected to strong downwelling-favorable wind forcing and relatively continuous buoyancy inputs from the coast. All of these currents raise questions about the influence of wind forcing on deep fronts near the shore which remain relatively unexplored.

Both the APCC and deep intrusions form fundamental components of the wAP ecosystem, and it would seem that they explain important aspects of the horizontal distribution of plankton on the shelf. Looking at the relative abundances of different types of phytoplankton, Prézelin et al. (2004) noticed that off the west coast of Adelaide Island, diatoms dominated over phytoflagellates, while near the coast there was co-dominance of these two groups. Diatoms tend to dominate in environments where there is sufficient supply of silica-rich water, as is the case with the oceanic water intrusions studied in Chapter 4 (Prézelin et al., 2000; Serebrennikova and Fanning, 2004). This suggests that the APCC front, which separates the relatively fresh, presumably silica-poor water near the shore from the regions on the mid-shelf more likely to receive the high-silica intrusions, might create a favorable environment for phytoflagellates near the coast, by limiting the supply of silica to the diatom population. 
Overall, what makes the study of regions like the wAP challenging is the combination of a deep shelf with complicated bathymetry, and a relatively weak stratification. This, combined with the high latitude location of these sites, results in flows with relatively small dynamical scales following complicated paths strongly influenced by the bathymetry. Future observations and numerical models must be designed to resolve these small scales in order to understand some of the processes outlined in this thesis. 


\section{Bibliography}

Ashjian, C., Rosenwaks, G., Wiebe, P., Davis, C., Gallager, S., Copley, N., Lawson, G., Alatalo, P., 2004. Distribution of zooplankton on the continental shelf off Marguerite Bay, Antarctic Peninsula, during Austral Fall and Winter, 2001. Deep Sea Research II 51 (17-19), 2073-2098.

Auad, G., Hendershott, M., Winant, C., 1998. Wind-Induced Currents and BottomTrapped Waves in the Santa Barbara Channel. Journal of Physical Oceanography $28(1), 85-102$.

Baines, P., 1974. The Generation of Internal Tides over Steep Continental Slopes. Philosophical Transactions of the Royal Society of London. Series A, Mathematical and Physical Sciences 277 (1263), 27-58.

Baines, P., 1995. Topographic Effects in Stratified Flows. Cambridge University Press.

Beardsley, R., Limeburner, R., Owens, B., McDonald, M., Hildebrand, J., Wiggins, S., Sirovic, A., Thiele, D., Pirzl, R., 2002. Report of R/V Laurence M. Gould cruise LMG2-1A to the western Antarctic Peninsula 6 february to 3 march 2002. Tech. Rep. 4, United States Southern Ocean Global Ocean Ecosystems Dynamics Program.

Beardsley, R. C., Limeburner, R., Owens. W. B., 2004. Drifter measurements of surface currents near Marguerite Bay on the western Antarctic Peninsula shelf during austral summer and fall, 2001 and 2002. Deep-Sea Research II 51, 19471964. 
Bolmer, S., Beardsley, R., Pudsey, C., Morris, P., Wiebe, P., Hofmann, E., Anderson, J., Maldonado, A., 2004. A high-resolution bathymetry map of Marguerite Bay and adjacent western Antarctic Peninsula shelf southern ocean globec program. Tech. Rep. WHOI-2004-02, Woods Hole Oceanographic Institution.

Capella, J., Ross, R., Quetin, L., Hofmann, E., 1992. A note on the thermal structure of the upper ocean in the Bransfield Strait-South Shetland Islands region. Deep-sea research. Part A. Oceanographic research papers 39 (7-8), 1221-1229.

Comiso, J., 1999, updated 2005. Bootstrap sea ice concentrations for NIMBUS-7 SMMR and DMSP SSM/I, January 2001 to March 2002. Boulder, CO, USA, digital Media.

Cook, A. J., Fox, A. J., Vaughan D. G., Ferrigno J. G., 2005. Retreating glacier fronts on the Antarctic Peninsula over the past half-century. Science 308, 541-544.

Costa, D., Crocker, D., 1996. Marine mammals of the Southern Ocean. Foundations for Ecological Research West of the Antarctic Peninsula, R. Ross, E. Hofmann and L. Quetin, eds., Amer. Geophys. Union, Antarctic Research Series 70, 287-301.

Dierssen, H. M., Smith, R. C., Vernet, M., 2002. Glacial meltwater dynamics in coastal waters west of the Antarctic Peninsula. Proceedings of the National Academy of Sciences 99 (4), 1790-1795.

Emery, W., Thompson, R., 1998. Data analysis methods in physical oceanography. Pergamon Press Inc.

Fach, B., Klinck, J., 2006. Transport of Antarctic krill (Euphausia superba) across the Scotia Sea. Part I: Circulation and particle tracking simulations. Deep-sea research. Part 1. Oceanographic research papers 53 (6), 987-1010.

Fahrbach, E., Rohardt, G., Krause, G., 1992. The Antarctic coastal current in the southeastern Weddell Sea. Polar Biology 12 (2), 171-182. 
Flagg, C. N., Vermersch, J. A., Beardsley, R. C., 1976. 1974 MIT New England Shelf Dynamics Experiment (1974) Data Report, Part II: The moored array. Tech. Rep. Report 76-1, Massachusetts Institute of Technology.

Fong, D., Geyer, W. R., 2001. Response of a river plume during an upwelling favorable wind event. Journal of Geophysical Research 106 (C1), 1067-1084.

Fraser, W., Trivelpiece, W., 1996. Factors controlling the distribution of seabirds: winter-summer heterogeneity in the distribution of Adélie penguin populations. Antarct Res Ser 70, 257-272.

Garrett, C., Kunze, E., 2007. Internal tide generation in the deep ocean. Annual Review of Fluid Mechanics 39, 57-87.

Gill, A., 1982. Atmosphere-Ocean Dynamics. Vol. 30 of International Geophysics Series. Academic Press.

Guo, Z., Bromwich, D., Cassano, J., 2003. Evaluation of Polar MM5 Simulations of Antarctic Atmospheric Circulation. Monthly Weather Review 131 (2), 384-411.

Harangozo, S., 2006. Atmospheric circulation impacts on winter maximum sea ice extent in the west Antarctic Peninsula region(1979-2001). Geophysical Research Letters 33 (2), doi:10.1029/2005GL024978.

Heywood, K., Garabato, A., Stevens, D., Muench, R., 2004. On the fate of the Antarctic Slope Front and the origin of the Weddell Front. Journal of Geophysical Research 109, C06021.

Hofmann, E., Klinck, J., 1998. Hydrography and circulation of the antarctic continental shelf: $150^{\circ} \mathrm{E}$ to the Greenwich Meridian. In: Robinson, A., Brink, K. (Eds.), The Sea. Vol. 11. John Wiley \& Sons, Inc., Ch. 35, pp. 997-1042.

Hofmann, E., Klinck, J., Costa, D., K.L., D., Torres, J., Fraser, W., 2002. U.S. Southern Ocean Global Ocean Ecosystem Dynamics Program. Oceanography 15 (2), 6474 . 
Hofmann, E., Klinck, J., Lascara, C., Smith, D., 1996. Water mass distribution and circulation west of the Antarctic Peninsula and including Bransfield Strait. In: Ross, R., Hofmann, E., Langdon, B. (Eds.), Foundations for ecological research west of the Antarctic Peninsula. Vol. 70 of Antarctic Research Series. American Geophysical Union, pp. 61-80.

Hofmann, E. E., Wiebe, P., Costa, D. P., Torres, J. J., 2004. An overview of the southern ocean global ocean ecosystems dynamics program. Deep Sea Research II 51 (17-19), 1921-1924, doi:10.1016/j.dsr2.2004.08.007.

Holloway, P., 1985. A Comparison of Semidiurnal Internal Tides from Different Bathymetric Locations on the Australia North West Shelf. Journal of Physical Oceanography $15(3), 240-251$.

Huntley, M. E., Niiler, P. P., 1995. Physical control of population dynamics in the Southern Ocean. ICES J. mar. Sci. 52, 457-468.

Hyatt, J., Beardsley, R. C., Owens, W. B., 2006. Characterization of sea ice cover, motion and dynamics in Marguerite Bay, Antarctic Peninsula. Deep Sea Research Part IISubmitted.

King, J. C., 1994. Recent climate variability in the vicinity of the Antarctic Peninsula. International journal of climatology 14 (4), 357-369.

Klinck, J., 1998. Heat and salt changes on the continental shelf west of the antarctic peninsula between january 1993 and february 1994. Journal of Geophysical Research 103 (C4), 7617-7636.

Klinck, J. M., Hofmann, E. E., Beardsley, R. C., Salihoglu, B., Howard, S., 2004. Water-mass properties and circulation on the west Antarctic peninsula continental shelf in austral Fall and Winter 2001. Deep-Sea Research II 51, 1925-1946.

Kundu, P., Allen, J., 1976. Some three-dimensional characteristics of low-frequency current fluctuations near the oregon coast. Journal of Physical Oceanography $6(2)$, $181-199$. 
Large, W., Pond, S., 1981. Open Ocean Momentum Flux Measurements in Moderate to Strong Winds. Journal of Physical Oceanography 11 (3), 324-336.

Lascara, C. M., Hofmann, E. E., Ross, R. M., Quetin, L. B., 1999. Seasonal variability in the distribution of antarctic krill, euphausia superba, west of the antarctic peninsula. Deep Sea Research I 46 (6), 951-984.

Lawson, G., 2006. Distribution, Patchiness, and Behavior of Antarctic Zooplankton, Assessed Using Multi-Frequency Acoustic Techniques. Ph.D. thesis, MIT/WHOI Joint Program in Oceanography.

Lawson, G., Wiebe, P., Ashjian, C., Gallager, S., Davis, C., Warren, J., 2004. Acoustically-inferred zooplankton distribution in relation to hydrography west of the Antarctic Peninsula. Deep Sea Research II.

Leaman, K., 1980. Some Observations of Baroclinic Diurnal Tides over a Near-Critical Bottom Slope. Journal of Physical Oceanography 10 (10), 1540-1551.

Legg, S., 2004. Internal Tides Generated on a Corrugated Continental Slope. Part II: Along-Slope Barotropic Forcing. Journal of Physical Oceanography 34 (8), 18241838.

Lentz, S., Helfrich, K., 2002. Buoyant gravity currents along a sloping bottom in a rotating fluid. Journal of Fluid Mechanics 464, 251-278.

Lentz, S. J., Largier, J., 2006. The influence of wind forcing on the Chesapeake Bay buoyant coastal current. Journal of Physical Oceanography 36 (7), 1305-1316.

Lilly, J., Rhines, P., 2002. Coherent Eddies in the Labrador Sea Observed from a Mooring. Journal of Physical Oceanography 32 (2), 585-598.

Limeburner, R., Alessi, C. A., Beardsley, R. C., Rosenfeld, L. K., Lentz, S. J., Send, U., Winant, C. D., Allen, J. S., Halliwell Jr., G. R., Brown, W. S., Irish, J. D., 1983. CODE-2: Moored Array and Large-Scale Data Report. Tech. Rep. 85-35, Woods Hole Oceanographic Institution. 
Massom, R., Stammerjohn, S., Smith, R., Pook, M., Iannuzzi, R., Adams, N., Martinson, D., Vernet, M., Fraser, W., Quetin, L., Ross, R. M., Massom, Y., Krouse, H. R., 2006. Extreme anomalous atmospheric circulation in the west antarctic peninsula region in austral spring and summer 2001/02, and its profound impact on sea ice and biota. Journal of climate 19 (15), 3544-3571.

Meredith, M., Renfrew, I., Clarke, A., King, J., Brandon, M., 2004. Impact of the 1997/98 ENSO on upper ocean characteristics in Marguerite Bay, western Antarctic Peninsula. Journal of Geophysical Research 109, C09013.

Meredith, M. P., Brandon, M. A., Wallace, M. I., Clarke, A., Leng, M. J., Renfrew, I. A., van Lipzig, N., King, J. C., 2006. On the seasonal freshwater budget of northern Marguerite Bay, Antarctic Peninsula Accepted for Publication in DSR Special Issue.

Meredith, M. P., King, J. C., 2005. Rapid climate change in the ocean west of the Antarctic Peninsula during the second half of the 20th century. Geophysical Research Letters 32 (L19604).

Moffat, C., Beardsley, R., Limeburner, R., Owens, W., Caruso, M., Hyatt, J., 2005. Southern ocean globec moored array and automated weather station data report. Tech. Rep. WHOI-2005-07, Woods Hole Oceanographic Institution.

Murphy, E., Watkins, J., Reid, K., Trathan, P., Everson, I., Croxall, J., Priddle, J., Brandon, M., Brierley, A., Hofmann, E., 1998. Interannual variability of the South Georgia marine ecosystem: biological and physical sources of variation in the abundance of krill. Fisheries Oceanography 7 (3-4), 381-390.

Murphy, E., Watkins, J., Trathan, P., Reid, K., Meredith, M., Thorpe, S., Johnston, N., Clarke, A., Tarling, G., Collins, M., Forcada, J., Shreeve, R., Atkinson, A., Korb, A., Whitehouse, M., Ward, P., Rodhouse, P., Enderlein, P., Hirst, A., Martin, A., Hill, S., Staniland, I., Pond, D., Briggs, D., Cunningham, N., Fleming, A., 2007. Spatial and temporal operation of the Scotia Sea ecosystem: a review of large-scale 
links in a krill centred food web. Philosophical Transactions of the Royal Society B: Biological Sciences 362 (1477), 113-148.

Niiler, P., Illeman, J., Hu, J., 1990. RACER: Lagrangian drifter observations of surface circulation in the Gerlache and Bransfield Straits. Antarctic Journal of the United States 25, 134-137.

Orsi, A., Whitworth, T., Nowlin, W., 1995. On the meridional extent and fronts of the Antarctic Circumpolar Current. Deep Sea Research Part I: Oceanographic Research Papers 42 (5), 641-673.

Padman, L., Jones, Fricker, H. A., Coleman, R., Howard, S., Erofeeva, S., 2002. A new tidal model of the Antarctic ice shelves and seas. Annals of Glaciology 34, $247-254$.

Pawlowicz, R., Beardsley, R., Lentz, S., 2002. Classical tidal harmonic analysis including error estimates in MATLAB using T_TIDE. Computers \& Geosciences 28 (8), 929-937.

Pedlosky, J., 2003. Waves in the Ocean and Atmosphere: Introduction to Wave Dynamics. Springer.

Perovich, D. K., Elder, B. C., Claffey, K. J., Stammerjohn, S., Smith, R., Ackley, S. F., Krouse, H. R., Gow, A. J., 2004. Winter sea-ice properties in Marguerite Bay, Antarctica. Deep-Sea Research II 51, 2023-2039.

Potter, J., Paren, J., 1985. Interaction between ice shelf and ocean in George VI Sound, Antarctica. In: Jacobs, S. (Ed.), Oceanology of the Antarctic Continental Shelf. Vol. 43 of Antarctic Research Series. American Geophysical Union, pp. 35-58.

Prézelin, B., Hofmann, E., Mengelt, C., Klinck, J., 2000. The linkage between upper circumpolar deep water (UCDW) and phytoplankton assemblages on the west antarctic peninsula continental shelf. Journal of Marine Research 58, 165-202. 
Prézelin, B., Hofmann, E., Moline, M., Klinck, J., 2004. Physical forcing of phytoplankton community structure and primary production in continental shelf waters of the Western Antarctic Peninsula. Journal of Marine Research 62 (3), 419-460.

Rhines, P., 1970. Edge-, bottom-, and rossby waves in a rotating stratified fluid. Geophysical Fluid Dynamics 1, 273-302.

Rhines, P., 1977. The dynamics of unsteady currents. In: Goldberg, E. D., McCane, I., O’Brien, J., Steele, J. (Eds.), The Sea. Vol. 6. Wiley-Interscience, pp. 189-318.

Rignot, E., Casassa, G., Gogineni, S., Kanagaratnam, P., Krabill, W., Prichard, H., Rivera, A., Thomas, R., Turner, J., Vaughan, D., 2005. Recent ice loss from the Fleming and other glaciers, Wordie Bay, West Antarctic Peninsula. Geophysical Research Letters 32 (L07502).

Serebrennikova, Y. M., Fanning, K. A., 2004. Nutrients in the Southern Ocean GLOBEC region: variations, water circulation, and cycling. Deep-Sea Research II $51,1981-2002$.

Shearman, R., 2005. Observations of near-inertial current variability on the New England shelf. J. Geophys. Res 110.

Sievers, H., Nowlin, W., 1984. The stratification and water masses at drake passage. Journal of Geophysical Research 89 (C6), 10489-10514.

Smith, D., Klinck, J., 2002. Water properties on the west antarctic peninsula continental shelf: a model study of effects of surface fluxes and sea ice. Deep-Sea Research Part II 49, 4863-4886.

Smith, D. A., Hofmann, E., Klinck, J., Lascara, C., 1999. Hydrography and circulation of the west antarctic peninsula continental shelf. Deep-Sea Research I 46, 925-949.

Stammerjohn, S., Smith, R., 1996. Spatial and temporal variability of western Antarctic Peninsula sea ice coverage. Foundations for Ecological Research West of the Antarctic Peninsula 70, 81-104. 
Stammerjohn, S. E., Drinkwater, M. R., Smith, R. C., Liu, X., 2003. Iceatmosphere interactions during sea-ice advance and retreat in the western antarctica peninsula region. Journal of Geophysical Research 108 (C10), 3329, doi:10.1029/2002JC001543.

Thompson, R. O., Luyten, J., 1976. Evidence for bottom-trapped topographic rossby waves from single moorings. Deep-Sea Research 23, 629-635.

Torrence, C., Compo, G., 1998. A practical guide to wavelet analysis. Bulletin of The American Metorological Society 79 (1), 61-78.

van Lipzig, N. P. M., King, J. C., Lachlan-Cope, T. A., van den Broeke, M. R., 2004. Precipitation, sublimation, and snow drift in the Antarctic Peninsula region from a regional atmospheric model. Journal of Geophysical Research 109 (D24106), doi:10.1029/2004JD004701.

Vaughan, D., Doake, C., 1996. Recent atmospheric warming and retreat of ice shelves on the Antarctic Peninsula. Nature 379 (6563), 328-331.

Vaughan, D. G., 2006. Recent trends in melting conditions on the Antarctic Peninsula and their implications for ice-sheet mass balance and sea level. Arctic, Antarctic, and Alpine Research 38 (1), 147-152.

Weller, R., 1982. The Relation of Near-Inertial Motions Observed in the Mixed layer During the JASIN (1978) Experiment to the Local Wind Stress and to the QuasiGeostrophic Flow Field. Journal of Physical Oceanography 12 (10), 1122-1136.

Whitney, M., Garvine, R., 2005. Wind influence on a costal buoyant overflow. Journal of Geophysical Research 110 (C03014), doi:10.1029/2003JC002261.

Wiebe, P., Hofmann, E., Beardsley, R. C., Ribic, C., Chapman, E., Ashjian, C., Gallager, S., Davis, C., Koz-lowski, W., Friedlaender, A., Berchok, C., Rutherford, C., Warren, J., Fisher, K., 2001. Report of RV/IB Nathaniel B. Palmer cruise 01-03 to the western antarctic peninsula 24 april to 5 june 2001. United States southern ocean global ocean ecosystems dynamics program. Tech. Rep. Number 2. 
Wiebe, P., Stanton, T., Greene, C., Benfield, M., Sosik, H., Austin, T., Warren, J., Hammar, T., 2002. BIOMAPPER-II: an integrated instrument platform for coupled biological and physical measurements in coastal and oceanic regimes. IEEE Journal of Oceanic Engineering 27 (3), 700-716.

Yankovsky, A., Chapman, D., 1997. A simple theory for the fate of buoyant coastal discharges. Journal of Physical Oceanography 27, 1386-1400.

Zhou, M., Niiler, P., Hu, J., 2002. Surface currents in the Bransfield and Gerlache Straits, Antarctica. Deep Sea Research I 49 (2), 267-280. 